\title{
Cyclic and Isothermal Oxidation Resistance of ASPS Thermal Barrier Coating Systems
}

\author{
by \\ Xiaolong Li
}

A thesis submitted to the Faculty of Graduate and Postdoctoral Affairs in partial fulfillment of the requirements for the degree of

Master of Applied Science

in

Mechanical Engineering

Carleton University

Ottawa, Ontario

(C) 2014

Xiaolong Li 


\title{
Cyclic and Isothermal Oxidation Resistance of ASPS Thermal Barrier Coating Systems
}

by

\section{Xiaolong Li}

A thesis submitted to the Faculty of Graduate and Postdoctoral Affairs in partial fulfillment of the requirements for the degree of

\author{
Master of Applied Science \\ in \\ Mechanical Engineering
}

Professor Xiao Huang, Thesis Supervisor

Dr. Qi Yang, Thesis Co-Supervisor

Professor Metin I. Yaras, Chair, Department of Mechanical and Aerospace Engineering 


\section{Abstract}

To systematically study the oxidation performances of thermal barrier coatings (TBCs) deposited by axial suspension plasma spraying (ASPS) method, isothermal and cyclic oxidation tests were conducted at a peak temperature of $1080^{\circ} \mathrm{C}$. The $\mathrm{TBC}$ systems are based on two different nickel-base superalloy substrates (CMSX-4 or IN738LC), platinum aluminide bond coat and yttria stabilized zirconia (8YSZ) top coat with either vertical cracks (VC) or columnar structure. After the oxidation tests, the samples were analyzed using a scanning electron microscope (SEM) and an X-Ray diffractometer. Samples with IN738LC substrate demonstrated longer isothermal oxidation lives whereas samples with CMSX-4 substrate showed greater cyclic oxidation lives. Outward elemental diffusion (of $\mathrm{W}$ and $\mathrm{Ta}$ ) in TBC system containing CMSX-4 contributed to reduced isothermal oxidation life while the mismatch of coefficients of thermal expansion (CTE) between TGO, bond coat and substrate was believed to be responsible for early failure of TBC system with IN738LC substrate. TBC systems with columnar YSZ overall had longer isothermal oxidation life while vertically cracked YSZ seemed to result in longer cyclic life. $\mathrm{Cr}_{2} \mathrm{O}_{3}$ and spinels (CS), in addition to thermally grown aluminum oxide (TGO), were detected on tested TBC samples. The growth of spinels highly depended upon a coating's accessibility to oxygen and test duration and was found to contribute the spallation of the coating layer. 


\section{Acknowledgements}

- I would like to thank my supervisor Prof. Xiao Huang for her great guidance throughout this research program; and I give thanks to my co-supervisor Dr, Qi Yang for his valuable advices towards experiments and countless time he spent helping me with EDS and XRD analysis.

- To Ms. Olga Lupandina, for generously providing her experimental advice throughout long period of experimental procedure.

- I want to thank the National Research Council of Canada for allowing us the access to the equipment needed for this research.

- I am very grateful to Mrs. F. Lingnau at Chromalloy American Corporation for providing PtAl coating.

- This research could not have been accomplished without the financial support from Natural Science and Engineering Research Council of Canada. I also want to express my gratitude to my mother Ms. Yanzhe Sun for always supporting me financially and spiritually throughout the graduate study. 


\section{Table of Contents}

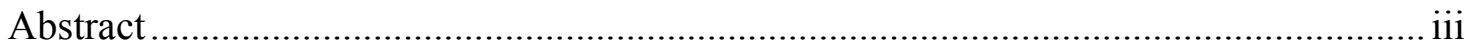

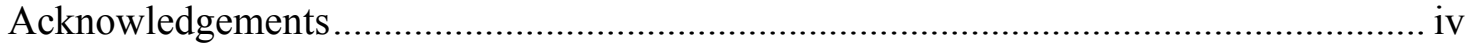

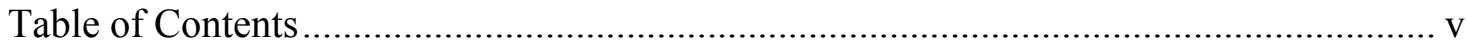

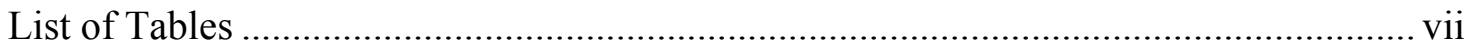

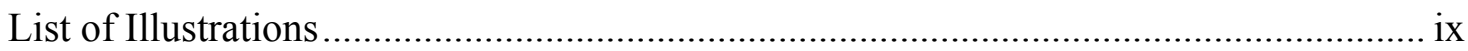

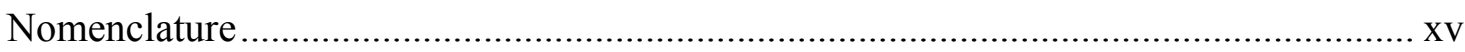

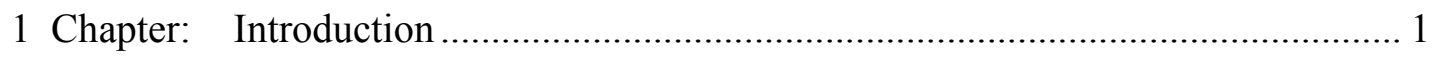

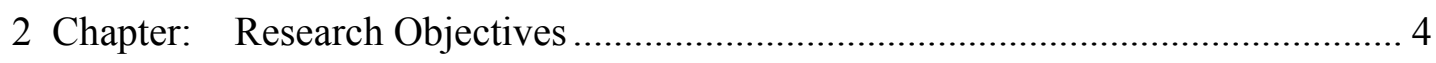

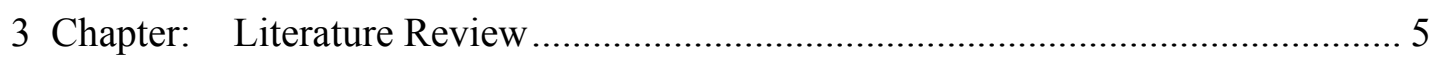

3.1 Gas Turbines and Blade Materials.............................................................. 5

3.2 Thermal Barrier Coating System............................................................. 10

3.3 Techniques for YSZ Ceramic Top Coating Deposition ............................... 27

3.4 Isothermal Oxidation of TBCs and Microstructure Changes ......................... 45

3.5 Cyclic Oxidation Life of TBCs and Microstructure Changes ........................ 47

4 Chapter: Materials and Experimental Procedures................................................. 50

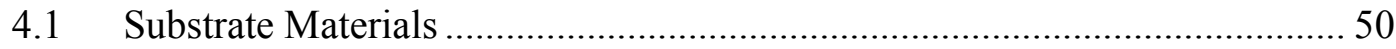

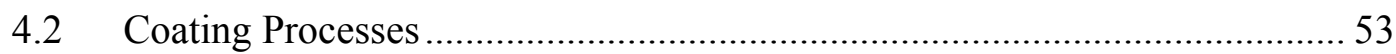

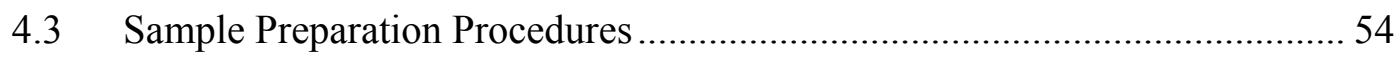

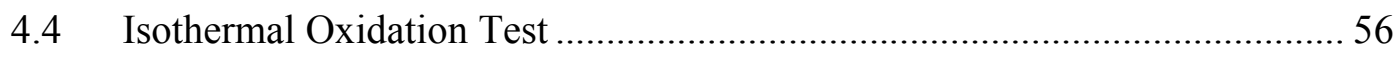

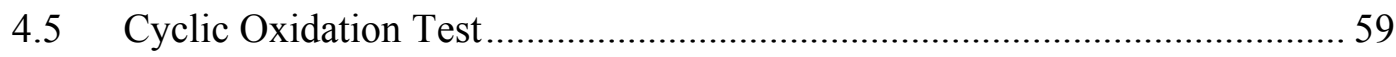

4.6 Scanning Electron Microscopy (SEM) and Energy Dispersive Spectrum

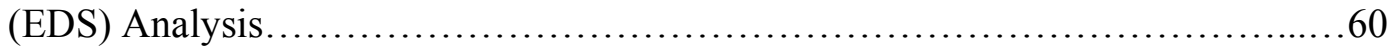

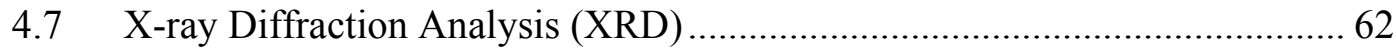

5 Chapter: Microstructure and Composition of As-Coated Samples......................... 64

6 Chapter: Isothermal Oxidation Test Result and Discussion .................................. 71

6.1 Isothermal Oxidation Lifetime of TBCs........................................................ 71

6.2 Microstructure Analysis of Isothermally Oxidized Samples........................ 73

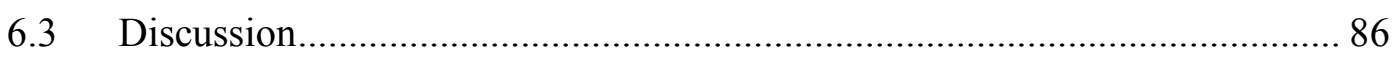




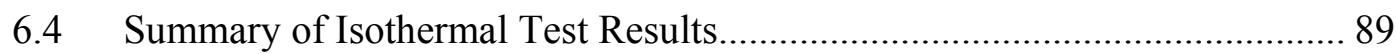

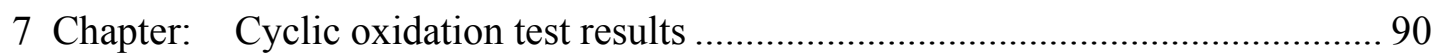

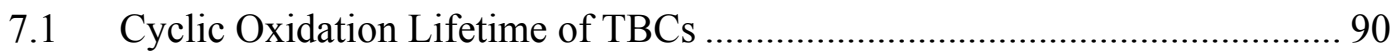

7.2 Microstructure Analysis of Cyclic Oxidation Tested Samples ..................... 92

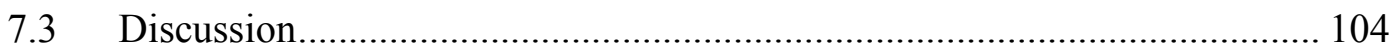

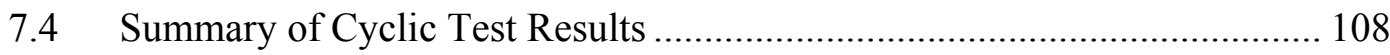

8 Chapter: Conclusion and Future Work ............................................................... 109

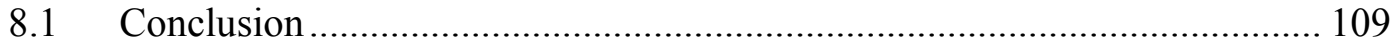

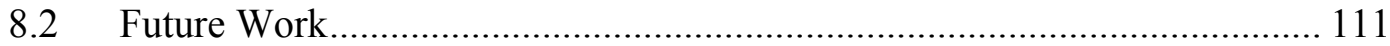

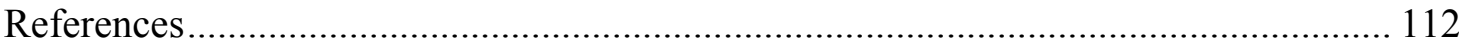




\section{List of Tables}

Table 3-1. Commercial nickel based superalloys and compositions (wt\%) [24,39] .......... 9

Table 3-2. Rotor inlet temperatures for typical gas turbine engines [37] 10

Table 3-3. Beneficial and detrimental aspects of alloying elements in metallic coatings $[73,76]$ 19

Table 3-4. Ceramic materials and their characteristics [94] 25

Table 3-5. Summarized properties of APS, ASPS and EB-PVD coatings [17] 44

Table 4-1. Experimental data for thermophysical properties of IN738 and CMSX-4 (927$\left.1127^{\circ} \mathrm{C}\right)[152]$ 50

Table 4-2. Chemical composition of the substrate materials 50

Table 4-3. Samples used in isothermal oxidation test. 58

Table 4-4. Samples used in cyclic oxidation test 60

Table 5-1. Chemical compositions of PtAl bond coat (layers and substrate near the bond coat) (wt \%) measured by EDS 70

Table 6-1. EDS analysis results of Iso\#1 (wt \% and at \%) 76

Table 6-2. EDS analysis results of Iso\#3 (wt $\%$ and at $\%$ ) 78

Table 6-3. EDS analysis results of Iso\#2 (wt $\%$ and at $\%$ ) 82

Table 6-4. EDS analysis results of Iso\#4 (wt $\%$ and at $\%)$ 85

Table 7-1. EDS analysis results of Cyc\#1 (wt $\%$ and at $\%$ ) 94

Table 7-2. EDS results of Cyc\#3 (wt $\%$ and at $\%$ ) 97

Table 7-3. EDS results of Cyc\#2 (wt $\%$ and at $\%$ ) 100

Table 7-4. EDS analysis results of Cyc\#4 (wt $\%$ and at $\%)$ 103 
Table 7-5. Averaged coefficient of thermal expansion (CTE) of substrate, YSZ and TGO 107 


\section{List of Illustrations}

Figure 3-1. Gas turbine and operating principle and applications (A) propulsions for aircraft and (B) industrial power generation [26] 6

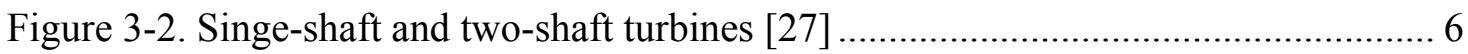

Figure 3-3. Microstructure of a typical Ni-base superalloy [38] ................................. 8

Figure 3-4. Proportion of alloying element additions to Ni-base alloy from 1965 to 2005 $[35]$

Figure 3-5. Thermal barrier coating system for gas turbine application [8] 11

Figure 3-6. Typical microstructures of plain aluminide coatings, outward-grown (a) and inward-grown (b) [50]. 13

Figure 3-7. Ni-Pt-Al phase diagram at $1100^{\circ} \mathrm{C}[51]$ 13

Figure 3-8. Surface rumpling of a (Ni, Pt)Al bond coat [54] 14

Figure 3-9. Two layered $\gamma-\gamma$ ' NiPtAl coating [60].... 15

Figure 3-10. Void formation at bond coat/ TGO interface [63] 16

Figure 3-11. Oxidation and hot corrosion performances of different overlay coatings $[66,70,71]$ 17

Figure 3-12. Isothermal $\mathrm{Ni}-\mathrm{Cr}-\mathrm{Al}$ ternary phase diagram (a) at $1150^{\circ} \mathrm{C}$, (b) at $850^{\circ} \mathrm{C}$ $[73,75]$ 18

Figure 3-13. (a) Maximum crack length vs. TGO thickness under cyclic oxidation. (b) Maximum crack length vs. number of cycles under cyclic oxidation [88].

Figure 3-14. Crack propagation in the APS coatings at $1050{ }^{\circ} \mathrm{C}$ due to discontinuities opening after 300 cycles (a) and crack propagation associated with the CSN after 500 cycles (b)[88] 23 
Figure 3-15. Durability of TBC with different concentrations of $\mathrm{Y}_{2} \mathrm{O}_{3}$ [97]

Figure 3-16. Industrial production system of EB-PVD: 1. Central vapor deposition chamber; 2. Target storage rooms; 3. Horizontal transmission and rotation components; 4. Transmission components for target material; 5. Vacuum chamber $[99,101] \ldots \ldots \ldots \ldots \ldots \ldots . . .28$

Figure 3-17. ED-PVD equipment and process set up [102] 29

Figure 3-18. Scanning electron micrographs of an EB-PVD coating (a) finished surface [106] and (b) cross section showing its columnar microstructure [105] 30

Figure 3-19. Thermal conductivity of zirconia and zirconia top coatings applied by EBPVD and PS methods [106] 30

Figure 3-20. Scanning electron micrograph of EB-PVD top coat cross-section [109] .... 31

Figure 3-21. Effects of the coating thickness on the thermal conductivity of EB-PVD PYSZ coatings at different temperatures [110] 32

Figure 3-22. (a) Air plasma spray process [118] and (b) A typical plasma-spraying system with radial power injection system [120]. 34

Figure 3-23. Cross section showing microstructure of lamellar APS coating [121] ........ 35

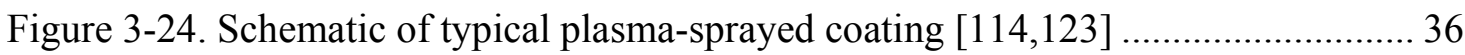

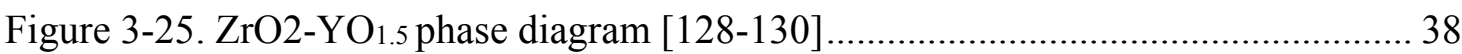

Figure 3-26. Cross-sections of plasma sprayed agglomerated YSZ powder with an approximate size of a) $90 \mu \mathrm{m}$, b) $50 \mu \mathrm{m}$, c) $20 \mu \mathrm{m}$ [132]

Figure 3-27. Stages that suspension droplets undergo during the plasma spraying [134] 40

Figure 3-28. Two-zone microstructure of SPS coating [136] 41

Figure 3-29. VC YSZ coating (cross section) [144] 43

Figure 3-30. Cross sectional morphology of columnar coating by ASPS method [17] ... 44 
Figure 3-31. TGO formed in TBC after $336 \mathrm{~h}$ of isothermal oxidation at $950^{\circ} \mathrm{C}[148] \ldots 46$

Figure 3-32. Spallation and cracking at top coat/bond coat interface after $336 \mathrm{~h}$ of oxidation at $1050^{\circ} \mathrm{C}[148]$ 46

Figure 3-33. Weigh changes of TBCs in a function of oxidation time at $1100^{\circ} \mathrm{C}$ [149].. 47

Figure 3-34. Surface morphology of YSZ top coat after 300 cycles [150] 48

Figure 3-35. Weight changes of TBCs with different bond coats as a function of cyclic oxidation life [151]

Figure 4-1: $\gamma / \gamma^{\prime}$ structure of IN738LC Superalloy 51

Figure 4-2. $\gamma / \gamma^{\prime}$ structure of CMSX-4 superalloy 52

Figure 4-3. ASPS deposition process [17] 54

Figure 4-4. Equipment used in sample preparation 56

Figure 4-5. STT-1600C-4-12 high temperature tube furnace used in isothermal oxidation test 57

Figure 4-6. CM Rapid Temp Furnace used in cyclic oxidation test 59

Figure 4-7. Philips XL30S FEG SEM 61

Figure 4-8. VegaII-XMU SEM 62

Figure 4-9. Bruker AXS D8 Discover Diffractometer for XRD analysis. 63

Figure 5-1. Top surface morphologies of columnar ( $a$ and b) and VC coatings (c and d) 65

Figure 5-2. Cross-sections of columnar structured and VC TBC coatings 65

Figure 5-3. X-ray diffraction pattern from coating top surface before oxidation test 67

Figure 5-4. PtAl bond coat with IN738 (a) and CMSX-4 (b) substrate 69

Figure 6-1. Isothermal oxidation life (hours).... 71 
Figure 6-2. Visual observations of Iso\#1-4 (every $100 \mathrm{~h}$ )

Figure 6-3. Microstructures of Sample Iso\#1 (IN738LC with PtAl + columnar YSZ) after oxidation test

Figure 6-4. Microstructures of Sample Iso\#3 (CMSX-4 with PtAl + columnar YSZ) after isothermal oxidation test 78

Figure 6-5. X-ray diffraction pattern from the backside of the spalled YSZ (Iso\#3, CMSX-4 with PtAl + columnar YSZ)

Figure 6-6. X-ray diffraction pattern of bond coat/substrate (Iso\#3, CMSX-4 with PtAl + columnar YSZ) 79

Figure 6-7. Microstructures of sample Iso\#2 (IN738LC with PtAl + VC YSZ) after oxidation test 81

Figure 6-8. X-ray diffraction pattern from the backside of spalled YSZ (sample Iso\#2, IN738LC with PtAl + VC YSZ) 83

Figure 6-9. X-ray diffraction pattern from the exposed bond coat/substrate surface (sample Iso\#2, IN738LC with PtAl + VC YSZ)

Figure 6-10. Microstructures of Iso\#4 (CMSX-4 with PtAl + VC YSZ) after oxidation test.

Figure 6-11. X-ray diffraction pattern from the exposed bond/coat substrate surface (sample Iso\#4, CMSX-4 with PtAl + VC YSZ) 86

Figure 7-1. Cyclic oxidation life (in terms of number of cycles) 90

Figure 7-2. Visual observations of Cyc\#1-4 (images taken every 100 cycles) 92

Figure 7-3. Microstructures of Sample Cyc\#1 (IN738LC with PtAl + columnar YSZ) after oxidation test 94 
Figure 7-4. X-ray diffraction pattern from the backside of spalled YSZ (sample Cyc\#1, IN738LC with PtAl + columnar YSZ)

Figure 7-5. X-ray diffraction pattern from the exposed bond coat/substrate surface (sample Cyc\#1, IN738LC with PtAl + columnar YSZ)

Figure 7-6. Microstructures of Sample Cyc\#3 (CMSX-4 with PtAl + columnar YSZ) after oxidation test

Figure 7-7. X-ray diffraction pattern from the backside of spalled YSZ (sample Cyc\#3, CMSX-4 with PtAl + columnar YSZ) 98

Figure 7-8. X-ray diffraction pattern from bond coat/substrate surface (sample Cyc\#3, CMSX-4 with PtAl + columnar YSZ) 98

Figure 7-9. Microstructures of sample Cyc\#2 (IN738LC with PtAl + VC YSZ) after oxidation test 99

Figure 7-10. X-ray diffraction pattern from the backside of spalled YSZ (Cyc\#2, IN738LC with PtAl + VC YSZ) 100

Figure 7-11. X-ray diffraction pattern from the exposed substrate/bond coat surface (Cyc\#2, IN738LC with PtAl + VC YSZ) 101

Figure 7-12. Microstructures of sample Cyc\#4 (CMSX-4 with PtAl + VC YSZ) after cyclic oxidation test 102

Figure 7-13. X-ray diffraction pattern from the backside of spalled YSZ (Cyc\#4, CMSX4 with PtAl + VC YSZ) 103

Figure 7-14. X-ray diffraction pattern from the exposed bond coat/substrate surface (Cyc\#4, CMSX-4 with PtAl + VC YSZ) 104

Figure 7-15. Failure of TGO due to thermal expansion mismatch 106 
Figure 7-16. Mean coefficient of expansion (CTE) of different types of Ni-base

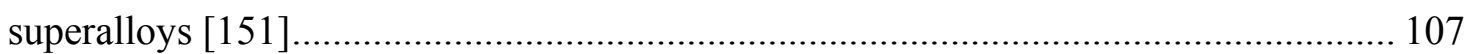




\section{Nomenclature}

$\begin{array}{ll}\text { APS } & \text { Air plasma spray } \\ \text { ASPS } & \text { Axial suspension plasma spray } \\ \text { CMSX-4 } & \text { A single crystal Ni-based superalloy manufactured by Canon Muskogan } \\ \text { CS } & \text { Cr2 }_{2} \text { 3 and spinel } \\ \text { CSN } & \text { Cr2 }_{2} \text { 3, spinel and NiO } \\ \text { CTE } & \text { Coefficient of thermal expansion } \\ \text { EB-PVD } & \text { Electron beam physical vapor deposition } \\ \text { IDZ } & \text { Inter-diffusion zone } \\ \text { IN738 } & \text { Inconel 738 Ni-based superalloy manufactured by Inco Ltd. } \\ \text { OEM } & \text { Original equipment manufacturer } \\ \text { PS } & \text { Plasma spray } \\ \text { SEM } & \text { Scanning electron microscope } \\ \text { SOD } & \text { Stand-off distance } \\ \text { SPS } & \text { Suspension plasma spray } \\ \text { TBC } & \text { Thermal barrier coating } \\ \text { TCP } & \text { Topologically close-packed } \\ \text { TGO } & \text { Thermally grown oxide } \\ \text { VRD } & \text { Vertical crack } \\ \text { X-ray diffraction }\end{array}$




\section{Chapter: Introduction}

Modern gas turbines operate at high temperature and constantly increasing the inlet temperature is required to improve turbine efficiency $[1,2]$. The hot sections of gas turbines are subjected to not only high temperature [3], but also severe oxidizing and corrosive environments [4]. Therefore, the efficiency of a gas turbine engine is highly dependent on the thermal and mechanical properties of the materials used for the hot section components such as the turbine blades [5]. Nickel-based superalloys are widely used for gas turbine blades due to their high temperature resistance and high strength at elevated temperature. These superalloys can work for thousands of hours even at a high temperature of $1100^{\circ} \mathrm{C}[6]$. With the application of thermal barrier coatings (TBCs) on gas turbine blades and vanes, metal surface temperature can be reduced by $100^{\circ} \mathrm{C}$ to $300^{\circ} \mathrm{C}$, depending upon thickness, composition and structure, leading to a significant increase of turbine efficiency $[7,8]$.

Combining the low thermal conductivities of YSZ and the excellent oxidation/corrosion resistance of bond coat, thermal barrier coating systems prevent superalloy substrate from many different types of environmental degradation [7]. There are two typical types of bond coats: traditional $\mathrm{MCrAlY}(\mathrm{M}=\mathrm{Ni}$ or/and $\mathrm{Co})$ overlay coatings and platinummodified aluminum (PtAl) diffusion coatings [8]. PtAl coatings have exhibited better protection against high temperature oxidation damage than MCrAlY coatings due to their ability to form a slow-growing alumina scale [9]. The addition of platinum to the aluminide coating improves the oxidation resistance by promoting selective oxidation of aluminum and enhances coating stability and scale adhesion in return [10]. 
The YSZ ceramic top coats are usually deposited by the air plasma spraying (APS) method or electron beam physical vapor deposition (EB-PVD) technique. APS method is a more commonly used commercial deposition technique for gas turbine blades due to its low cost, high deposition rate and large range of applicable coating compositions [11]. The YSZ coatings deposited by APS exhibit high thermal resistance because of the inherent laminar structure [12]. However, the presence of porosity and micro-cracks and the lack of strain tolerant microstructure features in the traditional APS coatings lead to coating spallation during exposure to high temperature, particularly under cyclic conditions [13]. On the contrary, EB-PVD deposited YSZ coatings have shown superior strain and thermo-shock tolerance due to columnar microstructures. They also exhibit better resistance to spallation, lower surface roughness, better thickness uniformity and superior adherence to the substrate over those processed by plasma spraying [14]. However, the equipment costs of EB-PVD systems are much higher than plasma spraying ones and the deposition rate is relatively low $[15,16]$.

More recently, a new axial suspension plasma spray (ASPS) technology has emerged; with this new technology, more durable TBCs with comparable performance as EB-PVD can be produced with lower equipment and operating costs. Some of the coatings produced using ASPS, such as that with columnar ASPS structure, exhibit much higher bond strength to bond coat and better strain tolerance than APS coatings, although the thermal insulation capability may be slightly compromised [17]. In traditional suspension plasma spraying, fine particles (usually in $\mathrm{nm}$ scale) suspended in a liquid carrier are injected directly into the plasma stream, instead of powder injection; in the case of ASPS, the suspension liquid is injected axially, providing more acceleration to the suspension 
[18]. The ASPS deposition process, through controlling the processing parameters, can produce coatings with columnar structure or dense coatings with vertical cracks (VCs). For example, while columnar structured coatings are deposited with a longer stand-off distance (SOD), dense coatings having more thermal insulation with vertical cracks for better strain tolerance can be produced with a shorter SOD [17]. Similar to the columnar structure, $\mathrm{VC}$ reduces the tensile stress in the YSZ top coat upon heating and compressive stress upon cooling [19]. Therefore, VC and columnar coatings usually have longer oxidation lives than lamellar APS coatings.

The oxidation behaviors of TBCs are influenced by many factors. It was reported that large variations of TBC life are caused by the difference in rates of interdiffusion, $\mathrm{Al}$ depletion and TGO growth and affected by substrate materials [20]. Life of a TBC can be reduced by the formation of Kirkendall porosity at substrate/bond coat interface [21], and the spallation of top coat because of forming mixed oxides and spinels [22]. The thermal cycling rate also affects TBC lifetime [23]. However, ASPS TBC coatings with different structures (laminar, VC and columnar) under both isothermal and cyclic conditions have not been systematically characterized and well understood. The objective of this work is to investigate the effects of substrate composition and top coat microstructure on both isothermal and cyclic lifetimes of ASPS TBCs. 


\section{Chapter: Research Objectives}

Currently, there is a lack of systematic evaluation of TBC coatings with different substrate material and top coat structures, including laminar-structured APS coatings, VC- or columnar- structured ASPS coatings, under both isothermal and cyclic conditions. Additionally, since the top coat, bond coat and substrate form an integrated part, the change in bond coat or substrate composition will also have impact on the performance of a system. As such, this research was initiated with the following objectives:

I. To study the isothermal/cyclic oxidation behaviors and microstructure changes of three different types of thermal barrier coatings (TBCs): conventional APS, vertically cracked and columnar-structured ASPS coatings.

II. To characterize the effects of substrates (CMSX-4 vs. IN738) on the isothermal and cyclic oxidation behaviors of different TBC systems.

III. To analyze the isothermal and cyclic oxidation failure mechanisms of various TBC coating systems.

IV. To recommend to industry the preferable combination of substrate, bond coat and ASPS ceramic top coat based on the TBC systems studied. 


\section{Chapter: Literature Review}

\subsection{Gas Turbines and Blade Materials}

Modern gas turbine engines are mainly employed for aircraft propulsion and industrial power generation [24]. A gas turbine engine mainly consists of three sections: a compressor, a combustion chamber and a turbine. The compressor draws in air and compresses it to a high pressure level for the combustion process; the compressed air and fuel are mixed, ignited and burned in the combustion chamber; the expanded air flow is then blown out though the exhaust nozzle [25]. There are two types of power which can be generated by a gas turbine: thrust power, which is used in aviation as aircraft propulsion, and shaft power, which is produced by land-base gas turbine for industrial application, as shown schematically in Figure 3-1 [26]. Gas turbines can also be classified into single-shaft and two-shaft turbine (Figure 3-2). In the single-shaft turbine, the turbine drives both compressor and power coupling by the same shaft, whereas in a two-shaft turbine, the compressor is decoupled from shaft, and is driven by the gas generator turbine before the power turbine. The single-shaft gas turbine is mainly used for electricity generation due to the requirement of constant speed while two-shaft turbine is usually applied in propulsion applications as the speed and load vary [27]. 

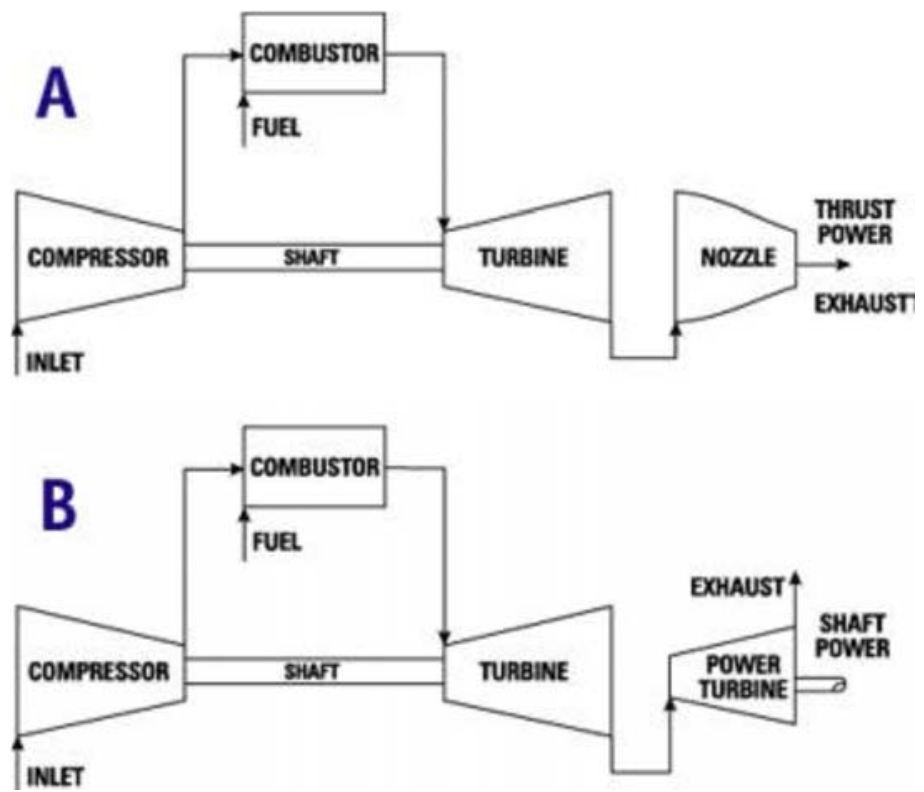

Figure 3-1. Gas turbine and operating principle and applications (A) propulsions for aircraft and (B) industrial power generation [26]

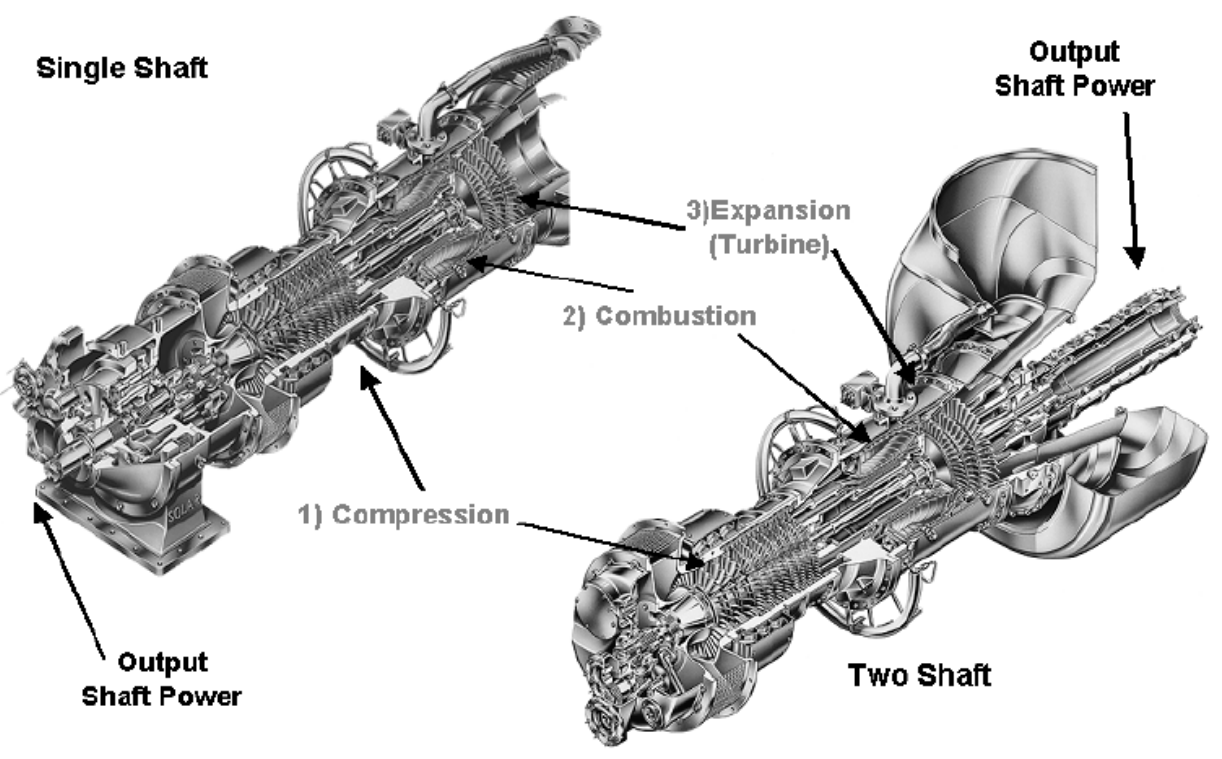

Figure 3-2. Singe-shaft and two-shaft turbines [27] 
The efficiency of a gas turbine engine highly depends on the thermal and mechanical properties of the materials used for the hot section components such as the turbine blades [5]. However, the turbine blades are subjected not only to high temperature [3], but also to severe oxidizing and corrosive environments [4]. The severe operating environment can cause damage to the blades due to oxidation, corrosion and erosion, and consequently reduce the blade life [28]. Moreover, creep failure can occur to the blades that are under stresses due to centrifugal load and vibration caused by high speed rotation $[29,30]$. Fatigue failure is another common failure of turbine blade due to frequent engine starts and shutdowns [31]. Therefore, blade materials must exhibit high thermal shock and oxidation resistance, and maintain high strength at elevated temperature [32].

Nickel-based superalloys, with a microstructure containing $\gamma^{\prime}\left(\mathrm{Ni}_{3} \mathrm{Al}\right)$ cubical precipitates embedded in the $\gamma$ phase Ni-base matrix [33] (Figure 3-3), are widely used for gas turbine blades due to their high temperature capability and high strength at elevated temperature that allow them to sustain thousands of hours of loading at a high temperature near $1100^{\circ} \mathrm{C}[6]$. In addition to nickel, Ni-base superalloy also contains chromium and cobalt for improving the corrosion resistance, and aluminum, for high oxidation resistance through forming a protective alumina scale [34]. Refractory elements such as molybdenum, tantalum, tungsten and rhenium are also included to improve high temperature mechanical strength. Since 1965, the $\mathrm{Cr}$ content has been gradually decreased from $15 \mathrm{wt} \%$ to $3 \mathrm{wt} \%$, due to the need to stabilize high temperature microstructure and prevent TCP phase formation, and the amount of $\mathrm{Al}$ and refractory elements has increased, as shown in Figure 3-4 [35]. These compositional changes have increased the demand on coating materials to provide corrosion/oxidation resistance for 
gas turbine blade materials. A summary of the common Ni-base superalloys used in gas turbine are provided in Table 3-1 [24,39].

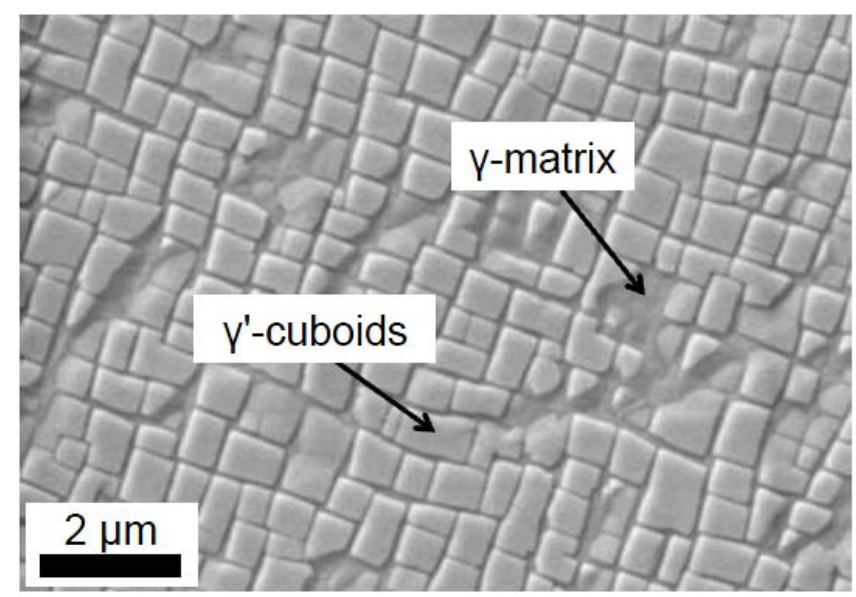

Figure 3-3. Microstructure of a typical Ni-base superalloy [38]

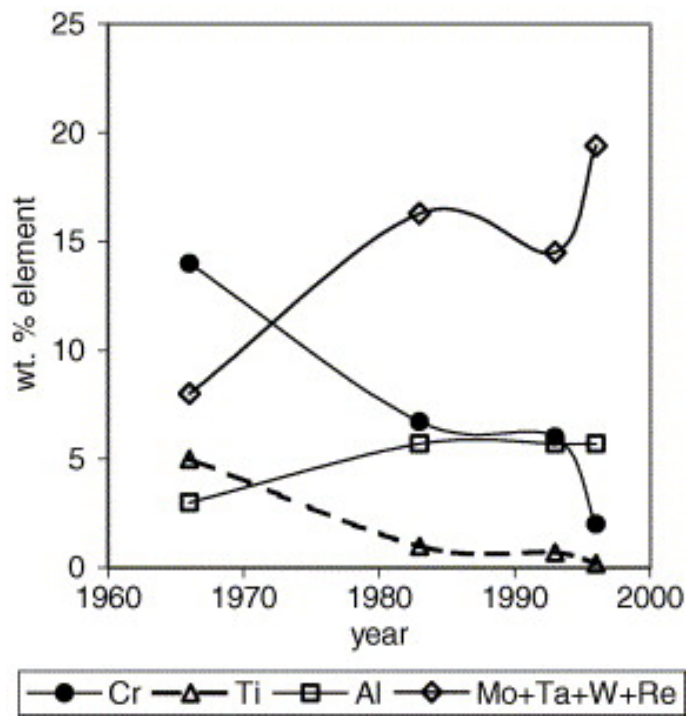

Figure 3-4. Proportion of alloying element additions to Ni-base alloy from 1965 to 2005 [35] 
Table 3-1. Commercial nickel based superalloys and compositions (wt\%) $[24,39]$

\begin{tabular}{|l|c|c|c|c|c|c|c|c|c|c|c|c|c|c|c|}
\hline Alloy & $\mathrm{Ni}$ & $\mathrm{Cr}$ & $\mathrm{Cr}$ & $\mathrm{Co}$ & $\mathrm{Fe}$ & $\mathrm{W}$ & $\mathrm{Mo}$ & $\mathrm{Ti}$ & $\mathrm{Al}$ & $\mathrm{C}$ & $\mathrm{B}$ & $\mathrm{Nb}$ & $\mathrm{Re}$ & $\mathrm{Ta}$ & $\mathrm{Hf}$ \\
\hline U-500 & BAL & 18.5 & 18.5 & 18.5 & - & - & 4 & 3 & 3 & 0.07 & 0.006 & - & - & - & - \\
\hline RENE-77 & BAL & 15 & 15 & 17 & - & - & 5.3 & 3.35 & 4.25 & 0.07 & 0.02 & - & - & - & - \\
\hline IN738 & BAL & 16 & 16 & 8.3 & 0.2 & 2.6 & 1.75 & 3.4 & 3.4 & 0.10 & 0.001 & - & - & 1.75 & - \\
\hline GTD-111 & BAL & 14 & 14 & 9.5 & - & 3.8 & 1.5 & 4.9 & 3.0 & 0.10 & 0.01 & - & - & 2.8 & - \\
\hline CMSX-4 & BAL & 6.5 & 6.5 & 9.0 & - & 6.0 & 0.6 & 1 & 5.6 & - & - & - & 3.0 & 6.5 & 0.10 \\
\hline RENE N5 & BAL & 7.0 & 7.0 & 7.5 & - & 5.0 & 1.5 & - & 6.2 & 0.05 & - & - & 3.0 & 6.5 & 0.15 \\
\hline $\begin{array}{l}\text { PWA } \\
1480\end{array}$ & BAL & 10.0 & 10.0 & 5.0 & - & 4.0 & - & 1.5 & 5.0 & - & - & - & - & 12.0 & - \\
\hline
\end{tabular}

One of the best ways to improve gas turbine efficiency is increasing inlet temperature [36]. Reports show that an increase of $56^{\circ} \mathrm{C}$ in gas turbine inlet temperature capability can lead to $8-13 \%$ improvement in output. The continuous development of gas turbine materials has contributed to the increase of turbine firing temperature, hence turbine operating efficiencies [24]. The rotor inlet temperatures of typical gas turbine engines are shown in Table 3-2 [37]. As the current turbine inlet temperatures in most modern gas turbines exceed the maximum allowable temperature for most Ni-based superalloys [36], the first few stages of gas turbine blades and vanes are commonly coated with an alumina/chromia forming layer (i.e., bond coat) followed by a ceramic thermal barrier outer layer [35]. 
Table 3-2. Rotor inlet temperatures for typical gas turbine engines [37]

\begin{tabular}{|c|c|c|c|}
\hline Engine & $\begin{array}{c}\text { Rotor inlet temp. } \\
/{ }^{\circ} \mathrm{C}\end{array}$ & $\begin{array}{c}\text { Power output } \\
\text { /MW }\end{array}$ & $\begin{array}{c}\text { Predicted } \\
\text { efficiency/ \% }\end{array}$ \\
\hline Westinghouse 501G & 1426 & 240 & 58 \\
\hline Siemens V84/3a & 1310 & 170 & 57 \\
\hline Alston GT26 & 1240 & 281 & 57 \\
\hline GE 7FA & 1290 & 150 & 55 \\
\hline
\end{tabular}

\subsection{Thermal Barrier Coating System}

Thermal barrier coatings (TBCs) are nowadays widely applied to gas turbine blades and vanes to provide oxidation and hot corrosion protection [40]. The state-of-the-art TBC system usually consists of a metallic bond coat and a ceramic top coat of partially yttrium-stabilized zirconia (YSZ) (Figure 3-5) [8]. A scale of thermally grown oxide (TGO), usually alumina in nature, forms between the ceramic top coat and bond coat after oxidation. The insulating property of yttria-stabilized zirconia (YSZ) ceramic coatings and the oxidation and corrosion resistance of the metallic bond coat can together provide environmental protection and achieve a reduction of surface temperature up to 100 to $300^{\circ} \mathrm{C}$. With the use of TBC system, the performance and efficiency of gas turbine engines are greatly improved $[7,8]$. 


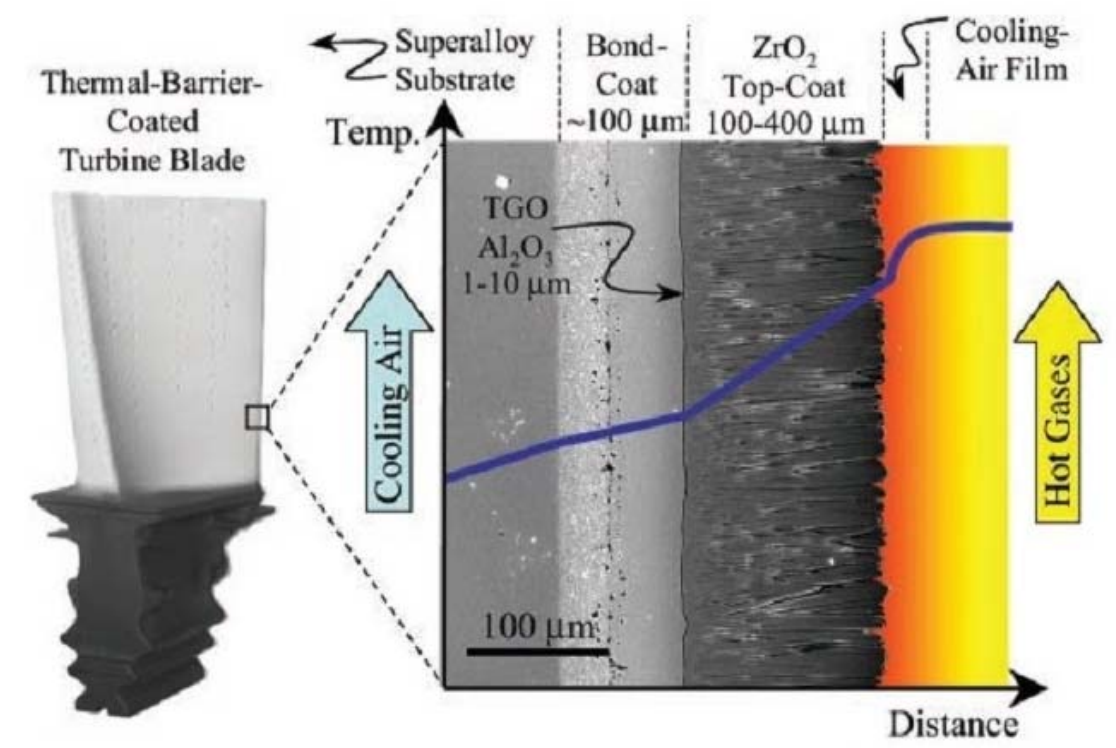

Figure 3-5. Thermal barrier coating system for gas turbine application [8]

\subsubsection{Bond Coat}

Bond coat is applied to enhance the hot corrosion and oxidation resistance of the superalloy substrate. Thus it must have high resistance against oxidation and corrosion, the required interface stability and coating adhesion as well as suitable mechanical strength. The bond coat is normally $75-150 \mu \mathrm{m}$ in thickness $[8,41]$. The usual bond coat forms a thin, adherent, and dense TGO layer on the surface upon exposure to oxygen [42]. There are two typical bond coatings: aluminide diffusion coatings (such as platinum-modified aluminium diffusion coatings) and MCrAlY ( $\mathrm{M}=\mathrm{Ni}$ or/and $\mathrm{Co}$ ) overlay coatings [43].

\subsubsection{Aluminide Diffusion Bond Coat}

Aluminide diffusion coatings have exhibited good protection against high temperature oxidation damage. The addition of platinum to the aluminide coating can improve the oxidation resistance by further promoting selective oxidation of aluminium, enhancing 
scale adhesion, and stabilizing interdiffusion between bond coat and substrate $[10,44,45]$. The Pt addition can also help to reduce the void growth along the TGO/bond coat interface and modify the morphology of TGO and bond coat/substrate $[46,47]$. R. Swadzba et al. examined the effects of Pt-modified coatings on the cyclic oxidation resistance of coated system and found that the oxide layer formed on the Pt-modified aluminide coating exhibited better adhesion in comparison to simple aluminide coatings and was able to maintain an oxide layer with higher amount of desirable $\alpha$-alumina [48].

Aluminide coatings can exhibit a two-layer or three-layer structure, which are inwardgrown (Al diffusion inwards) and outward-grown ( $\mathrm{Ni}$ and other substrate elements outward diffusion) respectively. Two-layer structure consists of an outer layer and an inner interdiffusion zone (IDZ) (Figure 3-6 (a)) while three-layer structure has an intermediate layer between outer and inner layer (Figure 3-6 (b)) [49,50].

For Pt-aluminide coatings, the phase in the outer layer is dependent on both $\mathrm{Pt}$ and $\mathrm{Al}$ compositions, as shown in Figure 3-7 [51]. $\beta-(\mathrm{Ni}, \mathrm{Pt}) \mathrm{Al}$ is the most common phase in the outer layers $[50,52]$. The outer layer can also exhibit single phase $\xi-\mathrm{PtAl}_{2}$ or a mixed $\xi+$ $\beta$ structure. The intermediate layer usually exhibits $\beta$ phase (with Pt in solid solution) and some fine precipitates. More precipitates can be found in the IDZ. Pt concentration in each layer is determined by the thickness of Pt layer and the ensuing heat treatment [49]. It is reported that there exists an optimum level of $\mathrm{Pt}$ content in $\beta$-(Ni,Pt)Al coatings, beyond which a brittle $\xi$ phase will form [53]. 


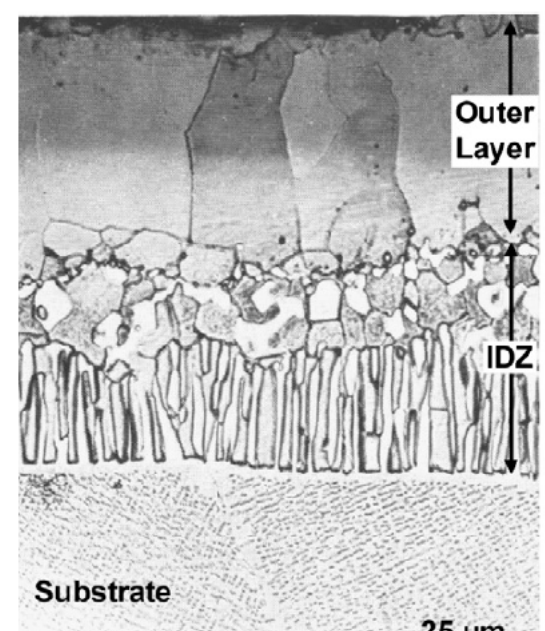

(a)
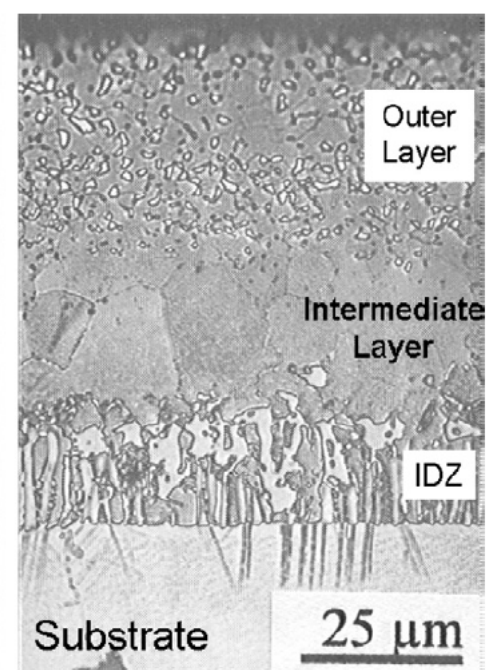

(b)

Figure 3-6. Typical microstructures of plain aluminide coatings, outward-grown (a) and inwardgrown (b) [50]

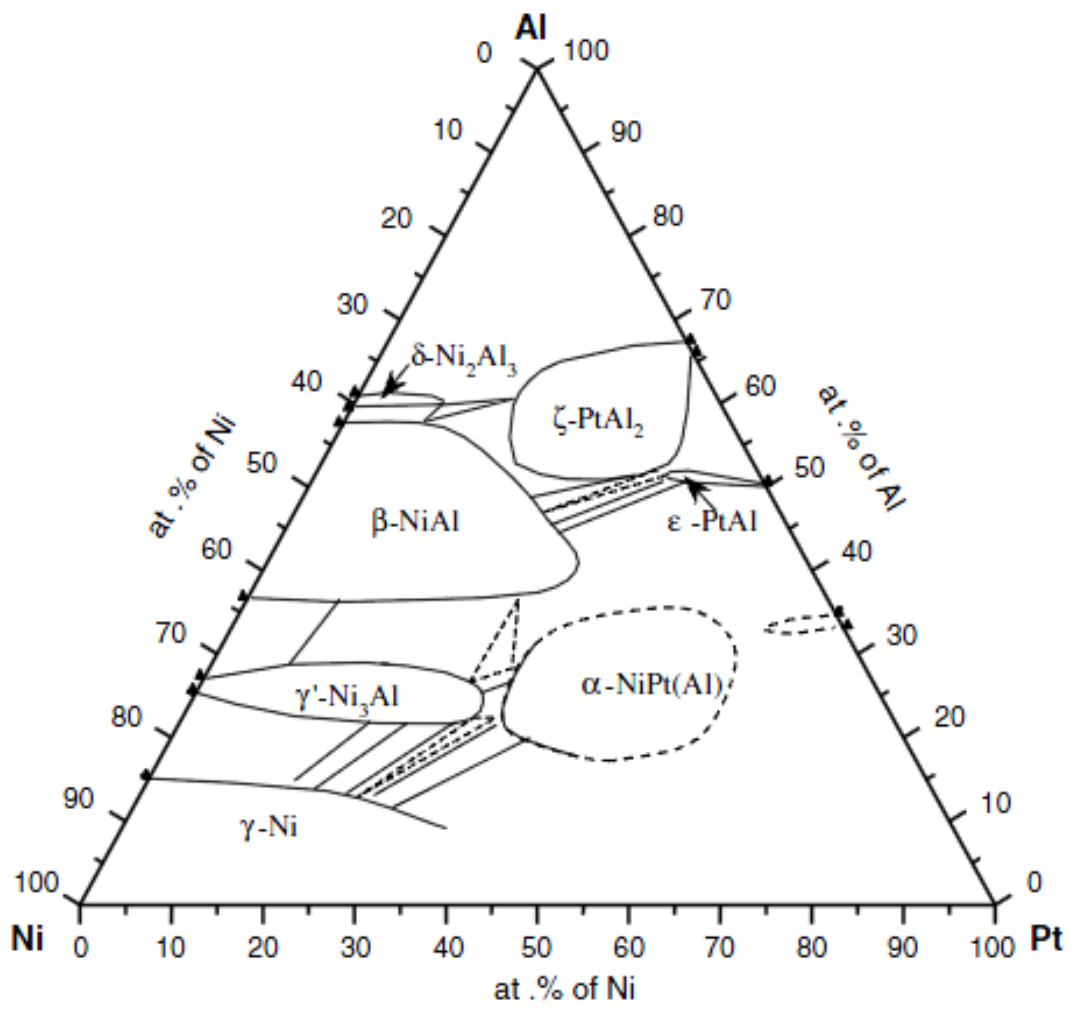

Figure 3-7. Ni-Pt-Al phase diagram at $1100^{\circ} \mathrm{C}[51]$ 
Despite its protective nature, $\beta$ - $(\mathrm{Ni}, \mathrm{Pt}) \mathrm{Al}$ coatings for Ni-base superalloy will degrade over time due to $\mathrm{Al}$ depletion and elemental inter-diffusion between coating and the substrate. Surface rumpling (Figure 3-8) and detrimental phase transformation in $\beta$ (Ni,Pt)Al coatings can lead to coating spallation and failure of TBC system [54,55]. Rumpling usually occurs during thermal cycling oxidation when the bond coat is subjected to repeated heating and cooling. Balint et al. reported that thermal expansion mismatch and phase transformation in the bond coat induce large stresses and the bond coat is especially susceptible to rumpling during thermal exposure [56].

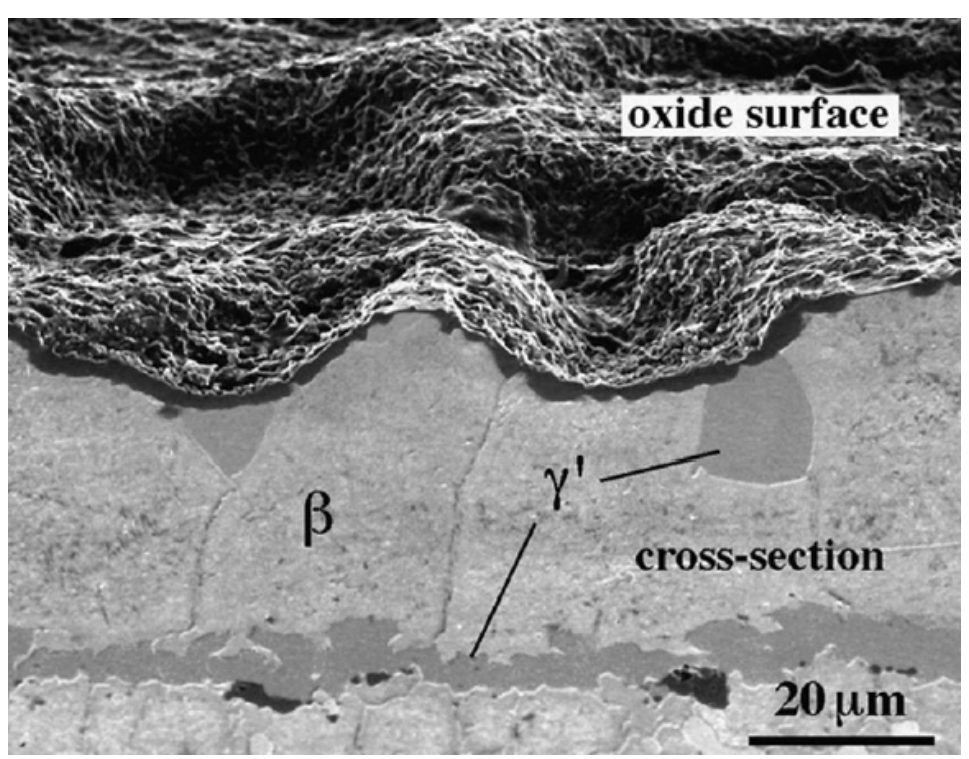

Figure 3-8. Surface rumpling of a ( $\mathrm{Ni}, \mathrm{Pt}) \mathrm{Al}$ bond coat [54]

Compared to $\beta$-(Ni,Pt)Al, $\gamma-\gamma^{\prime}$ NiPtAl coatings can form adherent alumina scales with significantly reduced rumpling during thermal cycling. Furthermore, since Ni-based superalloys also have the typical $\gamma-\gamma^{\prime}$ phase, $\gamma-\gamma^{\prime}$ NiPtAl coatings are more compatible with substrate in terms of phase constitution and thermal expansion, which is beneficial to TBC life $[57,58] \cdot \gamma-\gamma^{\prime}$ NiPtAl coatings usually show good high temperature oxidation resistance and increased amount of Pt can improve the adherence of scale [59]. But $\gamma-\gamma$ ' 
NiPtAl coatings are very sensitive to oxidation temperature and superalloy substrate composition [55].

Referring to Figure $3-7, \gamma-\gamma^{\prime}$ NiPtAl can be achieved by introducing less Al during aluminization. A typical $\gamma-\gamma^{\prime}$ NiPtAl coating consists of two layers (Figure 3-9), an outer layer (primary $\gamma^{\prime}$ phase) and a $\gamma+\gamma^{\prime}$ phase IDZ. In the IDZ, fewer precipitates are present compared to those in a $\beta$ phase coating as the solubility of various elements is higher in $\gamma^{\prime}$ phase than that in $\beta$ phase [49].

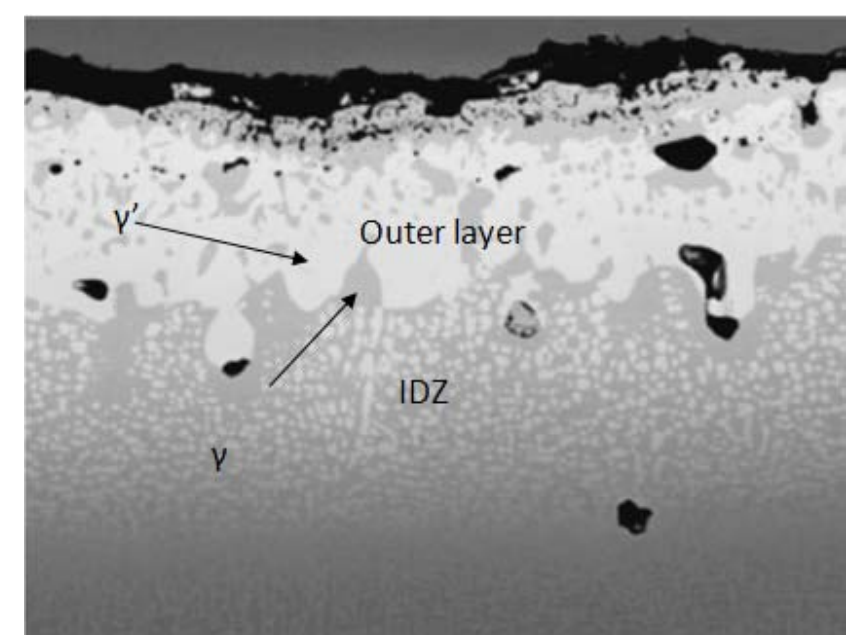

Figure 3-9. Two layered $\gamma-\gamma$ ' NiPtAl coating [60]

$\mathrm{Al}_{2} \mathrm{O}_{3}$ is the primary oxide on aluminide diffusion coatings, however, with the depletion of $\mathrm{Al}$, less protective phases such as mixed oxides (e.g. spinels, $\mathrm{Cr}_{2} \mathrm{O}_{3}$ ) form during oxidation exposure, and shorten the lifetime of TBC system [61]. The protective scale is likely to survive during isothermal high temperature exposure but will spall during thermal cycling as thermal stresses develop. The difference in coefficients of thermal expansion among bond coat, TGO and ceramic top coat and temperature gradient cause thermal stresses at the interfaces. It is also believed that the spallation of $\mathrm{Al}_{2} \mathrm{O}_{3}$ is related 
to the inter-diffusion between the substrate material and bond coat [57]. The diffusion of $\mathrm{Ni}, \mathrm{Ti}$, and refractory elements from substrate material to bond coat and TGO can cause the formation of voids (Figure 3-10), weakening the interface [49]. This is due to Kirkendall effect where the difference in diffusion fluxes on two sides results in the formation of vacancy flux (voids) [62].

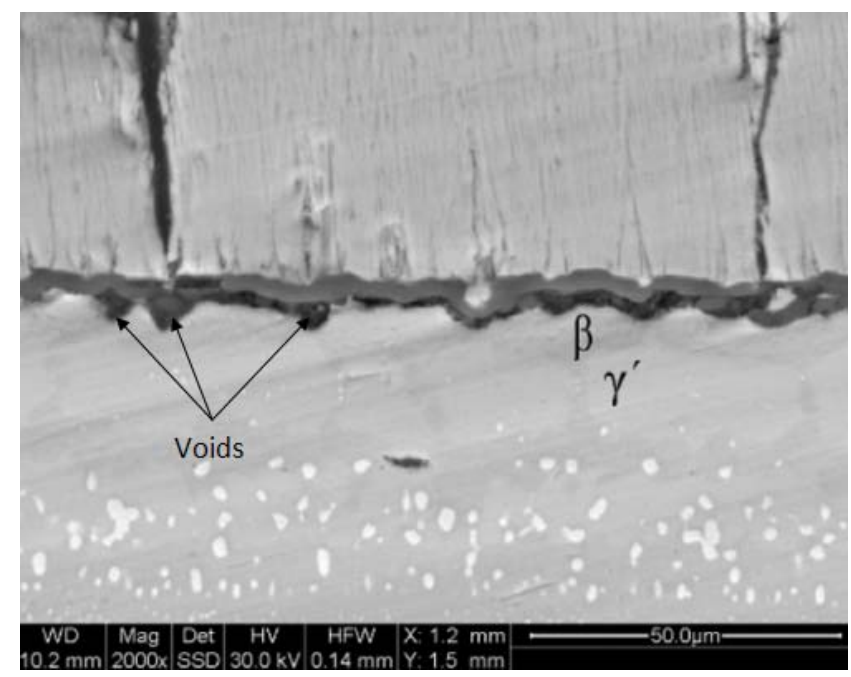

Figure 3-10. Void formation at bond coat/ TGO interface [63]

\subsubsection{MCrAIY Overlay Coatings}

Compared to the diffusion coatings, MCrAlY overlay coatings have better ductility due to the reduced $\mathrm{Al}$ content $[64,65]$. Moreover, the composition of MCrAlY can be easily designed to meet the requirements for different operating conditions [66]. For example, NiCrAlY alloys have higher ductility but lower hot corrosion resistance compared to CoCrAlY alloys [67]. CoNiCrAlY alloys were developed to have good coating ductility and high hot corrosion and oxidation resistance at the same time $[68,69]$. Figure $3-11$ shows the oxidation and hot corrosion performances of different overlay coatings, in comparison to aluminide coatings. 


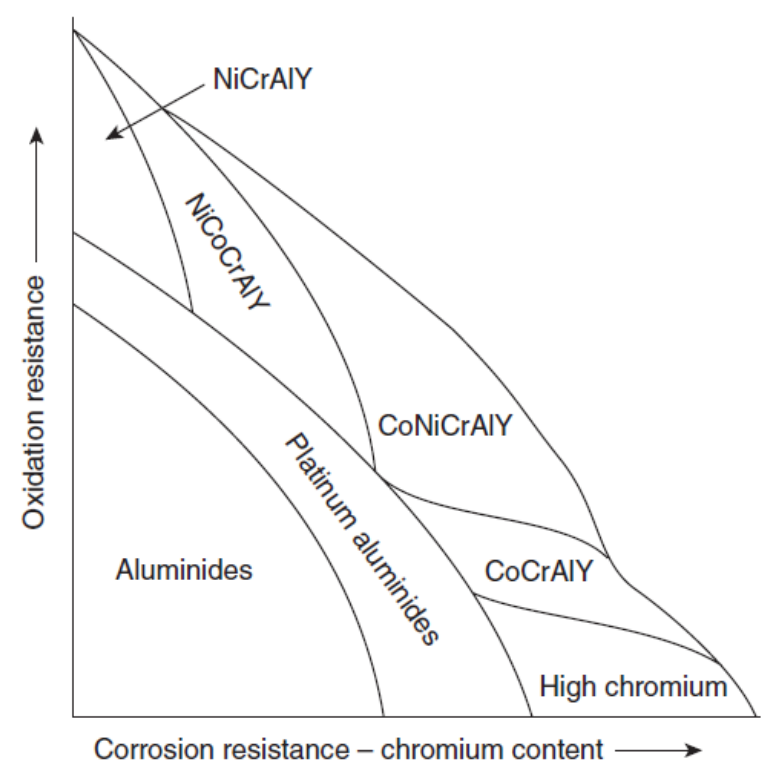

Figure 3-11. Oxidation and hot corrosion performances of different overlay coatings [66,70,71]

MCrAlYs are further classified into FeCrAlY, NiCrAlY, CoCrAlY and CoNiCrAlY. FeCrAlY coating compositions were the first MCrAlYs investigated. One particular alloy had the composition of $\mathrm{Fe}-25 \% \mathrm{Cr}-4 \% \mathrm{Al}-1.0 \% \mathrm{Y}$ when it was developed at General Electric during the nuclear programs in the 1960s [66,67]. This alloy exhibited exceptional bonding to alumina scale under cyclic oxidation condition as it assumes a body-centered cubic (BCC) structure, instead of a face-centered cubic (FCC) structure as most of the other overlay coatings [42]. The addition of yttrium in the MCrAlY in general helps improve the bond coat adhesion by segregating to the bond coat/TGO interface and increase oxidation resistance [72]. Due to the increased utilization of Ni- and Co- base superalloys in gas turbines, NiCrAlY, CoCrAlY and CoNiCrAlY were developed to match the substrate composition/microstructure [66]. They all exhibit excellent oxidation and corrosion resistance in high temperature oxidizing environment, which makes them the preferred materials for bond coatings used in TBC systems[67]. 
Ni-base MCrAlY type of coatings usually consists of either $\beta$-NiAl phase or $\beta$-aluminide phase in a $\gamma$ solution matrix. The oxidation and hot corrosion behavior, as well as phase stability, are associated with the $\beta / \gamma$ phase ratio. As shown in a $\mathrm{Ni}-\mathrm{Cr}-\mathrm{Al}$ ternary phase diagram (Figure 3-12), the $\beta+\gamma$ phase field indicates desired composition of MCrAlY coatings. When the temperature reduces from $1150^{\circ} \mathrm{C}$ to $850^{\circ} \mathrm{C}$, the $\mathrm{MCrAlY}$ (with composition represented by the small square) transforms from $\beta+\gamma$ to $\alpha-(\mathrm{Cr})+\gamma$; this phase change is accompanied by a significant volume change due to thermal expansion. Addition of appropriate amount of Co can help reduce the volume change and improve the ductility of MCrAlY bond coatings [73].

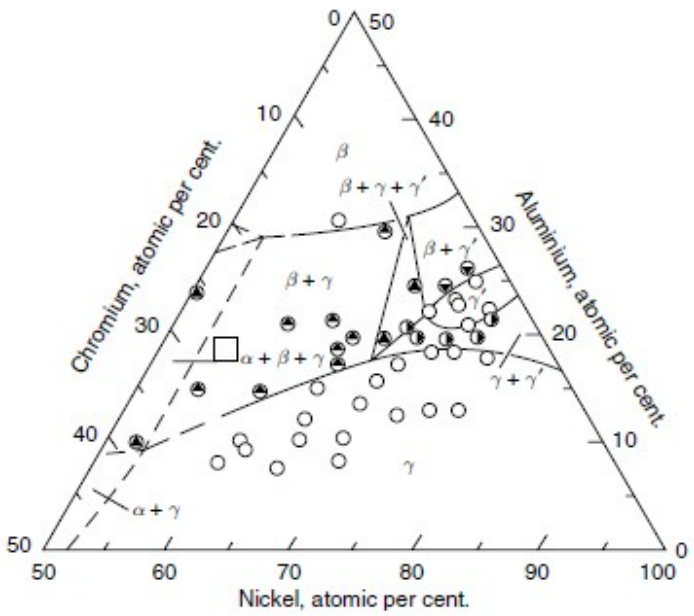

(a)

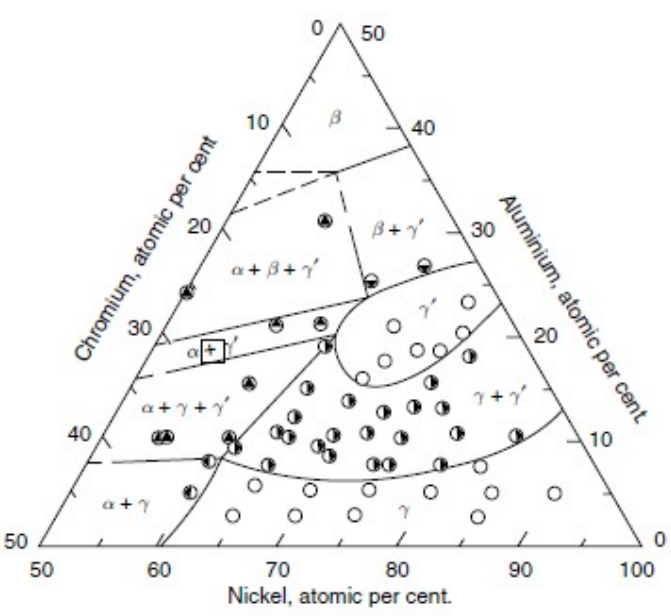

(b)

Figure 3-12. Isothermal $\mathrm{Ni}-\mathrm{Cr}-\mathrm{Al}$ ternary phase diagram (a) at $1150^{\circ} \mathrm{C}$, (b) at $850^{\circ} \mathrm{C}[73,75]$

Similarly, the concentration of Al affects the performance of bond coat as well. Brandl et al. had carried out isothermal tests on NiCoCrAlY with $8 \mathrm{wt} \%$ and $12 \mathrm{wt} \% \mathrm{Al}$ in air and in $\mathrm{He}$ with $1 \% \mathrm{O}_{2}$. The results showed that the oxide scale on the coatings with $8 \mathrm{wt} \% \mathrm{Al}$ had cracked after $500 \mathrm{~h}$ while for the coating with $12 \mathrm{wt} \% \mathrm{Al}$, the scale was still uniform even after $4000 \mathrm{~h}$ [74]. The beneficial and detrimental aspects of several alloying 
elements in MCrAlY coatings are summarized in Table 3-3. MCrAlY bond coats are usually deposited using thermal spray or electron-beam physical-vapor deposition method [8]. The details of deposition methods are further discussed in the next section.

Table 3-3. Beneficial and detrimental aspects of alloying elements in metallic coatings $[73,76]$

\begin{tabular}{|c|c|c|}
\hline $\begin{array}{l}\text { Elemental } \\
\text { Constituent }\end{array}$ & Beneficial Aspects & Detrimental Aspects \\
\hline $\mathrm{Ni}$ & $\begin{array}{l}\text { Major constituent of substrate } \\
\text { alloy. Provides strength. }\end{array}$ & $\begin{array}{l}\text { Prone to destructive interaction } \\
\text { with sulfur. }\end{array}$ \\
\hline Co & $\begin{array}{l}\text { Major constituent of substrate } \\
\text { alloy. } \\
\text { Provides microstructural stability } \\
\text { and strength. }\end{array}$ & $\begin{array}{l}\text { Prone to destructive interaction } \\
\text { with sulfur. }\end{array}$ \\
\hline $\mathrm{Al}$ & $\begin{array}{l}\text { Constituent of substrate alloy. } \\
\text { Major contributor to strengthening. } \\
\text { Contributes to oxidation resistance. }\end{array}$ & $\begin{array}{l}\text { Large concentration lowers } \\
\text { melting point. }\end{array}$ \\
\hline $\mathrm{Cr}$ & $\begin{array}{l}\text { Constituent of substrate alloy. } \\
\text { Contributes to oxidation resistance } \\
\text { to } 1500^{\circ} \mathrm{F}\left(816^{\circ} \mathrm{C}\right) \text {. } \\
\text { Reduces } \mathrm{Al} \text { requirement for } \\
\text { formation of alumina scale. } \\
\text { Imparts resistance to hot corrosion. }\end{array}$ & Lowers creep strength. \\
\hline $\mathrm{Ta}$ & $\begin{array}{l}\text { Enhances hot corrosion and } \\
\text { oxidation resistance. } \\
\text { Improves strength. }\end{array}$ & \\
\hline $\mathrm{Si}$ & $\begin{array}{l}\text { Enhances oxidation and type II hot } \\
\text { corrosion resistance. }\end{array}$ & $\begin{array}{l}\text { Large concentration leads to } \\
\text { formation of brittle phases. }\end{array}$ \\
\hline $\begin{array}{l}\mathrm{Hf}, \mathrm{Y}, \mathrm{Y}_{2} \mathrm{O}_{3} \\
\text { oxides of other } \\
\text { reactive elements }\end{array}$ & $\begin{array}{l}\text { Improves adherence of alumina } \\
\text { and chromia scales. }\end{array}$ & Large amounts are detrimental. \\
\hline $\mathrm{Pt}$ & $\begin{array}{l}\text { Improves oxidation and hot } \\
\text { corrosion resistance. }\end{array}$ & \\
\hline
\end{tabular}

\subsubsection{Bond Coat Application Process}

For overlay coatings, aluminizing can be accomplished by using thermal spraying methods, chemical vapor deposition (CVD) or physical vapor deposition (PVD). In all of the thermal spraying methods, a fine powder is heated and melted, and then injected to 
impact with the cool substrate, where it solidifies. In CVD method, a chemical process takes place when in contact with a heated material and the reaction leads to condensation/deposition. PVD processes are further divided into thermal evaporation, ion sputtering and ion plating [77]. In thermal evaporation process, the metallic material is evaporated at high temperature and high vacuum level, and the vapor is condensed on the cool substrate surface. Ion sputtering uses a cathode electrode to emit atoms and atomic clusters (sputter) so that the substrate material is bombarded by positive ions and energetic particles. In ion plating process, an electron beam is used to evaporate the target material. The metal vapor is then ionized partially to increase the coating adhesion [77].

Pack and slurry cementation processes are the most commonly used methods for aluminide diffusion coating deposition. It is based on the following reaction:

$\mathrm{Al}+\mathrm{NH}_{4} \mathrm{Cl} \rightarrow \mathrm{AlCl}(\mathrm{g}) \rightarrow \mathrm{Al}$

The pack powder usually consists of pure $\mathrm{Al}$ powder, $\alpha-\mathrm{Al}_{2} \mathrm{O}_{3}$ filler and $\mathrm{NH}_{4} \mathrm{Cl}$ activator, and parts to be coated are buried within the powder during coating process. When pack powder materials are suspended in a binder, it forms a slurry which can be coated onto the substrate by dipping or spraying before being heated [77,78]. A post coating heat treatment is then applied to obtain good bonding between substrate and bond coat and encourage diffusion. For PtAl diffusion coatings, a platinum layer is first deposited by electroplating and followed by a diffusion heat treatment. After plating of platinum, aluminide coating is then applied $[79,80]$. 


\subsubsection{TGO}

Thermally grown oxide (TGO) is a thin oxidized layer $(1-10 \mu \mathrm{m}$ in thickness) formed between top coat and bond coat as a result of high temperature oxidation [8]. The oxygen is either from hot gas penetrating through porosities and microcracks in the top coat or the downward and upward diffusion of oxygen ions from coatings themselves [81]. TGO consists mainly of $\alpha-\mathrm{Al}_{2} \mathrm{O}_{3}$ and other minor $\mathrm{Cr} / \mathrm{Ni}$-containing oxides as well as $\mathrm{NiAl}_{2} \mathrm{O}_{4}$ spinels. Since the diffusion rate of ions in $\alpha-\mathrm{Al}_{2} \mathrm{O}_{3}$ is slow, a continuous $\alpha-\mathrm{Al}_{2} \mathrm{O}_{3}$ scale can suppress TGO growth during oxidation. Therefore $\alpha$-alumina is the most desirable constituent of TGO [82]. This oxide scale can protect the substrate from further oxidation. A fast growing TGO, however, can impose stresses on the interfaces of TGO/ bond coat and $\mathrm{TGO} /$ top coat leading to crack linkage and propagation and eventually the failure of TBCs $[81,83]$. It was reported that the formation of porous spinel and nickel oxide causes large volume expansion and tensile stress, contributing to the failure of TBCs [82].

TGO growth plays an important role in the ultimate failure of TBC system. Defects coupled with stress and TGO waviness are thought to be the main reason why small cracks can grow and cause the spallation of top coat $[84,85]$. Chen et al. have found that the TGO with a stable $\mathrm{Al}_{2} \mathrm{O}_{3}$ layer had a low growth rate and less tendency for crack propagation, which led to better $\mathrm{TBC}$ durability [86]. There exists an Al-depletion criterion based on the combined time and temperature for MCrAlY bond coatings; if the aluminum concentration falls to about 8 at $\%$, other mixed oxides and spinels will grow and these mixed oxides and spinels cannot act as a protective scale, resulting in increased oxidation rate [87]. According to Buschinelli et al., three types of defects were found 
during TGO growth under thermal cycling: vertical columnar cracks, cavities and horizontal cracks parallel to TGO. Among the three imperfections, horizontal cracks were believed to be the main reason for the TBC failure [83]. The TGO thickness showed an increasing relationship with maximum crack length, or vice versa (Figure 3-13 (a)). The maximum crack length also increased with the increasing number of cycles as shown in (Figure 3-13 (b)) [88].

TGO growth during cyclic test follows a three-stage course. A rapid TGO growth occurs at the beginning of oxidation, followed by a nearly linear growth, and finally an accelerated growth ensues (very similar to the creep deformation mechanism). The last stage is related to heterogeneous and substantial growth of mixed oxides and spinels [88]. Crack nucleation and void formation are usually located near oxide cluster and spinels (CS) layer [89], as shown in Figure 3-14 (a). The discontinuities which are common in APS coatings can also develop into fully open cracks (Figure 3-14 (b)) [88]. This evidence indicates that the formation of non-protective oxides and discontinuities are detrimental to the life of TBC systems [86].

Toscano at al. stated that the rate of yttrium depletion is another important lifetime governing factor. They found that yttrium partitioning in alumina based TGO increased the TGO growth rate and resulted in the loss of yttrium in the coating [90]. When the concentration of yttrium in the coatings is under a critical level, it can no longer improve the adherence of TGO, leading to the failure of TBCs. The time required for yttrium exhaustion is related to both initial yttrium content and the total yttrium reservoir, which is proportional to the bond coat thickness [90]. 


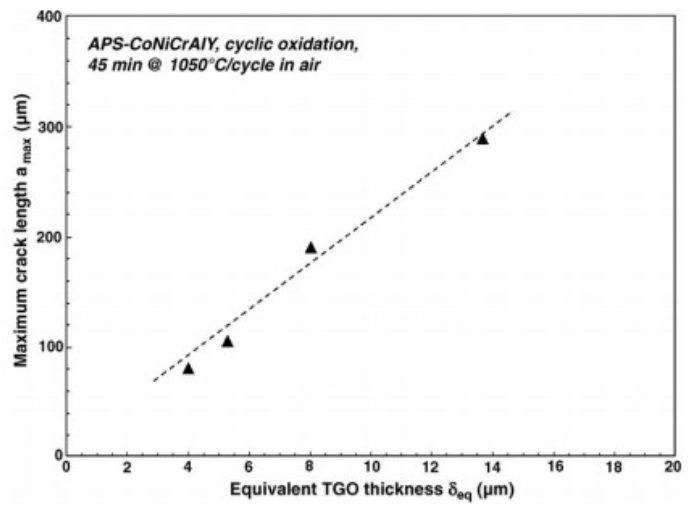

(a)

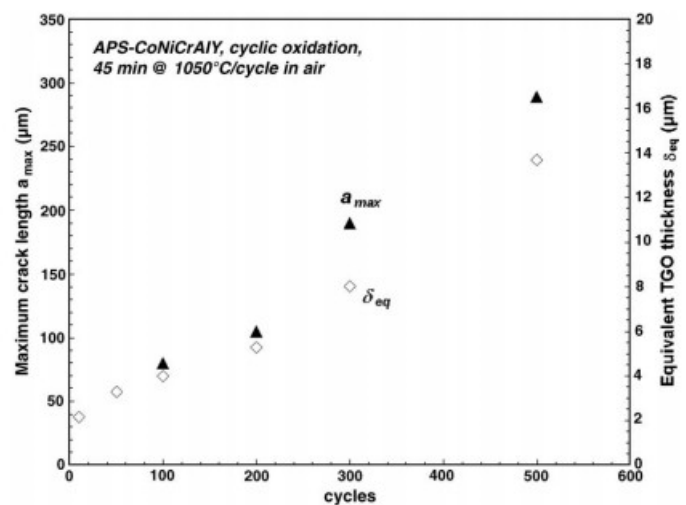

(b)

Figure 3-13. (a) Maximum crack length vs. TGO thickness under cyclic oxidation. (b) Maximum crack length vs. number of cycles under cyclic oxidation [88]
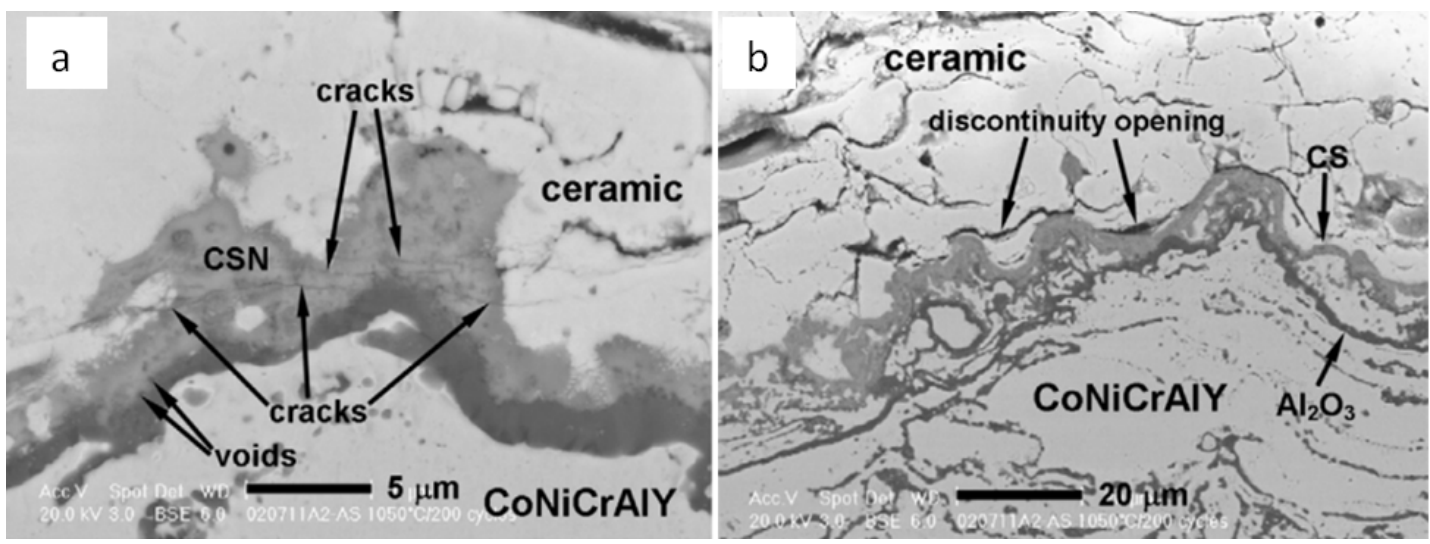

Figure 3-14. Crack propagation in the APS coatings at $1050{ }^{\circ} \mathrm{C}$ due to discontinuities opening after 300 cycles (a) and crack propagation associated with the CSN after 500 cycles (b) [88]

TGO growth plays a controlling role in TBC lifetime. Therefore, in order to improve the performance of TBC system, all factors such as $\mathrm{Al}$ or $\mathrm{Y}$ depletion, growth of chromia, spinels, $\mathrm{NiO}(\mathrm{CSN})$, and thickening of TGO layers must be characterized. Improvement to $\mathrm{TBC}$ deposition techniques, bond coat compositions and pre-oxidation treatments are some of the approaches used to prolong TBC's durability. Baufeld et al. investigated the effect of pre-treatments on Pt-Al bond coats before the deposition of ceramic top coats. 
Under cyclic thermal test with a maximum temperature of $1100^{\circ} \mathrm{C}$ and a cycle length of 1 hour, the result showed that the specimens annealed at $1080^{\circ} \mathrm{C}$ for 4 hours either in vacuum or ArH atmosphere had significant longer lifetimes (2-3 times longer) than those without pre-treatment [91].

\subsubsection{Ceramic Top Coat}

The top coat provides thermal insulation to the metallic substrate and prolongs the lifetime of the hot components of aero- and land-based gas turbines, in combination with the internal cooling scheme. Ceramic coatings have low thermal conductivities, usually in the order of several $\mathrm{W} / \mathrm{m} \cdot \mathrm{K}$ [92]. There are some basic requirements for the ceramic top coats, such as low thermal conductivities, high melting points, absence of phase transformation between room temperature and working temperature, thermal expansion matching to bond coat material, good adherence to the bond coat and low sintering rate $[92,93,94]$. Among those factors, thermal expansion coefficient (CTE) and thermal conductivity are the most important properties for selecting ceramic top coat material [92,95,96]. Table 3-4 shows the characteristics of different ceramic materials [94]. 
Table 3-4. Ceramic materials and their characteristics [94]

\begin{tabular}{|c|c|c|}
\hline Materials & Advantages & Disadvantages \\
\hline $7-8 \mathrm{YSZ}$ & $\begin{array}{l}\text { (1) high thermal expansion coefficient } \\
\text { (2) low thermal conductivity } \\
\text { (3) high thermal-shock resistance }\end{array}$ & $\begin{array}{l}\text { (1) sintering above } 1473 \mathrm{~K} \\
\text { (2) phase transformation }(1443 \mathrm{~K}) \\
\text { (3) corrosion } \\
\text { (4) oxygen-transparent }\end{array}$ \\
\hline $\begin{array}{l}\text { Mullite } \\
\left(3 \mathrm{Al}_{2} \mathrm{O} 3 \cdot 2 \mathrm{SiO}_{2}\right)\end{array}$ & $\begin{array}{l}\text { (1) high corrosion resistance } \\
\text { (2) low thermal conductivity } \\
\text { (3) good thermal-shock resistance } \\
\text { below } 1273 \mathrm{~K}\end{array}$ & $\begin{array}{l}\text { (1) crystallization }(1023-1273 \mathrm{~K}) \\
\text { (2) very low thermal expansion } \\
\text { coefficient }\end{array}$ \\
\hline $\begin{array}{l}\text { Alumina } \\
\left(\mathrm{Al}_{2} \mathrm{O}_{3}\right)\end{array}$ & $\begin{array}{l}\text { (1) high corrosion resistance } \\
\text { (2) high hardness } \\
\text { (3) not oxygen-transparent }\end{array}$ & $\begin{array}{l}\text { (1) phase transformation (1273 K) } \\
\text { (2) high thermal conductivity } \\
\text { (3) very low thermal expansion } \\
\text { coefficient }\end{array}$ \\
\hline $\mathrm{YSZ}+\mathrm{CeO}_{2}$ & $\begin{array}{l}\text { (1) high thermal expansion coefficient } \\
\text { (2) low thermal conductivity } \\
\text { (3) high corrosion resistance } \\
\text { (4) less phase transformation between } \\
m \text { and t phase than YSZ } \\
\text { (5) high thermal-shock resistance }\end{array}$ & $\begin{array}{l}\text { (1) increased sintering rate } \\
\text { (2) } \mathrm{CeO}_{2} \text { precipitation }(>1373 \mathrm{~K} \text { ) } \\
\text { (3) } \mathrm{CeO}_{2} \text {-loss during spraying }\end{array}$ \\
\hline $\mathrm{La}_{2} \mathrm{Zr}_{2} \mathrm{O}_{7}$ & $\begin{array}{l}\text { (1) very high thermal stability } \\
\text { (2) low thermal conductivity } \\
\text { (3) low sintering rate } \\
\text { (4) not oxygen-transparent }\end{array}$ & $\begin{array}{l}\text { (1) relatively low thermal } \\
\text { expansion coefficient }\end{array}$ \\
\hline $\mathrm{La}_{2} \mathrm{Ce}_{2} \mathrm{O}_{7}$ & $\begin{array}{l}\text { (1) very high thermal stability } \\
\text { (2) high thermal expansion coefficient } \\
\text { (3) low thermal conductivity } \\
\text { (4) high corrosion resistance }\end{array}$ & $\begin{array}{l}\text { (1) } \mathrm{CeO}_{2} \text {-loss during spraying } \\
\text { (2) relatively high sintering rate } \\
(>1523 \mathrm{~K})\end{array}$ \\
\hline Silicates & $\begin{array}{l}\text { (1) cheap, readily available } \\
\text { (2) high corrosion resistance }\end{array}$ & $\begin{array}{l}\text { (1) decomposition into } \mathrm{ZrO}_{2} \text { and } \\
\mathrm{SiO}_{2} \text { during } \\
\text { thermal spraying } \\
\text { (2) very low thermal expansion } \\
\text { coefficient }\end{array}$ \\
\hline $\mathrm{SrZrO}_{3}$ & $\begin{array}{l}\text { (1) high thermal expansion coefficient } \\
\text { (2) low thermal conductivity } \\
\text { (3) low sintering rate }\end{array}$ & $\begin{array}{l}\text { (1) phase transformations } \\
\text { (2) SrO-loss during spraying }\end{array}$ \\
\hline
\end{tabular}


Zirconia $\left(\mathrm{ZrO}_{2}\right)$ is typically used for ceramic top coats because of the low thermal conductivity, high CTE and high thermal shock resistance [94]. Pure $\mathrm{ZrO}_{2}$ undergoes a phase transformation from tetragonal $(t)$ to monoclinic $(m)$ at $950^{\circ} \mathrm{C}$ during cooling; this bring about a volume expansion of $\sim 4 \%$, causing shear strain to the structure This change volume affects the integrity of the coating during service and may lead cracking. The addition of dopant oxides such as $\mathrm{MgO}$ or $\mathrm{Y}_{2} \mathrm{O}_{3}$ can suppress the phase transformation and stabilize (or partially stabilize) the $t$ phase when being cooled to room temperature [92]. According to the high temperature durability rig testing performed at NASA the optimum amount of yttria, as shown in Figure 3-15, is $7 \mathrm{wt} \%$ [97]. It is a resulted of the fact that $7-8 \mathrm{wt} \%$ yttria can stabilize the most desirable metastable phase $t$ ' for TBC application [98].

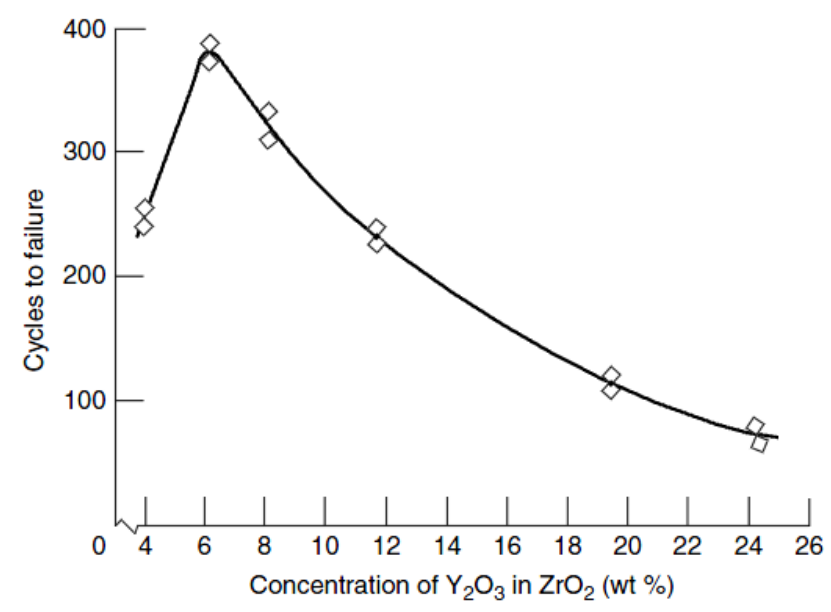

Figure 3-15. Durability of TBC with different concentrations of $\mathrm{Y}_{2} \mathrm{O}_{3}$ [97]

$\mathrm{Y}_{2} \mathrm{O}_{3}$ stabilized $\mathrm{ZrO}_{2}$ (YSZ) has low thermal conductivity, high melting point, relatively high fracture toughness, high thermal expansion, thus is widely used for TBC systems in gas turbine blade applications [82]. The YSZ top coat is typically applied over a bond coat by thermal spraying depositions such as air plasma spraying (APS), vacuum plasma 
spraying (VPS), or by electron beam physical vapor deposition (EB-PVD) [42]. The techniques for top coat deposition are introduced in the next subsection.

\subsection{Techniques for YSZ Ceramic Top Coating Deposition}

\subsubsection{Electron Beam Physical Vapor Deposition (EB-PVD)}

Physical vapor deposition for TBCs has been investigated by many researchers from US, UK, Germany and countries of the former Soviet Union since the 1980s. A significant development of this technique emerged in the 1990s, when the Paton Welding Institute in Ukraine invented a new EB-PVD technology which decreased the costs of this deposition method. Since then the EB-PVD technique has been widely applied to produce thermal barrier coatings by many OEMs [99].

TBCs produced by EB-PVD have shown a superior strain and thermo-shock tolerance due to the inherent columnar microstructures. They also exhibit good resistance to spallation, low surface roughness, high thickness uniformity and good adherence to the substrate over those processed by plasma spraying, and became the most promising protective coatings for stressed parts in the hot sections of gas turbine engines. The equipment and process costs of EB-PVD are much higher than APS but the superior performance of EB-PVD TBCs justifies its use for critical components such as turbine blades $[15,16]$.

\subsubsection{EB-PVD Equipment and Deposition Process}

EB-PVD technology introduces an electron beam as a heat source. First, an electron beam is formed at $2000^{\circ} \mathrm{C}$ in an electron gun, and then the electrons are accelerated by high voltage. When the target material is hit by the high-speed electrons, it starts to melt 
and vaporize; the vapour is directed to and deposits onto the substrate in a low pressure environment. EB-PVD method has a higher deposition rate and leads to a much stronger bonding between deposited coating and substrate than those deposited by APS method. Moreover, since the deposition parameters such as electron beam power, beam spot size and location can be easily controlled, it is possible for EB-PVD to obtain a coating with uniform thickness and smooth surface [100].

An example of EB-PVD system, which consists of one central vapor deposition chamber (main chamber), pre-vacuum chambers and electronic guns, is illustrated Figure 3-16 [99,101]. Among these guns one is for pre-heating the substrate materials in order to achieve the right deposition condition and the others are used for melting and evaporating the target materials. There are also vertical and horizontal transmission components and three water-cooled crucibles for target materials. The work piece can be fed into the main chamber by valves [99]. The pressure in the vacuum chamber is usually $10^{-3}$ torr to avoid collision between air and deposition atoms as well as reaction with $\mathrm{N}$ and $\mathrm{O}$. Figure 3-17 shows a typical EB-PVD facility and deposition process.

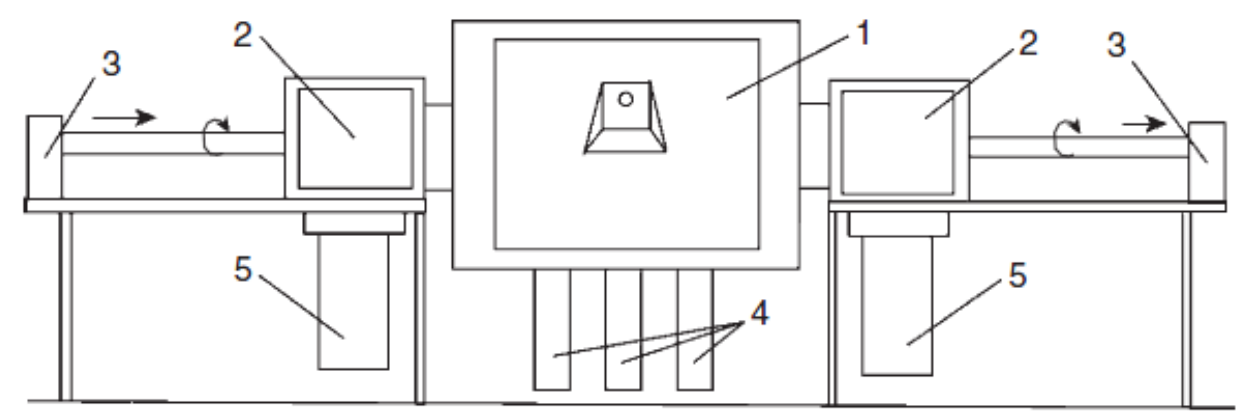

Figure 3-16. Industrial production system of EB-PVD: 1. Central vapor deposition chamber; 2.

Target storage rooms; 3. Horizontal transmission and rotation components; 4. Transmission components for target material; 5. Vacuum chamber $[99,101]$ 


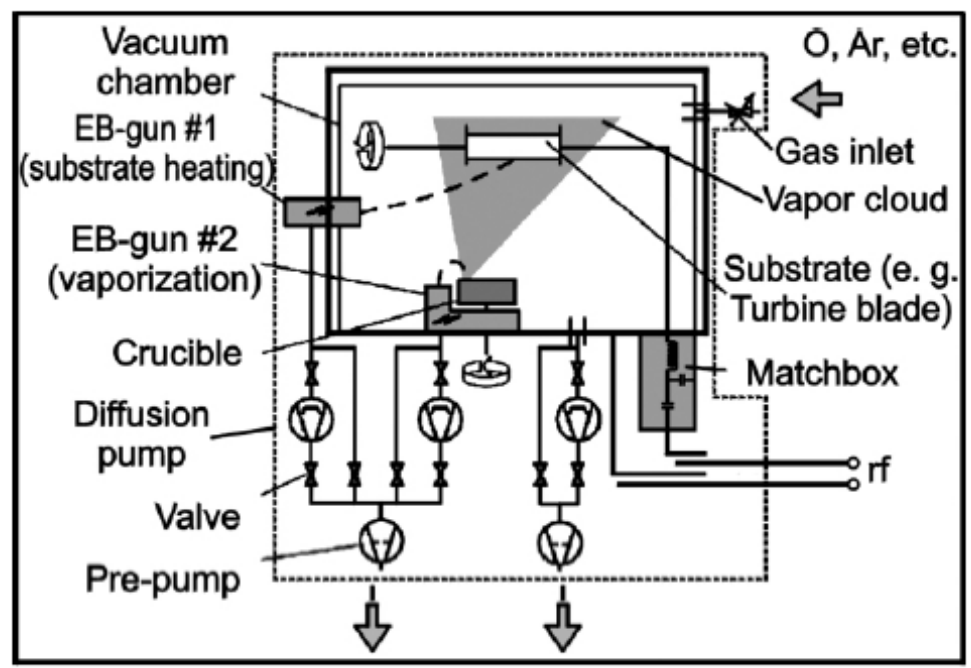

Figure 3-17. ED-PVD equipment and process set up [102]

\subsubsection{Microstructure of EB-PVD Coatings}

TBCs deposited by EB-PVD technique have a unique columnar microstructure (Figure 318) which provides superior tolerance against stresses, erosion and thermo shock, thus having a longer lifetime than those deposited by plasma spraying method [16]. The columnar grains can also suppress the cracking in TBCs parallel to the metallic-bonding layer interface $[103,104]$. However, this columnar structure, as demonstrated in Figure 319, has the disadvantage of a high thermal conductivity when compared to laminar structure, which is the inherent structure of APS due to the impact of molten powder particles. Thus one of the challenges for EB-PVD coatings is to lower the thermal conductivity through microstructure modification and composition optimization $[105,106]$ 


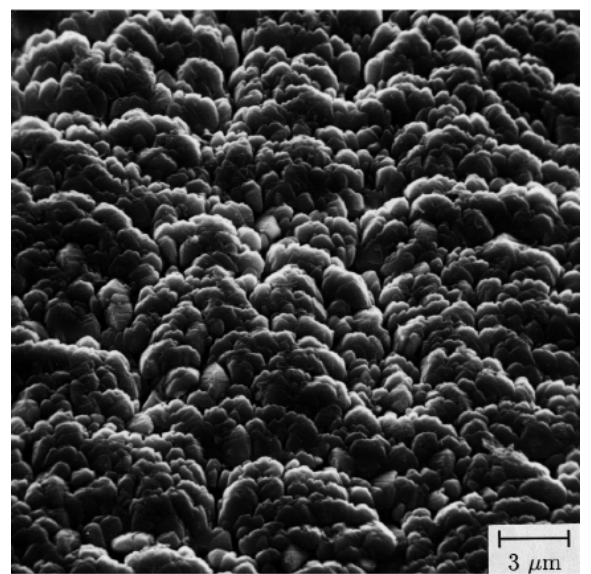

(a)

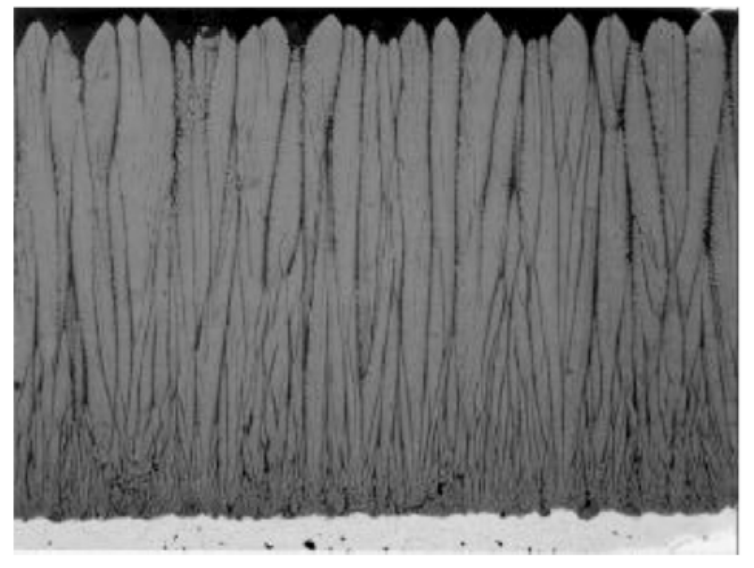

(b)

Figure 3-18. Scanning electron micrographs of an EB-PVD coating (a) finished surface [107] and (b) cross section showing its columnar microstructure [105]

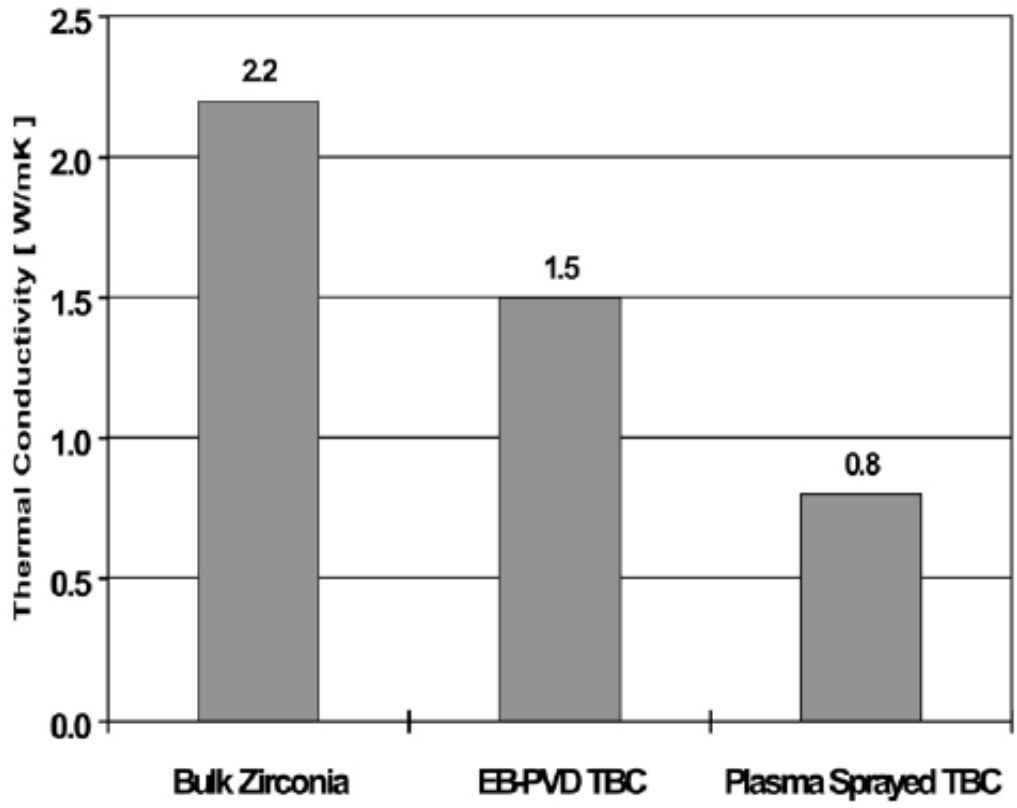

Figure 3-19. Thermal conductivity of zirconia and zirconia top coatings applied by EB-PVD and PS methods [106] 
Rotating the substrate material during coating deposition, in addition to facilitating a stable temperature and a uniform coating thickness, is also beneficial in lowering thermal conductivities of EB-PVD deposited coatings. "This rotation leads to the formation of unique banana-shaped intra-columnar pores and feather-like sub-columnar structure at the periphery of each individual column due to over-shadowing [108]." This feather-like sub-columnar structure increases the micro-porosity in the coating thus helps lower the thermal conductivity [108]. Furthermore, those columns are weakly connected with each other by inter-columnar gaps, which contribute to the higher thermo shock resistance [109], as shown in Figure 3-20.

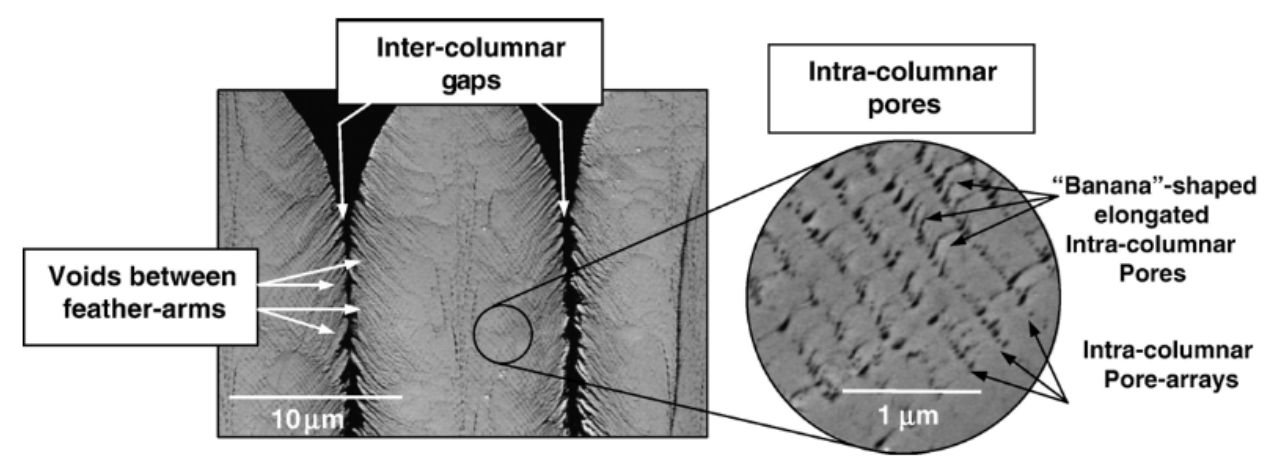

Figure 3-20. Scanning electron micrograph of EB-PVD top coat cross-section [109]

\subsubsection{Failure of EB-PVD Coatings}

During thermal exposure, sintering occurs in the EB-PVD coating, in order to decrease the surface energy, and leads to reduction in both inter- and intra-columnar porosities. Consequently, thermal conductivity will increase over the time. Renteria et al. conducted a series of tests to prove the assumption that the size and shape of intra-columnar pores could greatly affect thermal conductivity $[108,109]$. It was observed that the intracolumnar pores which retained the elongated shape were more resistant to sintering. High 
aspect-ratio, high density intra-columnar pore arrays also contributed to lower thermal conductivity and higher resistance against thermal property degradation. In addition to porosity, the thickness of the coating also affects thermal conductivity value due to microstructure changes during application process. According to Ratzer-Scheibe et al. [110], the thermal conductivities of free-standing YSZ coatings increased with increasing thickness. i.e., the thermal conductivity for a coating with a thickness of $300 \mu \mathrm{m}$ is $\sim 40 \%$ higher than that of a thinner layer of $\sim 50 \mu \mathrm{m}$. Figure 3-21 shows the effects of the coating thickness on the thermal conductivity of EB-PVD PYSZ coatings at different temperatures. This reason for the elevated thermal conductivity is due to the increase in both column size and grain size within each column at later stages of EB-PVD coating process when crystal structure becomes more perfect. As such for depositing thicker EBPVD coatings, periodic interruptions are needed to encourage new grain formation and create crystalline defects with the coating [111].

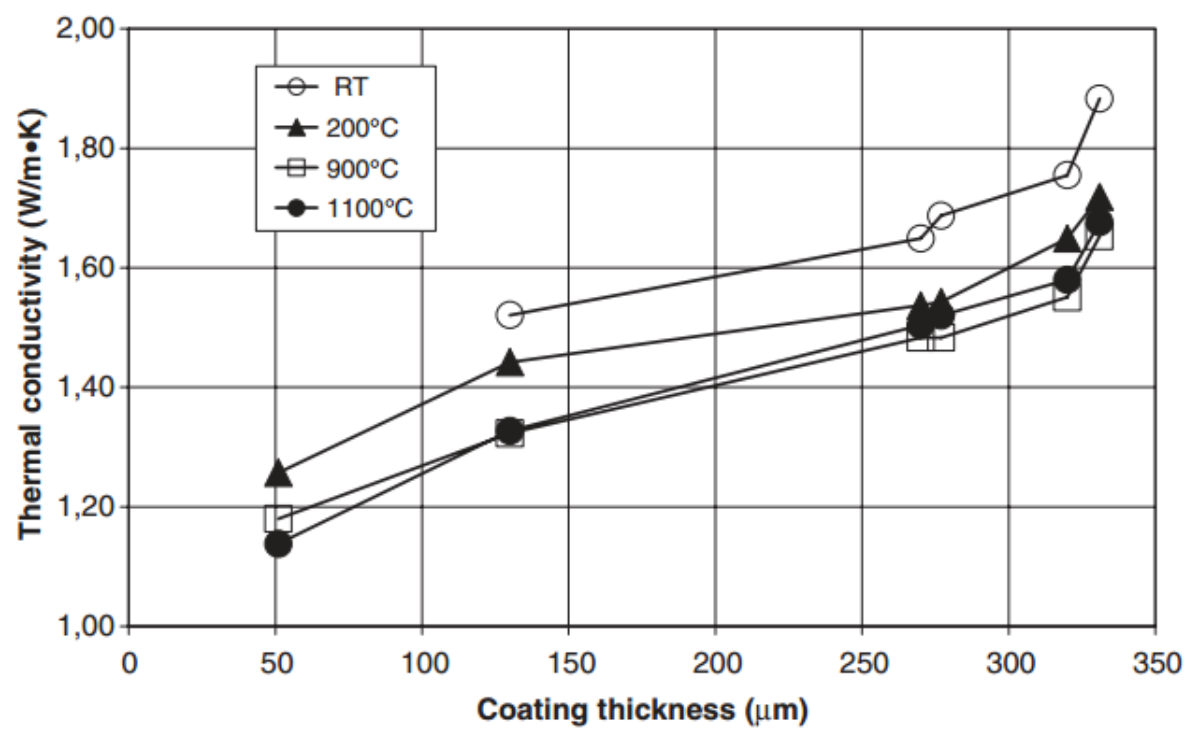

Figure 3-21. Effects of the coating thickness on the thermal conductivity of EB-PVD PYSZ coatings at different temperatures [110] 
The microstructure change of EB-PVD coatings during isothermal exposure also affects other properties. For example, after high temperature exposure, the feathery morphology of primary columns disappeared and necks formed between adjacent columns; this caused an increase in Young's modulus and consequently degraded the strain tolerance of TBCs [112]. During cyclic thermal exposure, thermal stresses, in combination with microstructure degradation, can lead to $\mathrm{TBC}$ spallation at the $\mathrm{TGO} /$ bond coat interface or at the top coat itself. Sridharan et al. reported that the failure usually occurs within the ceramic coat when tested with short-duration cycles, while the spallation mostly happens at the $\mathrm{TGO} /$ bond coat interface for cycling test with long duration per cycle [113].

\subsubsection{Air Plasma Spraying (APS)}

Since the 1960s, plasma sprayed thermal barrier coatings (PS-TBCs) have been used in diesel engines, aerospace and land-based gas turbine to reduce the surface temperature of hot section parts by $100^{\circ} \mathrm{C}$ to $200^{\circ} \mathrm{C}$ [114]. Although EB-PVD TBC coatings have superior strain/stress tolerance and smoother surface, the PS method is widely used in the gas turbine industry because of its low cost, high production efficiency, large range of coating thickness and easy control of compositions [11,114]. All metals, ceramic and polymer materials, can be sprayed with plasma spraying processes [115]. The melting temperature of the target material is required to be at least $300^{\circ} \mathrm{C}$ lower than its vaporization temperature to avoid low deposition efficiency [116]. Comparing to EBPVD coatings, APS ceramic coats exhibit increased thermal resistance due to the laminar structure [12]. However, the porosity and micro-cracks in the APS coatings can lead to premature failure of TBCs during high temperature oxidation $[8,117]$. 


\subsubsection{APS Deposition Process}

Air plasma spraying (APS), a coating process carried out at atmospheric pressure, uses a high temperature plasma jet to inject and melt the powder feedstock. In the plasma jet the feedstock powder gains speed and temperature and is propelled towards a substrate. At the surface of substrate material, the power particles are flattened and solidified, forming laminar-structured coatings [118]. Figure 3-22 (a) demonstrates the air plasma spray process [119]. A typical plasma spray system consists of: (1) a spray gun, to melt and accelerate the powder particles, (2) a feeder which supplies the powder to the gun, (3) gases as a media to generate the plasma and to carry the powder, (4) maybe a robot for controlling the torch and part movement, and (5) a power supply for the torch and control system [114]. Figure 3-22 (b) shows a typical plasma spray system using a direct current electric arc between two electrodes in the spray gun. The torch can heat up to $6000 \mathrm{~K}$ to $10000 \mathrm{~K}$ and is cooled with circulating water [120].

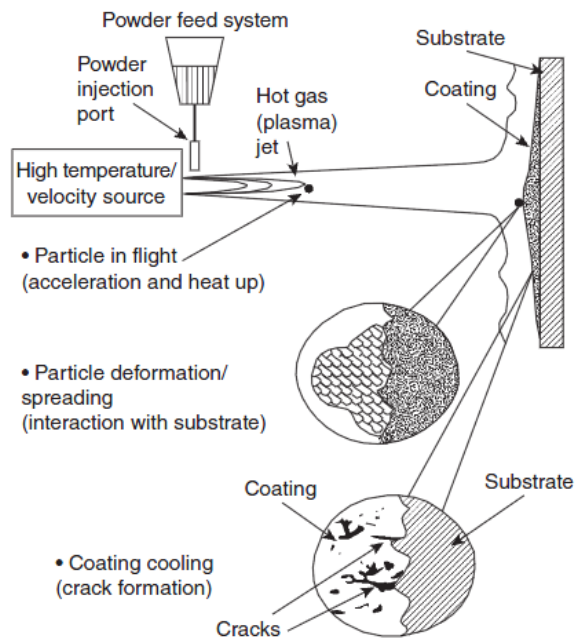

(a)

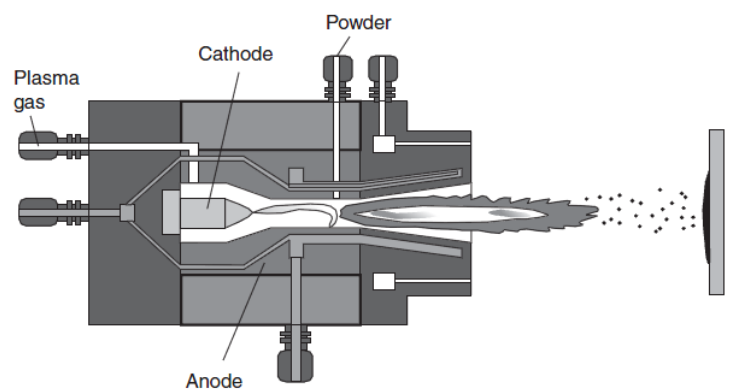

(b)

Figure 3-22. (a) Air plasma spray process [119] and (b) A typical plasma-spraying system with radial power injection system [120] 


\subsubsection{Microstructure of APS Coatings}

The morphology of APS coatings is characteristically a porous lamellar microstructure with micro-pores and micro-cracks in the coatings, as shown in Figure 3-23 [121]. The basic structure of APS coating is built up with pancake-shape splats due to the impact of molten powder particles [122] (Figure 3-24). The splat morphology can be affected by surface roughness of the bond coat and substrate orientation. The plasma spraying parameters can influence the temperature and velocity of particles hence the splat size and shape. The splats are usually about 1-50 $\mu \mathrm{m}$ thick and 10-50 $\mu \mathrm{m}$ in diameter $[114,123]$. Several layers of splats form a horizontal lamella and the boundaries between lamellae are distinctively visible on the cross sections of the coatings due to the differences in contrast (darker area usually contains more oxygen).

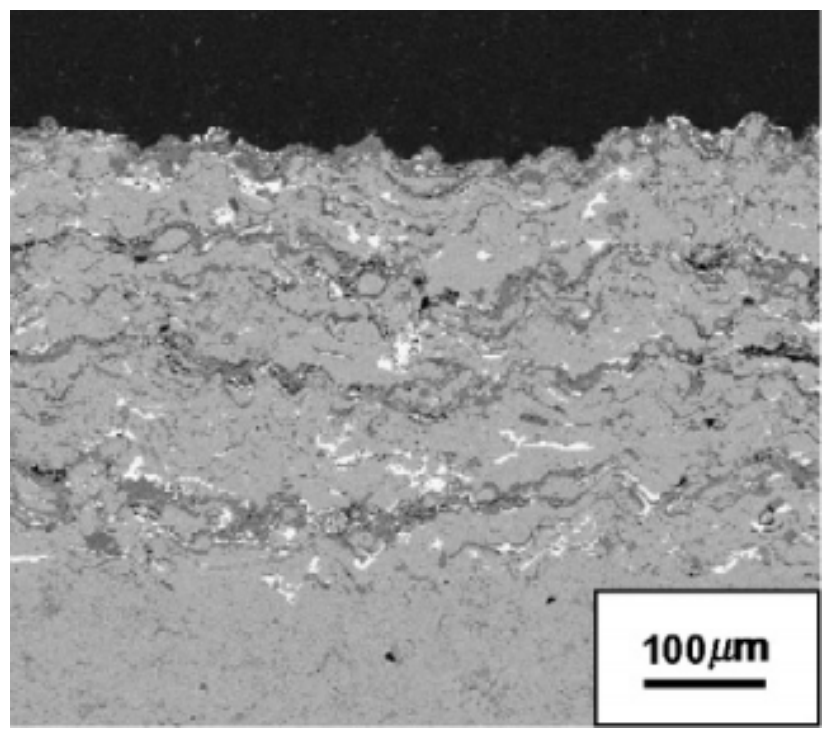

Figure 3-23. Cross section showing microstructure of lamellar APS coating [121] 


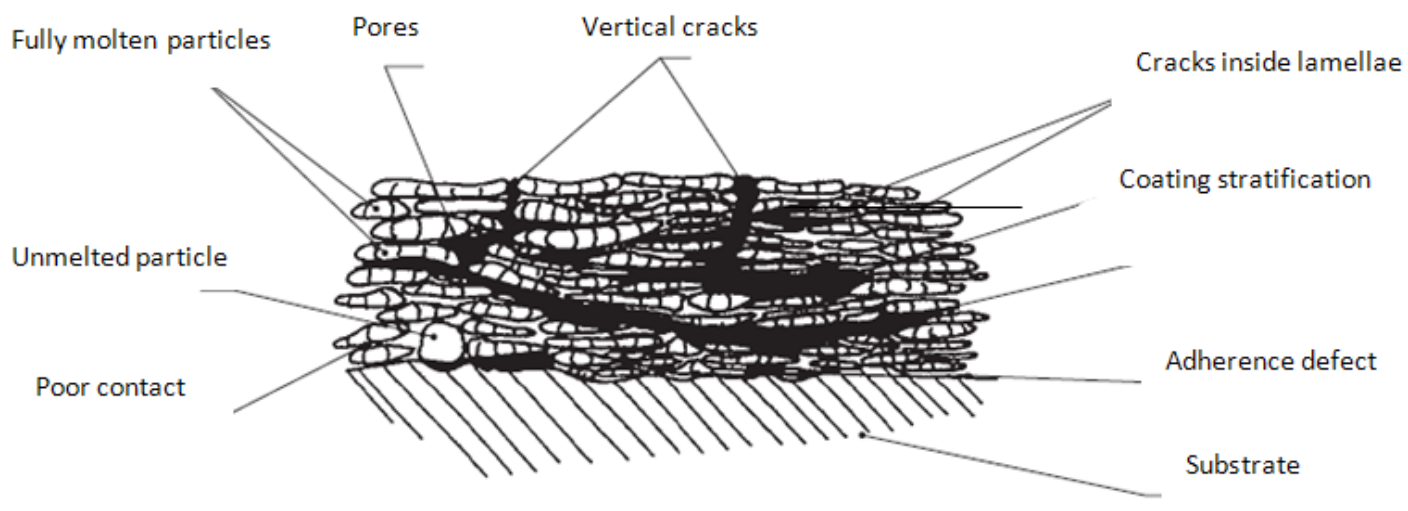

Figure 3-24. Schematic of typical plasma-sprayed coating [114,123]

In addition to horizontal delamination, vertical microcracks are also present in APS coatings, a result of the weak adhesion between lamellae and splats and quenching stress during spraying process [124]. Costil et al. showed that the thermal conductivity of plasma spraying coatings is affected more by large size horizontal cracks than the vertical microcracks. Since thermal conductivity depends on the contact between lamellae, coatings with macro horizontal cracks exhibit low thermal conductivity [115].

The high porosity of APS coatings results from the rapid solidification of lamellae. These pores and voids, with varying shapes and sizes, are usually found to be oriented parallel or perpendicular to the coating surface [114]. Splashing that happens during APS deposition process makes APS coatings more random-shaped. Montavon et al. concluded that the larger the impinging particles are, the higher the tendency that splashing occurs. The smaller sized particles are more likely to be vaporized in the plasma flame while the large size particles are partially melted or unmelted and have a low velocity (higher mass) for proper spreading to happen, thus unmelted particles can often be observed in the APS coatings [123]. The presence of large voids can also be explained by poor bonding of unmelted particles [124]. 


\subsubsection{Failure of APS TBCs}

Under isothermal and cyclic high temperature conditions, APS TBCs usually spall as a result of the stresses developed in the coatings [117]. The lifetime of TBCs can be influenced by thermal expansion mismatch between top coat and bond coat, adhesion of TGO to the bond coat, sintering effect (in increasing elastic modulus), detrimental phase transformation, corrosion, erosion and residual stresses from deposition process [125].

"A monoclinic phase $(m)$ and an yttrium-rich cubic phase $(c)$ are the room temperature equilibrium phases for YSZ" [126]. However, a non-equilibrium tetragonal phase $\left(t^{\prime}\right)$ is developed during the rapid cooling after the APS deposition process; this $t$ ' phase can decompose into a tetragonal phase $(t)$ (and cubic phase) at elevated temperature. When being cooled to room temperature, $t$ phase can transform back into $m$ phase, with an increasing volume of $4-5 \%$ [126]. This volume change can greatly affect the durability of the TBC system and lead to cracking. Helminiak et al. found that high- purity, lowdensity APS coatings are more resistant to phase transformation such as $t \rightarrow m+c$ as well as sintering [127]. Also, the thermal exposure temperature affects the stability of $t$ ' phase. For every YSZ system, there is an upper temperature limit, beyond which $t$ ' will decompose as shown in Figure 3-25 [128,129]. 


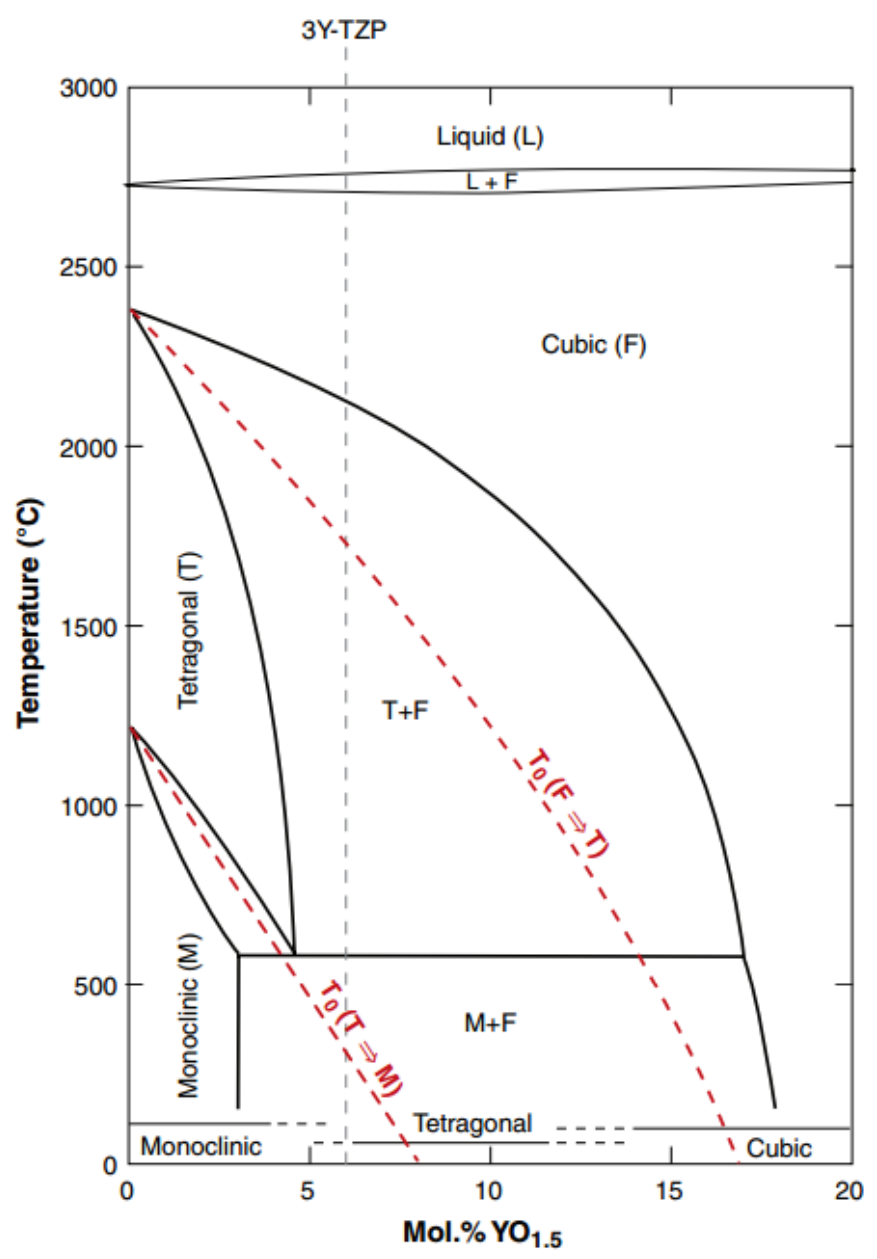

Figure 3-25. ZrO2-YO1.5 phase diagram [128-130]

\subsubsection{Nano-Structured TBC Coatings}

As traditional APS coatings cannot meet the increasing demand for certain aero-engine applications (high stress and thermal cycling), nanostructured coatings have been developed and studied in the last decades [18]. Nanostructured coatings have the advantages of lower thermal conductivity, higher thermal shock resistance and coefficient of thermal expansion, excellent mechanical properties and lower cost compared to EBPVD coatings [131]. 
Nanostructured TBCs can be generated using agglomerated powders with nanosized particles inside. When the powders are heated and accelerated in a flame or jet, partial melting will happen on the surface while the particles inside the powders keep the original shape. According to Yang et al., after thermal spraying, most of the agglomerated YSZ powders were partially molten whereas some could be fully molten [132]. The degree of melting in the agglomerated powders is related to the particle size. As shown in Figure 3-26, YSZ with an agglomerated powder size of $90 \mu \mathrm{m}$ only has a small degree of melting while the small sized powder is fully molten. Since nanostructure inside the powder is very beneficial to the reduction of thermal conductivity and increased thermal shock resistance, the agglomerated YSZ powder size needs to be controlled to prevent complete melting [132]

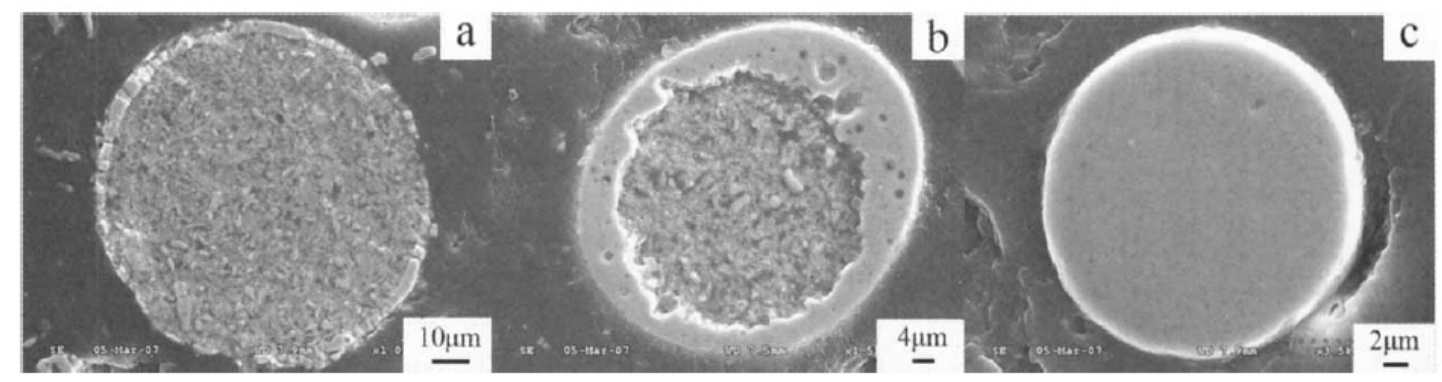

Figure 3-26. Cross-sections of plasma sprayed agglomerated YSZ powder with an approximate size

of a) $90 \mu \mathrm{m}$, b) $50 \mu \mathrm{m}$, c) $20 \mu \mathrm{m}[132]$

\subsubsection{Suspension Plasma Spraying (SPS)}

When the powders used in nanostructured thermal spray method have particle sizes of less than $1 \mu \mathrm{m}$, they cannot be injected into the plasma plume, due to nanoparticle's low weight and poor ability to flow [133]. This problem can be solved by suspending the fine particles in a liquid carrier and injecting the liquid suspension into the jet instead of powder alone. This method is referred to as suspension plasma spraying (SPS) [18]. 
During the ASPS deposition process, the suspension droplets undergo several changes: aerodynamic breakdown, evaporation of the liquid (carrier), evaporation of the solid powder material, sintering of fine solids, melting and further sintering into larger agglomerates, impact with the substrate. These stages are illustrated in Figure 3-27. In addition, splashing may occur due to liquid impact. Finally solidified nano/micro-sized crystals form on the substrate [134].

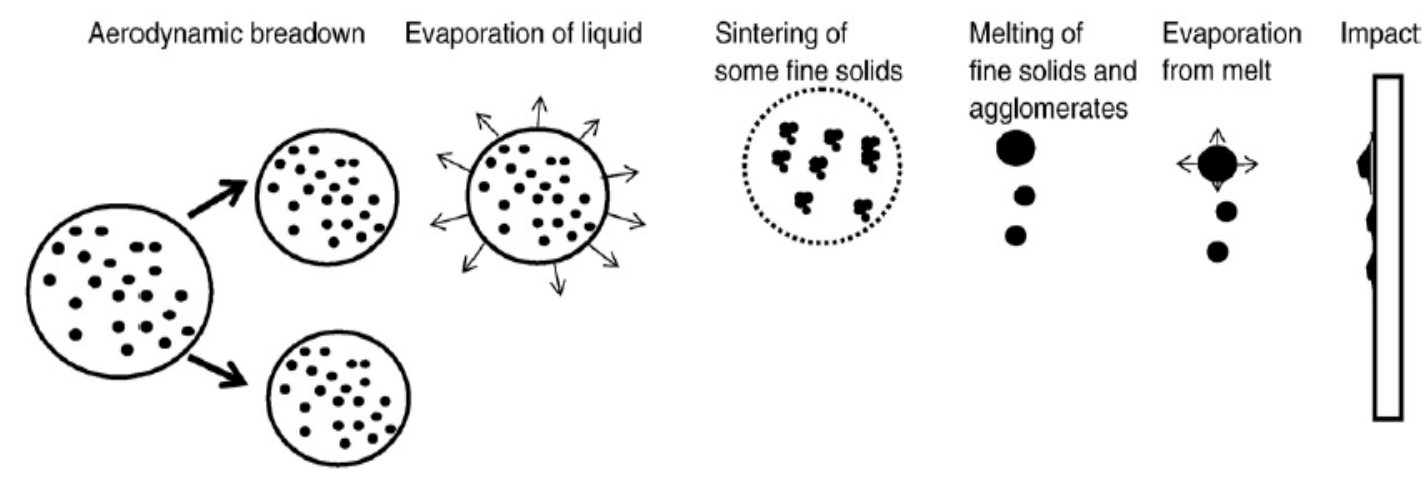

Figure 3-27. Stages that suspension droplets undergo during the plasma spraying [134]

\subsubsection{Microstructure of SPS Coatings}

Coatings obtained using SPS usually exhibit a two-zone microstructure, where the unmolten, partially sintered nanoparticles are surrounded by lamellar splats formed by molten and agglomerated fine solids [135], as shown in Figure 3-28 [136]. Porosity can be observed between lamellae in coatings processed by SPS. Vertical cracks, which were assumingly caused by the relaxation of thermal stresses, also appear inside lamellae grains [137].

Small pores between splats are formed due to the weak inter-splat contact [131]. "The coating porosity is affected by the melting degree of particles" [133]. More fully molten 
particles can result in a very dense coating. The formation of inter-lamellae cracks/voids and intra-lamellae cracks can also be attributed to gas entrapment and quenching stresses, respectively [133]. A wide range of different microstructures can be obtained by varying the deposition process and spray parameters, such as the initial size of powder, injection velocity, power loading in the suspension and the temperature of spraying $[134,138]$. Since the deposition rate of SPS is much lower than that of APS method, it is hard to obtain thick coatings by SPS method. Therefore SPS coatings usually have a smaller thickness ranging from 30 to $70 \mu \mathrm{m}[135]$.

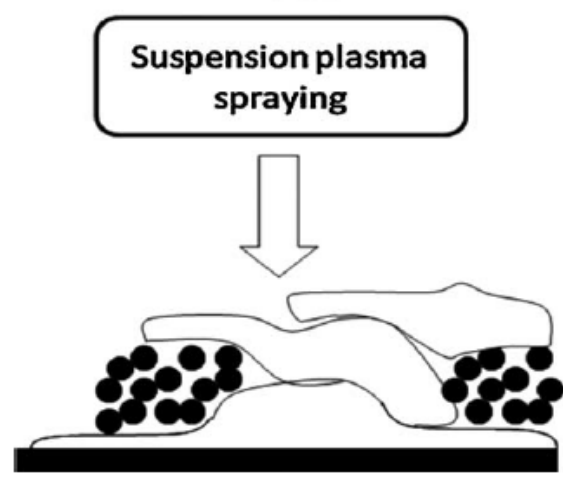

Figure 3-28. Two-zone microstructure of SPS coating [136]

\subsubsection{Thermal Cycling Behavior of SPS Coatings}

Compared to conventional APS coatings, SPS coatings exhibit the following improved behaviors during thermal exposure:

- Higher phase stability during thermal cycles [13]

- Lower TGO growth rate with the formation of continuous, uniform, dense, and thin TGO layers [139]

- Reduced formation and growth of spinels at $\mathrm{TGO} /$ top coat and $\mathrm{TGO} /$ bond coat interface [139] 
- Higher thermal cyclic oxidation resistance [140]

- Lower thermal diffusivity/conductivity [141]

- Less stress generated from thermal cycling [142]

All these features are desirable for a coating; as a result, nanostructured SPS coatings have longer lifetimes than conventional APS coatings.

\subsubsection{Vertically Cracked (VC) and Columnar Structured Coatings by SPS Method}

Lamellar structured SPS coatings are prone to spallation due to thermal stresses arisen from thermal cycling. Tensile stress develops in ceramic layer during heating because of the thermal expansion mismatch between underlying metal substrate, bond and ceramic top coat, whereas compressive stress is seen during cooling. The stresses accumulated in the coating will lead to crack initiation, growth and buckling. One way to reduce/relax the stress is to introduce vertical cracks (VC) within the ceramic layer. Figure 3-29 shows the cross-sectional microstructure of VC ceramic coating [144]. Similar to the columnar microstructure of EB-PVD coatings, VC coatings reduce the tensile stress by opening up at high temperature and also yield a lower level of compression during cooling, thus prolong the life of TBC [19]. The formation of vertically cracked coatings requires both high substrate temperature and high temperature gradient between surface and impinging particles [19]. The number of vertical cracks increases with higher plasma spray power input due to an elevated substrate temperature during spraying. Higher final deposition temperature also results in longer cracks throughout the coating thickness which are beneficial to stress relief [143]. 


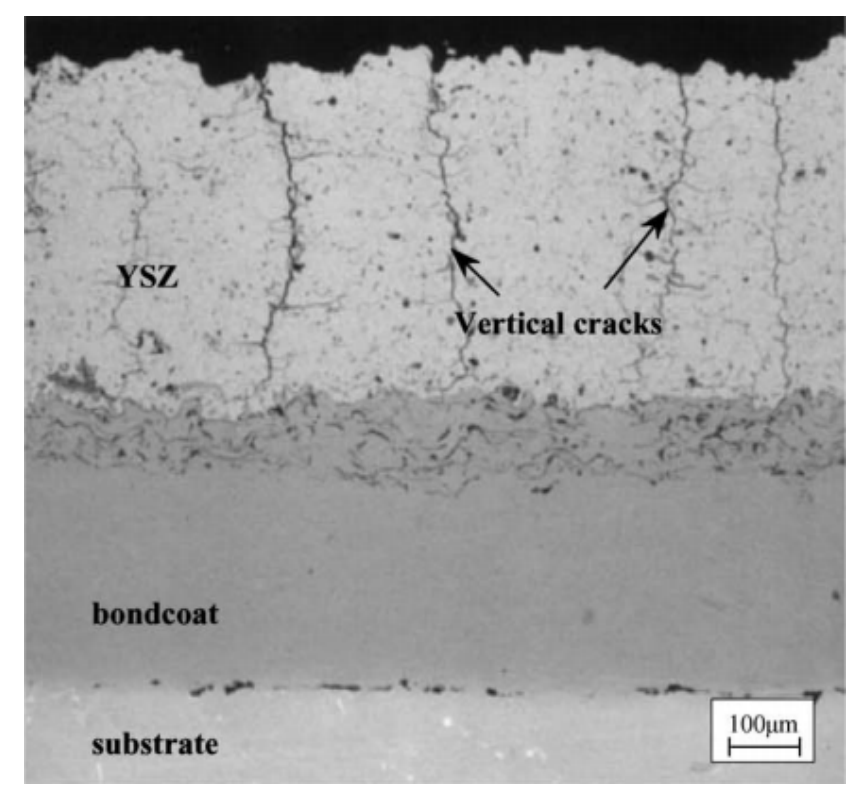

Figure 3-29. VC YSZ coating (cross section) [144]

In the suspension plasma spraying process, the molten droplets impact the surface of substrate and form splats. On the surface of the substrate, the formerly deposited layer, whether solidified or not, can still be melted again by the following layer thus the bonding between layers can be improved. Due to the tensile stress developed during deposition (denser coating increases elastic modulus, hence higher thermal stress), vertical microcracks start to grow in the deposited layer. Microcracks continue to propagate during the spraying process, helping reduce the stress in the following layers throughout the coating thickness. However if the coating is deposited at a lower temperature such as that in conventional SPS process the new layer is not able to re-melt the former layer, resulting in weak bonding between layers. To relieve the stresses, cracks grow horizontally between the layers instead of vertically, making APS coating more prone to spallation during use $[143,144,146]$. 


\subsubsection{Axial Suspension Spraying (ASPS)}

In axial suspension spraying (ASPS), a suspension of fine particles in a liquid carrier is axially injected into the plasma stream, providing more acceleration to suspension [18]. ASPS deposition process, through changing the processing parameters, can produce not only VC top coats but also columnar structured coatings, as shown in Figure 3-30. The properties of ASPS coatings are very similar to EB-PVD coatings, with higher bond strength and strain tolerance but slightly higher thermal conductivity than that of APS coatings (Table 3-5) [17]. The costs of SPS columnar structured and VC coatings are much less than that of EB-PVD coatings since plasma spraying is a relatively low-cost process with high deposition efficiency.

Table 3-5. Summarized properties of APS, ASPS and EB-PVD coatings [17]

\begin{tabular}{|l|l|l|l|}
\hline Properties & APS & ASPS & EB-PVD \\
\hline Bond Strength $(\mathrm{MPa})$ & $20-40$ & $50-82$ & $65-75$ \\
\hline Thermal Conductivity (W/m.K) & $0.9-1.5$ & $1-2$ & $1.7-2$ \\
\hline
\end{tabular}

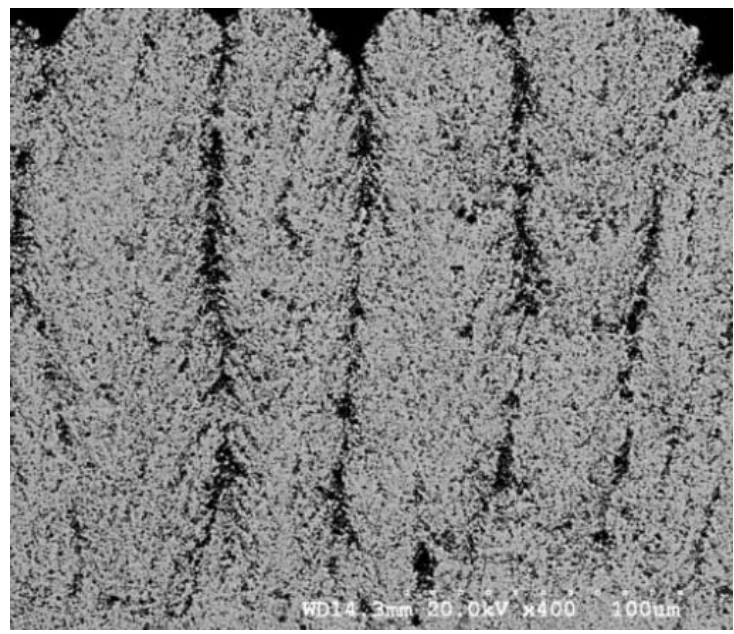

Figure 3-30. Cross sectional morphology of columnar coating by ASPS method [17] 
Although vertically cracked and columnar structured coatings have much longer thermal cycling lifetime than traditional lamellar structured APS coatings, they may still suffer from spallation after a long period of thermal exposure. However, the segmentation crack network can lead to the partial spallation rather than the spallation of the entire ceramic coating layer [143]. The causes of failure are reported to be similar to those of traditional APS coatings, such as phase change, growth of spinels between YSZ and TGO, stresses induced during thermal cycling, coefficient of thermal expansion mismatch, and rumpling of TGO [147].

\subsection{Isothermal Oxidation of TBCs and Microstructure Changes}

Some aero and industrial gas turbines are exposed to long term high temperature oxidation during service. During isothermal exposure, TBC coatings can experience various microstructural changes, which contribute to the coating failure.

Zhou et al. [22], who conducted isothermal test on APS YSZ + MCrAlY TBC system at $1050^{\circ} \mathrm{C}$ in pure $\mathrm{O}_{2}$ and $\mathrm{O}_{2}$ with $5 \%$ water vapor, found that the oxidation rate was very low in $\mathrm{O}_{2}$ and $\mathrm{Al}_{2} \mathrm{O}_{3}$ was the only oxide formed after $400 \mathrm{~h}$ of oxidation. However, chromia, spinels and $\mathrm{NiO}(\mathrm{CSN})$ was observed in the $\mathrm{TBC}$ in water vapor atmosphere after $400 \mathrm{~h}$ of oxidation. The morphologies of alumina were dense while those of CSN were porous [22].

Poza et al. [148] have compared the isothermal oxidation behaviors of TBC (APS YSZ + $\mathrm{NiCrAlY}$ ) at $950^{\circ} \mathrm{C}$ and $1050^{\circ} \mathrm{C}$. It is observed that the $\mathrm{TBC}$ tested at $1050^{\circ} \mathrm{C}$ had a higher TGO growth rate than the one tested at $950{ }^{\circ} \mathrm{C}$. $\mathrm{Al}_{2} \mathrm{O}_{3}$ and $\mathrm{Cr}_{2} \mathrm{O}_{3}$ were formed after $336 \mathrm{~h}$ at $950^{\circ} \mathrm{C}$, and some delamination at top coat/bond coat interface was clearly visible 
as shown in Figure 3-31; whereas at $1050^{\circ} \mathrm{C}$, NiO and spinels were found inside TGO after $336 \mathrm{~h}$. The fast growth of spinels and associated volume change had caused spallation of the top coat, as shown in Figure 3-32 [148].

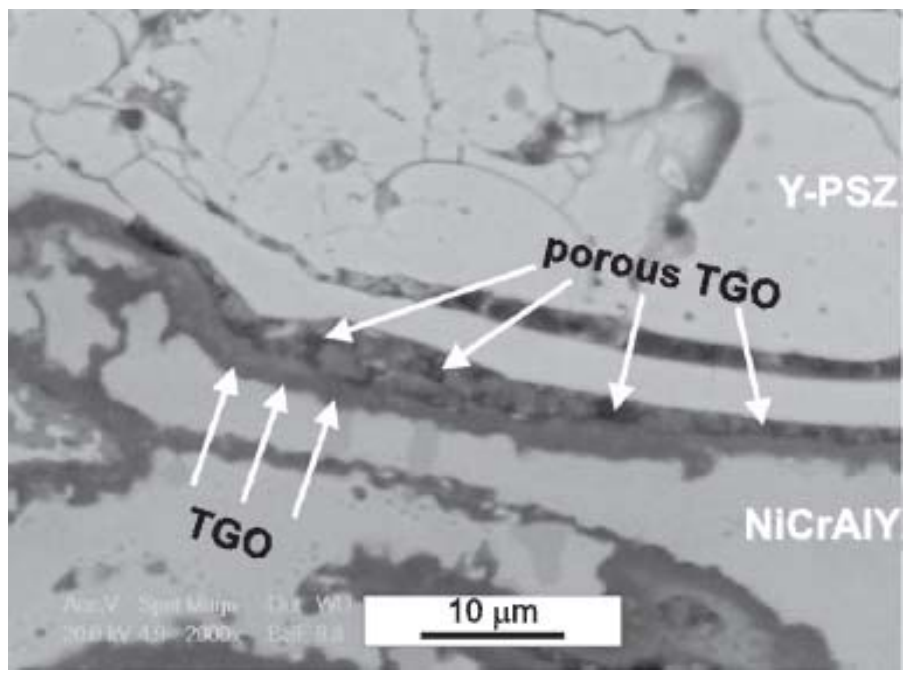

Figure 3-31. TGO formed in $\mathrm{TBC}$ after $336 \mathrm{~h}$ of isothermal oxidation at $950^{\circ} \mathrm{C}$ [148]

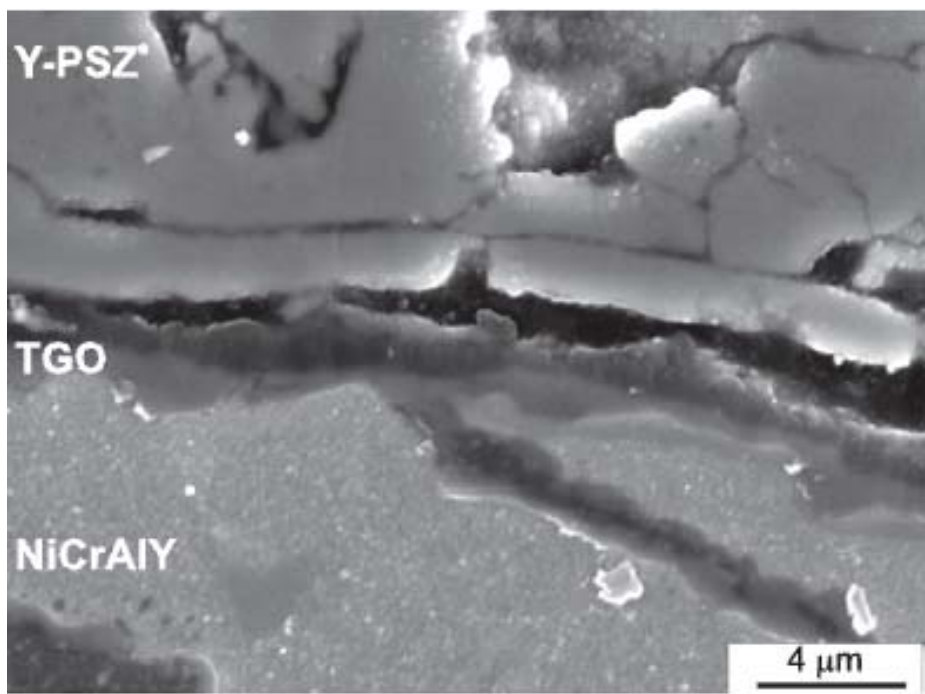

Figure 3-32. Spallation and cracking at top coat/bond coat interface after $336 \mathrm{~h}$ of oxidation at $1050^{\circ} \mathrm{C}[148]$ 
During isothermal oxidation, the weight of TBC system gradually increases and then slowly decreases due to partial spallation of top coat. Xu et al. [149] have investigated the weight change of $\mathrm{NiCrAlY}$ bond coats in the isothermal oxidation at $1100^{\circ} \mathrm{C}$. The weight changes of TBCs are shown in Figure 3-33. Mixed oxides and spinels were also found in the TGO layer after $400 \mathrm{~h}$ of oxidation [149].

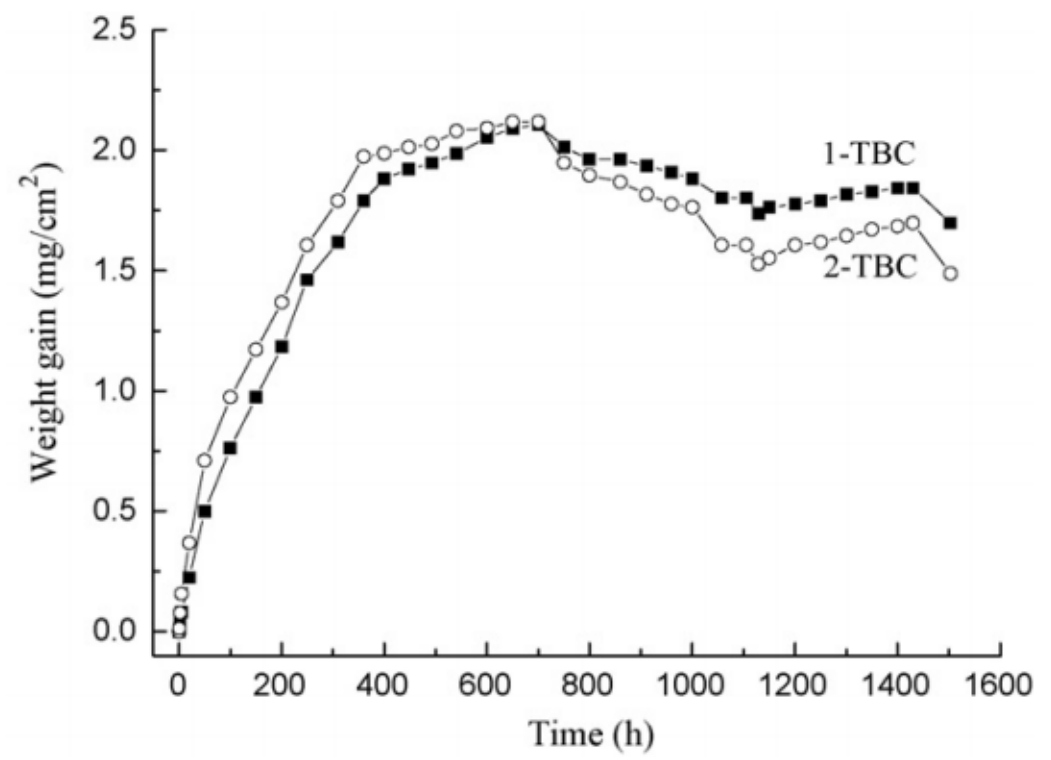

Figure 3-33. Weigh changes of $\mathrm{TBCs}$ in a function of oxidation time at $1100^{\circ} \mathrm{C}$ [149]

\subsection{Cyclic Oxidation Life of TBCs and Microstructure Changes}

Gas turbines are subjected to frequent starts and shut-downs during service, so it is very important to investigate the cyclic oxidation life of TBCs. A lot of research has been carried out to predict TBC's life during high temperature thermal cycling.

Li et al. [150] have investigated the cyclic oxidation behavior of TBC (EB-PVD YSZ top coat $+\mathrm{NiCrAlY}$ bond coat) at $1050^{\circ} \mathrm{C}$. The as-deposited $\mathrm{YSZ}$ top coat contained a nonequilibrium tetragonal phase $t^{\prime}$. Tetragonal phase $(t)$ was the only phase detected in 
YSZ coating within 200 cycles whereas after 300 cycles cubic and monoclinic (m) phases were observed, which was resulted from the decomposition of $t^{\prime}$ phase to $t$ phase and $t \rightarrow m+c$ transformation during thermal cycling. Microcracks can be observed in top coat after 300 cycles (Figure 3-34). Apart from phase change in the top coat, Al-depletion occurred in the bond coat and resulted in the formation of $\mathrm{NiO}$ and spinels [150].

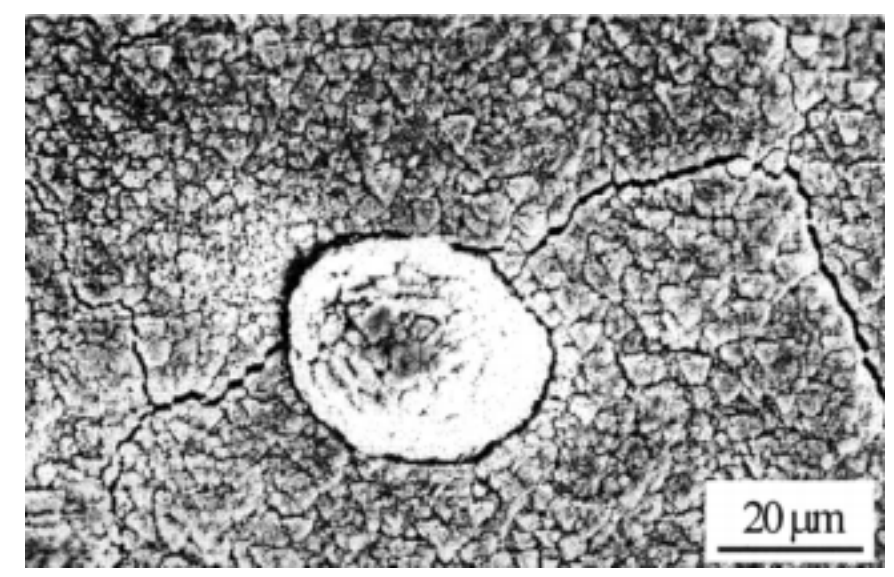

Figure 3-34. Surface morphology of YSZ top coat after 300 cycles [150]

In the cyclic oxidation test conducted by Chen et al. on APS TBCs with YSZ top coat and MCrAlY bond coat, $\mathrm{Al}_{2} \mathrm{O}_{3}, \mathrm{Cr}_{2} \mathrm{O}_{3}, \mathrm{NiO}$ and spinels was found in $\mathrm{TGO}$ after 300 cycles, before the coating suffered from spallation after 500 cycles. [85].

Tsai et al. conducted cyclic oxidation test at $1100^{\circ} \mathrm{C}$ for a TBC system. TBCs which were treated by aluminizing and platinum aluminizing processes showed $20 \%$ improved cyclic life than the ones with only high velocity oxygen fuel sprayed (HVOF) MCrAlY bond coat. Furthermore, only $\mathrm{Al}_{2} \mathrm{O}_{3}$ was detected on the aluminized and Pt-aluminized bond coats while $\mathrm{Al}_{2} \mathrm{O}_{3}$ and $\mathrm{NiAl}_{2} \mathrm{O}_{4}$ were found in the TGO of TBCs with MCrAlY bond coats. No significant phase change was observed in the YSZ top coat. All of the TBCs 
had a lifetime around $200 \mathrm{hrs}$, before spallation occurred to the top coatings, as shown in Figure 3-35 [151].

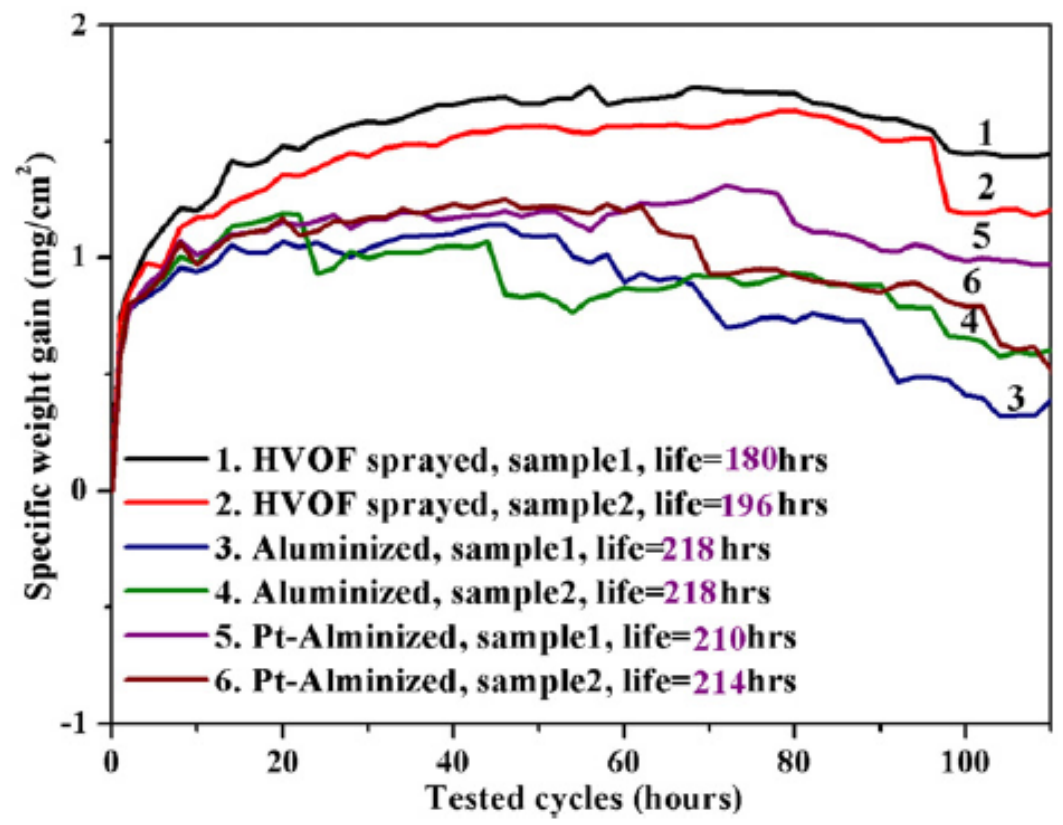

Figure 3-35. Weight changes of TBCs with different bond coats as a function of cyclic oxidation life [151] 


\section{Chapter: Materials and Experimental Procedures}

\subsection{Substrate Materials}

Two substrate materials, IN738LC and CMSX-4, were used in this study. IN738LC was cast by Sophisticated Alloy, Inc. and CMSX-4 by Howmet International. Their thermophysical properties and nominal chemical compositions are listed in Table 4-1 and Table 4-2.

Table 4-1. Experimental data for thermophysical properties of IN738 and CMSX-4 (927-1127 $\left.{ }^{\circ} \mathrm{C}\right)$ [152]

\begin{tabular}{|c|c|c|c|c|}
\hline & $\begin{array}{c}\text { Thermal capacity } \mathrm{C}_{\mathrm{p}} \\
\left(\mathrm{J} \mathrm{K}^{-1} \mathrm{Kg}^{-1}\right)\end{array}$ & Density $\rho$ & $\begin{array}{c}\text { Thermal } \\
\text { diffusivity a } \\
\left(\mathrm{xg} 0^{6} \mathrm{~m}^{2} \mathrm{~s}^{-1}\right)\end{array}$ & $\begin{array}{c}\text { Thermal conductivity k } \\
\left(\mathrm{W} \mathrm{m}^{-1} \mathrm{~K}^{-1}\right)\end{array}$ \\
\hline IN738 & $675-925$ & $7840-7702$ & $4.70-4.87$ & 24.9 \\
\hline CMSX-4 & $650-925$ & $8283-8193$ & $4.7-5.1$ & $21.9-24.4$ \\
\hline
\end{tabular}

Table 4-2. Chemical composition of the substrate materials

\begin{tabular}{|l|l|l|l|l|l|l|l|l|l|l|l|}
\hline & $\mathrm{Ni}$ & $\mathrm{Cr}$ & $\mathrm{Co}$ & $\mathrm{Mo}$ & $\mathrm{W}$ & $\mathrm{Ta}$ & $\mathrm{Nb}$ & $\mathrm{Al}$ & $\mathrm{Ti}$ & $\mathrm{Re}$ & $\mathrm{C}$ \\
\hline IN738LC & Bal & 16 & 8.5 & 1.7 & 2.6 & 1.7 & 0.9 & 3.4 & 3.4 & - & 0.11 \\
\hline CMSX-4 & Bal & 6.5 & 9 & 0.6 & 6 & 6.5 & - & 5.6 & 1 & 3 & - \\
\hline
\end{tabular}

\subsubsection{IN738LC}

IN738LC, which contains a large amount of refractory elements such as tungsten, molybdenum, tantalum and niobium (as highlighted in Table 4.2), is a precipitation strengthened nickel based superalloy [153]. The two-phase $\gamma / \gamma^{\prime}$ microstructure of as- 
received IN738LC substrate is shown in Figure 4-1. IN738LC is widely used to manufacture the hot section components of aero-engines and gas turbines due to its good phase stability, excellent strength and high corrosion resistance at elevated temperature [32]. However IN738LC usually shows very low ductility. Balikci et al. have reported that the ductility and fracture behavior as well as yield strength and tensile strength of IN738LC are affected by the microstructures and sizes of precipitates (primarily $\gamma^{\prime}$ ) [154]. For instance, microstructure with finer precipitate sizes usually exhibits lower ductility while coarser precipitates are linked to better ductility [155-156].

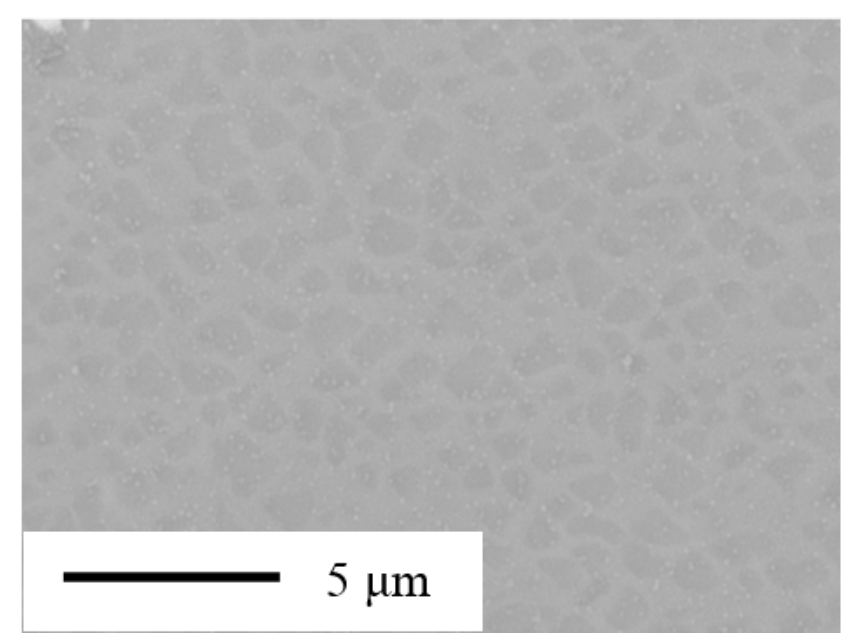

Figure 4-1: $\gamma / \gamma$ ' structure of IN738LC Superalloy

\subsubsection{CMSX -4}

CMSX-4 is a second generation nickel based single crystal superalloy; as shown in Figure 4-2, it is a two-phase material with cubical intermetallic $\gamma^{\prime}$ (Ni3Al) phase coherently embedded in $\gamma$ nickel solid solution matrix $[157,158]$. CMSX-4 exhibits excellent performance at high temperature because of the large volume fraction of the strengthening phase $\gamma^{\prime}[159]$. The $\gamma / \gamma^{\prime}$ structure also provides good ductility and strength at elevated temperature which make CMSX-4 a widely used material for blade 
applications in land-base gas turbines [160]. Adding refractory elements such as tantalum, tungsten and rhenium improves mechanical properties at high temperature, but consequently reduces the proportion of $\mathrm{Cr}$, which is beneficial for oxidation resistance. Therefore, a CMSX-4 substrate is usually coated with platinum aluminide to protect it from high temperature oxidation [161].

During high temperature exposure, coalescence of $\gamma^{\prime}$ precipitates and thickening of $\gamma$ phase channels would occur with increasing time and temperature, leading to rafting [33]. As the strength of $\gamma^{\prime}$ phase (an intermetallic compound) increases with temperature, the decrease in yield strength of matrix $\gamma$ due to high temperature can be compensated by the increasing strength of $\gamma^{\prime}$ precipitates. Thus CMSX-4 exhibits a stable behavior in strength between room temperature to approximately $900^{\circ} \mathrm{C}$. After $900^{\circ} \mathrm{C}, \gamma^{\prime}$ phase starts to dissolve, which leads to a rapid loss of strength [160] but an increase of ductility, a classical behavior of this kind of precipitation hardened high temperature alloy [162].

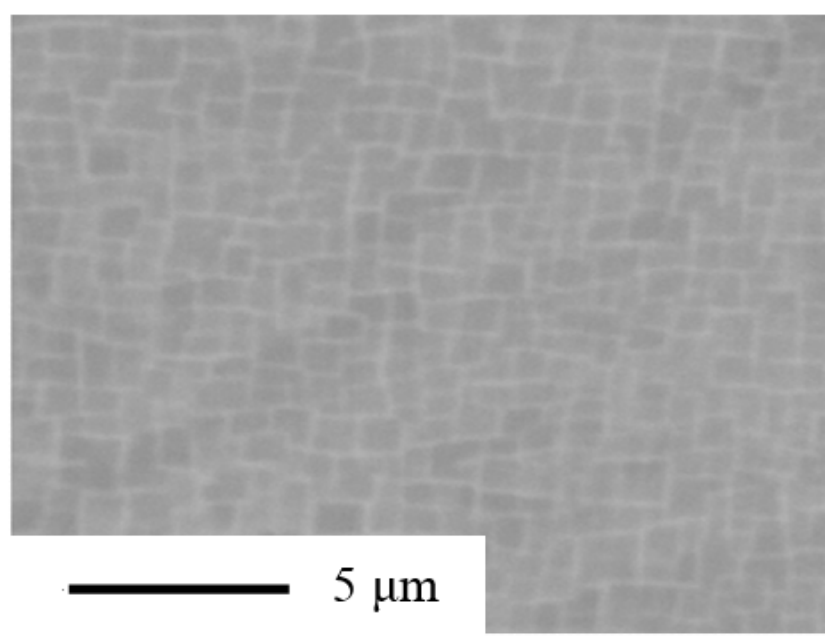

Figure 4-2. $\gamma / \gamma$ ' structure of CMSX-4 superalloy 
According to the steady-state scale morphology, when the concentration of $\mathrm{Cr}$ is higher than $15 \%$ and that of $\mathrm{Al}$ is higher than $3 \%$, the oxide scale formed usually mainly contains $\mathrm{Al}_{2} \mathrm{O}_{3}$ [163]. The $\mathrm{Cr} / \mathrm{Al}$ ratio in $\mathrm{IN738LC}$ is 4.7 compared to 1.25 in CMSX-4 [164]. The different concentrations of $\mathrm{Al}$ and $\mathrm{Cr}$ affect the oxides formed during thermal cycling.

\subsection{Coating Processes}

The samples were disk-shaped with a diameter of about $19 \mathrm{~mm}$ and a thickness of $5 \mathrm{~mm}$. The top YSZ coatings had an average thickness of $200 \mu \mathrm{m}$. The PtAl bond was applied by Chromalloy Inc. using standard process involving Pt plating, pack cementation and diffusion heat treatment. The columnar and VC 8YSZ coatings were applied using the Axial III ${ }^{\mathrm{TM}}$ plasma torch with a modified injector for suspension atomization and the NanoFeed ${ }^{\mathrm{TM}}$ suspension feeder (Northwest Mettech Corp., North Vancouver, Canada). The Axial $\mathrm{III}^{\mathrm{TM}}$ injects the atomized suspension feedstock axially to the direction of spray into the central core of the plasma. Axial injection overcomes the injection difficulties that arise when attempting to penetrate the plasma radially with fine particles or droplets. The NanoFeed is designed to feed submicron suspensions using mass flow control of both suspension and atomizing gas to provide uniform atomizing dynamics at the injector. An overview of the ASPS process is shown in Figure 4-3. The powder used was a customized $8 Y S Z$ (partially yttria stabilized zirconia with 8 wt $\%$ of yttria) with submicron powder sizes. After suspending the fine powders in ethanol liquid, the suspension feedstock was fed by Mettech Nanofeed 350 Suspension feeder to the injector with stable flow rate and injection pressure for the axial injection plasma spraying performed by Axial IIITM Torch. 


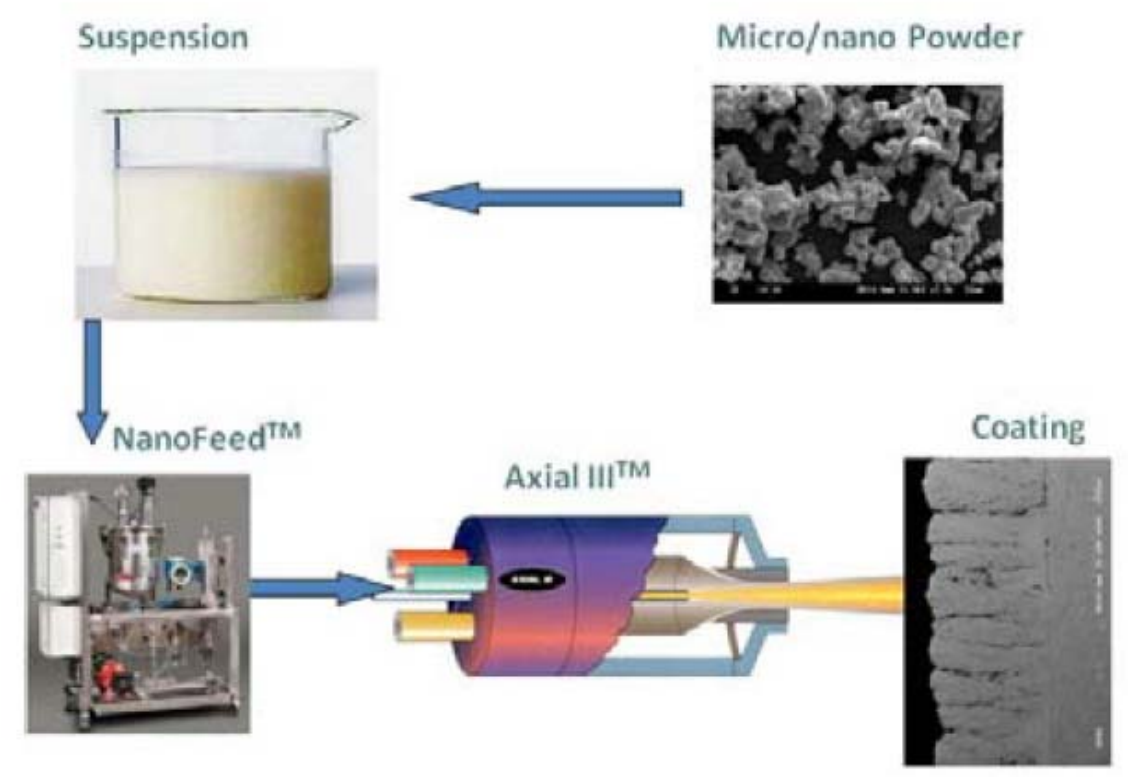

Figure 4-3. ASPS deposition process [17]

\subsection{Sample Preparation Procedures}

Before oxidation test, the as-received samples were heat-treated in C700 Oxy-Gon Vaccum Furnace (Oxy-Gon Industries, NH, USA) at $1080^{\circ} \mathrm{C}$ for four hours. The vacuum level was $10^{-4}-10^{-5}$ torr. After the pre-oxidation treatment, the samples were cut using a Buehler Isomet 2000 precision saw equipped with a Beta Diamond wafering blade at a rotating speed of $500 \mathrm{rpm}$ and a load of $250 \mathrm{~g}$. After sectioning, all samples were ultrasonically cleaned in alcohol for 10 mins. The sectioned samples were then mounted using a Streuers LaboPress 3 with Buehler PhenoCure 677 and Transoptic powders. Grinding and polishing were completed by using Buehler Ecomet 4 automatic grinding/polishing machine with an Automet 2 power head. Buehler-Met II silicon carbide papers of 180- , 240-, 320-, 400-, 600-, 800-, and 1200-grit sizes were used for grinding. Samples were subsequently polished using $1 \mu \mathrm{m}$ and $3 \mu \mathrm{m}$ diamond abrasives. 
Final polishing was performed with MasterMet colloidal silica polishing suspension and distilled water. Samples were ultrasonically cleaned in UltraMet 2 Sonic Cleaning Solution before and after each polishing section. The equipment used in sample preparation is shown in Figure 4-4.

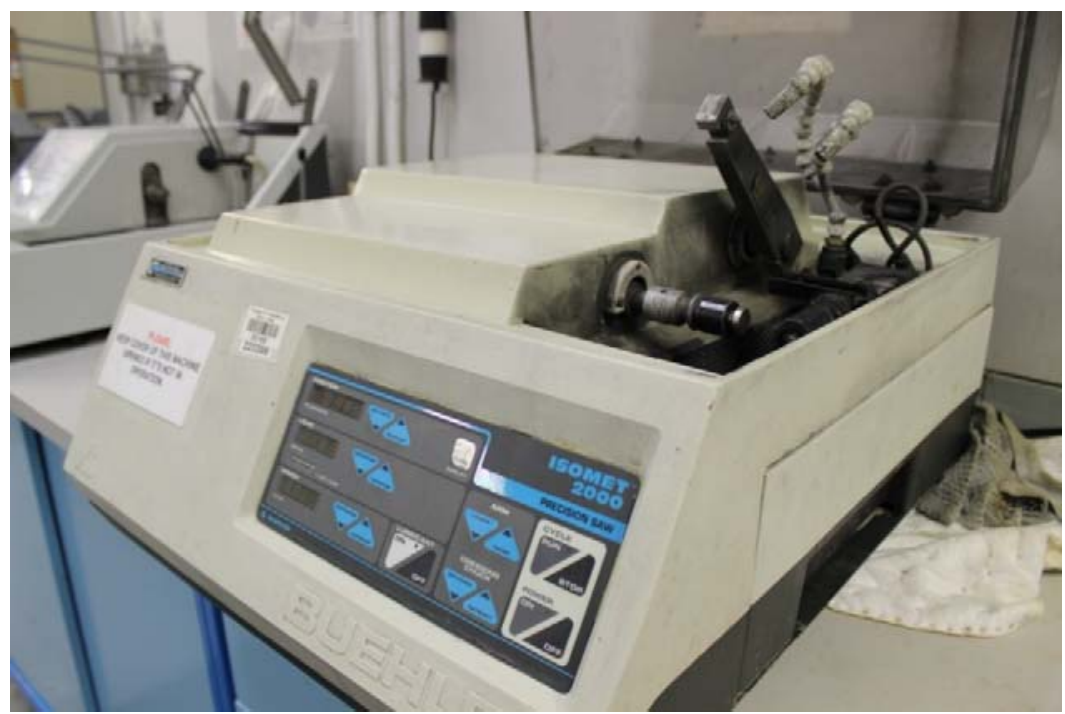

(a) Buehler Isomet 2000 precision saw

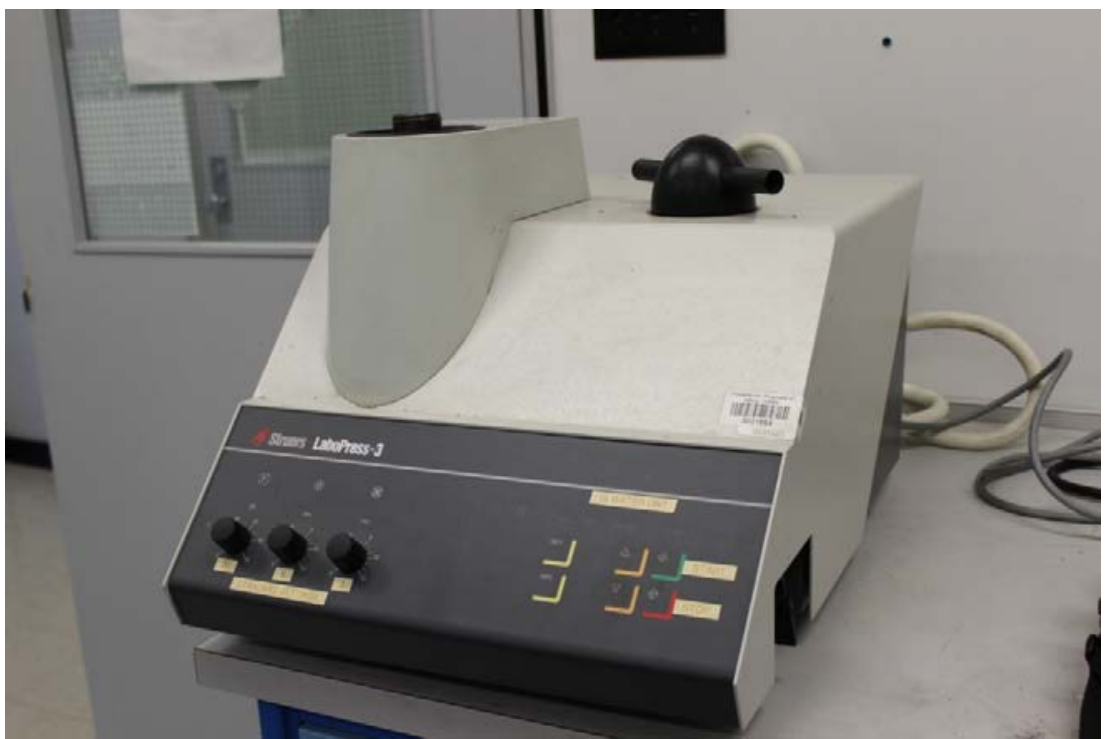

(b) Streuers LaboPress 3 mounting machine 


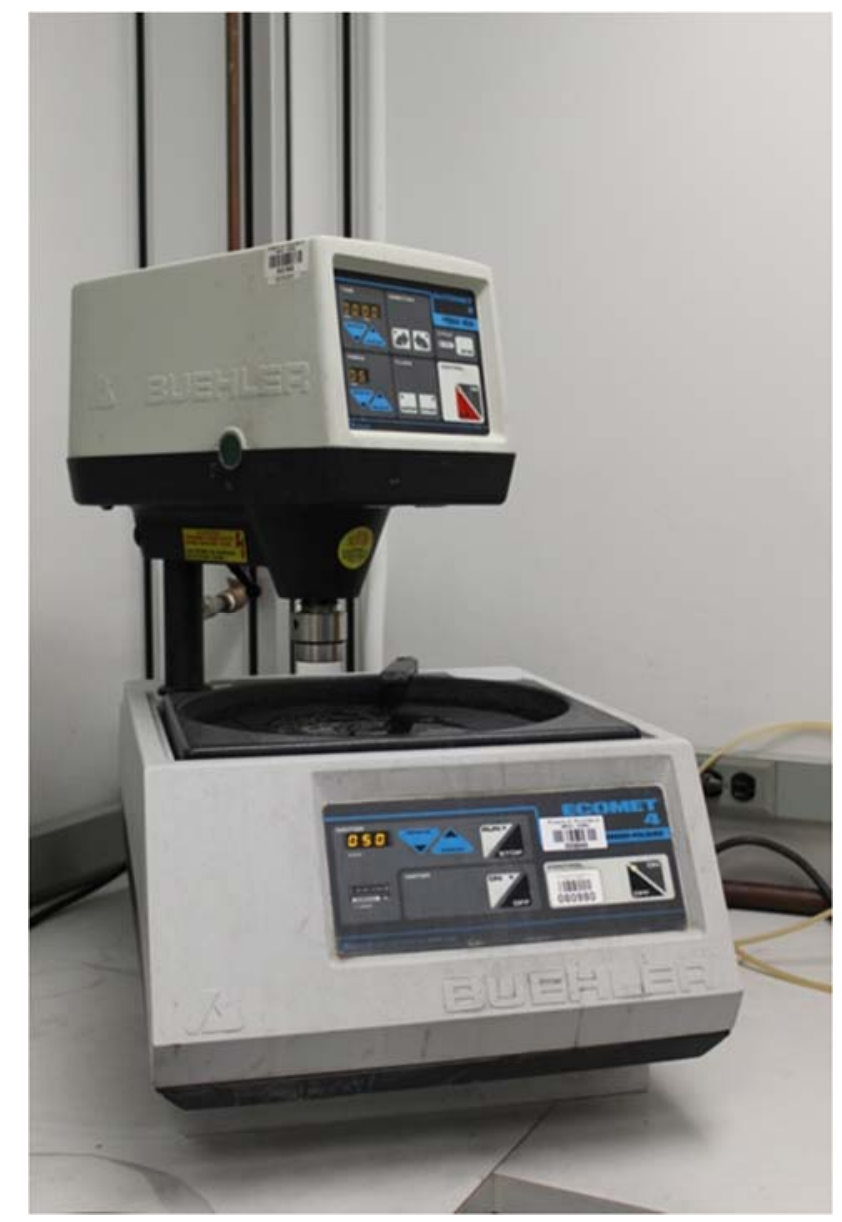

(c) Buehler Ecomet 4 automatic grinding/polishing machine with Automet 2 power head Figure 4-4. Equipment used in sample preparation

\subsection{Isothermal Oxidation Test}

The isothermal oxidation test was conducted at $1080^{\circ} \mathrm{C}$ for up to 1000 hours, using STT1600C-4-12 high temperature tube furnace (Sentro Tech Corp., USA), as shown in Figure 4-5. The temperature of $1080^{\circ} \mathrm{C}$ was chosen as other parallel tests (in our research group) were being conducted at the same temperature. Visual inspection was performed after every 100 hours. Samples were withdrawn from isothermal oxidation test once the failure criterion, i.e. more than $30 \%$ spallation of the top coatings, was reached. The top coatings usually spall as a large piece of more than $30 \%$ of the coating surface area. Thus, the 
failure criterion of $30 \%$ spallation seemed to be indicative of TBC failure. Details of samples used in the isothermal oxidation test are listed in Table 4-3.

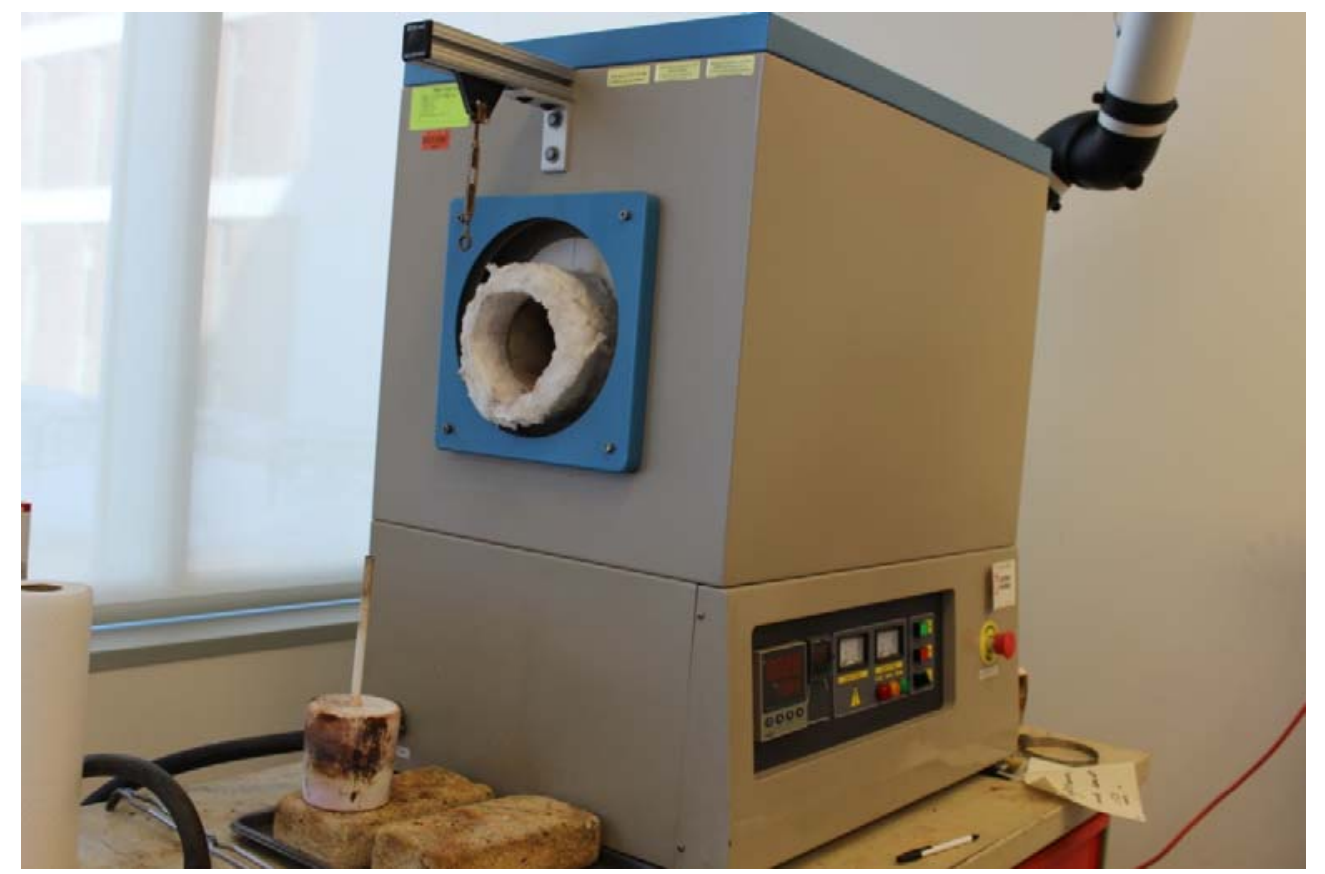

Figure 4-5. STT-1600C-4-12 high temperature tube furnace used in isothermal oxidation test 
Table 4-3. Samples used in isothermal oxidation test

\begin{tabular}{|c|c|c|c|}
\hline Group Number & Material Composition & $\begin{array}{c}\text { Appearance before } \\
\text { Isothermal Oxidation Test }\end{array}$ & $\begin{array}{c}\text { Oxidation } \\
\text { Test Sample } \\
\text { IDs }\end{array}$ \\
\hline 1 & $\begin{array}{l}\text { IN738LC with PtAl + } \\
\text { columnar } 8 \mathrm{YSZ}\end{array}$ & $19 \mathrm{~mm}$ & Iso\#1 \\
\hline 2 & $\begin{array}{c}\text { IN738LC with PtAl + } \\
\text { VC 8YSZ }\end{array}$ & $19 \mathrm{~mm}$ & Iso\#2 \\
\hline 3 & $\begin{array}{l}\text { CMSX-4 with PtAl+ } \\
\text { columnar } 8 \mathrm{YSZ}\end{array}$ & $19 \mathrm{~mm}$ & Iso\#3 \\
\hline 4 & $\begin{array}{c}\text { CMSX-4 with PtAl + VC } \\
\text { 8YSZ }\end{array}$ & $19 \mathrm{~mm}$ & Iso\#4 \\
\hline
\end{tabular}




\subsection{Cyclic Oxidation Test}

The cyclic oxidation test was conducted in air using a CM furnace (Rapid Temp Furnace supplied by Bloom Field, N.J., USA) as shown in Figure 4-6. In order to study the cyclic oxidation behavior of TBCs experienced by aero-engines, a one-hour cycle was chosen to simulate the frequent starts and stops. Each cycle consisted of heating to $1080^{\circ} \mathrm{C}$ (about $10 \mathrm{~min}$.) and holding for $30 \mathrm{~min}$. and then fan-cooling for $20 \mathrm{~min}$ (to $300^{\circ} \mathrm{C}$ ). Visual inspections were performed after every 100 cycles. Samples were withdrawn from test once the failure criterion, i.e. more than $30 \%$ spallation of the top coatings, was reached. Information of samples subjected to cyclic oxidation test is shown in Table 4-4.

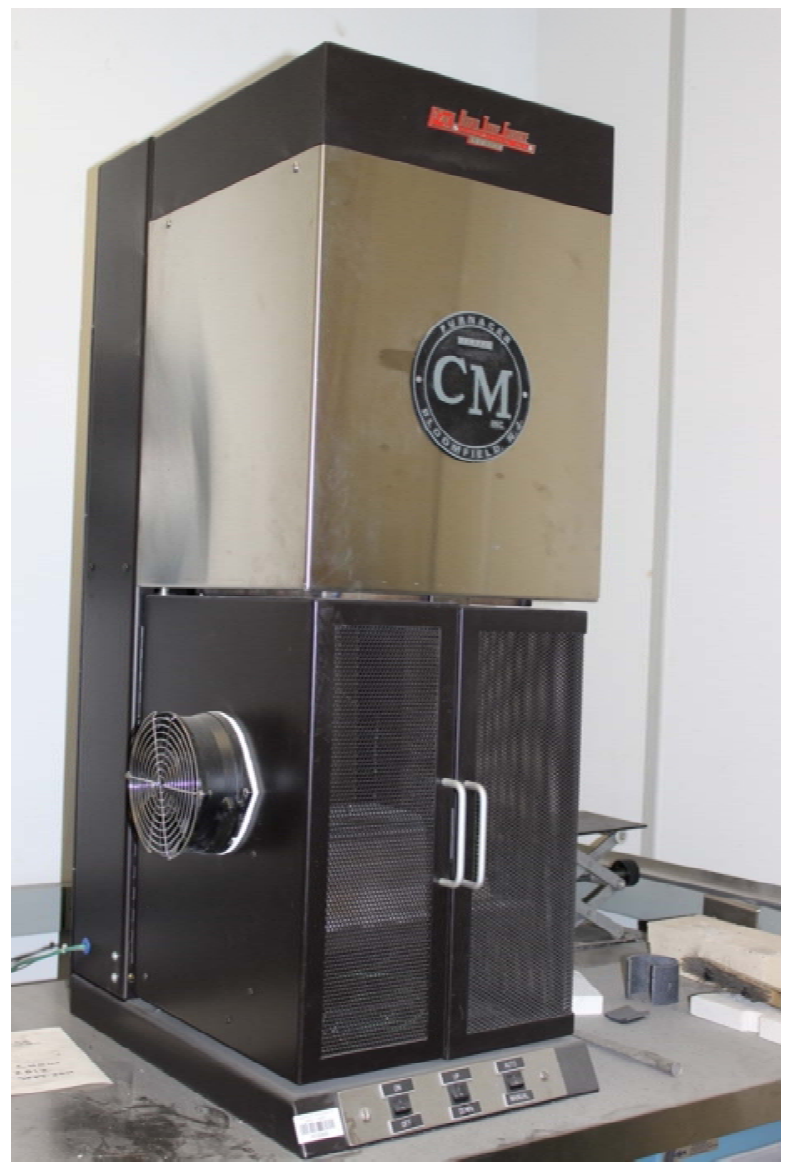

Figure 4-6. CM Rapid Temp Furnace used in cyclic oxidation test 
Table 4-4. Samples used in cyclic oxidation test

\begin{tabular}{|c|c|c|c|}
\hline Group Number & Material Composition & $\begin{array}{c}\text { Appearance before Cyclic } \\
\text { Oxidation Test }\end{array}$ & $\begin{array}{l}\text { Sample } \\
\text { IDs }\end{array}$ \\
\hline 1 & $\begin{array}{l}\text { IN738LC with PtAl + } \\
\text { columnar 8YSZ }\end{array}$ & $19 \mathrm{~mm}$ & Cyc\#1 \\
\hline 2 & $\begin{array}{c}\text { IN738LC with PtAl + } \\
\text { VC 8YSZ }\end{array}$ & & Cyc\#2 \\
\hline 3 & $\begin{array}{l}\text { CMSX-4 with PtAl + } \\
\text { columnar } 8 Y S Z\end{array}$ & & Cyc\#3 \\
\hline 4 & $\begin{array}{c}\text { CMSX-4 with PtAl + } \\
\text { VC 8YSZ }\end{array}$ & $19 \mathrm{~mm}$ & Cyc\#4 \\
\hline
\end{tabular}

\subsection{Scanning Electron Microscopy (SEM) and Energy Dispersive Spectrum}

\section{(EDS) Analysis}

Microscopic evaluation was carried out with two individual scanning electron microscope (SEM) models. Most of the SEM and EDS analysis was performed on a Philips XL30S Schottky-based field emission gun (FEG) SEM coupled with a Phoenix EDS detector system (Figure 4-7). The rest of SEM and EDS analysis was conducted by using VegaIIXMU SEM (Tescan, Neitherland) and INCA x-act EDS system (Oxford, England) as 
shown in Figure 4-8. EDS analysis can only provide a qualitative indication of elements at a certain area or point, but is not accurate enough to identity the stoichiometric ratio of elements in various phases. Microstructural constituents were identified by combining the results from X-ray diffraction and EDS analysis.

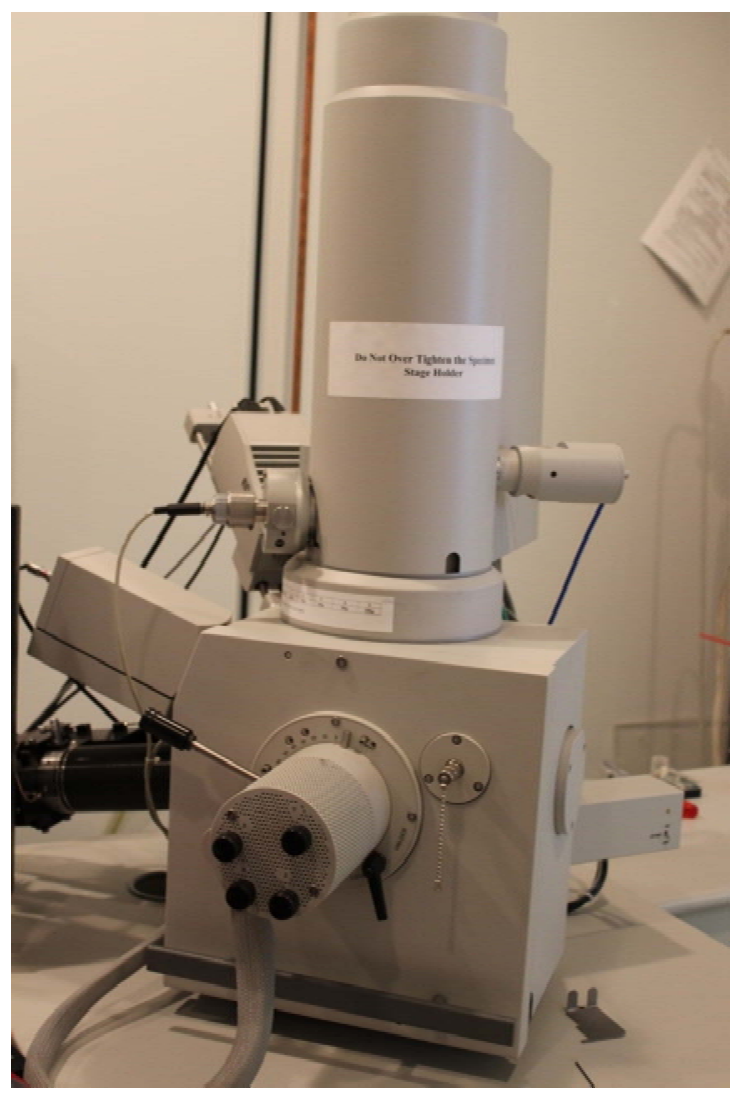

Figure 4-7. Philips XL30S FEG SEM 


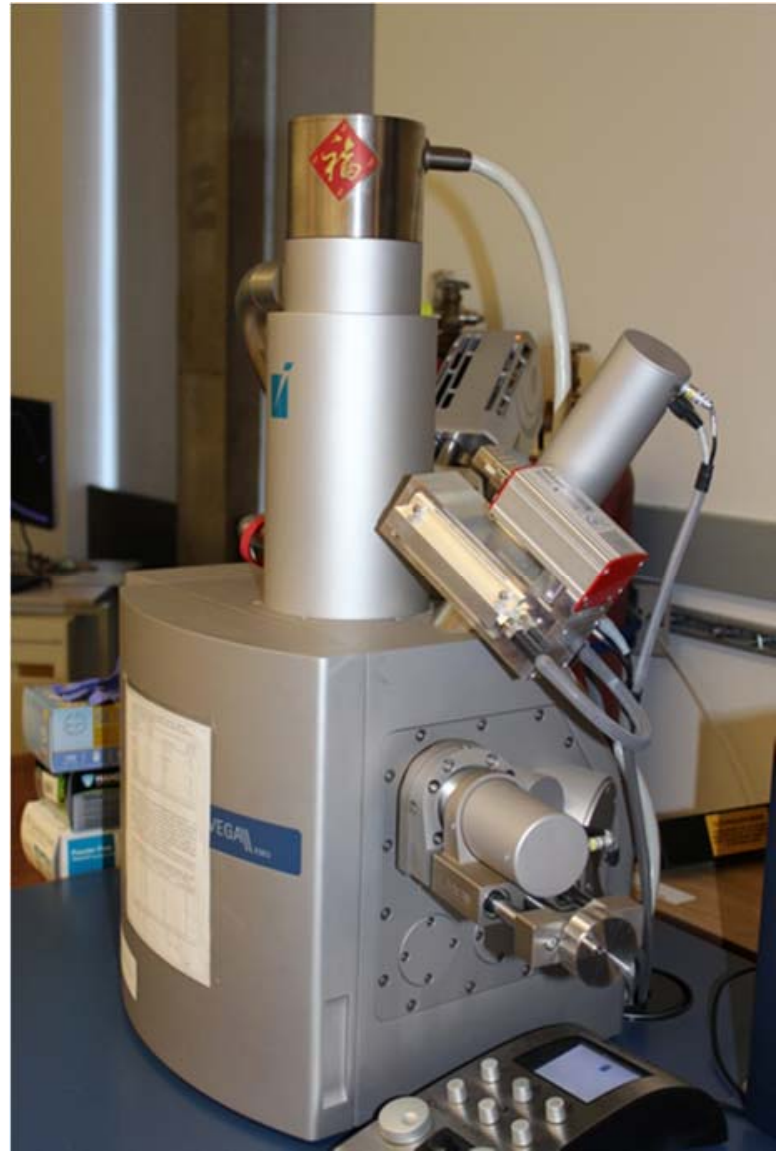

Figure 4-8. VegaII-XMU SEM

\subsection{X-ray Diffraction Analysis (XRD)}

The XRD analysis was performed using a Bruker AXS D8 Discover diffractometer, shown in Figure 4-9, controlled with General Area Detector Diffractometer Software (GADDS). The samples were scanned from $25-100^{\circ}$ (of $2 \theta$ angle) with a step size of $0.02 /$ step (1S). 


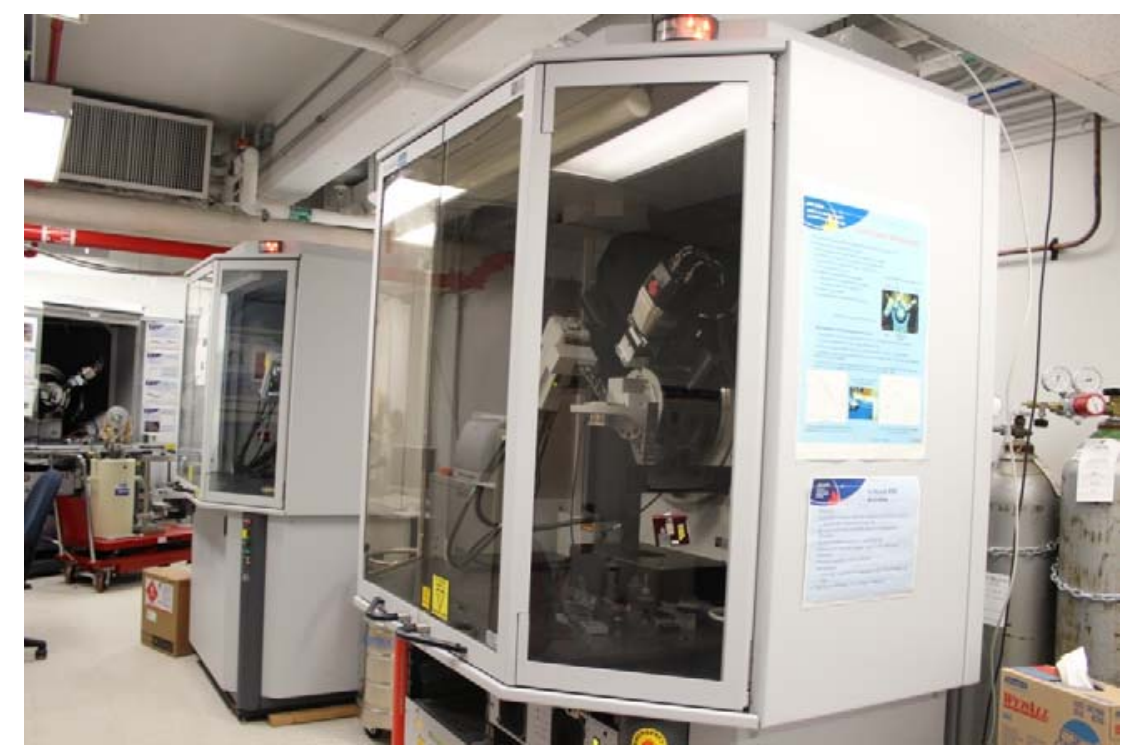

Figure 4-9. Bruker AXS D8 Discover Diffractometer for XRD analysis 


\section{Chapter: Microstructure and Composition of As-Coated Samples}

The surface morphologies of the columnar structured and VC YSZ coatings before oxidation tests are shown in Figure 5-1. The columnar YSZ coating has a "broccoli-like" feature with a few long surface cracks and visible surface pores (Figure 5-1 (a) and (b)) while VC coating has smoother and denser surface but numerous shorter, connected cracks (Figure 5-1 (c) and (d)). XRD analysis was performed on the top surfaces of samples Cyc\#1 to 4 and the results are shown in Figure 5-3. Traces of (Ni, Pt)Al ( $\beta$ phase from the bond coat) and $\gamma^{\prime}-\mathrm{Ni}_{3} \mathrm{Al}$ (strengthening phase in IN738LC and CMSX 4) phases are present in all samples, in addition to $\mathrm{ZrO}_{2}$, a main phase in YSZ. The cross-sectional microstructures of columnar and VC TBC are shown in Figure 5-2. Similar to that seen on the surface, columnar coatings have a rougher surface with more pores towards the top. And for VC coatings, most of the vertical cracks extend to about half of the YSZ total coating thickness. In the original test plan, a conventional plasma sprayed YSZ top coat was also included. However, the YSZ sprayed on PtAl bond coat immediately spalled off after spraying. As such this set of samples could not be included in this study. 


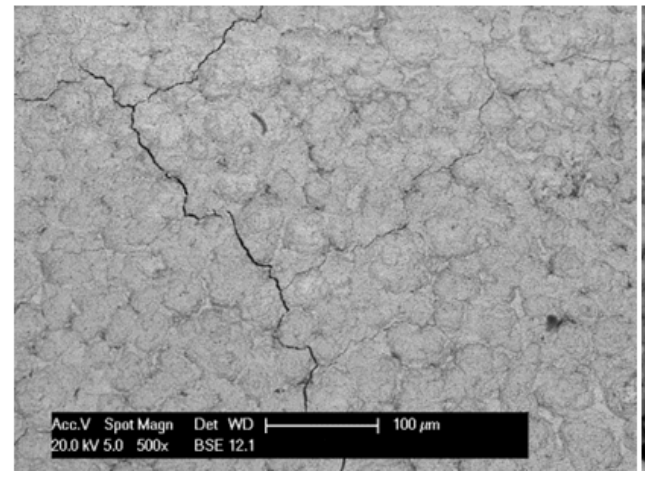

(a)

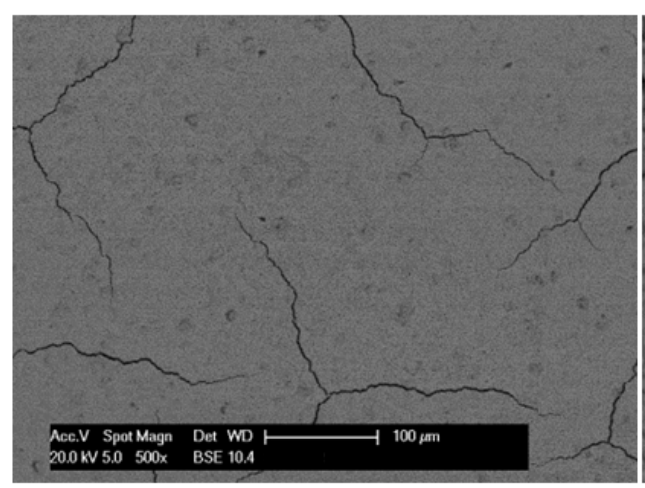

(c)

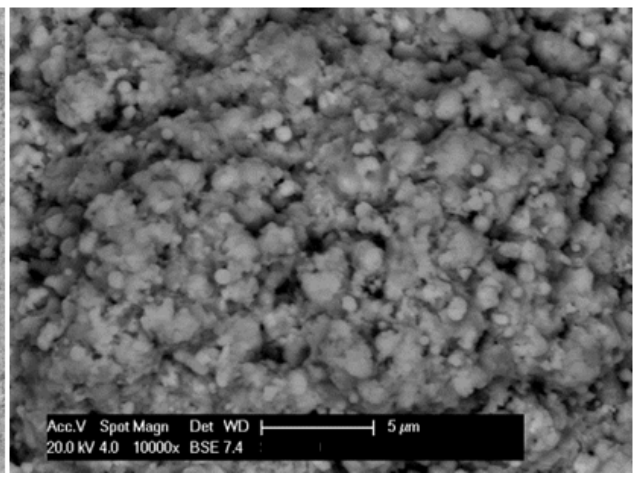

(b)

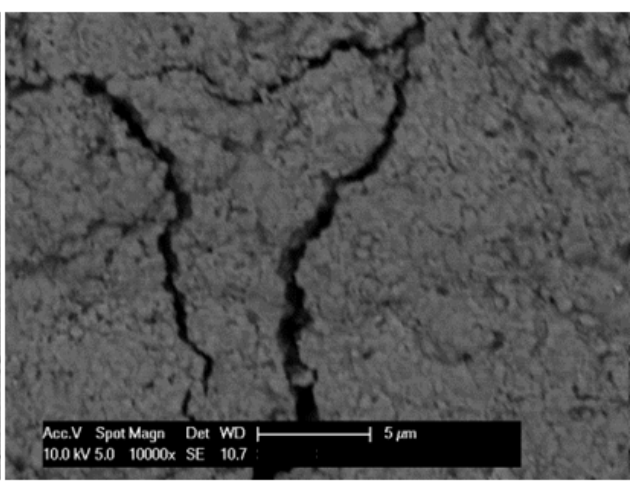

(d)

Figure 5-1. Top surface morphologies of columnar (a and b) and VC coatings (c and d)
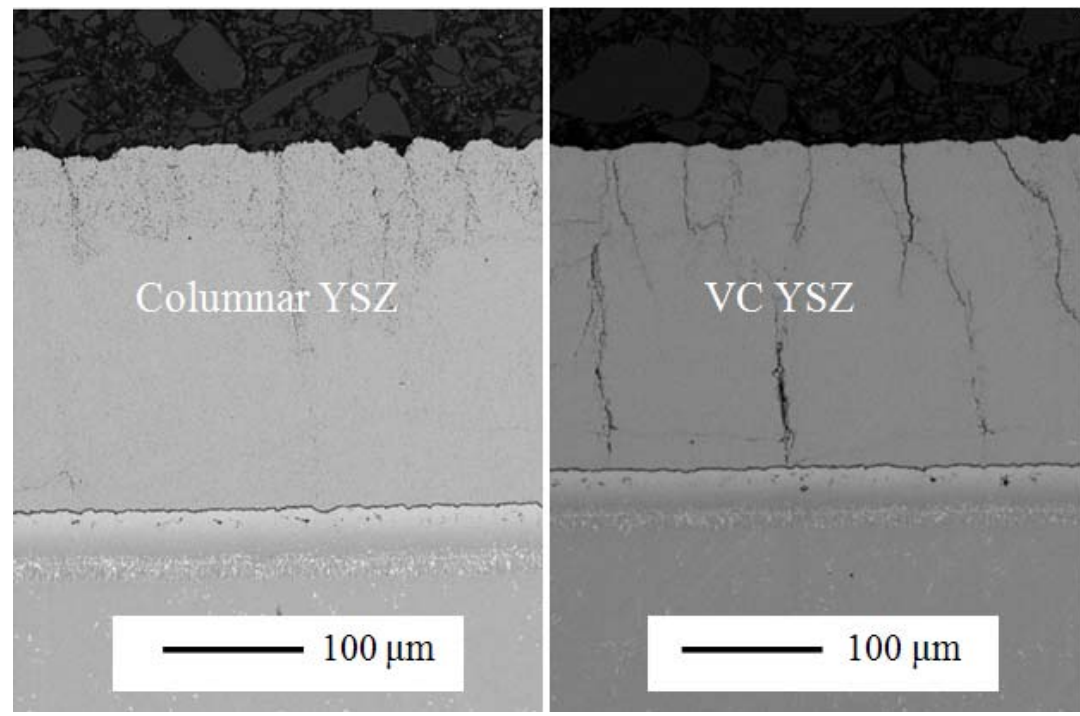

Figure 5-2. Cross-sections of columnar structured and VC TBC coatings 


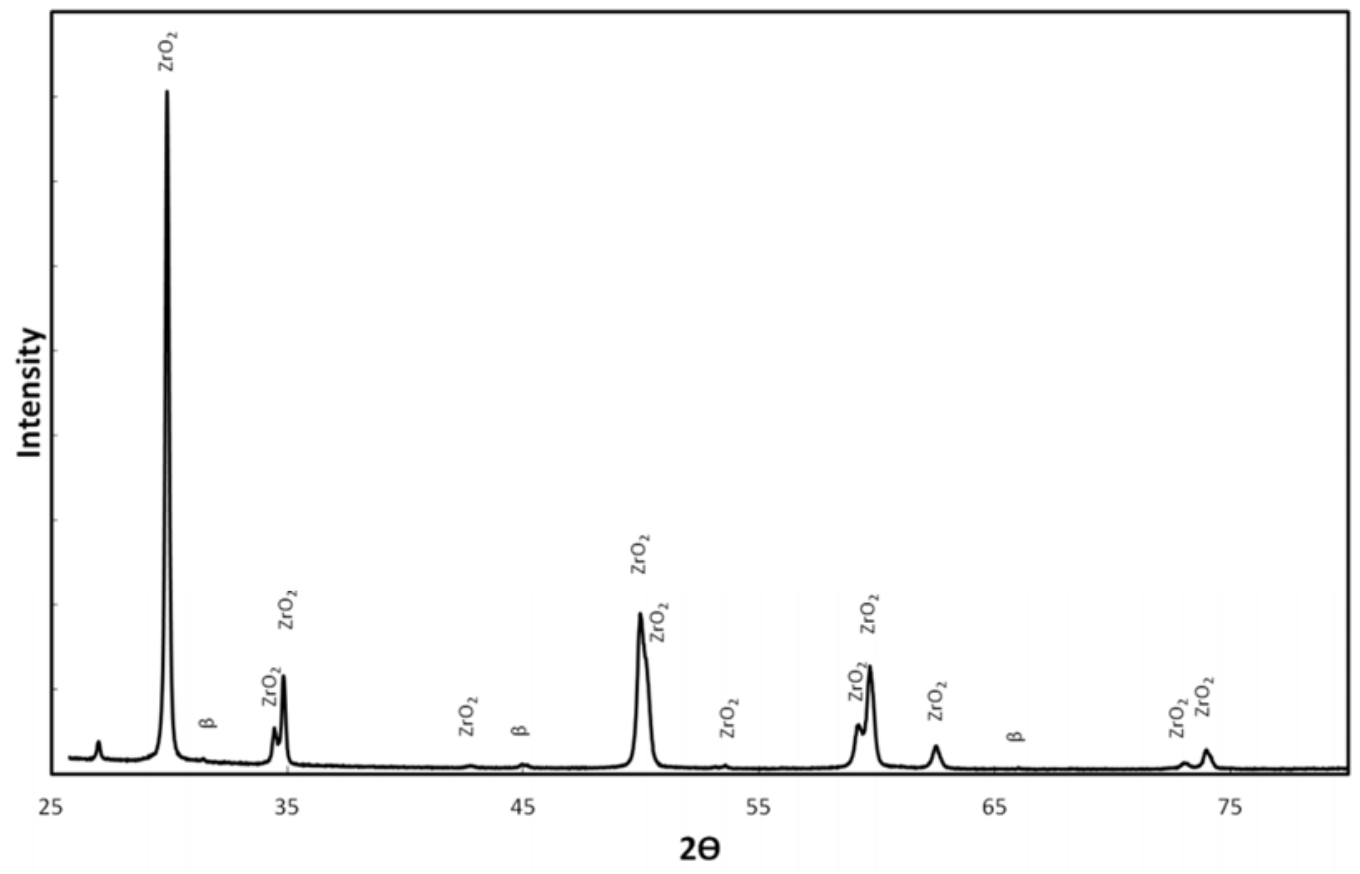

(a) IN738LC with PtAl + columnar 8YSZ

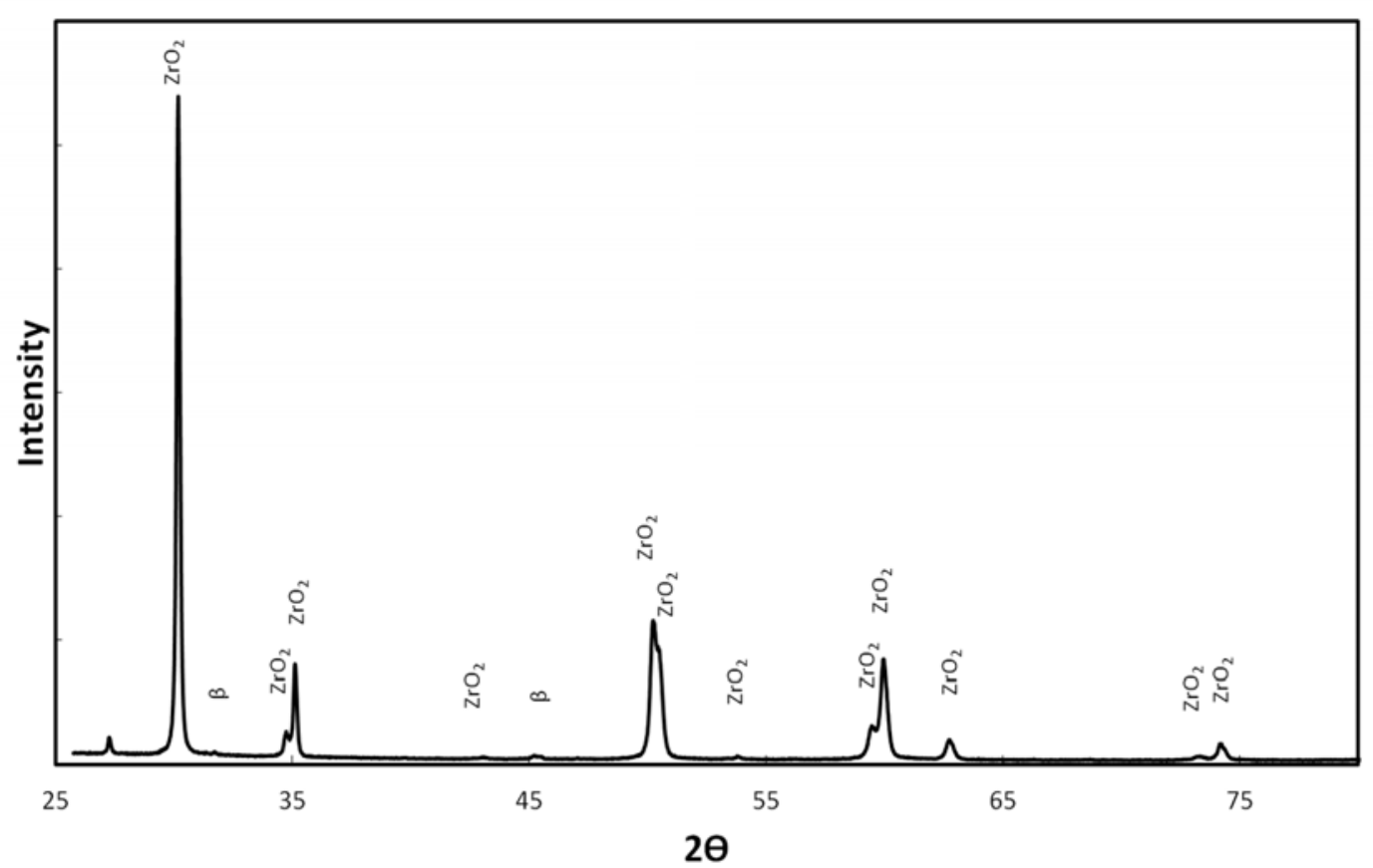

(b) IN738LC with PtAl + VC 8YSZ 


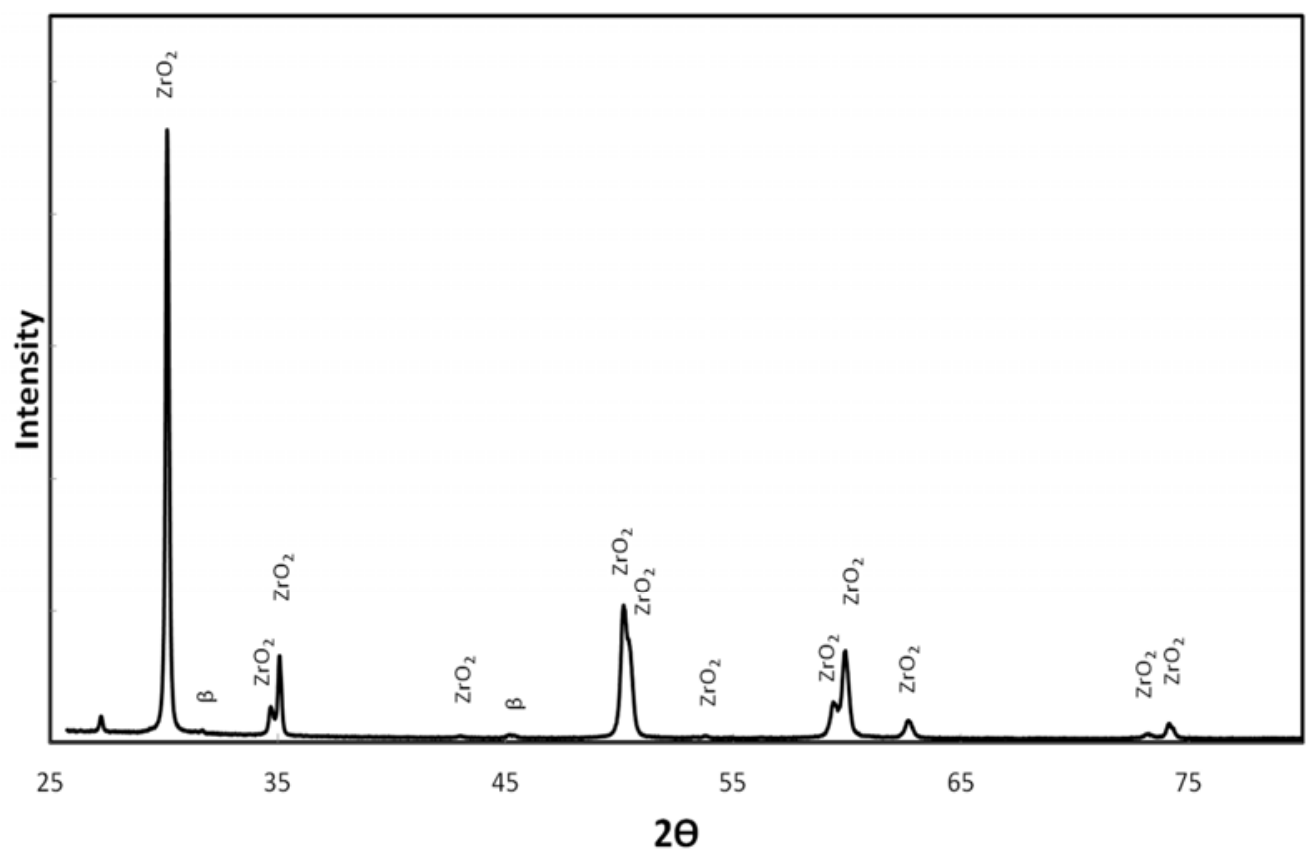

(c) CMSX-4 with PtAl + columnar 8YSZ

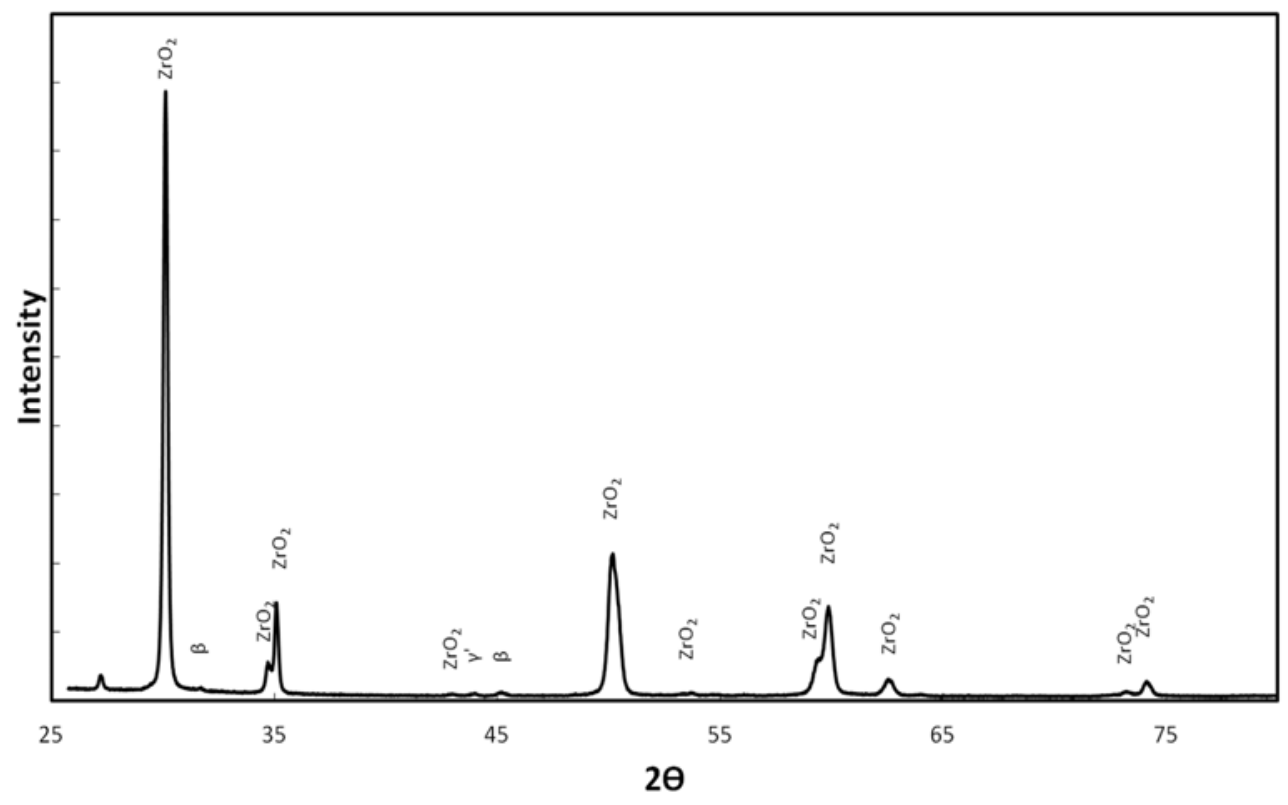

(d) CMSX-4 with PtAl + VC 8YSZ

Figure 5-3. X-ray diffraction pattern from coating top surface before oxidation test 
Morphologies of PtAl bond coat and IN738LC/CMSX-4 substrate are shown in Figure 54. A two-layered bond coat was presented on the IN738LC substrate whereas a threelayer bond coat was seen on CMSX-4 substrate. The chemical compositions of different bond coat layers and substrate (close to and far from bond coat) were measured by EDS analysis, as listed in Table 5-1. From the table it is obvious that the bond coat layer 1 on CMSX-4 contained more Pt and Al, while much more $\mathrm{Cr}$ and refractory elements $\mathrm{Ti}$, Ta and $\mathrm{W}$ were detected in the bond coat layer 1 on IN738LC. The difference in $\mathrm{Pt}$ concentrations resulted from the separation of bond coat layer into layer 1 (Pt rich) and layer 2 (Pt lean) on the surface of CMSX-4 substrate (Figure 5-4 (b), layer 1 and layer 2). Elements from the base metals, such as $\mathrm{Ni}, \mathrm{Cr}, \mathrm{Co}, \mathrm{Ta}, \mathrm{Ti}, \mathrm{W}$, were found in Layer 2 in Figure 5-4 (a) and layer 3 in Figure 5-4 (b)) due to diffusion. The EDS analysis also revealed that there were more Ta and $\mathrm{W}$ (less $\mathrm{Cr}$ ) in layer 3 of CMSX-4 While more $\mathrm{Cr}$ and $\mathrm{Ti}$ (and some $\mathrm{W}$ ) were found in bond coat layer 2 on IN738LC, illustrating the influence of base metal composition on coating microstructure. 


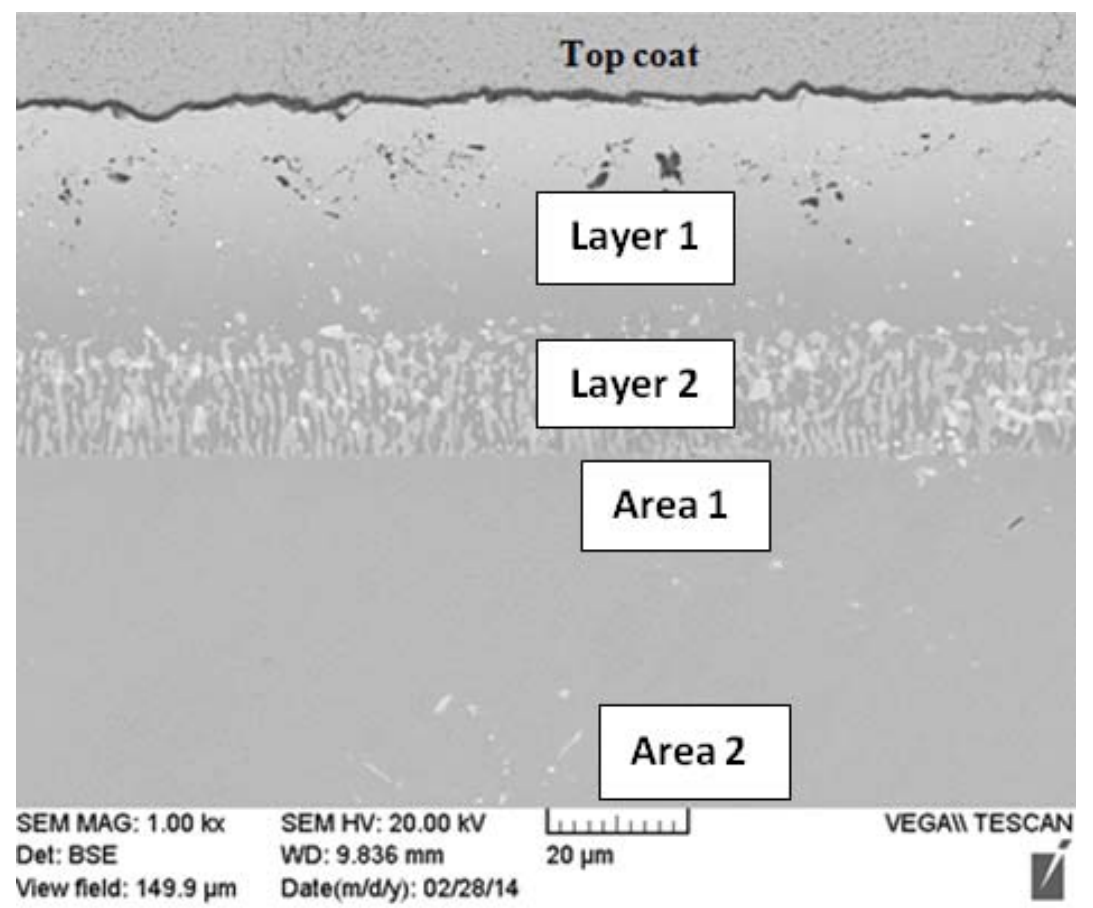

(a)

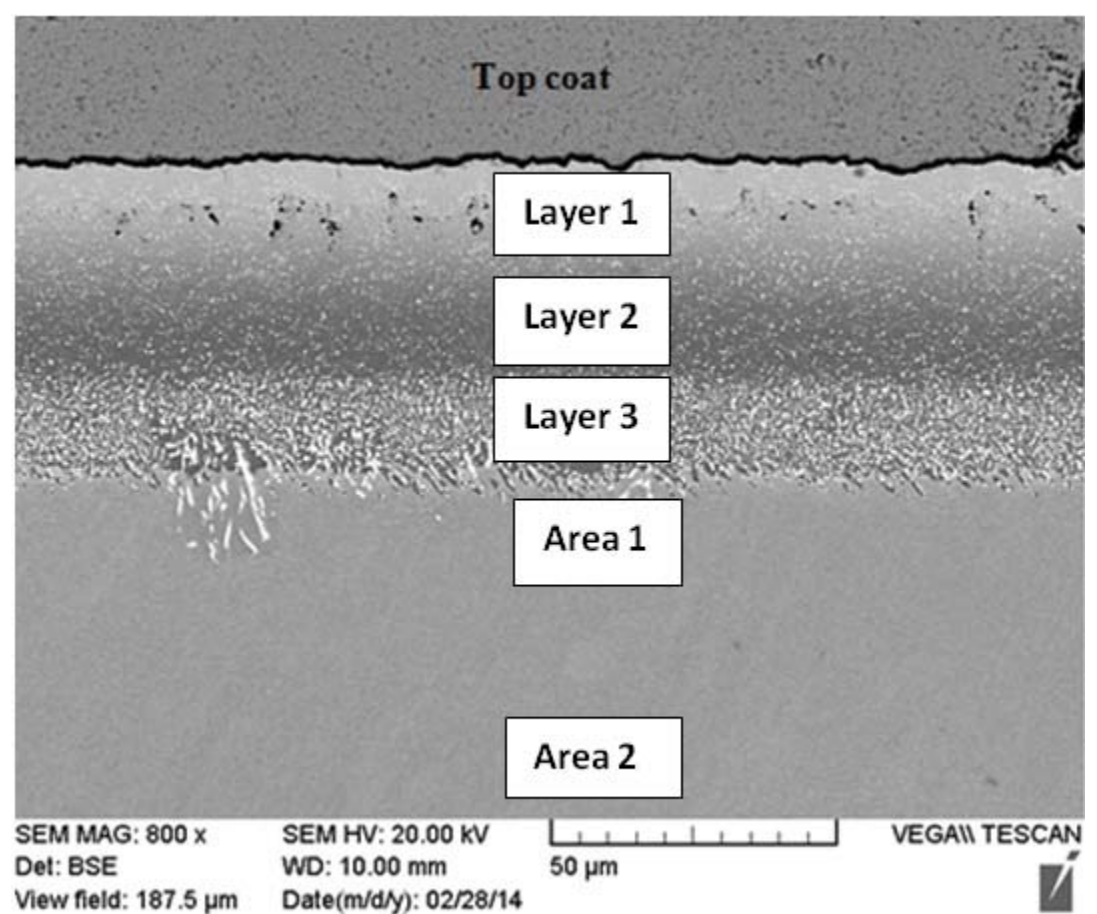

(b)

Figure 5-4. PtAl bond coat with IN738 (a) and CMSX-4 (b) substrate 
Table 5-1. Chemical compositions of PtAl bond coat (layers and substrate near the bond coat) (wt \%) measured by EDS

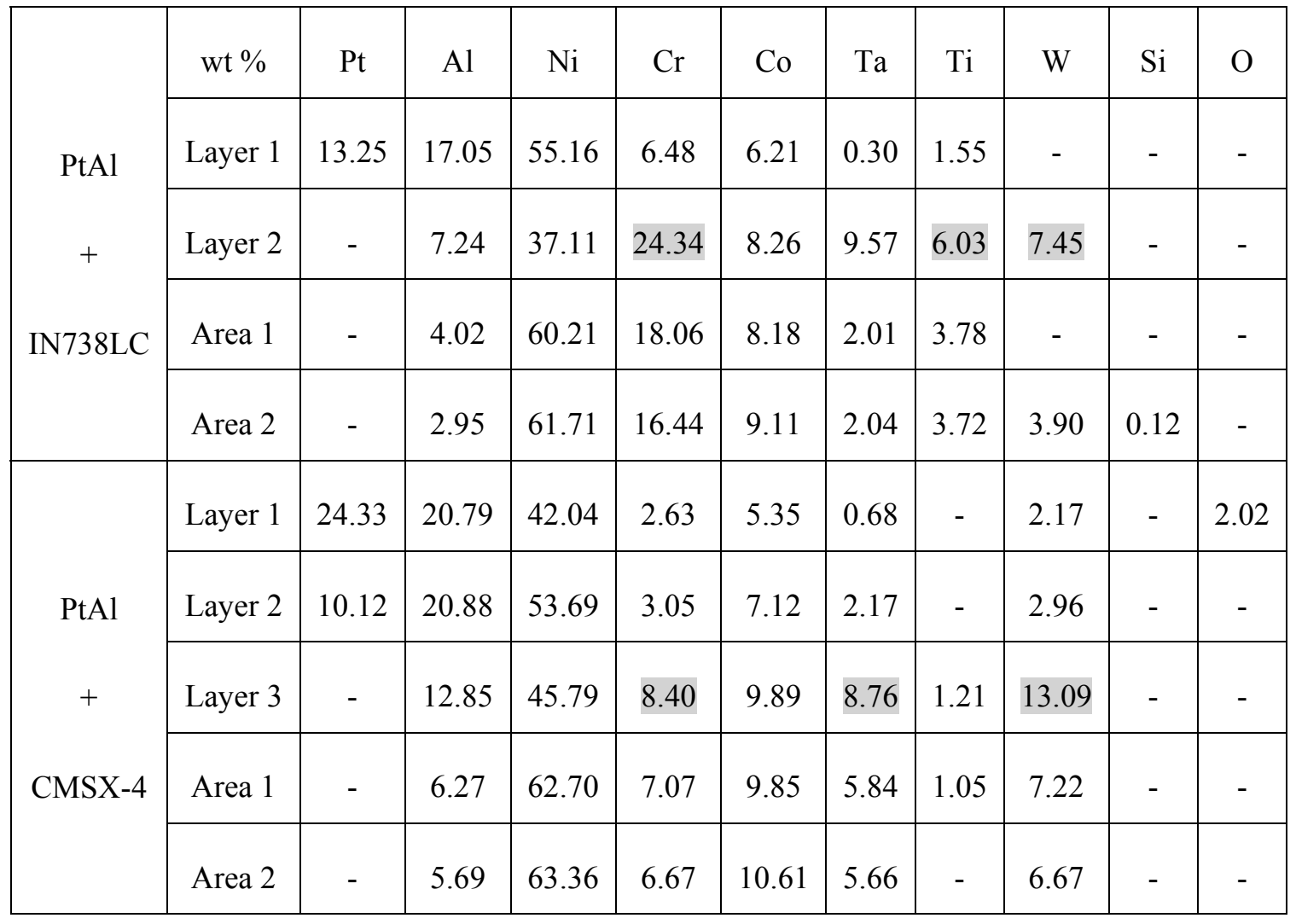




\section{Chapter: Isothermal Oxidation Test Result and Discussion}

\subsection{Isothermal Oxidation Lifetime of TBCs}

The isothermal oxidation lives of four samples are shown in Figure 6-1. The test was terminated after a total of 1000 hours (some samples did not fail when judged by the $30 \%$ spallation criterion). Iso\#1 has a life longer than $1000 \mathrm{~h}$ (spallation did not happen after 1000 hours), and the isothermal oxidation life for Iso\#2 is about $1000 \mathrm{~h}$ (the top coat completely lifted after 1000 hours but not so during inspection after 900 hours). Iso\#3 and Iso\#4 both have CMSX-4 substrates, and the resultant lives (300 h and $200 \mathrm{~h}$ ) are much shorter than similar samples with IN738LC as the substrate. Visual observations of Iso\#1-4 were taken every 100 hours, as shown in Figure 6-2 (a) - (d). Note that isothermally tested samples were in fact subjected to "cyclic" condition every 100 hours due the periodic visual inspection.

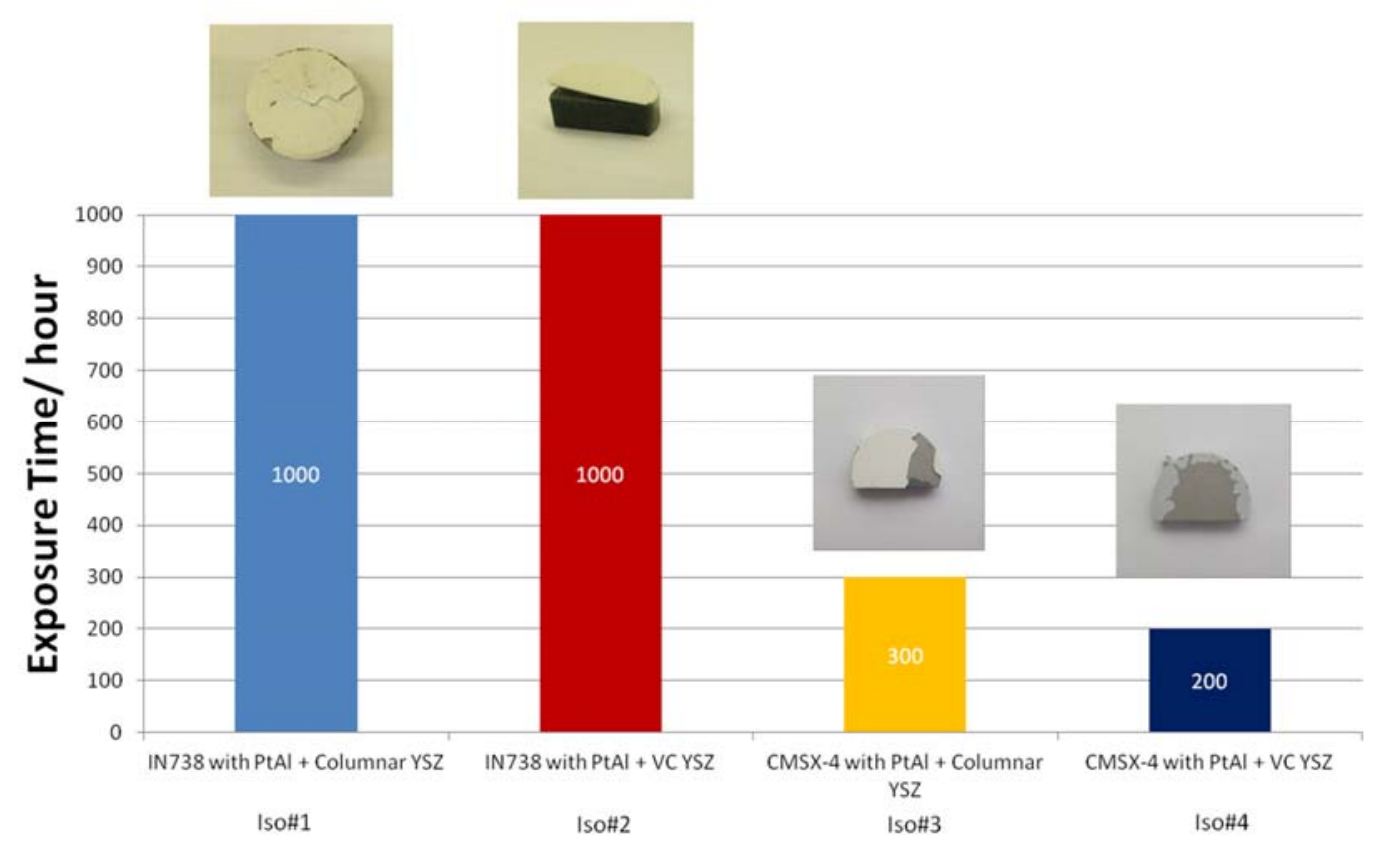

Figure 6-1. Isothermal oxidation life (hours) 

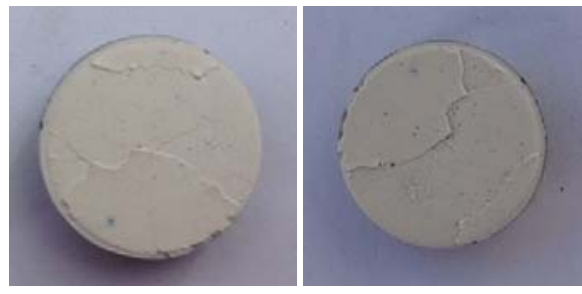

$100 \mathrm{~h}$

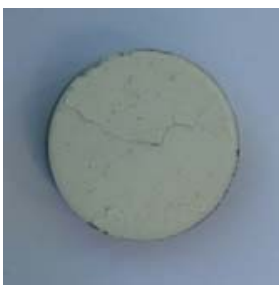

$600 \mathrm{~h}$
$200 \mathrm{~h}$

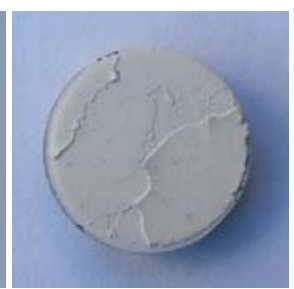

$700 \mathrm{~h}$

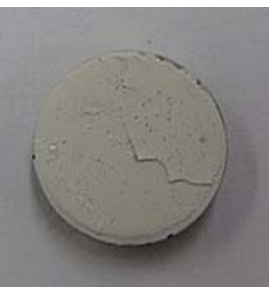

$300 \mathrm{~h}$

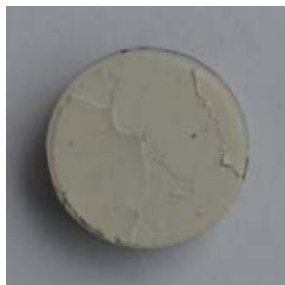

$800 \mathrm{~h}$

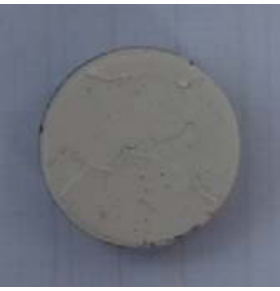

$400 \mathrm{~h}$

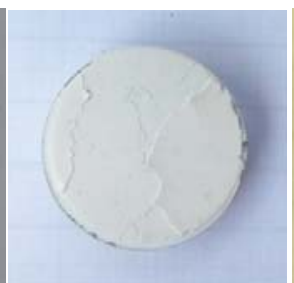

$900 \mathrm{~h}$

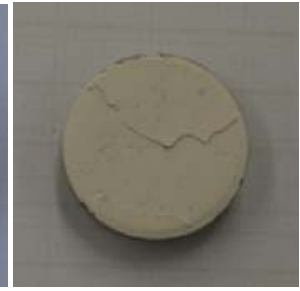

$500 \mathrm{~h}$

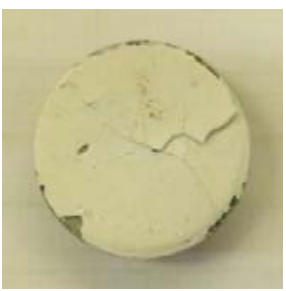

$1000 \mathrm{~h}$

(a) Iso\#1

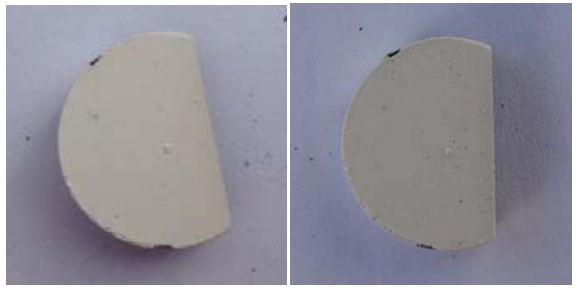

$100 \mathrm{~h}$

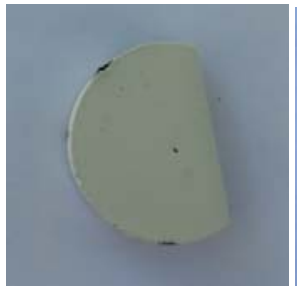

$600 \mathrm{~h}$
$200 \mathrm{~h}$

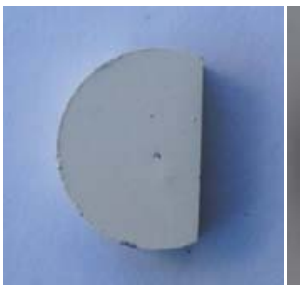

$700 \mathrm{~h}$

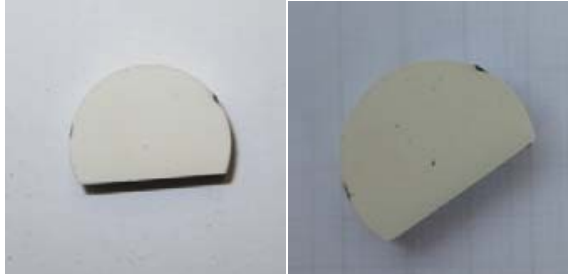

$300 \mathrm{~h}$

$400 \mathrm{~h}$ $500 \mathrm{~h}$
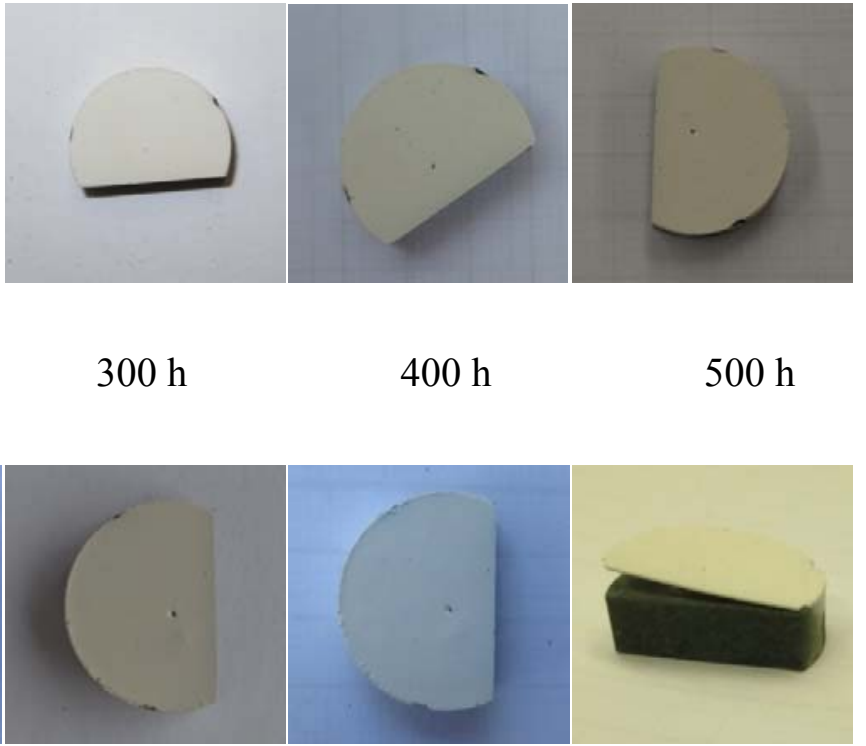

800 h

$900 \mathrm{~h}$

$1000 \mathrm{~h}$

(b) Iso\#2 


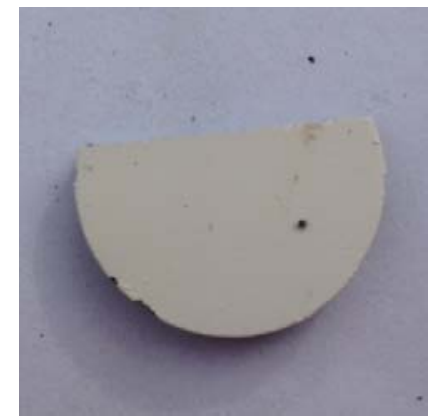

$100 \mathrm{~h}$

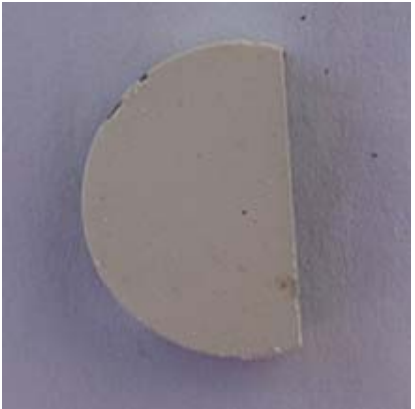

$200 \mathrm{~h}$

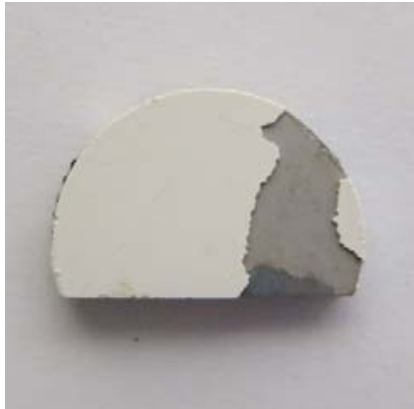

$300 \mathrm{~h}$

(c) Iso\#3

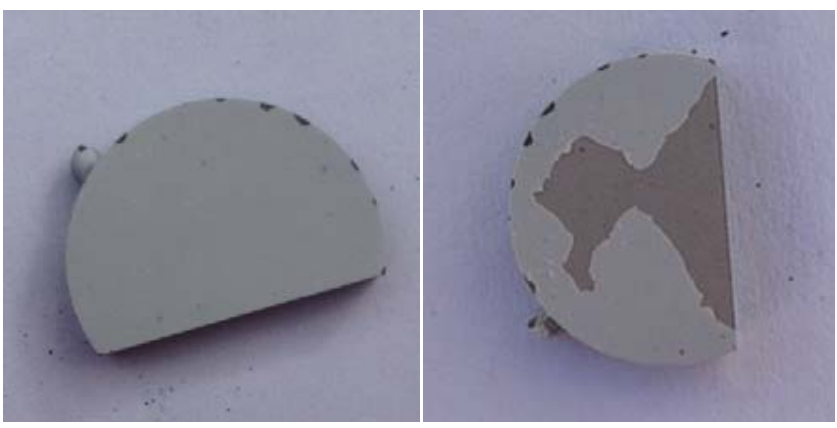

$100 \mathrm{~h}$

$200 \mathrm{~h}$

(d) Iso\#4

Figure 6-2. Visual observations of Iso\#1-4 (every 100 h)

\subsection{Microstructure Analysis of Isothermally Oxidized Samples}

\subsubsection{Samples with PtAl Bond Coat-Columnar Structured YSZ Top Coat}

The oxidized samples were analyzed by SEM and EDS on several locations including (a) top coating surface, (b) coating backside (the inside surface of spalled coating), (c) exposed bond coat/substrate surface and finally (d) the cross section. From the results 
obtained during isothermal oxidation test, columnar YSZ coating on IN738LC substrate (Iso\#1) had the longest life ( $>1000 \mathrm{~h}$ ) while the one with CMSX-4 substrate (Iso\#3) only lasted for 300 h. On sample Iso\#1 (coating remains intact but network of cracks formed), there is limited number of cracks formed on coating surface (not spalled off) (Figure 6-3 (a)), and a dense $\mathrm{Al}_{2} \mathrm{O}_{3}$ layer formed between $\mathrm{YSZ}$ and bond coat (Figure 6-3 (b)). The failure of TBCs is usually caused by fast growing of thermally grown oxide (TGO) [165]. Since the diffusion of ions in $\mathrm{Al}_{2} \mathrm{O}_{3}$ is slow, a continuous $\mathrm{Al}_{2} \mathrm{O}_{3}$ scale (as in this case) can suppress the growth of TGO during oxidation. While a continuous alumina has a beneficial effect on the life of TBCs, the formation of porous and less protective spinels ( $\left.\mathrm{Ni}(\mathrm{Al}, \mathrm{Cr})_{2} \mathrm{O}_{4}\right)$, nickel oxide and chromium oxide causes tensile stress due to large volume expansion [82] and is detrimental to coating life. Crack nucleation tends to occur inside mixed oxides and/or spinels from where the cracks continue to grow, leading to eventual spallation of TBCs [117]. Thus the growth of mixed oxides and spinels is not favorable to the service life of TBCs. A small amount of $\mathrm{NiAl}_{2} \mathrm{O}_{4}$ was detected on Iso\#1 by SEM/EDS analysis, as shown in Figure 6-3((c) and (d)). EDS analysis results of various phases found on Iso\#1 are summarized in Table 6-1 (some measurements are highlighted in the table to point out the most notable changes). 


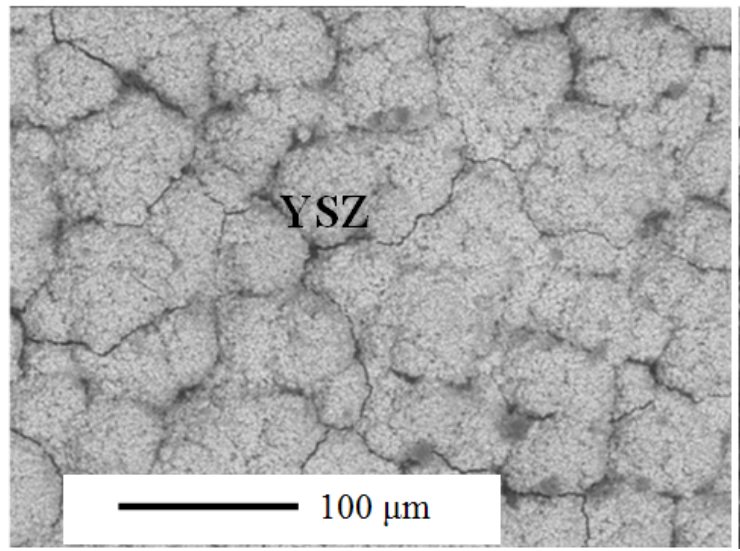

(a) Top coat surface

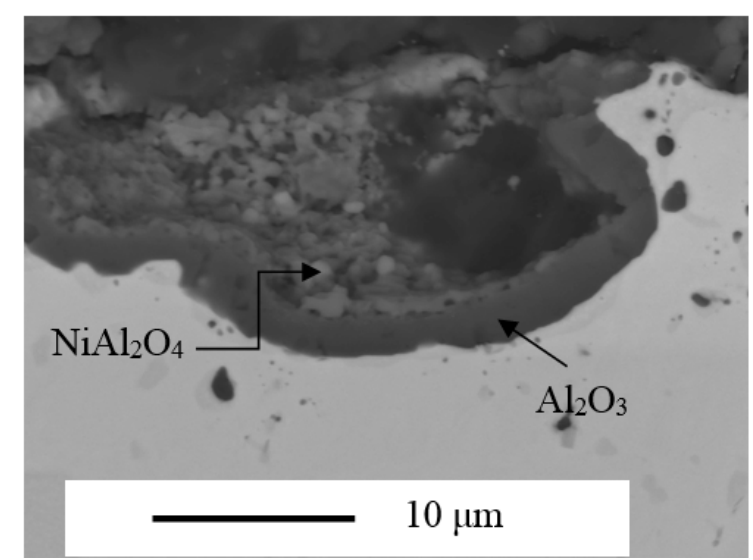

(c) Cross section

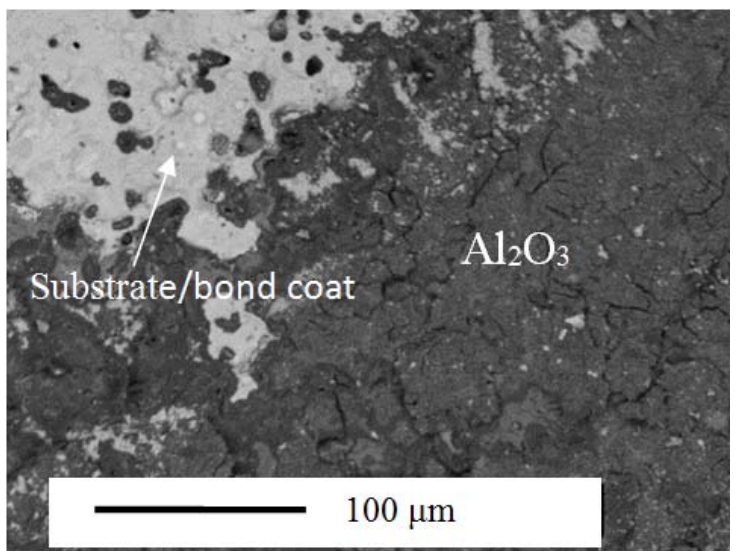

(b) Exposed substrate/bond coat

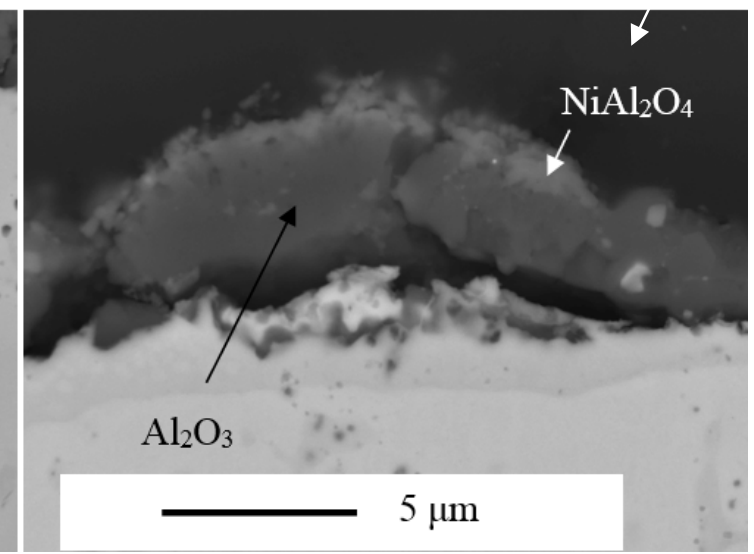

(d) Cross section

Figure 6-3. Microstructures of Sample Iso\#1 (IN738LC with PtAI + columnar YSZ) after oxidation test 
Table 6-1. EDS analysis results of Iso\#1 (wt \% and at \%)

\begin{tabular}{|c|c|c|c|c|c|c|c|c|c|c|}
\hline & Element & $\mathrm{O} *$ & $\mathrm{Ni}$ & $\mathrm{Al}$ & $\mathrm{Ta}$ & $\mathrm{Zr}$ & $\mathrm{Ti}$ & $\mathrm{Cr}$ & $\mathrm{Co}$ & $\mathrm{Si}$ \\
\hline $\begin{array}{c}\mathrm{Al}_{2} \mathrm{O}_{3} \text { (on } \\
\text { bond } \\
\text { coat/substrate } \\
\text { surface) }\end{array}$ & $\mathrm{Wt} \%$ & 41.83 & 1.22 & 41.84 & 1.7 & 2.27 & 6.88 & 4.26 & - & - \\
\cline { 2 - 12 } & 58.8 & 0.47 & 34.88 & 0.21 & 0.56 & 3.23 & 1.84 & - & - \\
\hline $\begin{array}{c}\mathrm{NiAl}_{2} \mathrm{O}_{4} \\
\text { (cross section) }\end{array}$ & $\mathrm{Wt} \%$ & 36.73 & 24 & 31.13 & - & - & 1.31 & 2.88 & 3.19 & 0.77 \\
\cline { 2 - 13 } & $\mathrm{At} \%$ & 57.07 & 10.16 & 28.68 & - & - & 0.68 & 1.38 & 1.34 & 0.68 \\
\hline
\end{tabular}

*note that semi-quantitative EDS analysis generates larger error on the analysis of non-metallic elements.

For sample Iso\#3, a network of cracks was well developed on the YSZ coating surface (Figure 6-4 (a)). On the spalled YSZ coating backside shown in Figure 6-4 (b), there is a good coverage of alumina (indicating the failure within TGO), with occasional bare patches of YSZ (failure from YSZ separating from TGO). However, very little alumina was found on the exposed bond coat/substrate surface, as shown in Figure 6-4 (c). This observation suggests that the failure/spallation site is mostly between $\mathrm{Al}_{2} \mathrm{O}_{3}$ and bond coat. Further examination of the cross section of sample Iso\#3 (Figure 6-4 (g) and (h)) confirms that the coating spallation had occurred at the TGO and bond coat interface during the isothermal test. W-rich and Ta-rich precipitants are observed on the exposed bond coat/substrate surface and inside the remaining TGO layer, as shown in Figure 6-4 (d) and (e). The elevated Ta and W in the CMSX-4 coating system may have weakened the TGO adhesion (with YSZ), leading to premature failure. Mixed oxides or spinels were not found during SEM/EDS analysis (probably due to the limited exposure time 
since mixed oxides are mostly formed as the oxidation process progresses to later stage). XRD analysis on the backside (the side facing the substrate) of the spalled 8 YSZ coating piece and bond coat/substrate surface further confirmed that only $\mathrm{Al}_{2} \mathrm{O}_{3}$ and $\mathrm{YSZ}$ existed (Figure 6-5 and Figure 6-6). EDS analysis results of Iso\#3 are summarized in Table 6-2.

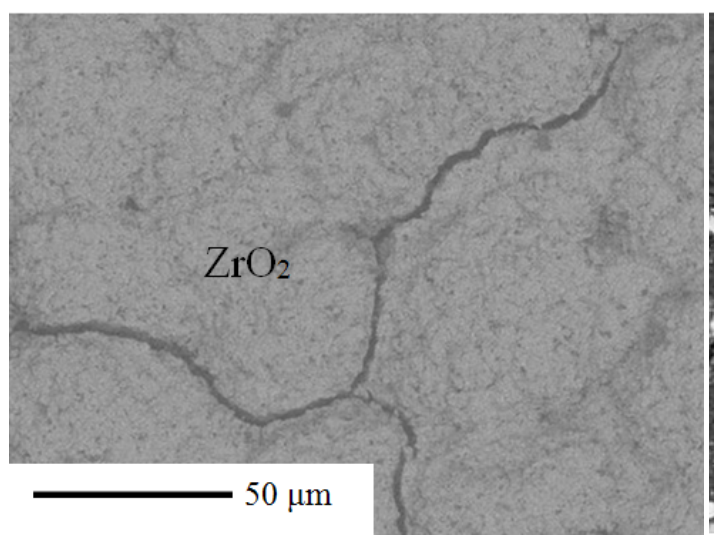

(a) YSZ top coat surface

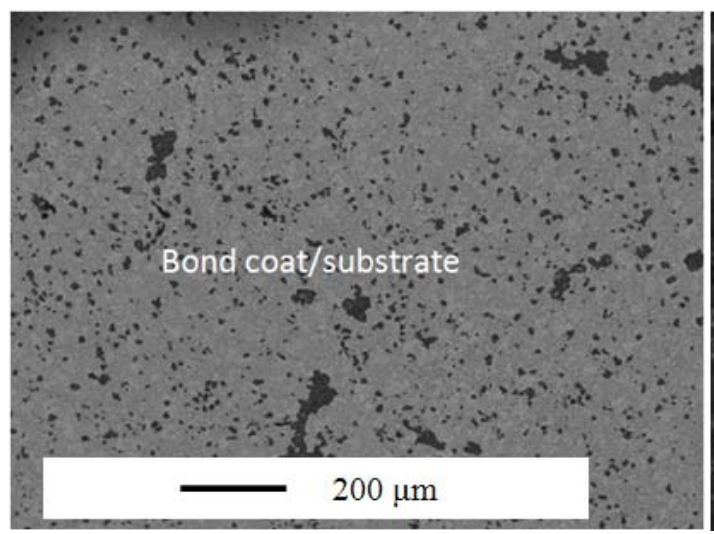

(c) Exposed bond coat/substrate

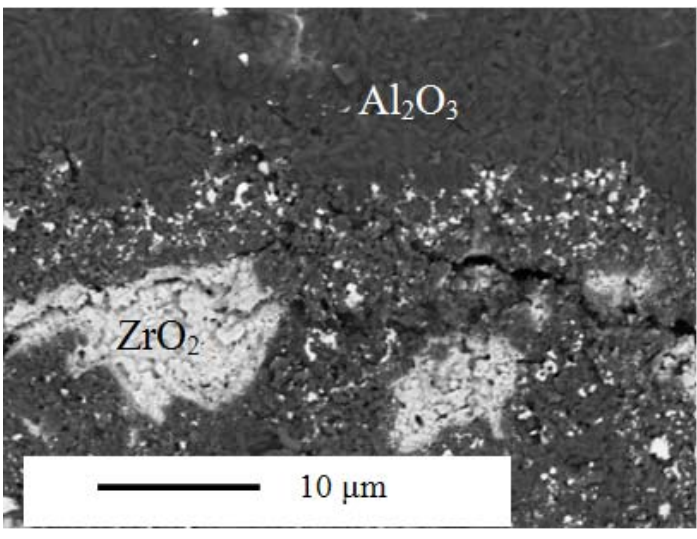

(b) Back side of the spalled YSZ

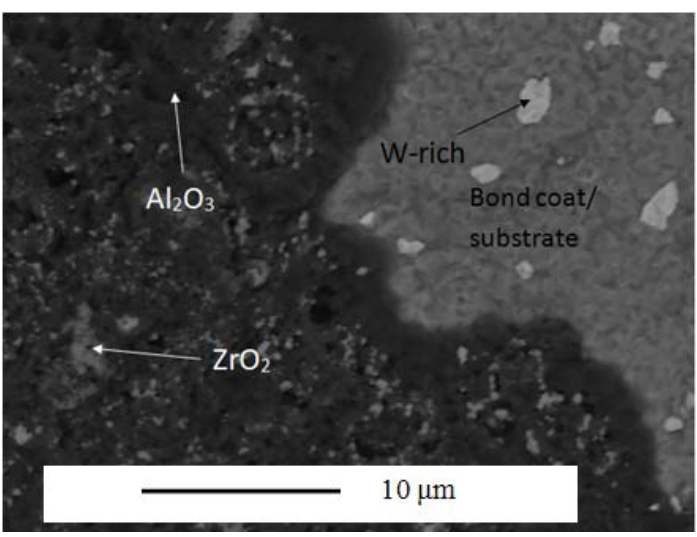

(d) Exposed bond coat/substrate 


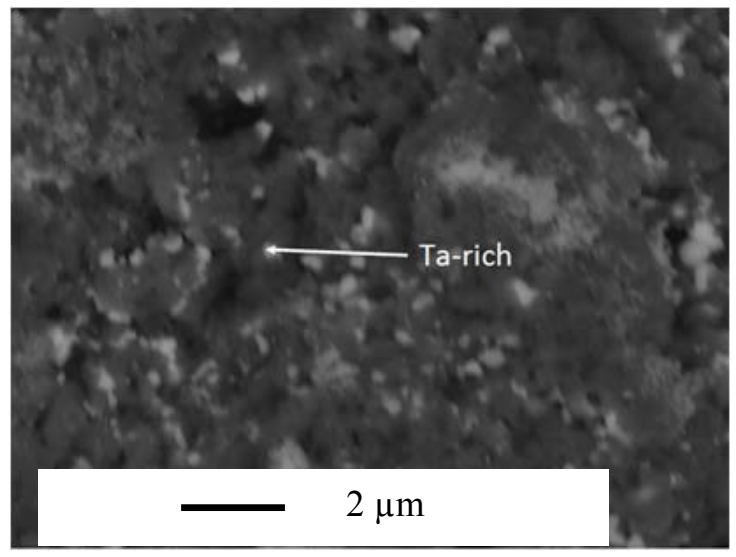

(e) TGO layer on (d)

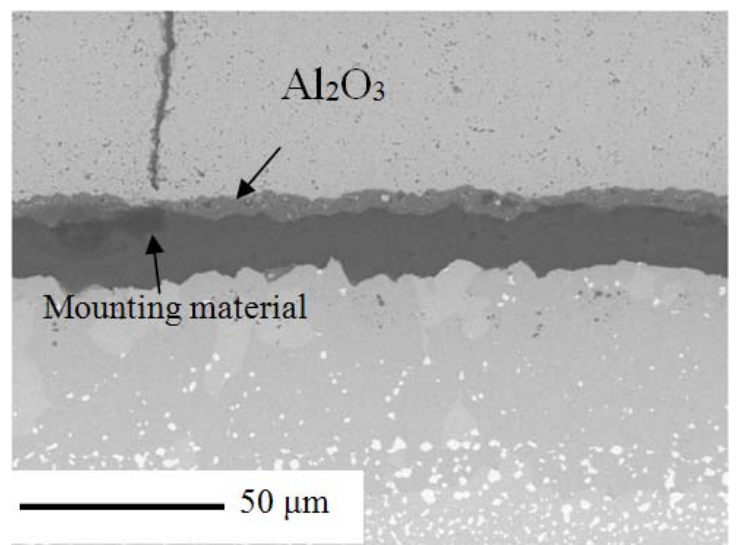

(g) Cross section

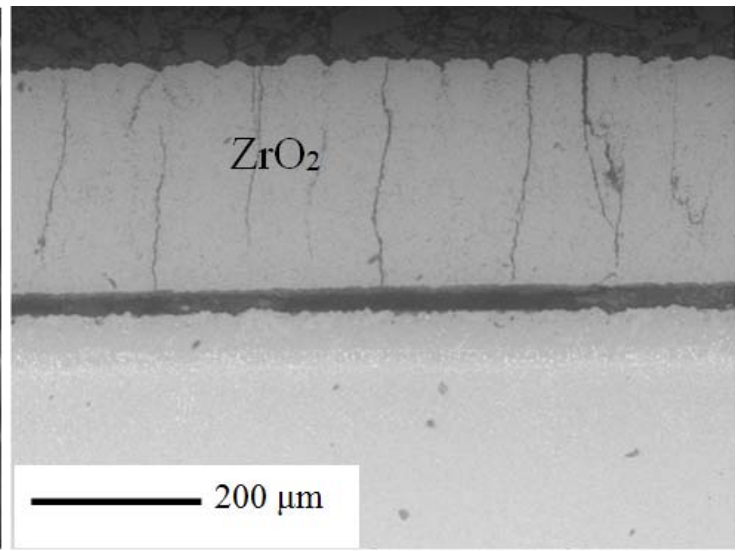

(f) Cross section

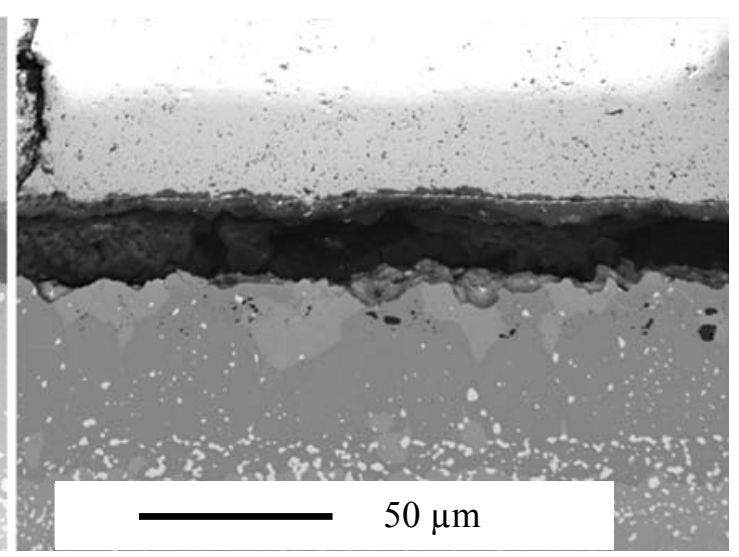

(h) Cross section

Figure 6-4. Microstructures of Sample Iso\#3 (CMSX-4 with PtAI + columnar YSZ) after isothermal oxidation test

Table 6-2. EDS analysis results of Iso\#3 (wt\% and at\%)

\begin{tabular}{|c|c|c|c|c|c|c|}
\hline & Element & $\mathrm{O}$ & $\mathrm{Al}$ & $\mathrm{Hf}$ & $\mathrm{Y}$ & $\mathrm{Zr}$ \\
\hline $\begin{array}{c}\mathrm{Al}_{2} \mathrm{O}_{3} \\
(\mathrm{YSZ} \text { backside) }\end{array}$ & $\mathrm{wt} \%$ & 45.08 & 54.92 & - & - & - \\
\cline { 2 - 7 } & $\mathrm{at} \%$ & 58.06 & 41.94 & - & - & - \\
\hline $\begin{array}{c}\mathrm{ZrO}_{2} \\
(\mathrm{YSZ} \text { backside) }\end{array}$ & $\mathrm{wt} \%$ & 28.11 & 1.05 & 1.39 & 9.54 & 59.9 \\
\cline { 2 - 7 } & $\mathrm{at} \%$ & 68.43 & 1.52 & 0.3 & 4.18 & 25.57 \\
\hline
\end{tabular}




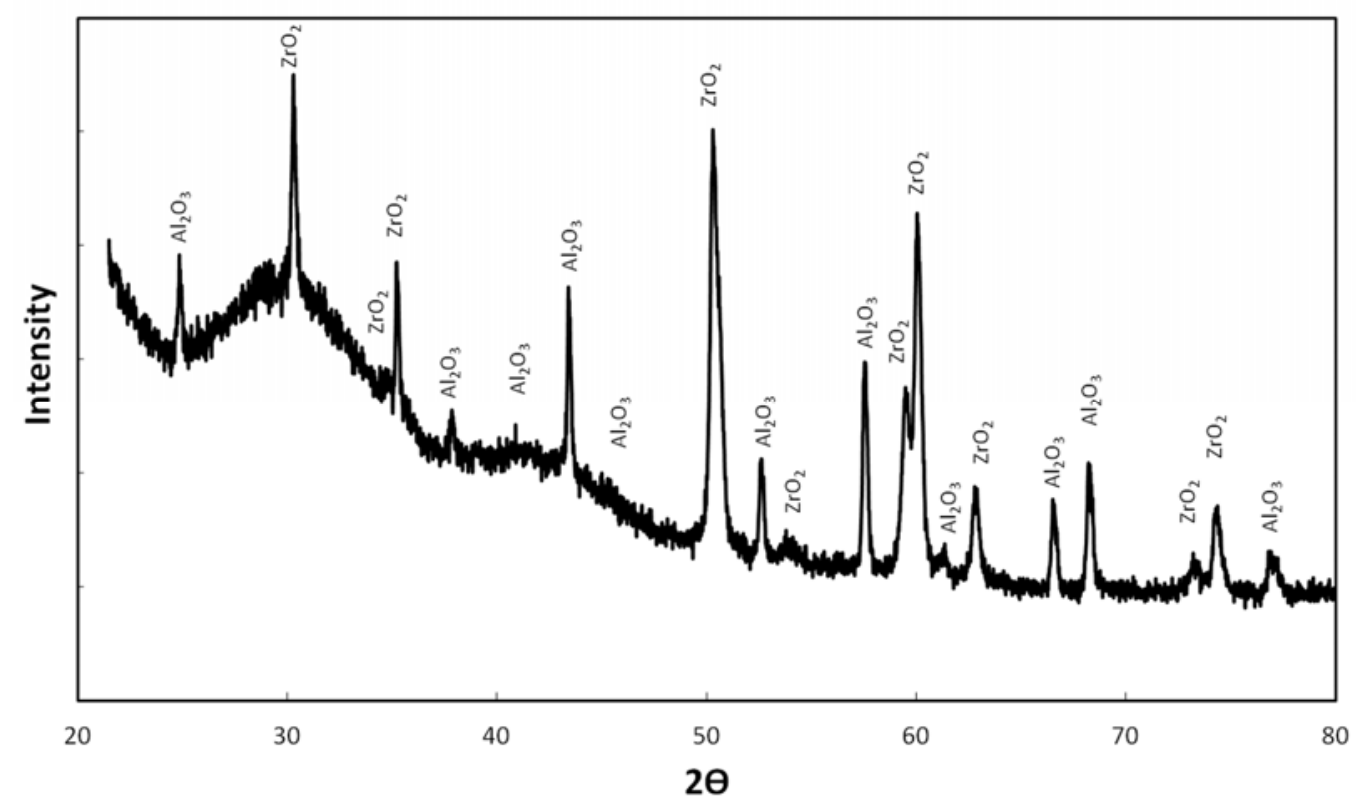

Figure 6-5. X-ray diffraction pattern from the backside of the spalled YSZ (Iso\#3, CMSX-4 with PtAl + columnar YSZ)

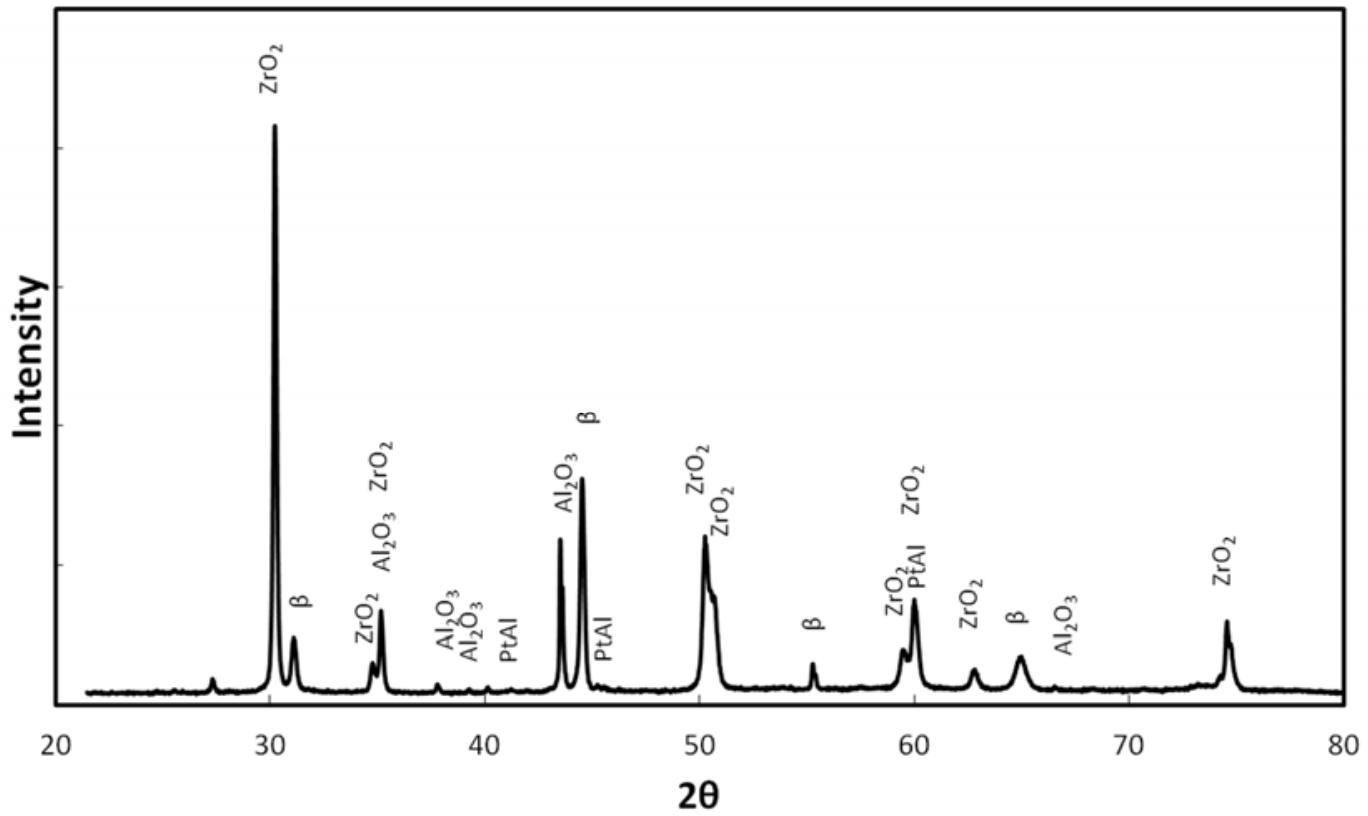

Figure 6-6. X-ray diffraction pattern of bond coat/substrate (Iso\#3, CMSX-4 with PtAl + columnar YSZ) 


\subsubsection{Samples VC YSZ Top Coat}

Coating spallation was observed on the sample with IN738LC substrate and VC 8YSZ (Iso\#2) after about $1000 \mathrm{~h}$ while the one with the CMSX-4 substrate and VC 8YSZ (Iso\#4) failed after $200 \mathrm{~h}$, a significant difference attributed to the influence of substrate compositions. A well developed network of cracks was found on the YSZ surface (Figure 6-7 (a)). On the spalled 8YSZ backside and exposed bond coat/substrate surface of Iso\#2, mixed oxides and spinels, such as $\mathrm{Cr}_{2} \mathrm{O}_{3}$ and $\mathrm{Ni}(\mathrm{Al}, \mathrm{Cr})_{2} \mathrm{O}_{4}$ (spinels), were detected (Figure 6-7 (b) - (e)), in addition to the presence of $\mathrm{Al}_{2} \mathrm{O}_{3}$ scale. Occasional bare substrate IN738 was also observed on the exposed bond coat/substrate surface (Figure 67 (f). As the test duration increases, oxygen continues its passage into bond coat/YSZ interface through cracks and porosity in the top coat and increases the growth of TGO. When Al becomes depleted and more $\mathrm{Cr}$ and $\mathrm{Ni}$ diffused outward from the substrate, $\mathrm{Cr}_{2} \mathrm{O}_{3}$ and $\mathrm{NiO}$ form on the bond coat surface. Due to the reaction of $\mathrm{NiO}+\mathrm{Cr}_{2} \mathrm{O}_{3}+$ $\mathrm{Al}_{2} \mathrm{O}_{3} \rightarrow \mathrm{Ni}(\mathrm{Al}, \mathrm{Cr})_{2} \mathrm{O}_{4}$, spinels also form inside or close to TGO usually in the later stage of oxidation [139]. Formation of chromia and spinels (CS) causes the volume change, and consequently introduces stresses and cracking, leading to TBC spallation [166]. Since Iso\#3 has been exposed to isothermal oxidation condition for 1000 hours, the prolonged exposure has resulted in the formation CS which led to the eventual failure of the TBC system. The reason Iso\#2 has slightly poorer performance than Iso\#1 is due to the increased oxygen accessibility through VC 8YSZ structure. XRD analysis on the backside of the spalled YSZ and the top surface of the exposed bond coat on sample Iso\#2 (Figure 6-8 and Figure 6-9) confirmed the presence of CS. EDS analysis results of Iso\#2 are summarized in Table 6-3. 


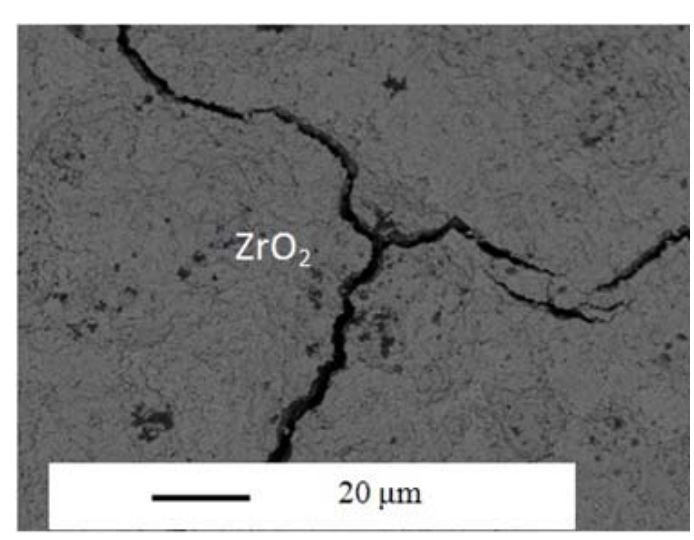

(a) Top of YSZ

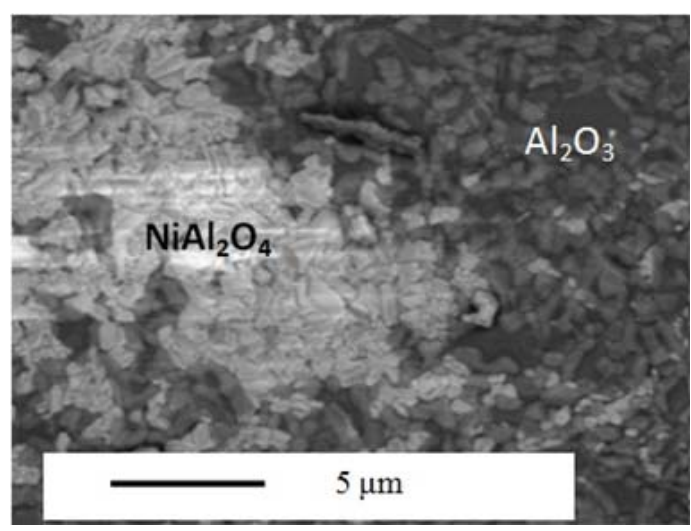

(c) Backside of spalled YSZ

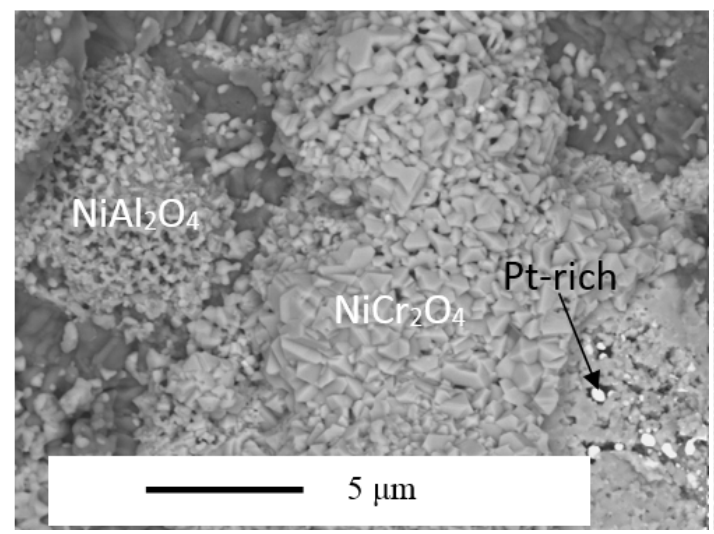

(e) Exposed bond coat/substrate

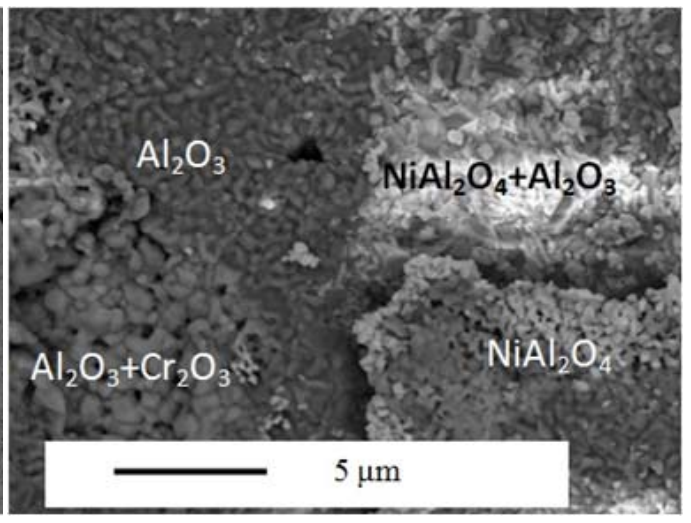

(b) Backside of spalled YSZ

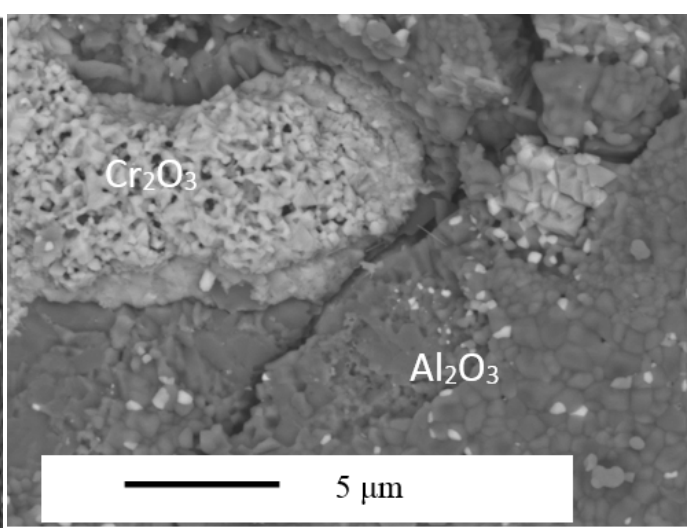

(d) Exposed bond coat/substrate

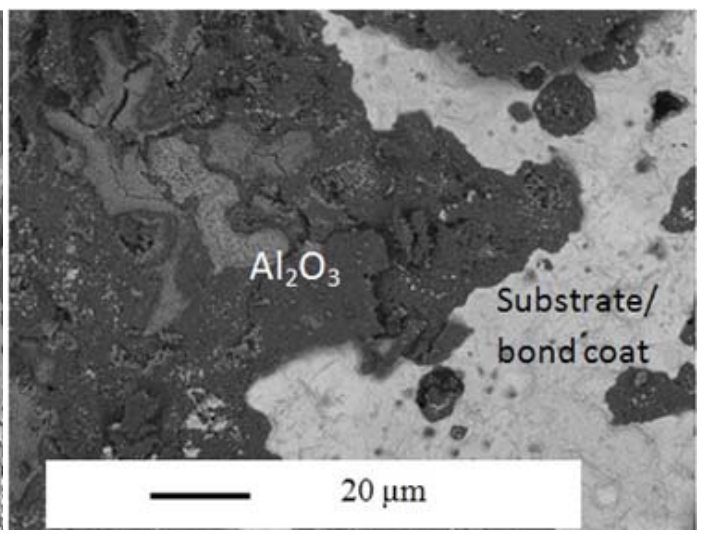

(f) Exposed bond coat/substrate

Figure 6-7. Microstructures of sample Iso\#2 (IN738LC with PtAl + VC YSZ) after oxidation test 
Table 6-3. EDS analysis results of Iso \#2 (wt\% and at\%)

\begin{tabular}{|c|c|c|c|c|c|c|c|}
\hline & Element & $\mathrm{O}$ & Co & $\mathrm{Ni}$ & Al & $\mathrm{Ti}$ & $\mathrm{Cr}$ \\
\hline $\mathrm{Cr}_{2} \mathrm{O}_{3}$ & $\mathrm{wt} \%$ & 30.67 & 7.41 & 8.95 & 3.34 & 7.54 & 42.08 \\
\hline (bond coat/substrate surface) & at $\%$ & 58.34 & 3.83 & 4.64 & 3.77 & 4.79 & 24.63 \\
\hline $\mathrm{NiCr}_{2} \mathrm{O}_{4}$ & $\mathrm{wt} \%$ & 27.35 & 6.08 & 16.27 & 0.34 & 1.5 & 48.47 \\
\hline (bond coat/substrate surface) & at $\%$ & 55.76 & 3.37 & 9.04 & 0.41 & 1.02 & 30.4 \\
\hline $\mathrm{NiAl}_{2} \mathrm{O}_{4}$ & wt $\%$ & 49.43 & 6.19 & 21.66 & 22.71 & - & - \\
\hline (YSZ backside) & at $\%$ & 70.13 & 2.39 & 8.38 & 19.11 & - & - \\
\hline $\mathrm{Al}_{2} \mathrm{O}_{3}$ & wt $\%$ & 42.13 & - & - & 57.87 & - & - \\
\hline (bond coat/substrate surface) & at $\%$ & 55.11 & - & - & 44.89 & - & - \\
\hline
\end{tabular}




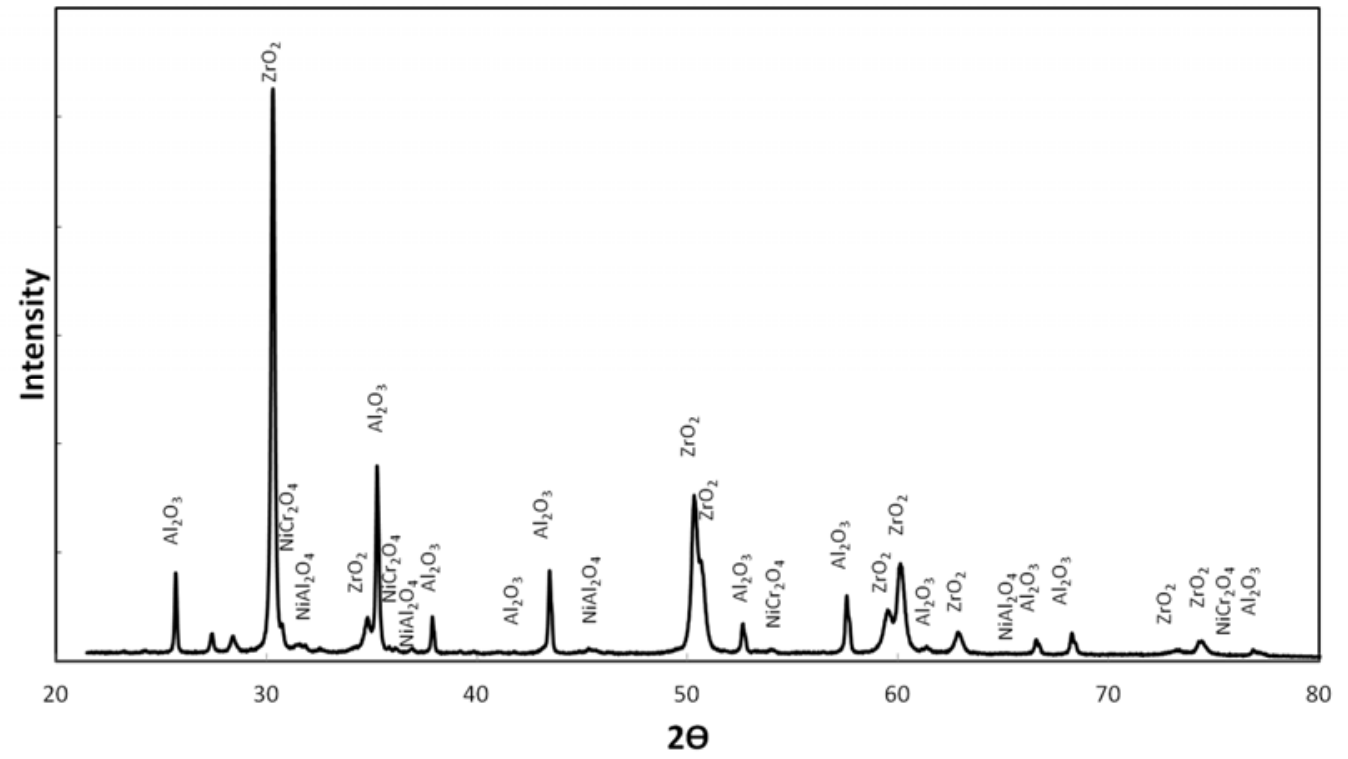

Figure 6-8. X-ray diffraction pattern from the backside of spalled YSZ (sample Iso\#2, IN738LC with PtAl + VC YSZ)

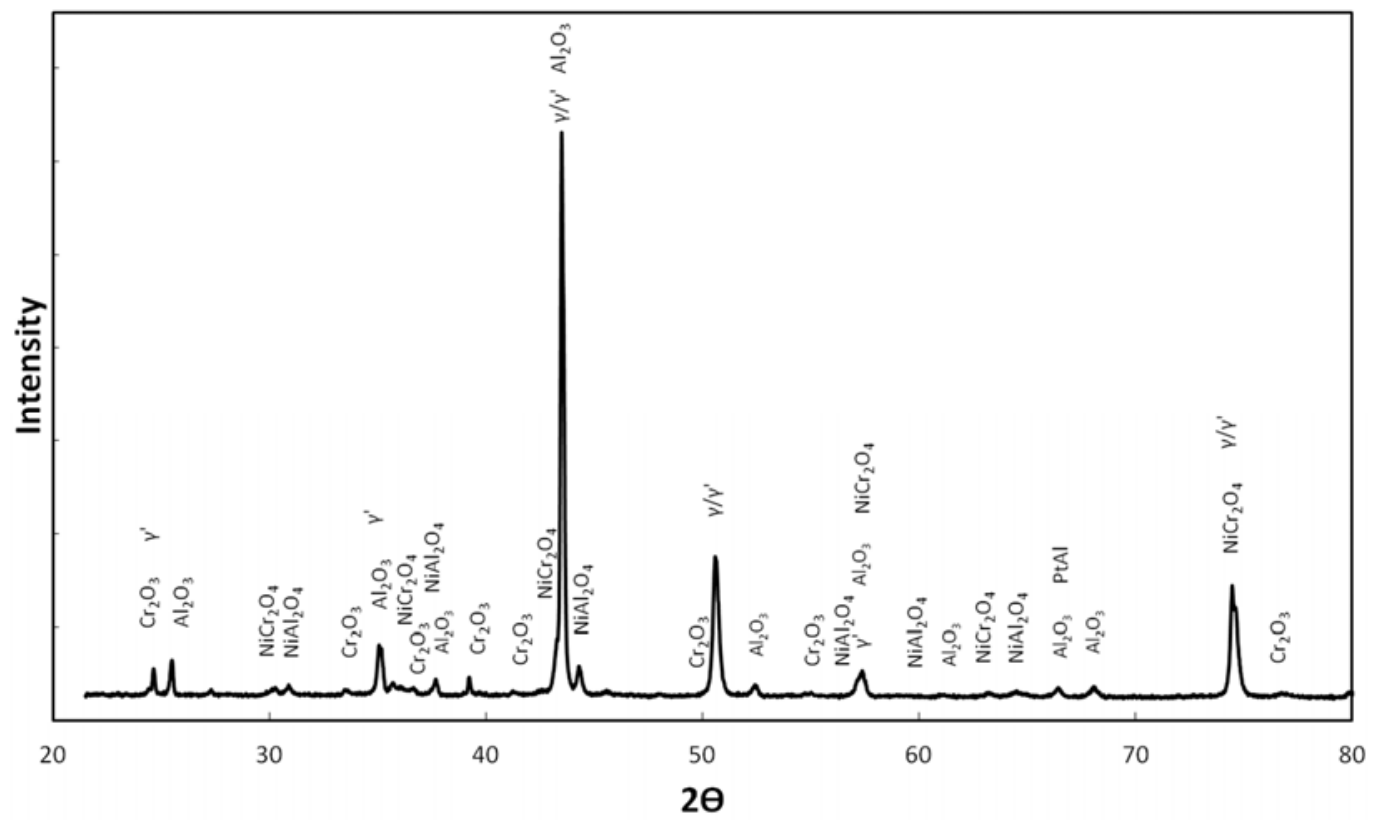

Figure 6-9. X-ray diffraction pattern from the exposed bond coat/substrate surface (sample Iso\#2, IN738LC with PtAl + VC YSZ) 
From the EDS analysis of the exposed bond coating/substrate surface of Iso\#4 after top coat spallation, the majority of the exposed surface has bond coat composition and there was occasional $\mathrm{Al}_{2} \mathrm{O}_{3}$ remaining on the surface. And there was no evidence of CS (Figure 6-10). XRD analysis, Figure 6-11, confirmed that no CS formed. The short oxidation duration of sample Iso\#4 (200 h), before final failure, might not be sufficient for the formation of CS (usually due to the $\mathrm{Al}$ depletion and outward diffusion of $\mathrm{Cr}$ and $\mathrm{Ni}$ ). The resulted morphology of exposed bond coat/substrate surface (due to top coat spallation) (Figure 6-10 (a) and (b)) was very similar to that of Iso\#3 (Figure 6-4 (c)), indicating the spallation occurred at $\mathrm{TGO} /$ bond coat interface. It is important to know that although the premature failure of sample Iso\#4 was not as a direct result of CS formation, the presence of $\mathrm{W}$ and Ta containing phases in the TGO (Figure 6-10 (a)-(c)) provided indication that outward diffusion of $\mathrm{Ta}$ and $\mathrm{W}$ had taken place, leading to void (Kirkendall effect) formation at the TGO/bond interface. This may be reason for the early spallation of sample Iso\#4. EDS analysis results of Iso\#4 are shown in Table 6-4. 


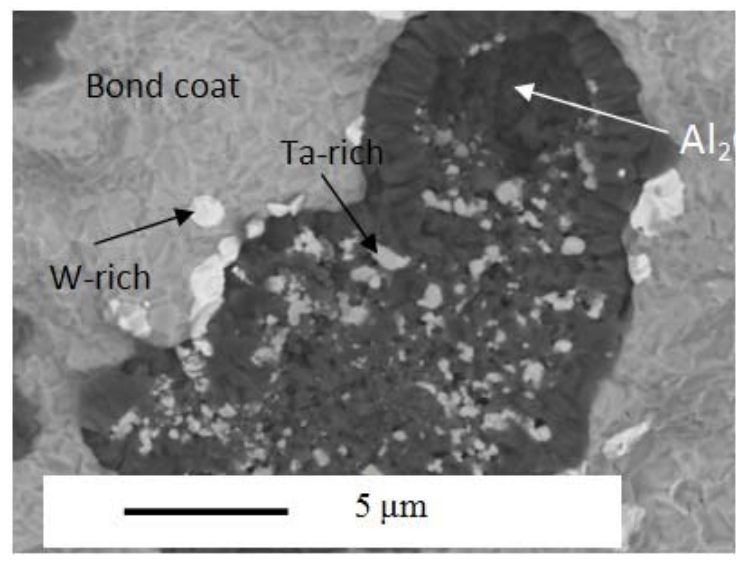

(a) Bond coat/substrate surface

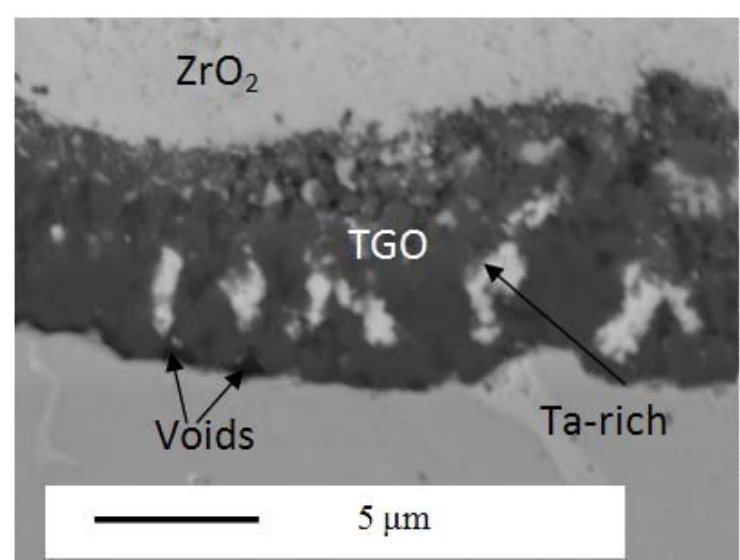

(c) Cross section where some YSZ still remained

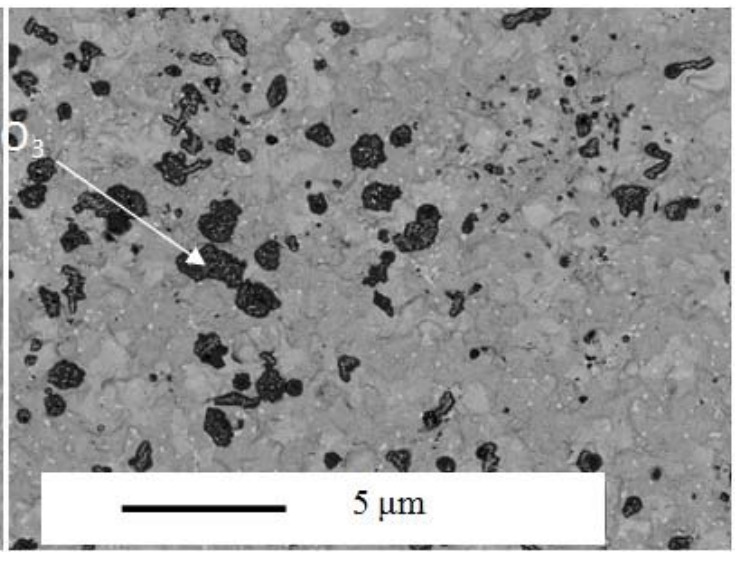

(b) Bond coat/substrate surface

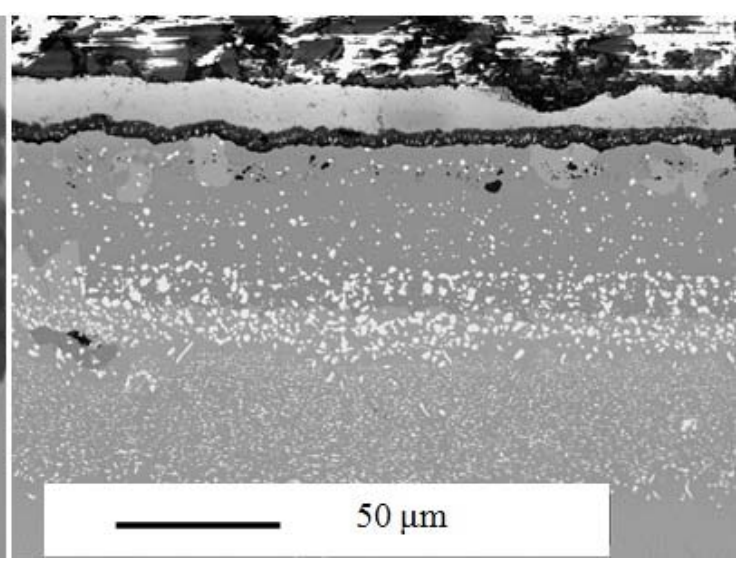

(d) Cross section

Figure 6-10. Microstructures of Iso\#4 (CMSX-4 with PtAl + VC YSZ) after oxidation test

Table 6-4. EDS analysis results of Iso\#4 (wt\% and at\%)

\begin{tabular}{|c|c|c|c|}
\hline \multirow{4}{*}{$\mathrm{Al}_{2} \mathrm{O}_{3}$} & Element & $\mathrm{O}$ & $\mathrm{Al}$ \\
\cline { 2 - 4 } & $\mathrm{wt} \%$ & 38.8 & 61.2 \\
\cline { 2 - 4 } & $\mathrm{at} \%$ & 51.67 & 48.33 \\
\hline
\end{tabular}




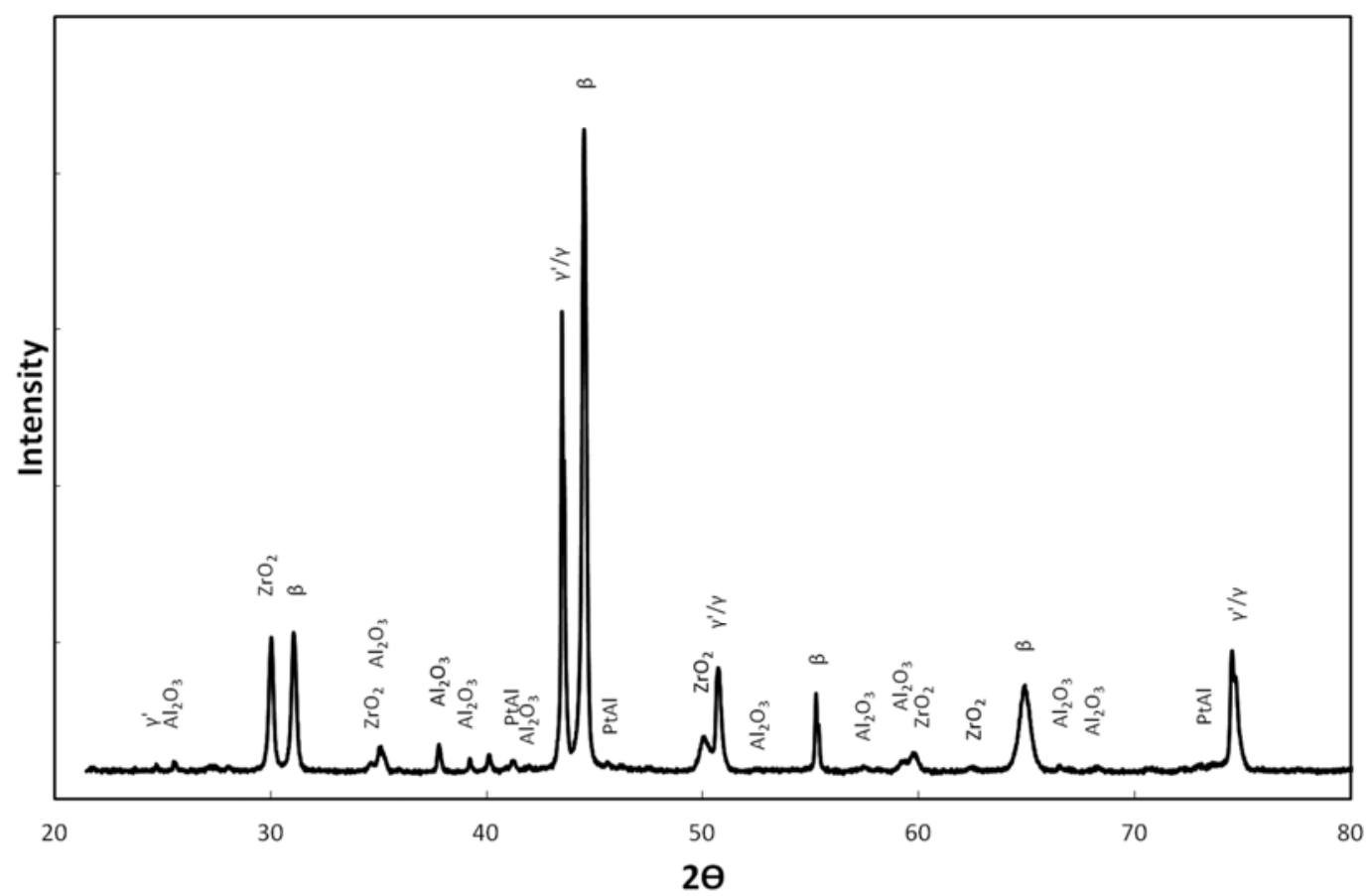

Figure 6-11. X-ray diffraction pattern from the exposed bond/coat substrate surface (sample Iso\#4, CMSX-4 with PtAl + VC YSZ)

\subsection{Discussion}

As clearly shown in Figure 6-1, the TBC systems with IN738LC substrate had much longer isothermal oxidation lifetimes than those with CMSX-4 substrate. Sample Iso\#1 and Iso\#2 (IN738LC substrate) had a lifetime of $\geq 1000 \mathrm{~h}$ while Iso\#3 and Iso\#4 failed prematurely after $300 \mathrm{~h}$ and $200 \mathrm{~h}$, respectively.

For the TBCs with IN738LC substrate, the oxides formed in sample Iso\#1 are different than that in Iso\#2. $\mathrm{Al}_{2} \mathrm{O}_{3}$ and a small amount of $\mathrm{NiAl}_{2} \mathrm{O}_{4}$ were observed in Iso\#1 after oxidation. However, a large amount of chromia and $\mathrm{Ni}(\mathrm{Al}, \mathrm{Cr})_{2} \mathrm{O}_{4}$ was observed in sample Iso\#2, both on exposed bond coating/substrate surface and the backside of spalled YSZ coating piece. After $1000 \mathrm{~h}$ exposure, spallation did not occur to sample Iso\#1 
(columnar YSZ); whereas sample Iso\#2 (with VC YSZ), failed after $1000 \mathrm{~h}$. A dense $\mathrm{Al}_{2} \mathrm{O}_{3}$ oxide layer and the lack of $\mathrm{CS}$ on sample Iso\#1 suggest the protective nature of columnar structured YSZ top coat, leading to lower rate of oxygen penetration than that with VC top coat (Iso\#2). Although VC top coat has fewer pores and voids than a columnar structured top coat, the through thickness cracks make it easier for oxygen to travel through and reach the bond coat, facilitating the continuous formation of TGO and $\mathrm{CS}$ once $\mathrm{Al}$ is depleted (from both inward diffusion and TGO formation).

Samples Iso\#3 and Iso\#4 with CMSX-4 substrate had much shorter lives than the ones with IN738LC substrate. The fact that no oxide other than alumina was found in Iso\#3 and Iso\#4 alluded that spinel phases only grow after certain duration in oxidizing environment when $\mathrm{Al}$ is sufficiently depleted. Formation of spinel phases was not likely responsible for the TBC failure of these two samples. However, there are a number of high contrast particles observed within the TGO on both samples after oxidation, as shown in Figure 6-4 (d)-(e), Figure 6-10 (a)-(c). They were identified as precipitates of heavy alloying elements (W and Ta) from CMSX-4, due to outward diffusion during isothermal exposure. When the fluxes from two sides of a diffusion couple are not equal, a vacancy flux is developed to balance the interdiffusion, leading to the formation of pores and voids, often at the interface [167]. Since there were far more outward diffusion (W, Ta, Cr, Ni for example), from substrate to TGO, occurred than inward diffusion (oxygen and $\mathrm{Al}$ ), from $\mathrm{TGO}$ to bond coat/substrate, according to Kirkendall effect, the large amount of outward diffusion cannot be compensated by the fewer amount of inward diffusion, voids formed along the interface [168]. Indeed, as seen in Figure 6-10 (c), there were voids formed at the interface of TGO and bond coat. Similar to that observed with 
IN738LC substrate, the columnar 8 YSZ top coat provided reduced oxygen permeability than VC top coat, as such, longer isothermal life was observed in sample Iso\#3.

Furthermore, failure location/mode of samples with CMSX-4 substrate was different from those with IN738LC substrate. In the cases of Iso\#1 and Iso\#2 (IN738LC), the YSZ top coat was separated from within the TGO, as most of the exposed bond coat/substrate and spalled YSZ were covered with $\mathrm{Al}_{2} \mathrm{O}_{3}$ layer (Figure 6-3 and Figure 6-7). However, from the observation of samples Iso\#3 and Iso\#4, the YSZ top coating spalled at the interface between TGO and bond coat/substrate. As shown in Figure 6-4 (g)-(h), the top coat along with $\mathrm{Al}_{2} \mathrm{O}_{3}$ (TGO) was completely separated from the bond coat/substrate (the dark bakelite material between them was introduced during sample preparation). Similarly, for Iso\#4, as shown in Figure 6-10 (b), only very scant $\mathrm{Al}_{2} \mathrm{O}_{3}$ remained on the bond coat/substrate surface after top coat spallation. Also, from the SEM image in Figure 6-10 (c), it is clear that most of the voids are present at the interface between TGO and bond coat/substrate. This provides an indication that the formation of voids contributed to the early failure of the TBCs with CMSX-4 substrate; and the outward diffusion of refractory elements (W, Ta and maybe Re) has caused the development of voids. 


\subsection{Summary of Isothermal Test Results}

The TBC system with IN738LC substrate exhibited longer isothermal oxidation life than the TBC system with CMSX-4 substrate. Sufficient evidence suggests that outward diffusion of refractory elements in CMSX-4 into TGO was responsible for short isothermal oxidation life as voids formed between TGO and bond coat/substrate interface due to diffusion. Additionally, columnar YSZ top coat provided better protection to the bond coating and substrate, delaying the coating failure in both systems with IN738LC and CMSX-4 substrate. 


\section{Chapter: Cyclic oxidation test results}

\subsection{Cyclic Oxidation Lifetime of TBCs}

The cyclic oxidation lives of four different samples are represented in Figure 7-1. All samples failed within 1000 cycles. Cyc\#1 and Cyc\#2 (both with IN738LC substrate) spalled after 365 and 300 cycles, respectively; whereas samples with CMSX-4 substrate, Cyc\#3 and Cyc\#4, experienced 500 and 1000 cycles, respectively, before failure. Visual observations were carried out every 100 cycles; the images are presented in Figure 7-2.

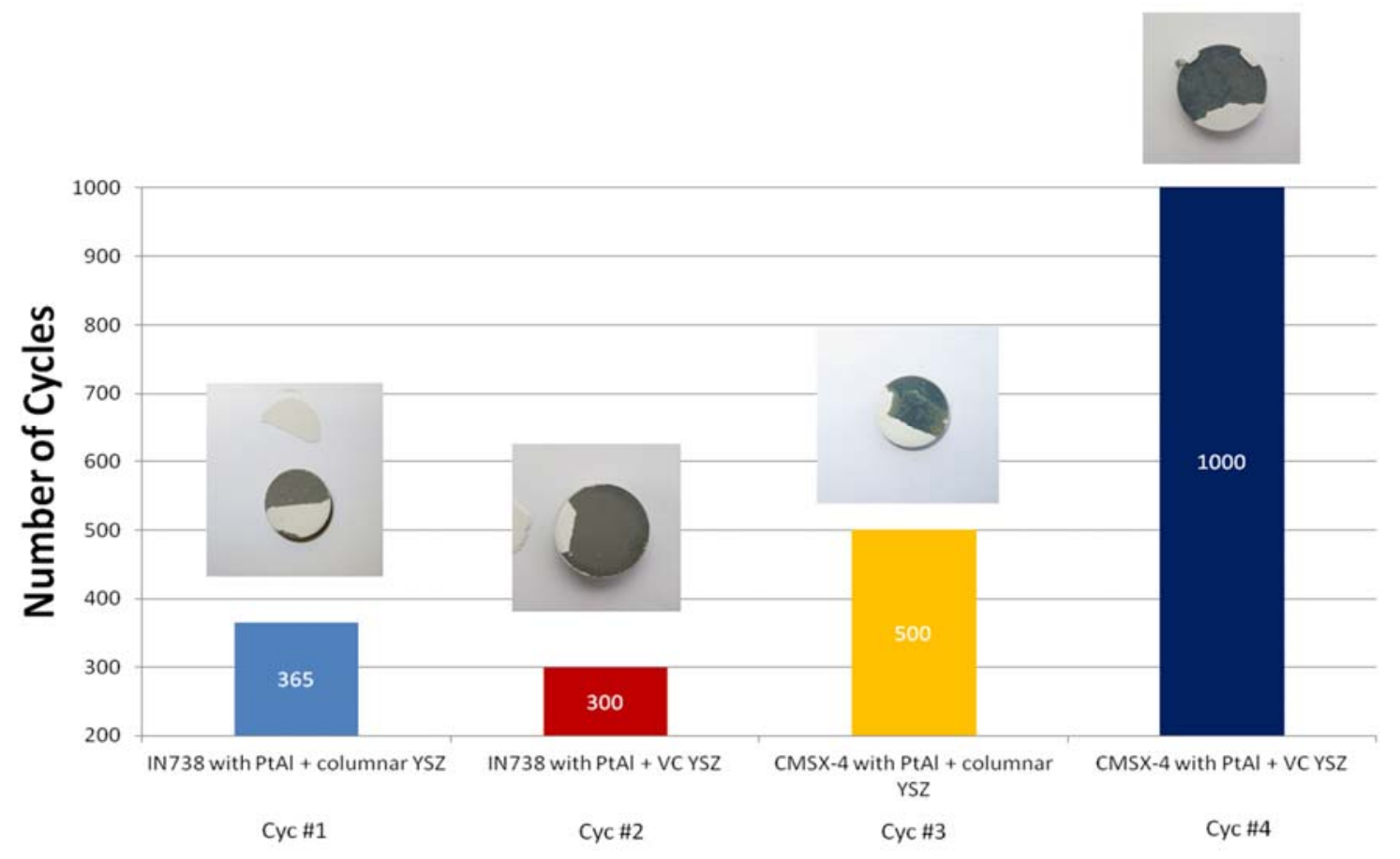

Figure 7-1. Cyclic oxidation life (in terms of number of cycles) 


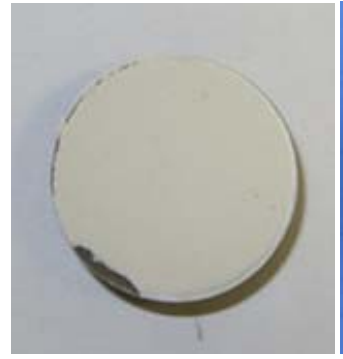

100 cycles

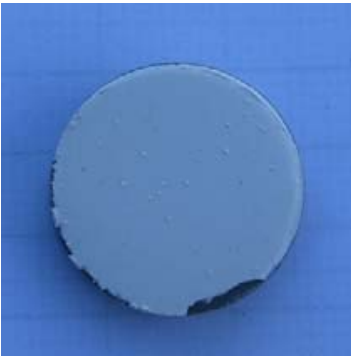

200 cycles

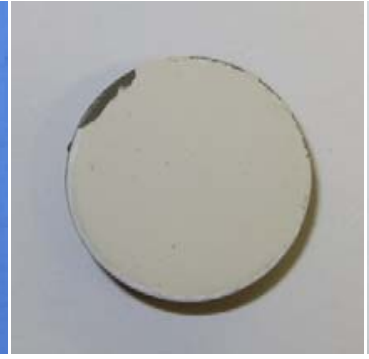

300 cycles

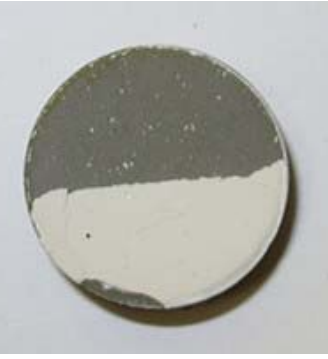

365 cycles

(a) $\mathrm{Cyc} \# 1$

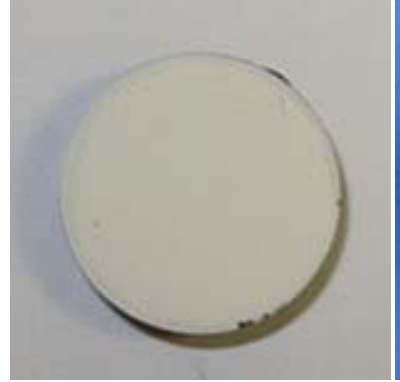

100 cycles

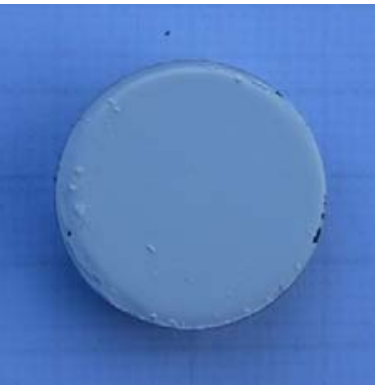

200 cycles

(b) $\mathrm{Cyc \# 2}$

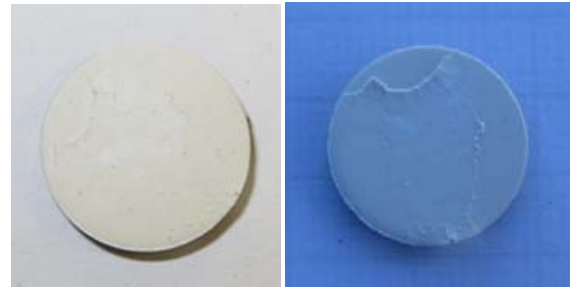

100 cycles $\quad 200$ cycles

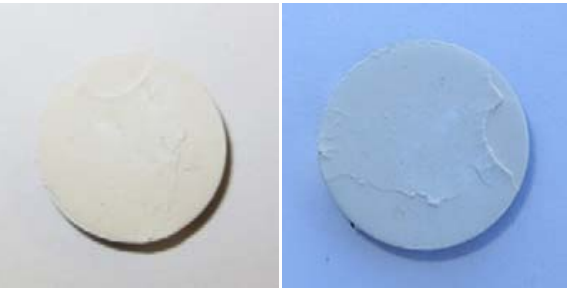

300 cycles

400 cycles

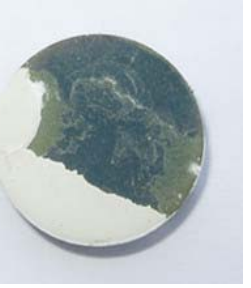

500 cycles

(c) $\mathrm{Cyc} \# 3$ 

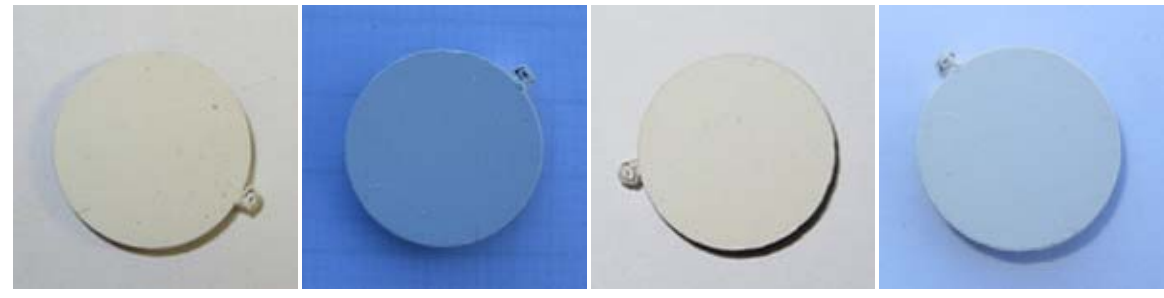

100 cycles

200 cycles

300 cycles

400 cycles

500 cycles
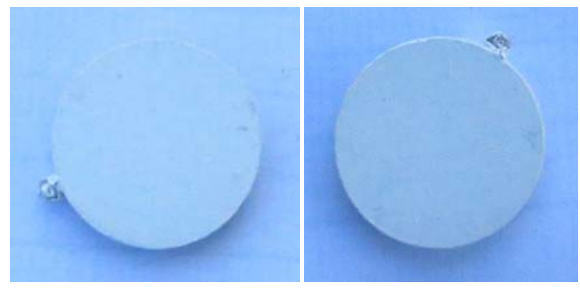

600 cycles

700 cycles

800 cycles

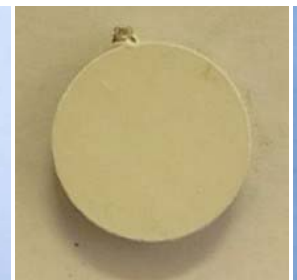

900 cycles

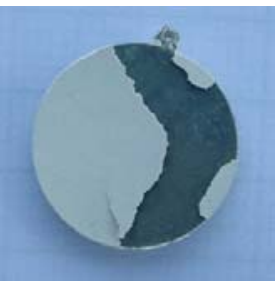

1000 cycles

(d) $\mathrm{Cyc} \# 4$

Figure 7-2. Visual observations of Cyc\#1-4 (images taken every 100 cycles)

\subsection{Microstructure Analysis of Cyclic Oxidation Tested Samples}

\subsubsection{Samples with PtAl Bond Coat and Columnar YSZ Top Coat}

During the cyclic oxidation test, sample Cyc\#1 (IN738LC with PtAl + columnar YSZ) failed after 365 cycles while sample Cyc\#3 (CMSX-4 with PtAl + columnar YSZ) was found to exceed the spallation limit after 500 cycles. SEM/EDS analysis of sample Cyc\#1 reveals both alumina and $\mathrm{NiAl}_{2} \mathrm{O}_{4}$ on the backside of spalled YSZ coating and bond coat/substrate surface, as shown in Figure 7-3 (a)-(c). From the cross sectional view of the microstructure, it is clear that YSZ has completely separated from the TGO and also vertical cracks have progressed to the interface between YSZ and TGO (Figure 7-3 (d), (e)). EDS analysis results of Cyc\#1 are summarized in Table 7-1. 
XRD analysis was carried out on both the backside of the spalled YSZ and the top surface of exposed bond coating/substrate; the diffraction spectra are given in Figure 7-4 and Figure 7-5. They further confirm that spinel $\left(\mathrm{NiAl}_{2} \mathrm{O}_{4}\right)$ and alumina $\left(\mathrm{Al}_{2} \mathrm{O}_{3}\right)$ are attached to the spalled YSZ, suggesting that spallation occurred within the TGO where sufficient amount of spinel has formed.

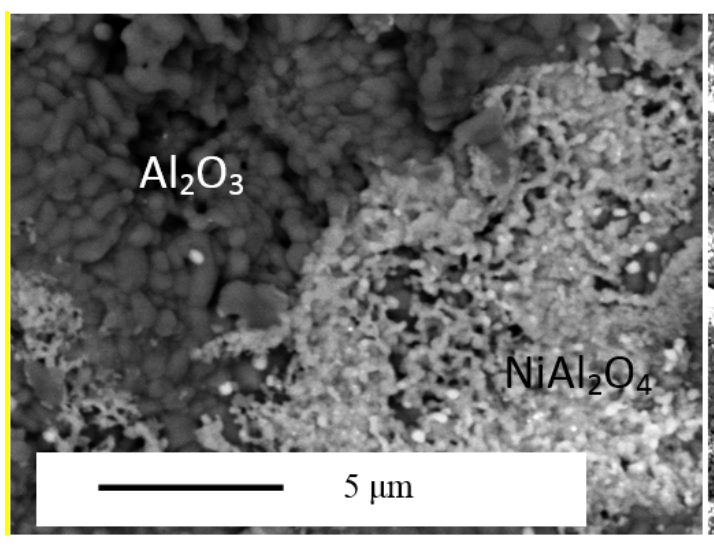

(a) Backside of spalled YSZ

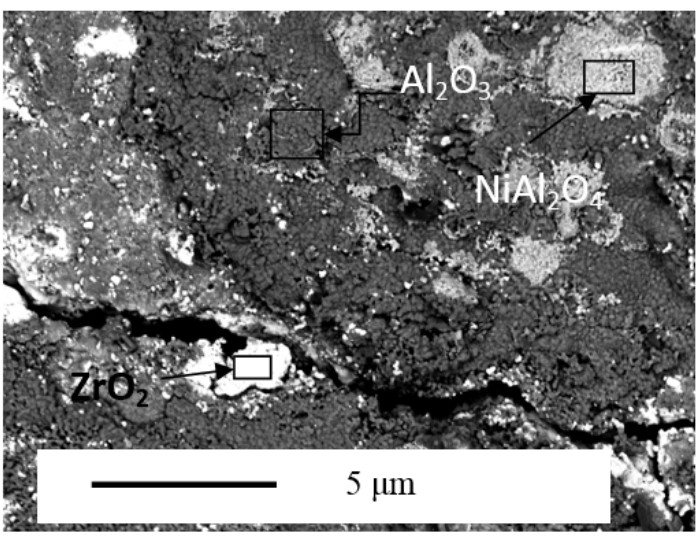

(b) Backside of spalled YSZ

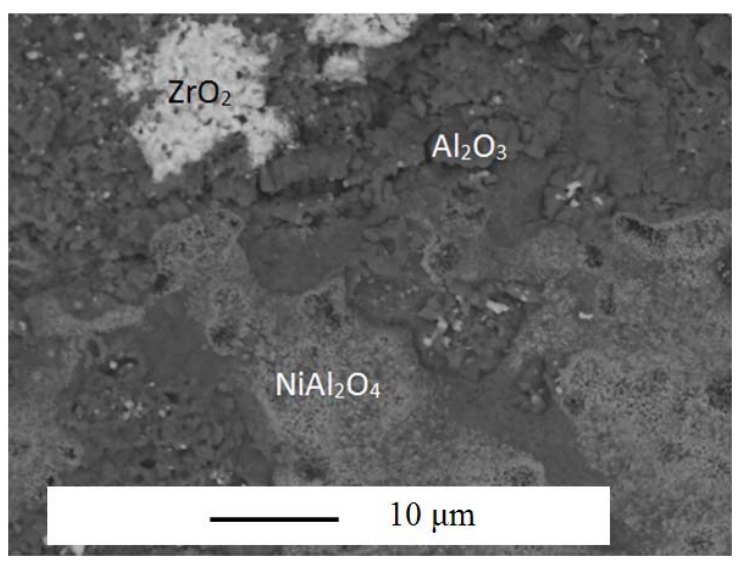

(c) Exposed bond coat/substrate 


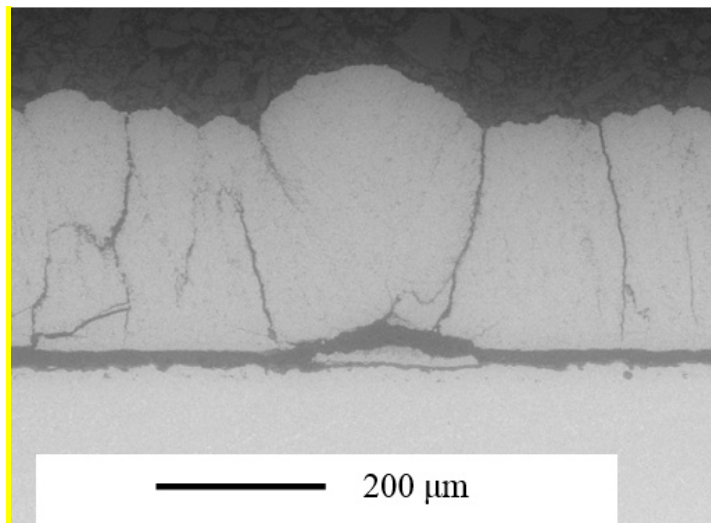

(d) Cross section

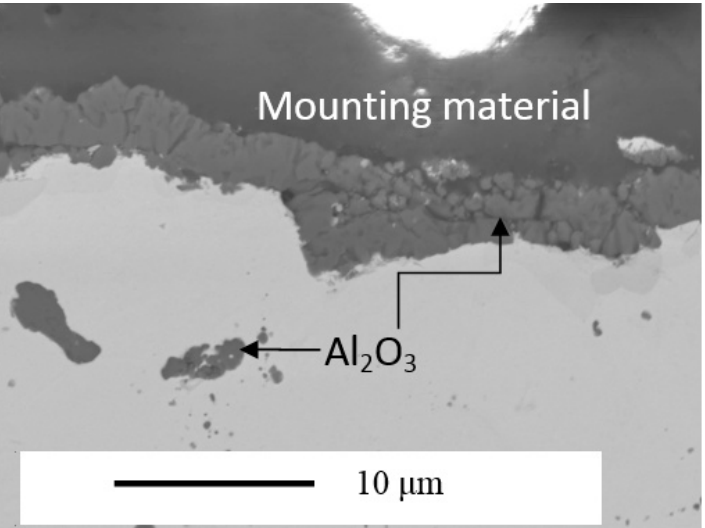

(e) Cross section

Figure 7-3. Microstructures of Sample Cyc\#1 (IN738LC with PtAI + columnar YSZ) after oxidation test

Table 7-1. EDS analysis results of Cyc\#1 (wt\% and at\%)

\begin{tabular}{|c|c|c|c|c|c|c|c|c|c|}
\hline & Elements & $\mathrm{Zr}$ & $\mathrm{Y}$ & $\mathrm{Al}$ & $\mathrm{Ni}$ & $\mathrm{Co}$ & $\mathrm{O}$ & $\mathrm{Cr}$ & $\mathrm{Ti}$ \\
\hline $\mathrm{NiAl}_{2} \mathrm{O}_{4}$ & wt $\%$ & - & - & 26.01 & 23.98 & 5.65 & 44.36 & - & - \\
\hline (YSZ backside) & at $\%$ & - & - & 22.73 & 9.63 & 2.26 & 65.38 & - & - \\
\hline $\mathrm{Al}_{2} \mathrm{O}_{3}$ & $w t \%$ & - & - & 55.05 & - & - & 44.95 & - & - \\
\hline (YSZ backside) & at $\%$ & - & - & 42.07 & - & - & 57.93 & - & - \\
\hline $\mathrm{ZrO}_{2}$ & wt $\%$ & 22.93 & 2.65 & 32.85 & - & - & 37.63 & 3.95 & - \\
\hline (YSZ backside) & at $\%$ & 6.4 & 0.76 & 31 & - & - & 59.9 & 1.93 & - \\
\hline $\mathrm{NiAl}_{2} \mathrm{O}_{4}$ (bond coat & wt $\%$ & - & - & 35.16 & 19.68 & 4.33 & 29.63 & 6.04 & 5.17 \\
\hline /substrate surface) & at $\%$ & - & - & 34.41 & 8.85 & 1.94 & 48.89 & 3.06 & 2.85 \\
\hline
\end{tabular}




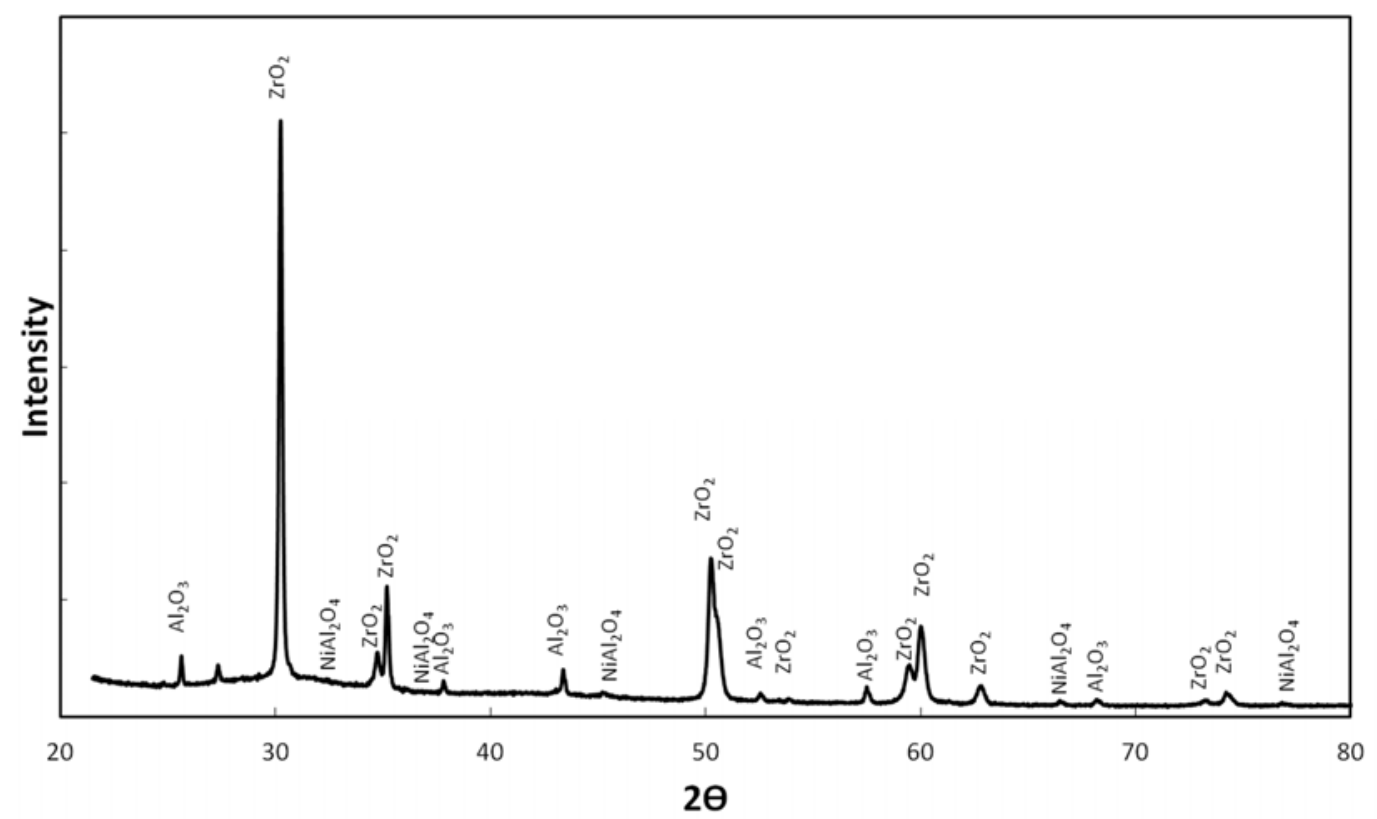

Figure 7-4. X-ray diffraction pattern from the backside of spalled YSZ (sample Cyc\#1, IN738LC with PtAl + columnar YSZ)

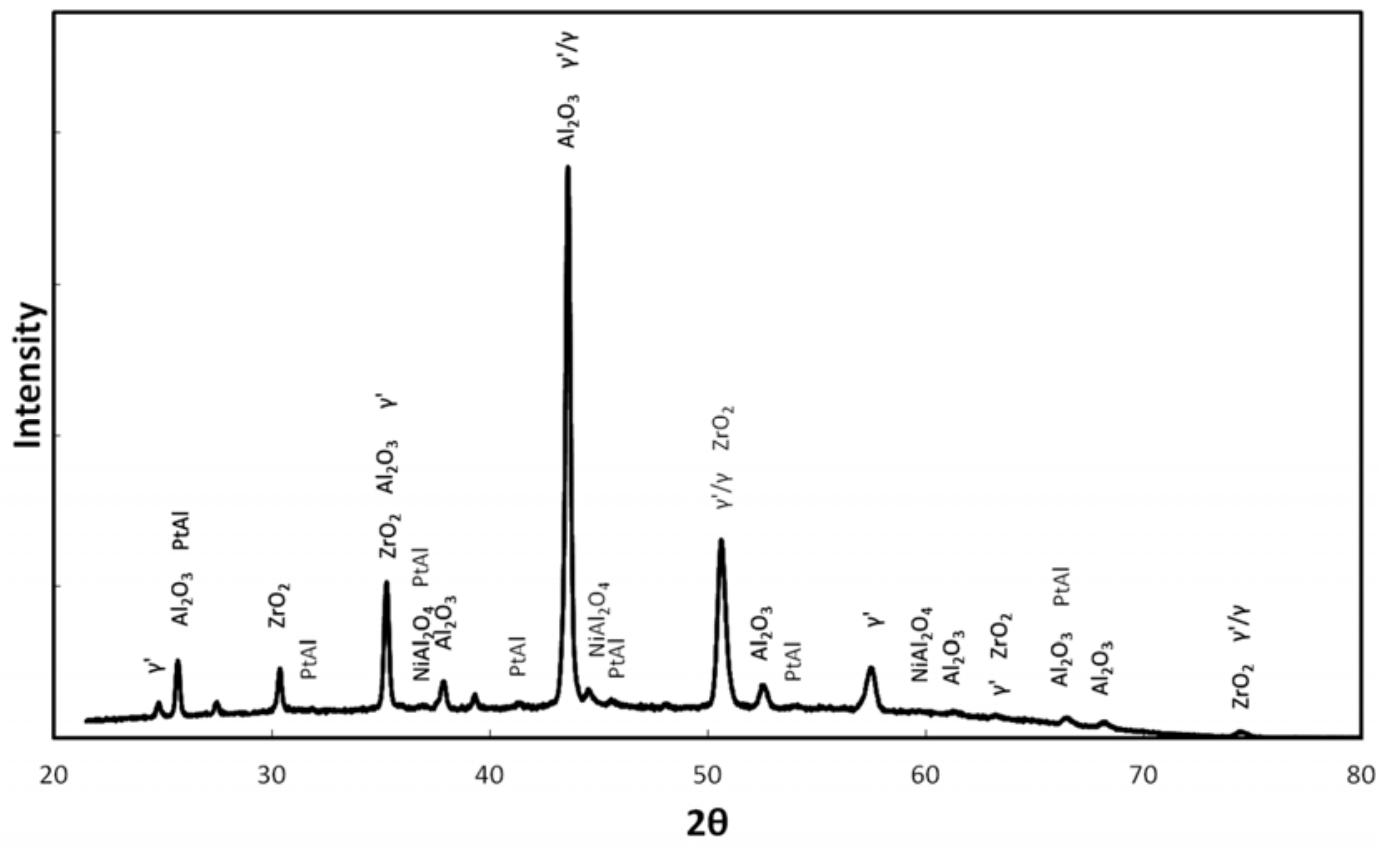

Figure 7-5. X-ray diffraction pattern from the exposed bond coat/substrate surface (sample Cyc\#1, IN738LC with PtAl + columnar YSZ) 
EDS analysis on the backside of spalled YSZ of sample Cyc\#3 and cross-section suggested that $\mathrm{NiAl}_{2} \mathrm{O}_{4}$ and $\mathrm{Al}_{2} \mathrm{O}_{3}$ also formed during the cyclic oxidation test (Figure 7-6 (a), (b) and (c)). In addition, $\mathrm{XRD}$ analysis detected the presence of $\mathrm{NiAl}_{2} \mathrm{O}_{4}, \mathrm{NiCr}_{2} \mathrm{O}_{4}$ and trace $\mathrm{Cr}_{2} \mathrm{O}_{3}$ on the backside of YSZ and the top surface of the exposed bond coat/substrate (Figure 7-7 and Figure 7-8). There is an increased amount of mixed oxide

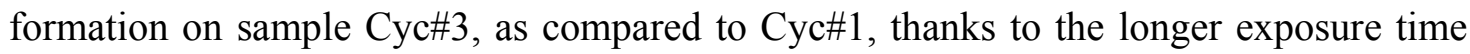
than that for Cyc\#1 (500 cycles vs. 365 cycles). In general, as the oxidation exposure time increases, $\mathrm{Al}$ becomes depleted and chromium and nickel oxide start to form leading to the reactions:

$\mathrm{NiO}+\mathrm{Cr}_{2} \mathrm{O}_{3} \rightarrow \mathrm{NiCr}_{2} \mathrm{O}_{4}$

$\mathrm{NiO}+\mathrm{Al}_{2} \mathrm{O}_{3} \rightarrow \mathrm{NiAl}_{2} \mathrm{O}_{4}$

Another microstructural change occurred to both samples after thermal cycling was the development of through vertical cracks (Figure 7-6 (d) and Figure 7-3 (d)) in the top coat. This is believed to be the result of thermal stresses developed during the heating-cooling cycles. With the through vertical cracks developing, oxygen can readily reach the TGO and accelerate Al depletion and the growth of mixed oxide(s). As such, spinels were found in both Cyc\#1 and Cyc\#3 after thermal cycling. EDS results from sample Cyc\#3 are summarized in Table 7-2. 


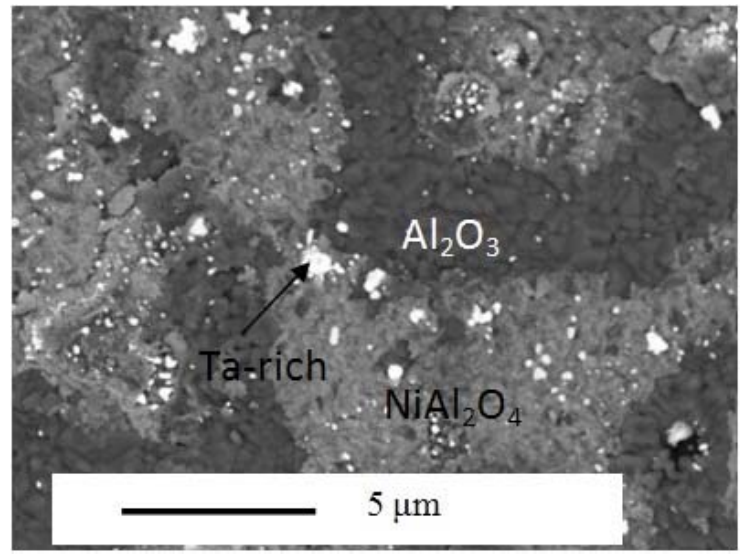

(a) Backside of spalled YSZ

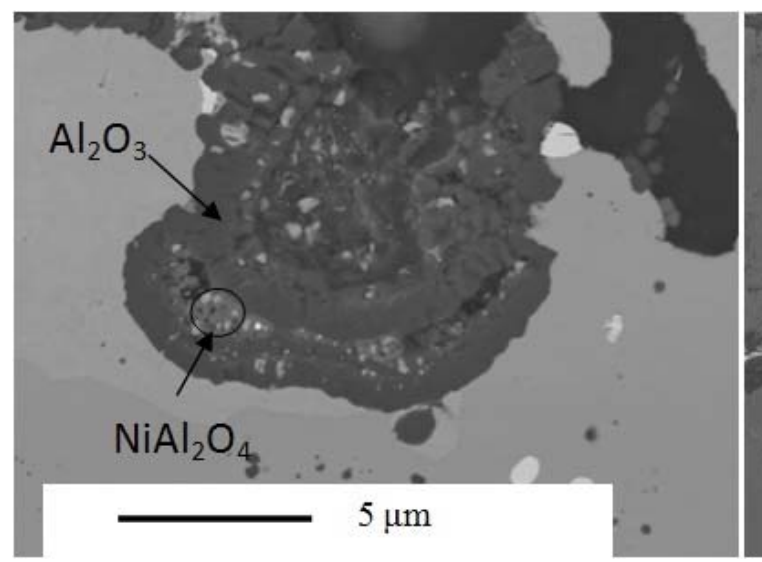

(c) Cross section

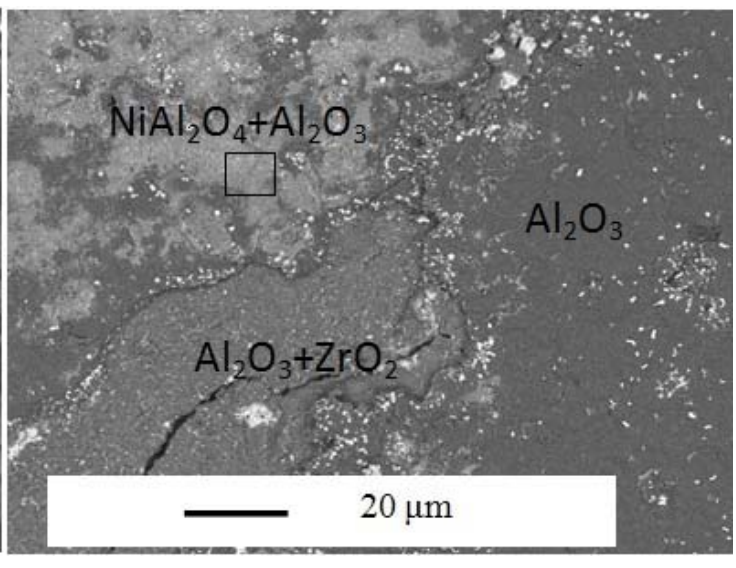

(b) Backside of spalled YSZ

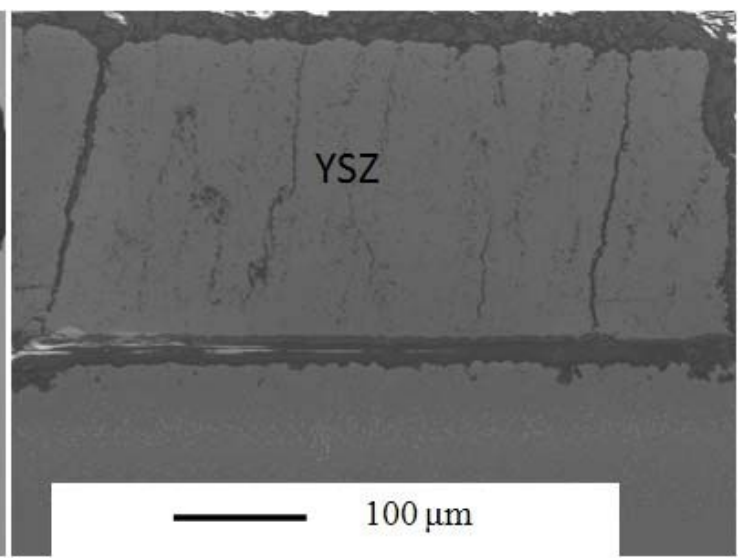

(d) Cross section

Figure 7-6. Microstructures of Sample Cyc\#3 (CMSX-4 with PtAl + columnar YSZ) after oxidation test

Table 7-2. EDS results of $\mathrm{Cyc} \# 3$ (wt\% and at $\%$ )

\begin{tabular}{|c|c|c|c|c|c|}
\hline & Elements & $\mathrm{Al}$ & $\mathrm{Ni}$ & $\mathrm{Co}$ & $\mathrm{O}$ \\
\hline \multirow{2}{*}{$\begin{array}{c}\mathrm{NiAl}_{2} \mathrm{O}_{4} \\
(\mathrm{YSZ} \text { backside })\end{array}$} & $\mathrm{wt} \%$ & 36.38 & 14.89 & 4.65 & 44.08 \\
\cline { 2 - 6 } & $\mathrm{at} \%$ & 30.39 & 5.72 & 1.78 & 62.11 \\
\hline $\begin{array}{c}\mathrm{Al}_{2} \mathrm{O}_{3} \\
(\mathrm{YSZ} \text { backside })\end{array}$ & $\mathrm{wt} \%$ & 55.82 & - & - & 44.18 \\
\cline { 2 - 6 } & at $\%$ & 42.83 & - & - & 57.17 \\
\hline
\end{tabular}




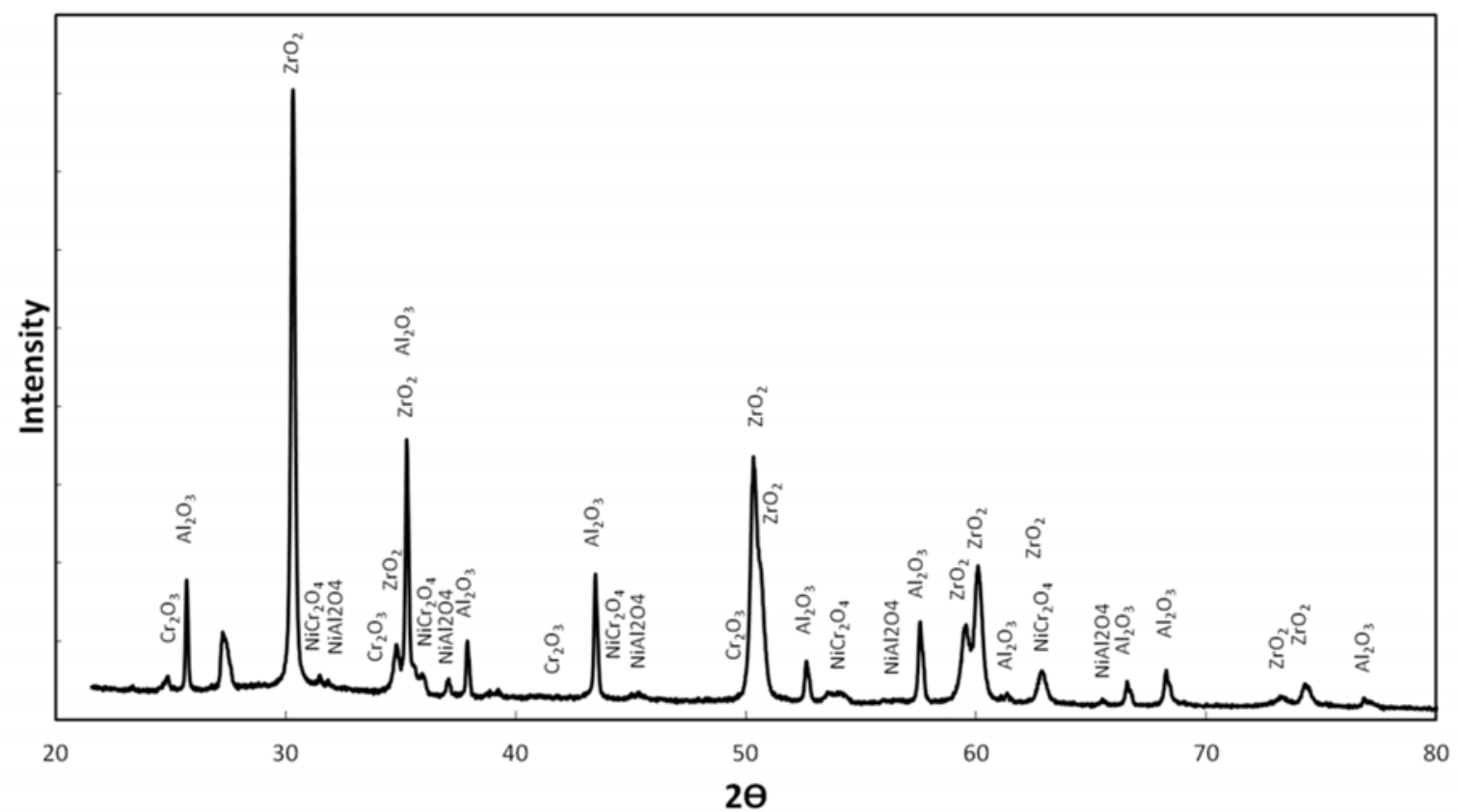

Figure 7-7. X-ray diffraction pattern from the backside of spalled YSZ (sample Cyc\#3, CMSX-4 with PtAl + columnar YSZ)

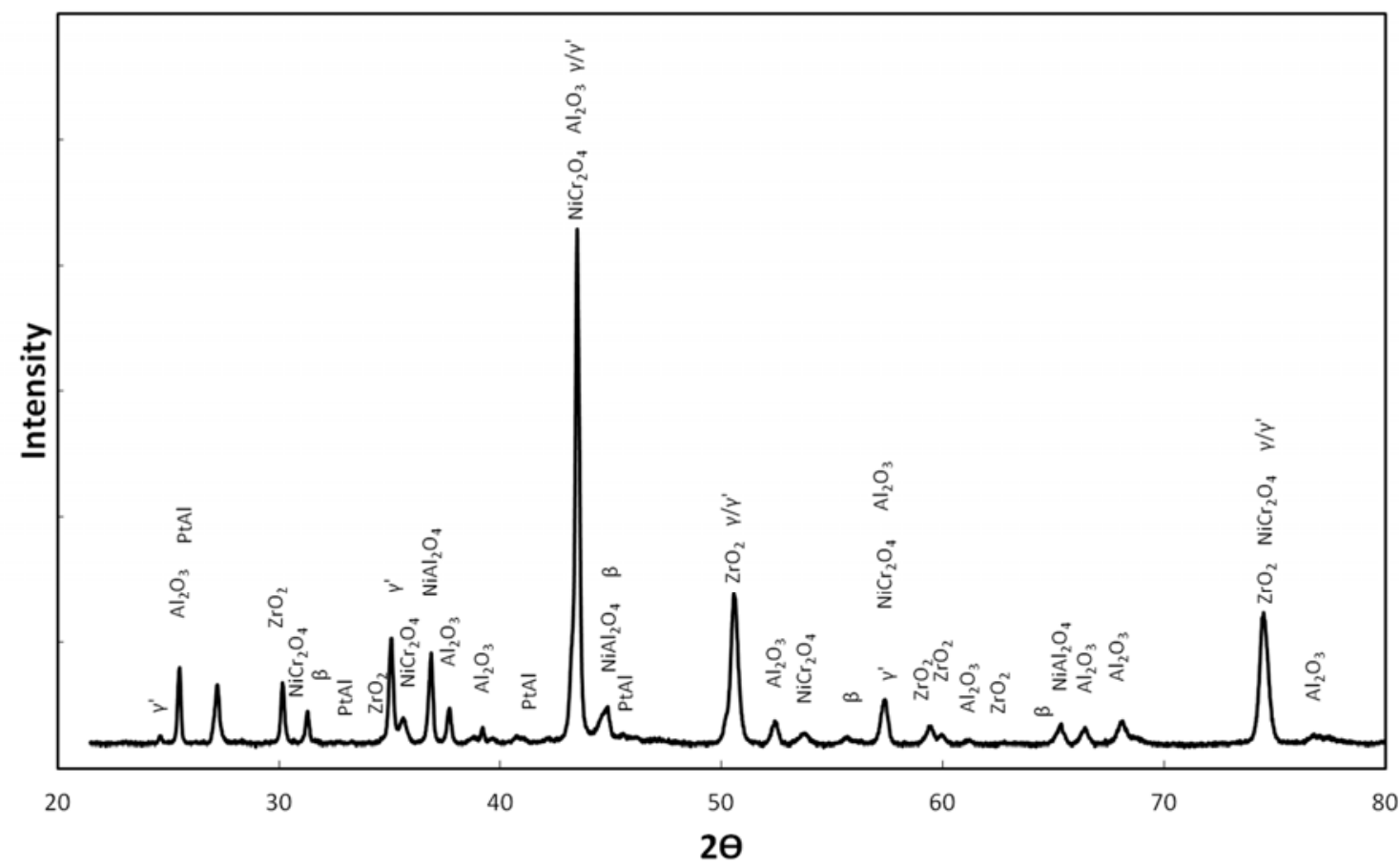

Figure 7-8. X-ray diffraction pattern from bond coat/substrate surface (sample Cyc\#3, CMSX-4 with PtAl + columnar YSZ) 


\subsubsection{Samples with PtAl Bond Coat and VC YSZ Top Coat}

During cyclic oxidation test, sample Cyc\#2 (IN738LC with PtAl + VC YSZ) failed after 300 cycles while Cyc\#4 (CMSX-4 with PtAl + VC YSZ) completed 1000 cycles before spallation. SEM/EDS analysis of sample Cyc\#2 revealed large coverage of $\mathrm{Al}_{2} \mathrm{O}_{3}$ on both the backside of spalled YSZ and exposed bond coat/substrate surface, whereas a small amount of $\mathrm{NiAl}_{2} \mathrm{O}_{4}$ was observed on the backside of spalled YSZ (Figure 7-9). XRD detected also a very small amount of $\mathrm{NiAl}_{2} \mathrm{O}_{4}$ on the backside of $\mathrm{YSZ}$ and bond coat/substrate surface, in addition to $\mathrm{Al}_{2} \mathrm{O}_{3}$ and $\mathrm{ZrO}_{2}$ (Figure 7-10 and Figure 7-11). These results are quite similar to that of $\mathrm{Cyc} \# 1$ : a small amount of $\mathrm{NiAl}_{2} \mathrm{O}_{4}$ formed after relative shorter oxidation cycles (365 cycles and 300 cycles). EDS results of Cyc\#2 are summarized in Table 7-3.

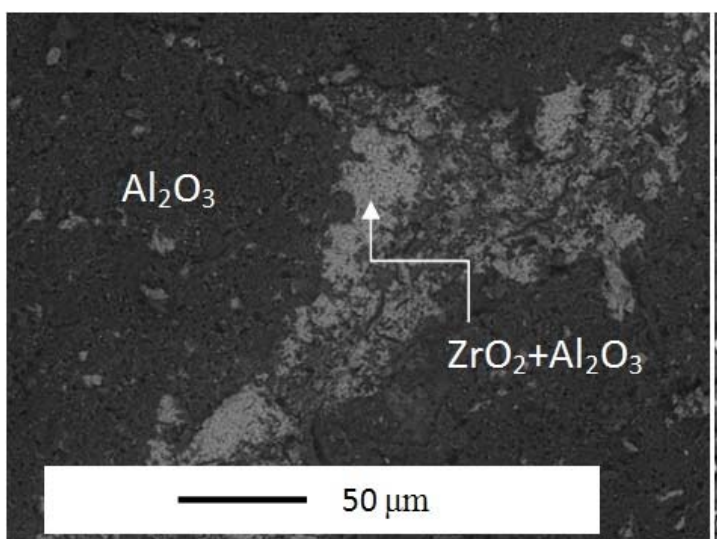

(a) Exposed bond coat/substrate

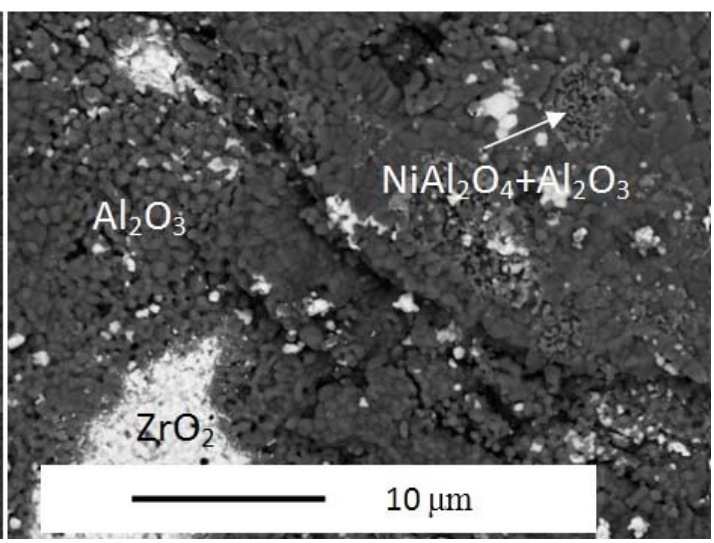

(b) Backside of spalled YSZ

Figure 7-9. Microstructures of sample Cyc\#2 (IN738LC with PtAl + VC YSZ) after oxidation test 
Table 7-3. EDS results of $\mathrm{Cyc} \# 2$ (wt\% and at\%)

\begin{tabular}{|c|c|c|c|c|c|c|c|c|}
\hline & Elements & $\mathrm{Zr}$ & $\mathrm{Y}$ & $\mathrm{Al}$ & $\mathrm{Ni}$ & $\mathrm{Cr}$ & $\mathrm{O}$ & $\mathrm{Si}$ \\
\hline \multirow{2}{*}{$\begin{array}{c}\mathrm{Al}_{2} \mathrm{O}_{3} \\
(\mathrm{YSZ} \text { backside })\end{array}$} & $\mathrm{wt} \%$ & - & - & 59.51 & - & - & 40.49 & - \\
\cline { 2 - 9 } & $\mathrm{at} \%$ & - & - & 46.56 & - & - & 53.44 & - \\
\hline $\begin{array}{c}\mathrm{ZrO}_{2} \\
(\mathrm{YSZ} \text { backside })\end{array}$ & $\mathrm{wt} \%$ & 56.92 & 5.93 & 2.92 & - & - & 33.23 & 1 \\
\cline { 2 - 10 } & $\mathrm{at} \%$ & 21.43 & 2.29 & 3.71 & - & - & 71.34 & 1.23 \\
\hline \multirow{2}{*}{$\begin{array}{c}\mathrm{NiAl} 2 \mathrm{O}_{4}+\mathrm{Al}_{2} \mathrm{O} 3 \\
(\mathrm{YSZ} \text { backside })\end{array}$} & $\mathrm{wt} \%$ & - & - & 49.62 & 3.08 & 3.75 & 43.55 & - \\
\cline { 2 - 10 } & $\mathrm{at} \%$ & - & - & 39.25 & 1.12 & 1.54 & 58.09 & - \\
\hline
\end{tabular}

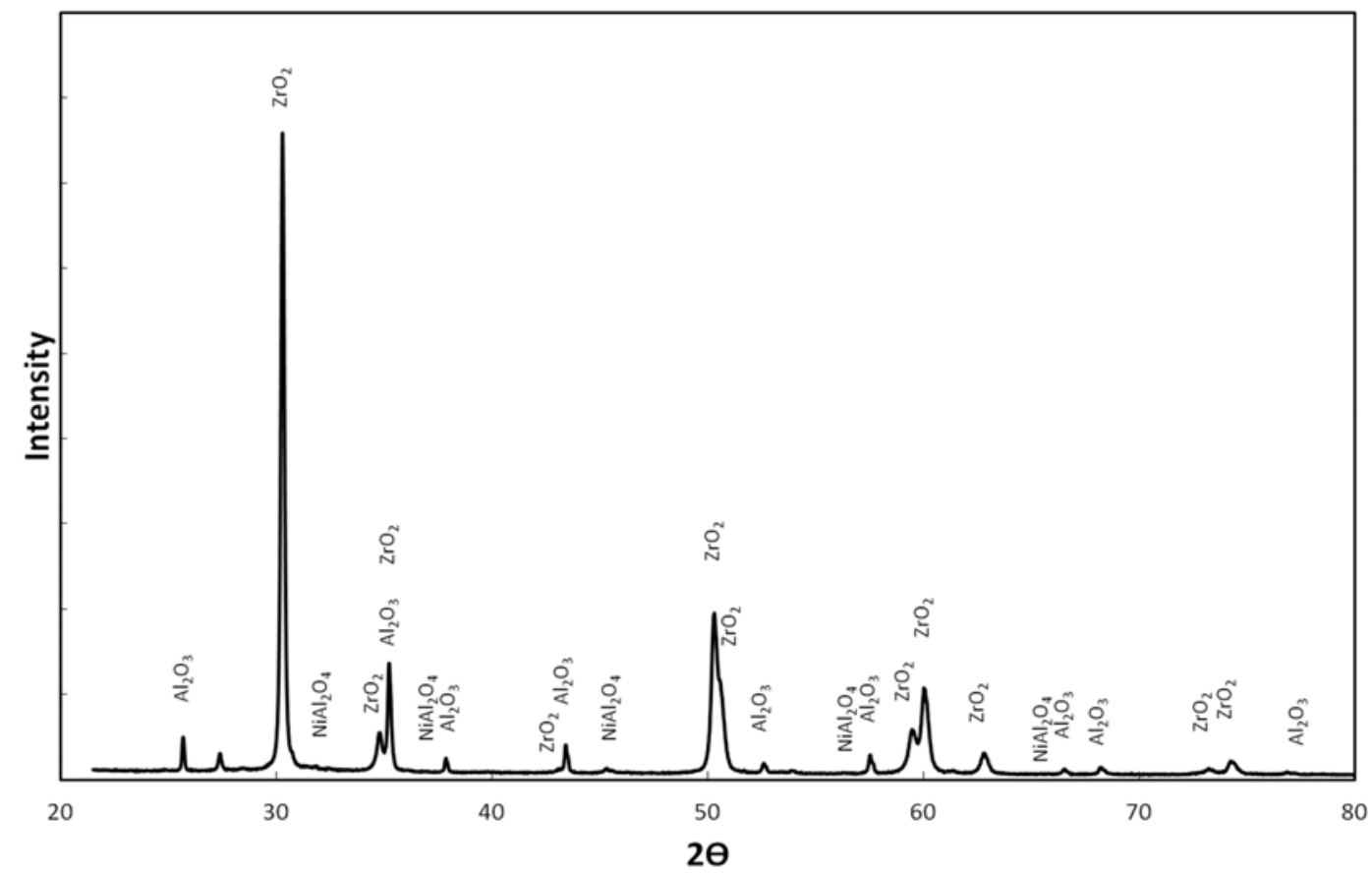

Figure 7-10. X-ray diffraction pattern from the backside of spalled YSZ (Cyc\#2, IN738LC with PtAl + VC YSZ) 


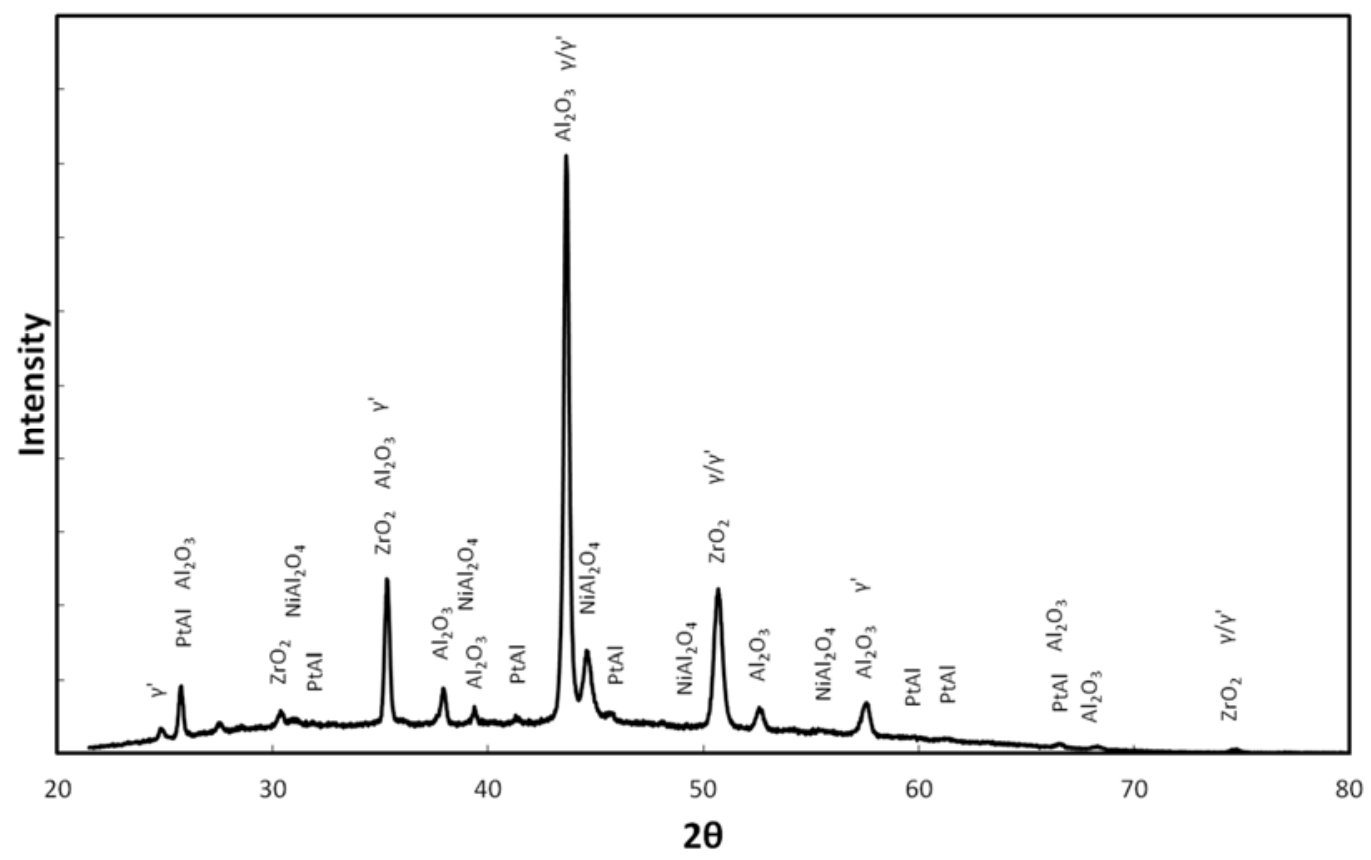

Figure 7-11. X-ray diffraction pattern from the exposed substrate/bond coat surface (Cyc\#2, IN738LC with PtAl + VC YSZ)

For the Cyc\#4 sample, larger amounts of alumina and spinels were found on both the backside of spalled YSZ and on top of the exposed bond coat/substrate surface (Figure 712, Figure 7-13 and Figure 7-14). In particular, $\mathrm{NiAl}_{2} \mathrm{O}_{4}$ was observed on backside of spalled YSZ, exposed bond coat/substrate surface and cross-section (Figure 7-12). $\mathrm{Cr}_{2} \mathrm{O}_{3}$ and $\mathrm{NiCr}_{2} \mathrm{O}_{4}$ were not detected in this sample.

The microstructure on the cross-section of Cyc\#4, Figure 7-12 (d) had similar features as that of Cyc\#3 with columnar top coat (Figure 7-6 (c)); yet sample Cyc\#4 with VC top coat experienced much longer cycles. The VC TBCs was able to accommodate the cyclic stress better than the columnar ones due to the ability to open during cooling and close during heating. It is also possible that YSZ on sample Cyc\#4 may have partially lifted 
from the bond coat (but with no cracking) at an earlier stage, relieving thermal stresses and delaying the visible spallation. EDS analysis results of Cyc\#4 are shown in Table 7-4.

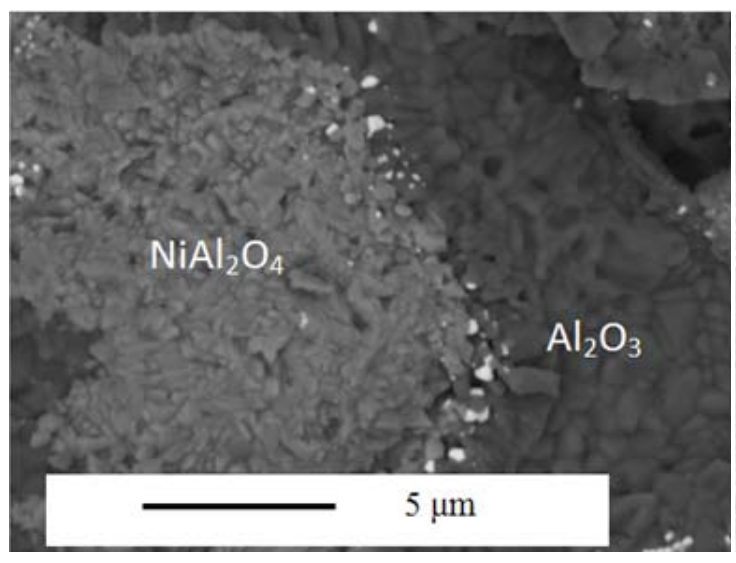

(a) Backside of spalled YSZ

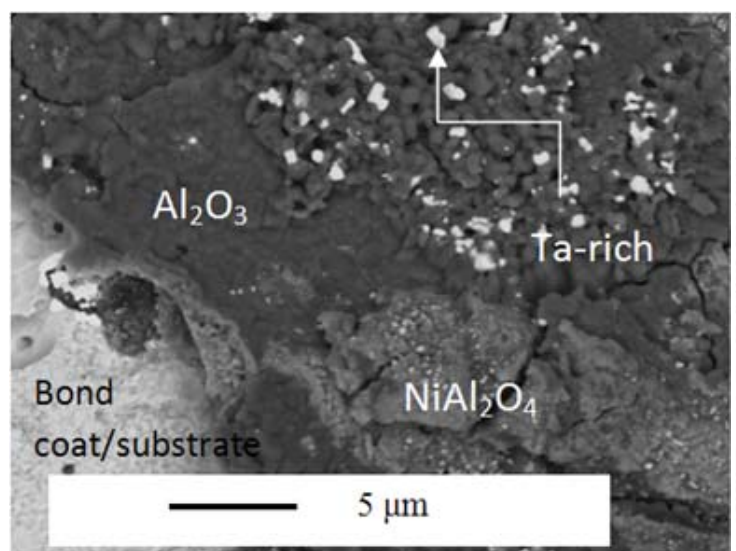

(c) Exposed bond coat/substrate

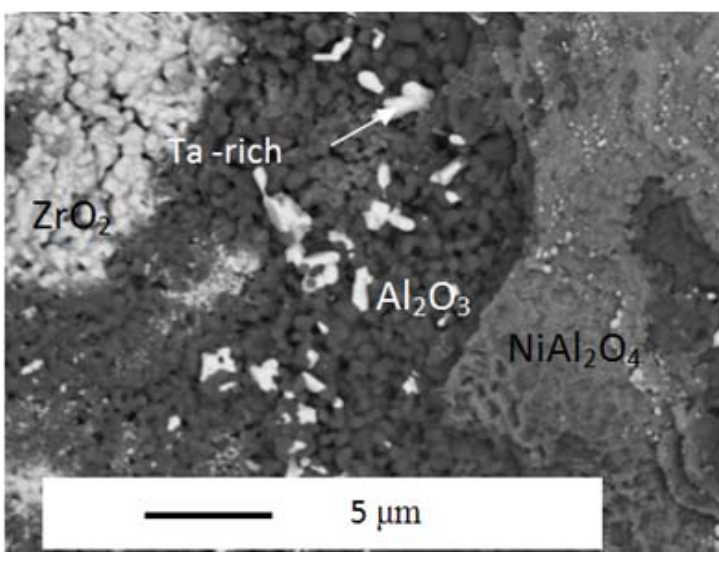

(b) Backside of spalled YSZ

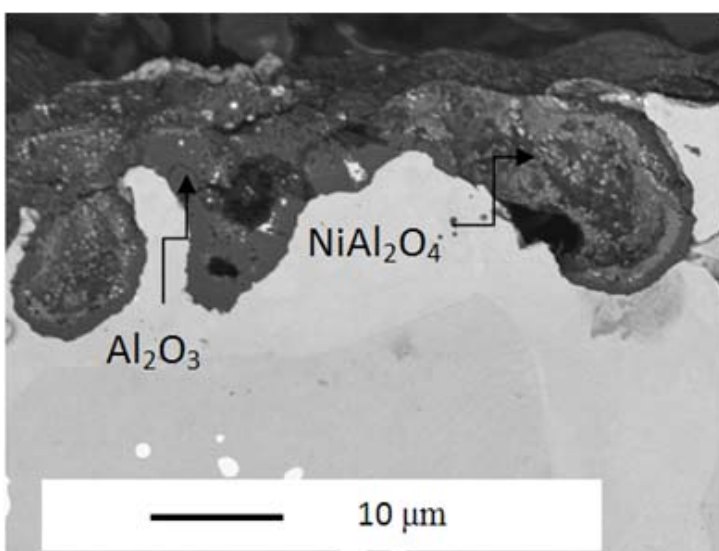

(d) Cross section

Figure 7-12. Microstructures of sample Cyc\#4 (CMSX-4 with PtAI + VC YSZ) after cyclic oxidation test 
Table 7-4. EDS analysis results of Cyc\#4 (wt\% and at\%)

\begin{tabular}{|c|c|c|c|c|c|c|c|c|c|}
\hline & Elements & $\mathrm{Zr}$ & $\mathrm{Y}$ & $\mathrm{Al}$ & $\mathrm{Ni}$ & $\mathrm{Cr}$ & $\mathrm{O}$ & $\mathrm{Si}$ & $\mathrm{Co}$ \\
\hline \multirow{2}{*}{$\begin{array}{c}\mathrm{Al}_{2} \mathrm{O}_{3}(\mathrm{YSZ} \\
\text { backside) }\end{array}$} & $\mathrm{wt} \%$ & - & - & 55.4 & - & - & 43.12 & 1.48 & - \\
\cline { 2 - 11 } & $\mathrm{at} \%$ & - & - & 42.76 & - & - & 56.14 & 1.1 & - \\
\hline \multirow{2}{*}{$\begin{array}{c}\mathrm{ZrO}_{2}(\mathrm{YSZ} \\
\text { backside) }\end{array}$} & $\mathrm{wt} \%$ & 66.73 & 3.72 & 1.45 & - & - & 25.61 & 2.49 & - \\
\cline { 2 - 11 } & $\mathrm{at} \%$ & 27.07 & 1.66 & 2.14 & - & - & 63.6 & 3.53 & - \\
\hline $\begin{array}{c}\mathrm{NiAl}_{2} \mathrm{O}_{4}(\mathrm{YSZ} \\
\text { backside) }\end{array}$ & $\mathrm{wt} \%$ & - & - & 35.04 & 19.26 & - & 41.08 & - & 4.62 \\
\cline { 2 - 10 } & $\mathrm{at} \%$ & - & - & 30.4 & 7.68 & - & 60.09 & - & 1.83 \\
\hline $\begin{array}{c}\mathrm{NiAl} \\
\text { coat/substrate } \\
\text { surface) }\end{array}$ & $\mathrm{wt} \%$ & - & - & 32.65 & 27.25 & - & 40.1 & - & - \\
\cline { 2 - 10 } & $\mathrm{at} \%$ & - & - & 28.95 & 11.1 & - & 59.96 & - & - \\
\hline
\end{tabular}

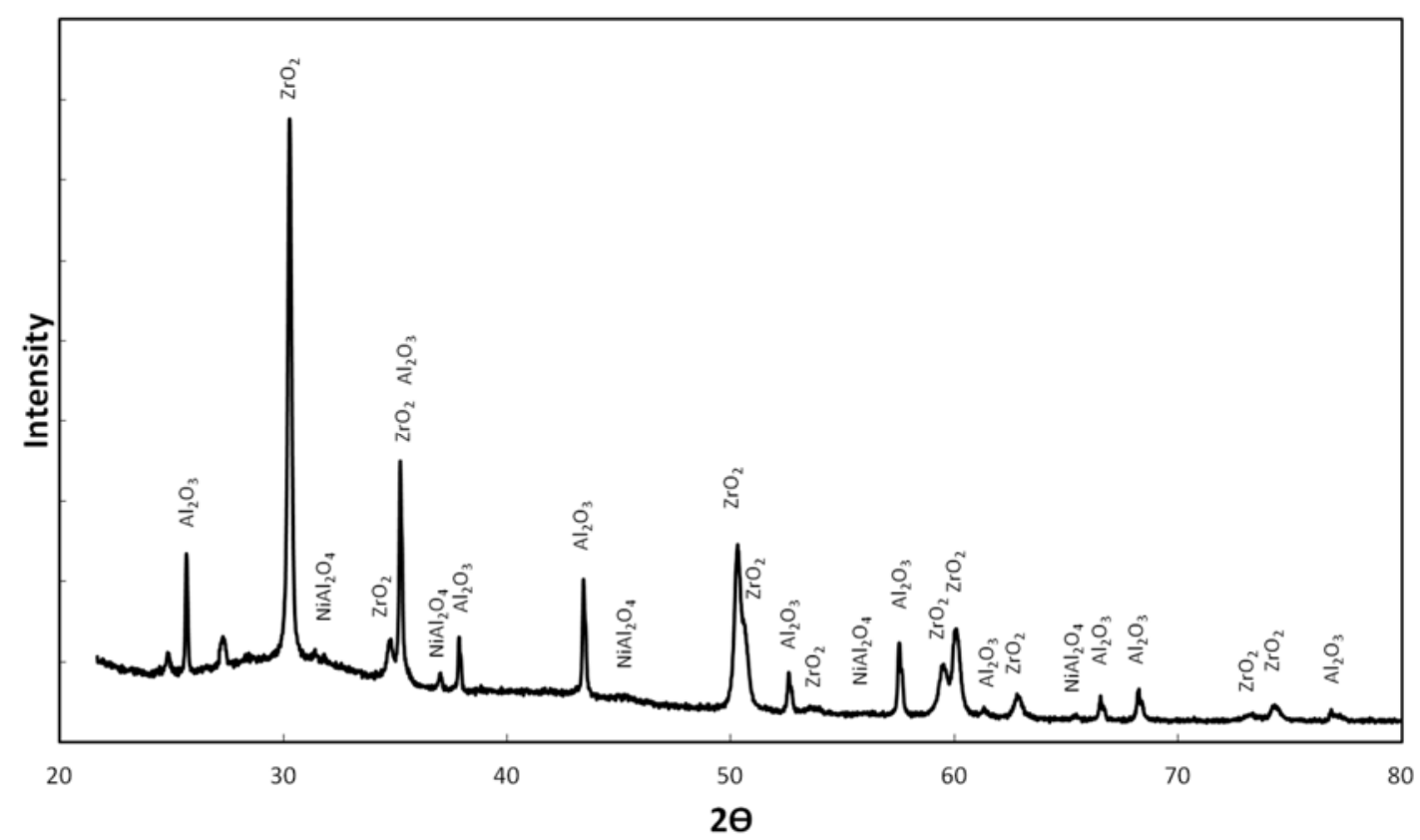

Figure 7-13. X-ray diffraction pattern from the backside of spalled YSZ (Cyc\#4, CMSX-4 with PtAl + VC YSZ) 


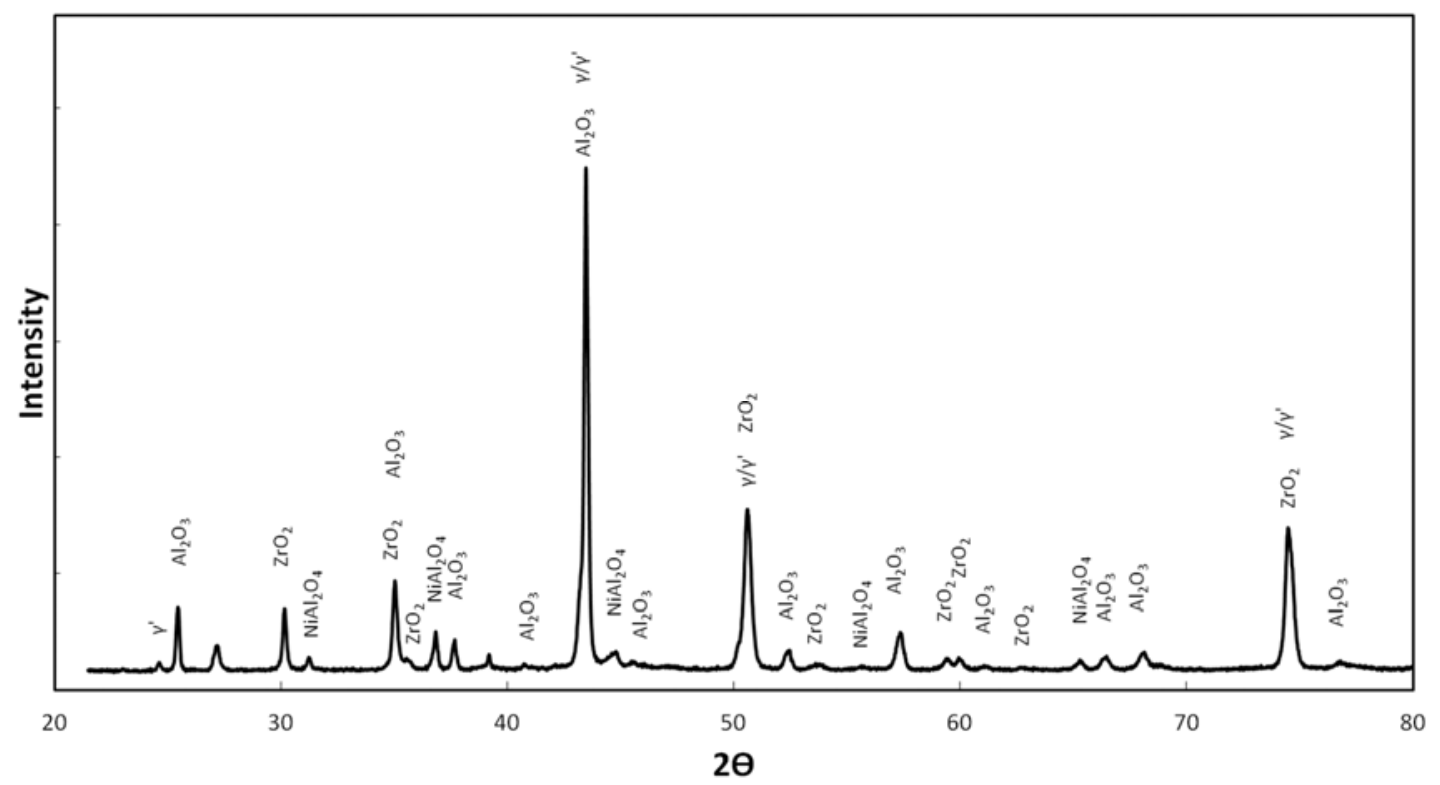

Figure 7-14. X-ray diffraction pattern from the exposed bond coat/substrate surface (Cyc\#4, CMSX4 with PtAl + VC YSZ)

\subsection{Discussion}

The cyclic oxidation behaviors of the TBCs with IN738LC substrate, Cyc\#1 and Cyc\#2, were quite similar. Both suffered from early YSZ top coat spallation after 365 and 300 cycles, respectively, due to thermal stresses and bond coat oxidation. Only a small amount of $\mathrm{NiAl}_{2} \mathrm{O}_{4}$ was found, compared to $\mathrm{Cyc} \# 4$, because of the shorter oxidation duration (180 and 150 hours, respectively, at peak temperature). As for the specific failure location, since alumina and $\mathrm{NiAl}_{2} \mathrm{O}_{4}$ were found on both the backside of the spalled YSZ and exposed bond coat/substrate surface (Figure 7-3), spallation of YSZ on sample Cyc\#1 was determined to have started from inside of the TGO. Similarly, for Cyc\#2 sample, alumina and $\mathrm{NiAl}_{2} \mathrm{O}_{4}$ were observed on both surfaces (Figure 7-9). Based on these observations, the cause of failure could be related to both thermal stress and the formation of mixed oxide, spinel in particular, within the alumina for the two TBC systems with IN 738LC as substrate. The difference between the VC and columnar YSZ 
in IN738LC was not significant since coating samples were only inspected every 100 cycles.

Samples Cyc\#3 and Cyc\#4 with CMSX-4 substrate also behaved similarly, in terms of oxide formation on the surface during cyclic oxidation test. They had longer cyclic oxidation lives than the ones with IN738LC substrates, reaching 500 and 1000 cycles, respectively. More CS phases were found in both samples, than that on samples Cyc\#1 and Cyc\#2 (IN738LC substrate); this is in part due to the longer exposure during cyclic test. As shown in Figure 7-6 and Figure 7-12, it is apparent that the failure locations on Cyc\#3 and Cyc\#4 are also within the TGO, similar to that of Cyc\#1 and Cyc\#2. The VC TBC seems to experience much longer cyclic life, owing to the better strain tolerance of VC and denser coating, hence less oxygen permeability.

Spinels are detected within all failed sample surfaces, indicating that all failure locations are inside the TGO layer. However, the samples with CMSX-4 substrate seem to experience longer cyclic life than those with IN738LC substrate in general (Figure 7-1). As illustrated schematically in Figure 7-15, TBCs experienced expansion and contraction during rapid heating and cooling. Since the TGO (mainly alumina) has the lowest CTE, it will experience the least expansion (heating) and contraction (cooling), this translates into tension during heating and compression during cooling and eventual failure within or near TGO. The top coatings spalled during cooling due to the contraction. 


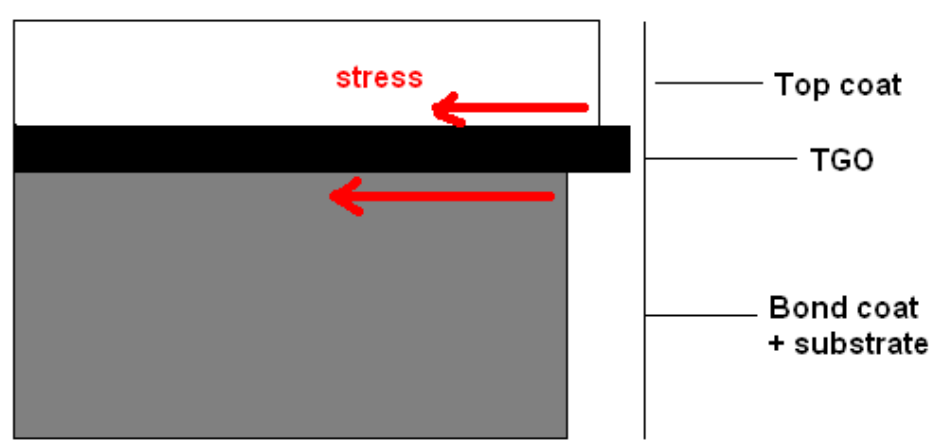

(a) Volume change during cooling

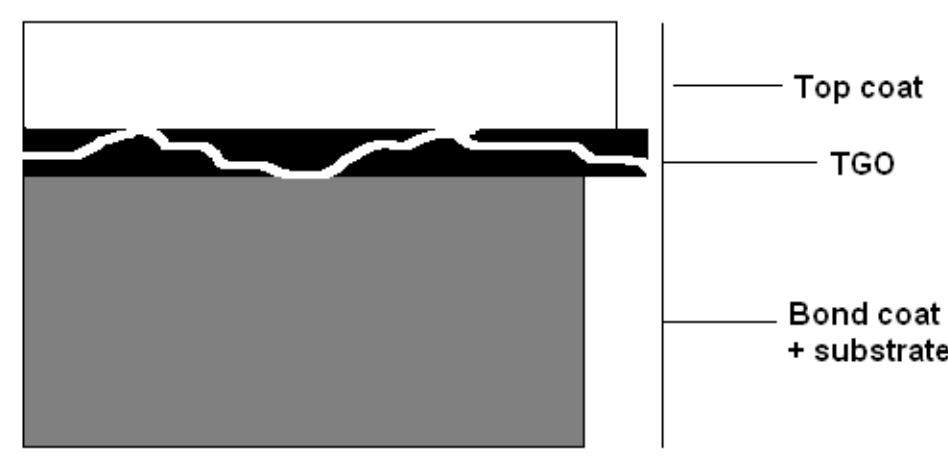

(b) Failure within TGO layer

Figure 7-15. Failure of TGO due to thermal expansion mismatch

Revisiting the chemical compositions of two alloys (Table 4-2) and the reported coefficients of thermal expansion (CTEs) in the temperature range of interest (Table 7-5 and Figure 7-16), it is realized that CMSX-4 has a lower CTE than IN738LC (15.6 vs. 17 $\left.\left(\mathrm{x} 10^{-6} / \mathrm{k}\right)\right)$ whereas the CTE of TGO is lower than both substrates and similar to YSZ. In general, an elevated $\mathrm{Al}$ content increases the volume percentage of $\gamma^{\prime}-\mathrm{Ni}_{3} \mathrm{Al}$ which reduces CTE. And the large amounts of $\mathrm{W}, \mathrm{Ta}$ and $\mathrm{Re}$ also play a role in reducing the CTE. The diffusional aluminide coating is likely to result in a lower CTE for IN738 and CMSX-4. One of the contributing factors for cyclic oxidation failure is thermal stress 
which in a multi-component system depends on temperature gradient and difference in CTE. It is believed that the localized differences in CTEs between TGO and CMSX-4 or IN738LC have played a role in determining the cyclic lives; the smaller difference in CTEs between CMSX-4/PtAl and TGO results in reduced thermal stresses during cyclic test hence longer cyclic life, provided that outward diffusion of alloying elements in CMSX-4 into TGO does not compromise the interfacial bonding too rapidly.

Table 7-5. Averaged coefficient of thermal expansion (CTE) of substrate, YSZ and TGO

\begin{tabular}{|l|l|l|}
\hline & CTE $\left(\times 10^{-6} / \mathrm{K}\right)$ & Reference \\
\cline { 1 - 2 } IN738LC & 17 & {$[152]$} \\
\cline { 1 - 2 } CMSX-4 & 15.6 & \\
\cline { 1 - 3 } 8YSZ & 10.8 & {$[169]$} \\
\cline { 1 - 2 } TGO (alumina) & 9.7 & {$[170]$} \\
\cline { 1 - 2 } $\mathrm{NiAl}$ & 15.1 & {$[171]$} \\
\hline $\mathrm{Ni} 3 \mathrm{Al}$ & 11.9 & {$[172]$} \\
\hline
\end{tabular}

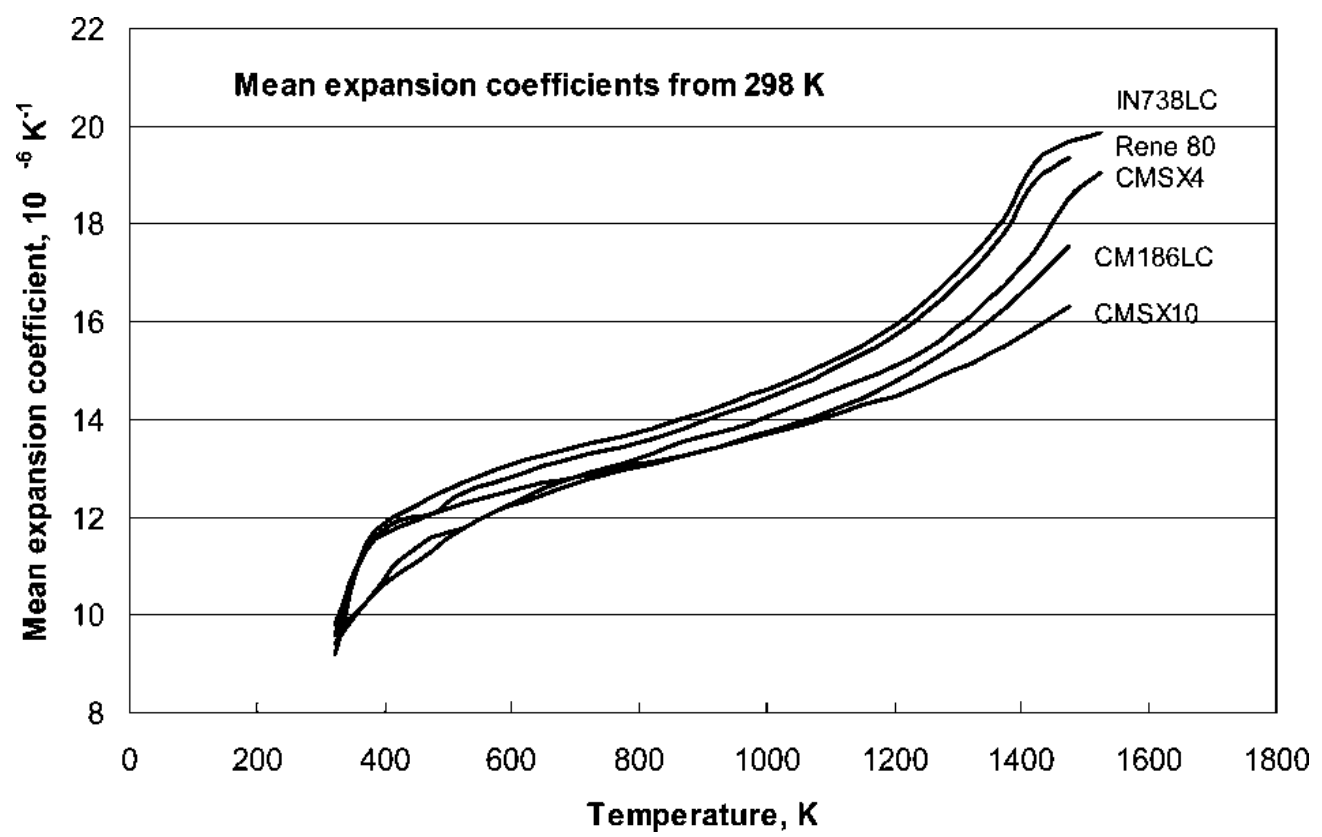

Figure 7-16. Mean coefficient of expansion (CTE) of different types of Ni-base superalloys [151] 


\subsection{Summary of Cyclic Test Results}

The cyclic oxidation resistance of TBC systems with two different ceramic top coats (columnar and vertically cracked) and substrates (IN738LC and CMSX-4) was examined in this study. The failure locations of all TBCs during cyclic test are within TGO, mostly associated with the formation of spinels. TBC systems with IN738LC substrate exhibited shorter cyclic oxidation life than that with CMSX-4 substrate. This could be attributed partially to the smaller thermal expansion mismatch between CMSX4/PtAl and TGO. The effect of different types of YSZ top coat (columnar vs. VC) on cyclic oxidation life was not conclusive for TBC systems with IN738LC substrate but VC YSZ on CMSX-4 has provided significant improvement to the total cycles to failure. 


\section{Chapter: Conclusion and Future Work}

\subsection{Conclusion}

In this research, it was observed that the TBC systems with IN738 substrate exhibited longer isothermal oxidation lives whereas the ones with CMSX-4 substrate had longer cyclic oxidation lives.

The results obtained so far suggest that outward diffusion of refractory elements from CMSX-4 into TGO was responsible for the short isothermal oxidation life of TBC system with CMSX-4; this outward diffusion resulted in voids between TGO and bond coat interface which coincided with the failure locations of TBC system with CMSX-4 substrate. On the other hand, the failure location of the TBC system with IN738LC substrate was within the TGO where a large amount of $\mathrm{Cr}_{2} \mathrm{O}_{3}$ and spinels formed as $\mathrm{Al}$ became depleted. In the same sample, outward diffusion of refractory elements into TGO was not observed likely due to the low percentages of $\mathrm{W}$, Ta and Re in IN738LC. Furthermore, columnar YSZ top coat provided has experienced longer isothermal oxidation life as the bond coat was better protected by the columnar structure; the improved isothermal oxidation performance impacted by columnar YSZ was observed in both systems with IN738LC and CMSX-4 substrate.

During cyclic oxidation test, the failure locations of all TBC samples were found to be inside TGO where sufficient amount of mixed oxides and spinels have formed. The TBC system with CMSX-4 substrate exhibited longer cyclic life partially due to the smaller thermal expansion mismatch between CMSX-4/PtAl and TGO. The effect of different types of YSZ top coat (columnar vs. VC) was not conclusive for TBC systems with 
IN738LC substrate but VC YSZ on CMSX-4 provided significant improvement to the total cycles to failure. The observation of all cyclic tested samples suggested that the growth of spinels, hence the initiation sites for cyclic failure, highly depended upon oxygen's accessibility to TGO.

The effect of refractory elemental diffusion from CMSX-4 into TGO has a significant impact on the isothermal oxidation lives of TBC systems. This was not envisioned at the start of this research. The result suggests that CMSX-4 with a PtAl/YSZ coating system may not be suitable for long-duration oxidative environment. Additionally, the difference in isothermal and cyclic oxidation performance between the two types of ASPS coatings were not thoroughly understood. This study showed that under identical condition, the columnar YSZ had better isothermal oxidation life whereas VC YSZ showed greater performance in cyclic oxidation test.

Based on the tests carried out in this study, it is recommended that for industrial gas turbine engines subjected to long-duration of oxidation, IN738LC substrate and columnar structured top coatings are beneficial; while for aero-engines, CMSX-4 combined with VC YSZ has the potential to be more durable 


\subsection{Future Work}

In this work, TBC samples with APS MCrAlY bond coat (with columnar and VC YSZ top coat) and APS YSZ on PtAl bond could not be generated due to immediate spallation. Future study is suggested to find an alternative bond coat to PtAl due to its high cost and limited coating facilities.

Additionally, more samples should be tested so that periodic sample removal allows for the observation of microstructural changes of TBCs as isothermal and cyclic oxidation progresses. This way the growth kinetic of TGO can be evaluated and used for life predication. Also the gradual oxidation process, particularly the stage where CS begins to grow, should be characterized with the availability of additional samples. 


\section{References}

[1] Y. C. Zhou, T. Hashida, "Coupled effects of temperature gradient and oxidation on thermal stress in thermal barrier coating system," International Journal of Solids and Structures, vol. 38, pp. 4235-4264, 2001.

[2] L. Pin, F. Ansart, J. Bonino, Y. L. Maoult, V. Vidal, P. Lours, "Reinforced sol-gel thermal barrier coatings and their cyclic oxidation life," Journal of the European Ceramic Society, vol. 33, pp. 269-276, 2013.

[3] K. A. Khor, Y.W. Gu, Z.L. Dong, "Mechanical behavior of plasma sprayed functionally graded YSZ/ NiCoCrAlY composite coatings," Surface and Coatings Technology, vol. 139, pp. 200-206, 2001.

[4] I. Spitsberg, K. More, "Effect of thermally grown oxide (TGO) microstructure on the durability of TBCs with PtNiAl diffusion bond coats, "' Materials Science and Engineering A, vol. 417, pp. 322-333, 2006.

[5] J. J. Day, "Gas Turbine Blade Hardfacing Process Development and Microstructural Study of the Interface," M.A.Sc. Thesis, Carleton University, Ottawa, Canada, 2004.

[6] R. Rettig, R. F. Singer, "Numerical modelling of precipitation of topologically closepacked phases in nickel-base superalloys,” Acta Materialia, vol.59, pp. 317-327, 2011.

[7] Y. H. Sohn, E. Y. Lee, B. A. Nagaraj, R. R. Biederman, R. D. Sisson Jr, "Microstructural characterization of thermal barrier coatings on high pressure turbine blades," Surface and Coatings Technology, vol. 146-147, pp. 132-139, 2001.

[8] N. P. Padture, M. Gell, E. H. Jordan, "Thermal Barrier Coatings for Gas-Turbine Engine Applications, "' Science, vol. 296, pp. 280-284, 2002. 
[9] I. Gurrappa, A. K. Gogia, "High performance coatings for titanium alloys to protect against oxidation," Surface and Coatings Technology, vol. 139, pp. 216-221, 2001.

[10] Y. H. Zhang, D. M. Knowles, P. J. Withers, "Microstructural development in Ptaluminide coating on CMSX-4 superalloy during TMF," Surface and Coatings Technology, vol.107, pp. 76-83, 1998.

[11] R. A. Miller, "Thermal Barrier Coatings for Aircraft Engines: History and Directions, ”Journal of Thermal Spray Technology, vol. 6, pp. 35-42, 1997.

[12] S. Sharafat, A. Kobayashi, Y. Chen, N. M. Ghoniem, "Plasma spraying of microcomposite thermal barrier coatings, "Vacuum, vol. 65, pp. 415-425, 2002.

[13] Y. Bai, Z. H. Han, H.Q. Li, C. Xu, Y .L. Xu, Z. Wang, C. H. Ding, J. F. Yang, "High performance nanostructured ZrO2 based thermal barrier coatings deposited by high efficiency supersonic plasma spraying Applied Surface Science,” vol. 257, pp.72107216,2011

[14] D. Zhang, Thermal barrier coatings prepared by electron beam physical vapor deposition (EB-PVD), in Thermal barrier coatings, H. Xu and H. Guo (EDs), Woodhead Publishing Series in Metals and Surface Engineering No. 39, 2011, pp. 3-24.

[15] E. Reinhold, P. Botzler, C. Deus, “EB-PVD process management for highly productive zirconia thermal barrier coating of turbine blades," Surface and Coatings Technology, vol. 120-121, pp. 77-83, 1999.

[16] U. Schulz, M. Schmucker, "Microstructure of ZrO2 thermal barrier coatings applied by EB-PVD, ” Materials Science and Engineering A, vol. 276, pp. 1-8, 2000. 
[17] Z. Tang et al. "Novel Thermal Barrier Coatings Produced by Axial Suspension Plasma Spray," in International Thermal Spray Conference and Exposition, Hamburg, Germany, 27-29 September, 2011.

[18] P. Carpio, E. Rayón , L. Pawłowski , A. Cattini, R. Benavente, E. Bannier M.D. Salvador, E. Sánchez, "Microstructure and indentation mechanical properties of YSZ nanostructured coatings obtained by suspension plasma spraying," Surface and Coatings Technology, vol. 220, pp. 237-243, 2013.

[19] M. Karger, R. Vaben, D. Stover, "Atmospheric plasma sprayed thermal barrier coatings with high segmentation crack densities: Spraying process, microstructure and thermal cycling behavior," Surface and Coatings Technology, vol. 206, pp. 16-23, 2011. [20] R. Eriksson, S. Johansson, H. Brodin, E. Broitman, L. Ostergren, X. Li, "Influence of substrate material on the life of atmospheric plasma sprayed thermal barrier coatings," Surface and Coatings Technology, vol. 232, pp. 795-803, 2013.

[21] L. He, Z. Xu, J. Li, R. Mu, S. He, G. Huang, "Substrate Effects on the HighTemperature Oxidation Behavior of Thermal Barrier Coatings," Journal of Materials Science and Technology, vol. 25, pp. 799-802, 2009.

[22] C. Zhou, J. Yu, S. Gong, H. Xu, "Influence of water vapor on the high temperature oxidation behavior of thermal barrier coatings," Materials Science and Engineering A, vol. 348, pp. 327-332, 2003.

[23] S. Ahmadian, E. H. Jordan, "Explanation of the effect of rapid cycling on oxidation, rumpling, microcracking and lifetime of air plasma sprayed thermal barrier coatings," Surface and Coatings Technology, vol. 244, pp.109-116, 2014. 
[24] M. P. Boyce, Gas Turbine Engineering Handbook, fourth edition, Waltham, MA: Elsevier Inc.

[25] P. Spittle, “Gas turbine technology,” Physics Education, vol. 38, no. 6, pp. 504-511, 2003.

[26] L. S. Langston, G. Opdyke, "Introduction to Gas Turbines for Non-Engineers," Global Gas Turbine News, vol. 37, no. 2, 1997.

[27] R. Kurz, “Gas turbine performance”, In Thirty-fourth Turbomachinery Symposium, J. Burnett (Ed), The Texas A\&M University System College station, Texas, pp.131-146, 12-15 September, 2005.

[28] Z. Mazur, A. Luna-Ramırez, J.A. Juarez-Islas, A. Campos-Amezcua, "Failure analysis of a gas turbine blade made of Inconel 738LC alloy," Engineering Failure Analysis, vol. 12, pp. 474-486, 2005.

[29] H. Oskarsson, "Material Challenges in Industrial Gas Turbines," Journal of Iron and Steel Research International, vol. 14, pp. 11-14, 2007.

[30] T. J. Carter, “Common failures in gas turbine blades, ” Engineering Failure Analysis, vol. 12 , pp. $237-247,2005$.

[31] D. Lee, I. Shin, Y. Kim, J. Koo, C. Seok, “A Study on Fatigue Life Prediction of Nibase superalloy,” Procedia Engineering, vol. 55, pp. 631-635, 2013.

[32] Y. Danis, C. Arvieu, E. Lacoste, T. Larrouy, J. Quenisset, “An investigation on thermal, metallurgical and mechanical states in weld cracking of Inconel 738LC superalloy," Material and Design, vol. 31, pp. 402-416, 2010. 
[33] B. Baufeld, M. Bartsch, M. Heinzelmann, "Advanced thermal gradient mechanical fatigue testing of CMSX-4 with an oxidation protection coating," International Journal of Fatigue, vol. 30, pp. 219-225, 2008.

[34] M. M. Amin, "Oxidation Behaviour of IN-738 LC Superalloys in the Presence of Ionic Salts at 1173 K, ” Portugaliae Electrochimica Acta, vol. 21, pp. 389-398, 2003.

[35] M. J. Pomeroy, "Coatings for gas turbine materials and long term stability issues," Material and Design, vol. 26, pp. 223-231, 2005.

[36] M. R. Reyhani, M. Alizadeh, A. Fathi, H. Khaledi, "Turbine blade temperature calculation and life estimation - a sensitivity analysis, " Propulsion and Power Research, vol. 2, no.2, pp. 148-161, 2013.

[37] I. G. Wright, T. B. Gibbons, "Recent developments in gas turbine materials and technology and implications for syngas firing," International Journal of Hydrogen Energy, vol. 32, pp. 3610-3621, 2007.

[38] M. Segersäll, "Nickel-Based Single-Crystal Superalloys - the crystal orientation influence on high temperature properties", Linköping Studies in Science and Technology, Licentiate Thesis No. 1568, Linköping University, Linköping, Sweden, 2013.

[39] Tresa M. Pollock, "Nickel-Based Superalloys for Advanced Turbine Engines: Chemistry, Microstructure, and Properties, ” Journal of Propulsion and Power, vol. 22 no.2, pp. 361-374, 2006.

[40] B. Goswami, A. K. Ray, S. K. Sahay, "Thermal barrier coating system for gas turbine application - A review, " High Temperature materials and processes, vol. 23, no.4 pp. 73-92, 2004. 
[41] Carlos G. Levi, "Emerging materials and processes for thermal barrier systems," Current Opinion in Solid State and Materials Science, vol. 8, pp. 77-91, 2004.

[42] P. Puetz, "Study of Bond Coating Pre-oxidation Heat Treatments for High Temperature Thin Film Sensors in Gas Turbine Engine Applications," M.A.Sc. thesis, Carleton University, Ottawa, Canada, 2010.

[43] G.W. Goward, "Progress in coatings for gas turbine airfoils, " Surface and Coatings Technology, vol. 108-109, pp. 73-79, 1998.

[44] M. S. Farrell, D. H. Boone, "Oxide Adhesion and Growth Characteristics on Platinum-Modified Aluminide Coatings, " Surface and Coatings Technology, vol. 32, pp. 69-84, 1987.

[45] G. Lehnert, H. Meinhardt, "Present State and Trend of Development of Surface Coating Methods against Oxidation and Corrosion at High Temperatures," Electrodeposition and Surface Treatment, vol. 1, pp. 71-76, 1972.

[46] F. Pedraza, A.D. Kennedy, J. Kopecek, P. Moretto, "Investigation of the microstructure of platinum-modified aluminide coatings," Surface and Coatings Technology, vol. 200, pp. 4032-4039, 2006.

[47] B. M. Warnes, D. C. Punola, "Clean diffusion coatings by chemical vapor deposition,” Surface and Coatings Technology, vol. 94-95, pp. 1-6, 1997.

[48] R. Swadźba, M. Hetmańczyk, J. Wiedermann, L. Swadźba, G. Moskal, "Microstructure degradation of simple, Pt-and Pt+ Pd-modified aluminide coatings on CMSX-4 superalloy under cyclic oxidation conditions," Surface and Coatings Technology, vol. 215, pp. 16-23, 2013. 
[49] D. K. Das, "Microstructure and high temperature oxidation behavior of Pt-modified aluminide bond coats on Ni-base superalloys," Progress in Materials Science, vol. 58, pp. $151-182,2013$.

[50] G. W. Goward, D. H. Boone, "Mechanisms of formation of diffusion aluminide coatings on nickel-base superalloys, ” Oxidation of Metals, vol. 3, pp. 475-495, 1971.

[51] S. Hayashi, S. I. Ford, D. J. Young, D. J. Sordelet, M. F. Besser, B. Gleeson, “ $\alpha-$ $\operatorname{NiPt}(\mathrm{Al})$ and phase equilibria in the Ni-Al-Pt system at $1150^{\circ} \mathrm{C}$, ” Acta Materialia, vol. 53, pp. 3319-3328, 2005.

[52] R. Pichoir, "Influence of the mode of formation on the oxidation and corrosion behaviour of NiAl-type protective coatings," in Materials and coatings to resist high temperature corrosion, D. R. Holmes, A. Rahmel (EDs), London: Applied Science Publishers, pp. 271-790, 1978.

[53] G. R. Krishna, D. K. Das, V. Singh, S. V. Joshi, "Role of Pt content in the microstructural development and oxidation performance of Pt-aluminide coatings produced using a high-activity aluminizing process," Materials Science and Engineering A, vol. 251, pp. 40-47, 1998.

[54] V. K. Tolpygo, D. R. Clarke, "Surface rumpling of a (Ni, Pt)al bond coat induced by cyclic oxidation," Acta materialia, vol. 48, pp. 3283-3293, 2000.

[55] J. A. Haynes, B. A. Pint, Y. Zhang, I. G. Wright, "Comparison of the oxidation behavior of $\beta$ and $\gamma-\gamma^{\prime}$ NiPtAl coatings, "Surface and Coatings Technology, vol. 204, pp. 816-819, 2009.

[56] D. S. Balint, J.W. Hutchinson, "An analytical model of rumpling in thermal barrier coatings, "Journal of the Mechanics and Physics of solids, vol. 53, pp. 949-973, 2005. 
[57] Y. Zhang, J.P. Stacy, B.A. Pint, J.A. Haynes, B.T. Hazel, B.A. Nagaraj, “Interdiffusion behavior of Pt-diffused $\gamma+\gamma$ ' coatings on Ni-based superalloys, " Surface and Coatings Technology, vol. 203, pp. 417-421, 2008.

[58] B. Gleeson, W. Wang, S. Hayashi, D. Sordelet, "Effects of Platinum on the Interdiffusion and Oxidation Behavior of Ni-Al-Based Alloys," Materials Science Forum, vol. 461-464, pp. 213-222, 2004.

[59] J. A. Haynes, B. A. Pint, Y. Zhang, I. G. Wright, "The effect of Pt content on $\gamma$ $\gamma^{\prime}$ NiPtAl coatings, "' Surface \& Coatings Technology, vol. 203, pp. 413-416, 2008.

[60] N. Vialas, D. Monceau, "Effect of Pt and Al content on the long-term, high temperature oxidation behavior and interdiffusion of a Pt-modified aluminide coating deposited on Ni-base superalloys," Surface and Coatings Technology, vol. 201, pp. 3846-3851, 2006.

[61] E. A. G. Shillington, D. R. Clarke, "Spalling Failure of a Thermal Barrier Coating associated with Aluminum Depletion in the Bond-Coat," Acta Materialia, vol. 47, pp. 1297-1305, 1999.

[62] F. Delogu, "Atomistic mechanism of the formation of a nanometer-sized amorphous metal by Kirkendall effect," Materials Chemistry and Physics, vol. 125, pp. 390-396, 2011.

[63] X. Zhou, Z. Xu, R. Mu, L. He, G. Huang, X. Cao, “Thermal barrier coatings with a double-layer bond coat on Ni3Al based single-crystal superalloy," Journal of Alloys and Compounds, vol. 591, pp.41-51, 2014.

[64] F. S. Petit and G. W. Goward, in Gas Coatings for High-Temperature Applications, E. Lang (ed.). Applied Science Publishers, p. 341, 1983. 
[65] W. Brandl, H. J Grabke, D. Toma, J. Keuger, "The oxidation behaviour of sprayed MCrAIY coatings, ” Surface and Coatings Technology, vol. 86-87, pp. 41-47, 1996.

[66] X. Peng, "Metallic coatings for high-temperature" in H. Xu, H. Guo (Eds), Thermal barrier coatings, Woodhead publishing, pp. 53-71, 2011.

[67] G. Goward, "Progress in coatings for gas turbine airfoils,” Surface and Coatings Technology, vol. 108-109, pp. 73-79, 1998.

[68] T. Rhys-Jones, "Coatings for Blade and Vane Applications in Gas Turbines," Corrosion Science, vol. 29, pp. 623-646, 1989.

[69] J. Nicholls, “Designing Oxidation-Resistant Coatings,” Journal of Metals, vol. 52, pp. $28-35,2000$.

[70] J. R. Nicholls, N. J. Simms, W. Y. Chan, H. E. Evans, "Smart overlay coatings concept and practice,” Surface and Coatings Technology, vol. 149, pp. 236-244, 2002.

[71] A. J. A. Mom, "High Temperature Coatings for Gas Turbines, an Overview," NLRReport, MP 81003U, Amsterdam, 1981.

[72] W. O. Soboyejo, P. Mensah, R. Diwan, J. Crowe, S. Akwabo, "High temperature oxidation interfacial growth kinetics in YSZ thermal barrier coatings with bond coatings of NiCoCrAlY with 0.25\% Hf, " Materials Science and Engineering A, vol. 528, pp. 22232230,2011

[73] S. Bose, "Oxidation and Corrosion-Resistant Coatings" in High temperature coatings, Elsevier, 2007.

[74] W. Brandl, H.J. Grabke, D. Tom, J. Kruger, "The oxidation behaviour of sprayed MCrAIY coatings, ”S Surface and Coatings Technology, vol. 86-87, pp. 41-47, 1996. 
[75] A. Taylor and R. W. Floyd, "The constitution of the nickel-rich alloys of the nickeltitanium-aluminum system, ’ J. Inst. Metals, vol. 81, pp. 451-464, 1952-1953

[76] J. R. Nicholls, “Designing oxidation resistant coatings,” JOM, vol. 52, vol. 28-35, 2000.

[77] M. D. Hanna "The Formation of Platinum Aluminide Coatings on In-738 and Their Oxidation Resistance," PhD thesis, University of Sheffield, 1982.

[78] T. Lu, D. Yao, C. Zhou, "Low-temperature Formation of Aluminide Coatings on Nibase Superalloys by Pack Cementation Process, " Chinese Journal of Aeronautics, vol. 23, pp. 381-385, 2010.

[79] D. Pan, M. W. Chen, P. K. Wright, K. J. Hemker, "Evolution of a diffusion aluminide bond coat for thermal barrier coatings during thermal cycling," Acta Materialia, vol. 51, pp. 2205-2217, 2003.

[80] I Gurrappa, "Platinum Aluminide Coatings for Oxidation Resistance of Titanium Alloys, "Platinum Metals Review, vol. 45, no. 3, pp.124-129, 2001.

[81] M. Saremi, A. Afraisiabi, A. Kobayshi, "Microstructural analysis of YSZ and YSZ/Al2O3 plasma sprayed thermal barrier coatings after high temperature oxidation," Surface and Coatings Technology, vol. 202, pp. 3233-3238, 2008.

[82] C. Zhu, A. Javed, P. Li, F. Yang, G.Y. Liang, P. Xiao, "A study of the microstructure and oxidation behavior of alumina/yttria-stabilized zirconia $\left(\mathrm{Al}_{2} \mathrm{O}_{3} / \mathrm{YSZ}\right)$ thermal barrier coatings," Surface and Coatings Technology, vol. 212, pp. 214-222, 2012.

[83] M. Buschinelli, X. Huang, W. Chen, "TGO evolution and coating property changes for EB-PVD TBC coatings under cyclic oxidation condition," paper presented at ASME 
Turbo Expo 2010: Power for land, Sea and Air. Glasgow, UK, Glasgow: ASME, pp. 891-898, June 14-18, 2010.

[84] H. J. Kim, M. E. Walte, "Characterization of the degraded microstructures of a platinum aluminide coating," Materials Science and Engineering A, vol. 360, pp. 7-17, 2003

[85] D. R. Mumm, A. G. Evans, "On the Role of Imperfections in the Failure of a Thermal Barrier Coating made by Electron Beam Deposition,” Acta Materialia, vol.48, pp. 1815-1827, 2000.

[86] W. R. Chen, X. Xu, B. R. Marple, D. R. Nagy, P. C. Patnaik, "TGO growth behaviour in TBCs with APS and HVOF bond coats, "Surface and Coatings Technology, vol. 202, pp. 2677-2683, 2008.

[87] D. R. Clarke, C. G. Levi, "Materials Design for the Next Generation Thermal Barrier Coatings,” Annual Review of Materials Research, vol. 33, pp. 383-417, 2003.

[88] W. R. Chen, X. Wu, B. R. Marple, P. C. Patnaik, "The growth and influence of thermally grown oxide in a thermal barrier coating," Surface and Coatings Technology, vol. 201, pp. 1074-1079, 2006.

[89] W. R. Chen, X. Wu, B. R. Marple, P. C. Patnaik, "Oxidation and crack nucleation/growth in an air-plasma-sprayed thermal barrier coating with NiCrAlY bond coat," Surface and Coatings Technology, vol. 197, pp. 109-115, 2005.

[90] J. Toscano, R. Vapen, A. Gil, M. Subanovic, D. Naumenko, L. Singheiser, W.J. Quadakkers, "Parameters affecting TGO growth and adherence on MCrAlY-bond coats for TBC's, ” Surface and Coatings Technology, vol. 201, pp. 3906-3910, 2006. 
[91] B. Baufeld, U. Schulz, "Life time dependency on the pre-coating treatment of a thermal barrier coating under thermal cycling," Surface and Coatings Technology, vol. 201, pp. 2667-2675, 2006.

[92] W. Ma, H. Dong, "Ceramic thermal barrier coating materials" in Thermal barrier coatings, H. Xu, H. Guo (Eds), Woodhead publishing, pp. 25-52, 2011.

[93] F. Cernuschi, P. Bianchi, M. Leoni, P. Scardi, “Thermal diffusivity/microstructure relationship in Y-PSZ thermal barrier coatings, ”Journal of Thermal Spray Technology, vol. 8, pp. 102-109, 1999.

[94] X. Cao, R. Vaßen D. Stöver, "Ceramic materials for thermal barrier coatings," Journal of the European Ceramic Society, vol. 24, pp. 1-10, 2004.

[95] A. Keyvani, M. Saremi, M. Heydarzadeh Sohi, Z. Valefi, "A comparison on thermomechanical properties of plasma-sprayed conventional and nanostructured YSZ TBC coatings in thermal cycling," Journal of Alloys and Compounds, vol. 541, pp. 488494, 2012.

[96] Y. Lang, Y. Dong, J. Zhou, C. Wang, "YSZ fiber-reinforced porous YSZ ceramics with lowered thermal conductivity: Influence of the sintering temperature," Materials Science and Engineering A, vol. 600, pp. 76-81, 2014.

[97] S. Stecura, "Optimization of $\mathrm{NiCrAl}-\mathrm{Y} / \mathrm{ZrO}_{2}-\mathrm{Y}_{2} \mathrm{O}_{3}$ thermal barrier system," NASA Tech. Memo. 86905, 1985, NASA, Cleveland, OH.

[98] K. H. Stern, Metallurgical and ceramic protective coatings. Chapman \& Hall, London, 1996.

[99] S. Gong, Q. Wu, "Ceramic thermal barrier coating materials," Thermal barrier coatings, H. Xu, H. Guo (Eds), Woodhead publishing, pp. 115-131, 2011. 
[100] D. Zhang, "Thermal barrier coatings prepared by electron beam physical vapor deposition (EB-PVD)," Thermal barrier coatings Woodhead publishing, H. Xu, H. Guo (Eds), pp. 3-24, 2011.

[101] H. B. Xu, S. K. Gong, F. S. Liu, "Electron beam physical vapor deposition technology in Barton Welding Institute of Ukraine," Aviation Engineering \& Maintenance, vol. 6, pp. 6-8, 1997.

[102] K. D. Bouzakis, A. Lontos, N. Michailidis, O. Knotek, E. Lugscheider, K. Bobzin, A. Etzkorn, "Determination of mechanical properties of electron beam-physical vapor deposition-thermal barrier coatings (EB-PVD-TBCs) by means of nanoindentation and impact testing," Surface and Coatings Technology, vol. 163-164, pp. 75-80, 2003.

[103] N. P. Padture, M. Gell, E. H. Jordan, “Thermal Barrier Coatings for Gas-Turbine Engine Applications,” Science, vol. 296, pp. 280-284, 2002.

[104] P. Morrell, D. S. Rickerby, The Proc. of an AGARD SMP Meeting on "Thermal Barrier Coatings", Aalborg, Denmark, pp. 20-21. (15th - 16th October, 1997).

[105] J. R. Nicholls, K. J. Lawson, A. Johnstone, D. S. Rickerby, "Methods to Reduce the Thermal Conductivity of EB-PVD TBCs, ” Surface and Coatings Technology, vol. 151 152, pp. 383-391, 2002.

[106] J. R. Nicholls, K. J. Lawson, D. S. Rickerby, P. Morrel (1999) “Advanced processing of TBC's for reduced thermal conductivity," NATO Workshop on Thermal Barrier Coatings, Aalborg, Denmark, AGARD-R-823, paper No. 6.

[107] M. E. Walter, B. Eigenmann, "The mechanical response of three EB-PVD thermal barriercoating microstructures," Material Science and Engineering A, vol. 282, pp. 49$58,2000$. 
[108] A. Flores Renteria, B. Saruhan, "Effect of ageing on microstructure changes in EBPVD manufactured standard PYSZ top coat of thermal barrier coatings, " Journal of the European Ceramic Society, vol. 26, pp. 2249-2255, 2006.

[109] A. Flores Renteria, B. Saruhan, U. Schulz, H.-J. Raetzer-Scheibe, “Effect of morphology on thermal conductivity of EB-PVD PYSZ TBCs," Surface \& Coatings Technology, vol. 201, pp. 2611-2620, 2006.

[110] H.-J. Ratzer-Scheibe, U. Schulz, T. Krell, "The effect of coating thickness on the thermal conductivity of EB-PVDPYSZ thermal barrier coatings," Surface and Coatings Technology, vol. 200, pp. 5636-5644, 2006.

[111] "Progress in Thermal Barrier Coatings," The American Ceramic Society, Wiley, pp. 123-124, 2009.

[112] X. Zhao, X. Wang, P. Xiao, "Sintering and failure behaviour of EB-PVD thermal barrier coating after isothermal treatment," Surface and Coatings Technology, vol. 200, pp. 5946-5955, 2006.

[113] S. Sridharan, L. Xie, E. H. Jordan, M. Gell, K. S. Murphy, "Damage evolution in an electron beam physical vapor deposited thermal barrier coating as a function of cycle temperature and time, ” Materials Science and Engineering A, vol. 393, pp. 51-62, 2005. [114] L. Chen, "Processing, microstructures and properties of thermal barrier coatings (TBCs) by plasma spraying (PS)", Thermal barrier coatings, H. Xu, H. Guo (Eds), Woodhead publishing, pp. 132-160 (2011).

[115] S. Costil, C. Verdy, R. Bolot, C. Coddet, "On the Role of Spraying Process on Microstructural, Mechanical, and Thermal Response of Alumina Coatings," Journal of Thermal Spray Technology, vol. 16, pp. 839-843, 2007. 
[116] F. Fauchais, “Understanding plasma spraying” Journal of Physics D: Applied Physics, vol. 37, pp. R86-R108, 2004.

[117] A. Rabiei, A. G. Evans, "Failure Mechanisms associated with the Thermally Grown Oxide in Plasma-Sprayed Thermal Barrier Coatings,” Acta Materialia, vol. 48, 3963-3976, 2000.

[118] M. Bounazef, S. Guessasma, G. Montavon, C. Coddet, "Effect of APS process parameters on wear behaviour of alumina-titania coatings," Materials Letters, vol. 58, pp. $2451-2455,2004$.

[119] S.Y. Semenov, "Experimental diagnostics and modeling of thermal spray deposition processes of nano-structured wear resistant and thermal barrier coatings" Doctoral Thesis Paper, AAI3076719, 2002.

http://digitalcommons.uconn.edu/dissertations/AAI3076719

[120] J. L. Xu, K. A. Khor, "Processing, Plasma spraying for thermal barrier coatings: processes and applications" Thermal barrier coatings, Woodhead publishing, $\mathrm{H}$. $\mathrm{Xu}, \mathrm{H}$. Guo (Eds), pp. 132-160, 2011.

[121] J. Cho, Y. Xiong, J. Kim, C. Lee, S. Hwang, "Tribological behavior of NiCr-base blended and nanostructured composite APS coatings by rig test," Wear, vol. 265, pp. $1565-1571,2008$.

[122] J. M. Houben, "Future development in Thermal Spraying," in Thermal Spray 1985, Long Beach, CA., ASM International, pp. 1-12, 1985.

[123] G. Montavon, S. Sampath, C. C. Berndt, H. Herman, C. Coddet, "Effects of the spray angle on splat morphology during thermal spraying," Journal of Thermal Spray Technology, vol. 4, pp. 67-74, 1995. 
[124] M. M. Verdian, M. Salehi and K. Raeissi, "Effect of feedstock particle size on microstructure of APS coatings prepared from mechanically alloyed nickel-titanium powders, " Surface Engineering, vol. 26, pp. 447-452, 2010.

[125] A. N. Khan, J. Lu, "Thermal cyclic behavior of air plasma sprayed thermal barrier coatings sprayed on stainless steel substrates," Surface and Coatings Technology, vol. 201, pp. 4653-4658, 2007.

[126] A. N. Khan, J. Lu, H. Liao, "Heat treatment of thermal barrier coatings," Materials and Engineering A, vol. 359, pp. 129-136, 2003.

[127] M. A. Helminiak, N. M. Yanar, F. S. Pettit, T. A. Taylor, G. H. Meier, "The behavior of high-purity, low-density air plasma sprayed thermal barrier coatings," Surface and Coatings Technology, vol. 204, pp. 793-796, 2009.

[128] H. G. Scott, "Phase Relationships in Zirconia-yttria system," Journal of Material Science, vol. 10, pp. 1527-1535, 1975.

[129] O. Fabrichnaya, F. Aldinger, "Assessment of thermodynamic parameters in the system $\mathrm{ZrO}_{2}-\mathrm{Y}_{2} \mathrm{O}_{3}-\mathrm{Al}_{2} \mathrm{O}_{3}$ ”, Zeitschr. Metallk. Mater. Res. Adv. Tech. vol. 95, pp. 27-39, 2004.

[130] J. Chevalier, L. Gremillard, S. Deville, "Low-Temperature Degradation of Zirconia and Implications for Biomedical Implants," Annual Review of Materials Research, vol. 37, pp. 1-32, 2007.

[131] Q. Yu, C. Zhou, H. Zhang, F. Zhao, “Thermal stability of nanostructured 13 wt\% $\mathrm{Al}_{2} \mathrm{O}_{3}-8 \mathrm{wt} \% \quad \mathrm{Y}_{2} \mathrm{O}_{3}-\mathrm{ZrO}_{2}$ thermal barrier coatings, "Journal of the European Ceramic Society, vol. 30, pp. 889-897, 2010. 
[132] X. Yang, Y. Yu, H. Liu, J. Bao, G. Ji, “Variety behavior in spraying process of nanoparticles agglomerated YSZ powder by APS, ” Journal of Iron and Steel Research, International, vol. 14, pp. 152-155, 2007.

[133] O. Racek, C. C. Berndt, D. N. Guru, J. Heberlein, "Nanostructured and conventional YSZ coatings deposited using APS and TTPR techniques," Surface and Coatings Technology, vol. 201, pp. 338-346, 2006.

[134] L. Pawlowski, "Suspension and solution thermal spray coatings," Surface and Coatings Technology, vol. 203, pp. 2807-2829, 2009.

[135] P. Carpio, Q. Blochet, B. Pateyron, L. Pawłowski, M. D. Salvador, A. Borrell, E. Sánche, "Correlation of thermal conductivity of suspension plasma sprayed yttria stabilized zirconia coatings with some microstructural effects," Material Letters, vol. 107, pp. 370-373, 2013.

[136] S. Kozerski, L. Łatka, L. Pawlowski, F. Cernuschi, F. Petit, C. Pierlot, H. Podlesak, J. P. Laval, "Preliminary study on suspension plasma sprayed $\mathrm{ZrO} 2+8$ wt.\% Y2O3 coatings, ”Journal of the European Ceramic Society, vol. 31, pp. 2089-2098, 2011.

[137] L. Łatka, A. Cattini, L. Pawłowski, S. Valette, B. Pateyron, J. Lecompte, R. Kumar, A. Denoirjean, "Thermal diffusivity and conductivity of yttria stabilized zirconia coatings obtained by suspension plasma spraying," Surface and Coatings Technology, vol. 208, pp. 87-91, 2012.

[138] K. VanEvery, M. M. Krane, R. W. Trice, "Parametric study of suspension plasma spray processing parameters on coating microstructures manufactured from nanoscale yttria-stabilized zirconia," Surface and Coatings Technology, vol. 206, pp. 2464-2473, 2012. 
[139] M. Daroonparvar, M. S. hussain, M. A. M. Yajid, "The role of formation of continues thermally grown oxide layer on the nanostructured NiCrAlY bond coat during thermal exposure in air,” Applied Surface Science, vol. 261, pp. 287-197, 2012.

[140] J. Sun, L. Zhang, D. Zhao, "Microstructure and thermal cycling behavior of nanostructured yttria partially stabilized zirconia (YSZ) thermal barrier coatings," Journal of Rare Earths, vol. 28, pp.198-201, 2010.

[141] C. Zhou, N. Wang, Z. Wang, S. Gong, H. Xu, "Thermal cycling life and thermal diffusivity of a plasma-sprayed nanostructured thermal barrier coating," Scripta Materialia, vol. 51, pp. 945-948, 2004.

[142] C. Zhou, N. Wang, H. Xu, "Comparison of thermal cycling behavior of plasmasprayed nanostructured and traditional thermal barrier coatings, " Materials Science and Engineering A, vol. 452-453, pp. 569-574, 2007.

[143] H. Guo, R. Yao, L. Zhou, "Plasma-sprayed thermal barrier coatings with segmentation cracks" in Thermal barrier coatings, H. Xu, H. Guo (Eds), Woodhead publishing, pp. 161-174, 2011.

[144] M. Madhwal, E. H. Jordan, M. Gell, "Failure mechanisms of dense verticallycracked thermal barrier coatings," Material Science and Engineering A, vol. 384, pp. 151-161, 2004.

[145] R. McPherson, "The Relationship between the Mechanism of Formation, Microstructure and Properties of Plasma sprayed Coatings," Thin Solid Films, vol. 83, pp. 297-310, 1981. 
[146] H. B. Guo, R. Vaben, D. Stover, "Atmospheric plasma sprayed thick thermal barrier coatings with high segmentation crack density," Surface and Coatings Technology, vol. 186, pp. 353-363, 200.

[147] Z. Lu, S. Myoung, H. Kim, M. Kim, J. Lee, Y. Jung, J. Jang, U. Paik, "Microstructure Evolution and Interface Stability of Thermal Barrier Coatings with Vertical Type Cracks in Cyclic Thermal Exposure," Journal of Thermal Spray Technology, vol. 22, pp. 617-679, 2013.

[148] P. Poza, J. Gomez-Garcia, C.J. Munez, "TEM analysis of the microstructure of thermal barrier coatings after isothermal oxidation,” Acta Materialia, vol. 60, pp. 71977206, 2012.

[149] Z. Xu, R. Mu, L. He, X. Cao, "Effect of diffusion barrier on the high-temperature oxidation behavior of thermal barrier coatings, " Journal of Alloys and Compounds, vol. 466, pp. 471-478, 2008.

[150] M. H. Li, X. F. Sun, S. K. Gong, Z. Y. Zhang, H. R. Guan, Z. Q. Hu, "Phase transformation and bond coat oxidation behavior of EB-PVD thermal barrier coating," Surface and Coatings Technology, vol. 176, pp. 209-214, 2004.

[151] P. Tsai, C. Tseng, C. Yang, I. Kuo, Y. Chou, J. Lee, “Thermal cyclic oxidation performance of plasma sprayed zirconia thermal barrier coatings with modified high velocity oxygen fuel sprayed bond coatings, " Surface and Coatings Technology, vol. 228 pp. S11-S14, 2013.

[152] P. N. Quested, R. F. Brooks, L. Chapman, R. Morrell, Y. Youssef, K. C. Mills, "Measurement and estimation of thermophysical properties of nickel based superalloys," Materials Science and Technology, vol. 25, pp. 154-162, 2009. 
[153] V. Jalilvand, H. Omidvar, M. R. Rahimipour, H. R. Shakeri, "Influence of bonding variables on transient liquid phase bonding behavior of nickel based superalloy IN738LC,” Materials and Design, vol. 52, pp. 36-46, 2013.

[154] E. Balikci, R.A. Mirshams, and A. Raman, "Tensile strengthening in the nickelbase superalloy IN738LC, ” JMEPEG, vol. 9, pp. 324-329, 2000.

[155] J.-T. Guo, D. Ranucci, “Low cycle fatigue behaviour of cast nickel-base superalloy IN738LC at room temperature," International Journal of Fatigue, vol. 5, pp. 95-97, 1983. [156] E. Balikci, R. Mirshams, A. Raman, "Fracture behavior of superalloy IN738LC with various precipitate microstructures, ” Materials Science and Engineering A, vol. 265, pp. 50-62, 1999.

[157] NiDi Nickel Development Institute, HIGH-TEMPERATURE HIGH-STRENGTH NICKEL BASE ALLOYS, 1995.

[158] B. Baufeld, U. Schulz, "Life time dependency on the pre-coating treatment of a thermal barrier coating under thermal cycling," Surface and Coatings Technology, vol. 201, pp. 2667-2675, 2006.

[159] G. Fleury, F. Schubert, H. Nickel, "Modelling of the thermo-mechanical behaviour of the single crystal superalloy CMSX-4," Computational Materials Science, vol. 7, pp. 187-193, 1996.

[160] P. Cavaliere, F. Panella, "Mechanical and microstructural behaviour of CMSX-4 Ni-based superalloy joined by capacitor discharge welding," Journal of Materials Processing Technology, vol. 183, pp. 297-300, 1997.

[161] J. H. Chen, J. A. Little, "Degradation of the platinum aluminide coating on CMSX4 at $1100^{\circ} \mathrm{C}$," Surface and Coatings Technology, vol. 92, pp. 69-77, 1997. 
[162] N.S. Stoloff, Superalloys II, Wiley, New York, 1987.

[163] J. Litz, A. Rahmel, M. Schorr, J. Weiss, "Scale formation on the Ni-base superalloys IN 939 and IN 738 LC, ”' Oxidation of Metals, vol. 32, pp. 167-184, 1989.

[164] S. Geng, F. Wang, S. Zhang, “Cross-sectional oxide distribution of cast IN738 and its sputtered coating at $1000^{\circ} \mathrm{C}$, " Surface and Coatings Technology, vol. 167, pp.161$164,2003$.

[165] J. Toscano, R. Vaßen, A. Gil, M. Subanovic, D. Naumenko, L. Singheiser, W. J. Quadakkers, "Parameters affecting TGO growth and adherence on MCrAlY-bond coats for TBC's, " Surface and Coatings Technology, vol. 201, pp. 3906-3910, 2006.

[166] W. R. Chen, X. Wu, B. R. Marple, and P. C. Patnaik, "Oxidation and crack nucleation/growth in an air-plasma-sprayed thermal barrier coating with NiCrAlY bond coat," Surface and Coatings Technology, vol. 197, no. 1, pp. 109-115, 2005.

[167] A. M. Gusak, K. N. Tu, "Interaction between the Kirkendall effect and the inverse Kirkendall effect in nanoscale particles, ” Acta Materialia, vol. 57, pp. 3367-3373, 2009. [168] H. Rafiee, S. Rastegari, H. Arabi, “Formation mechanism of IDZ during coating of IN738 by single step gas phase aluminizing, ” Canadian Metallurgical Quarterly, vol. 50, pp. 85-90, 2011.

[169] T. S. J. Irvine, P. Connor, "Solid Oxide Fuels Cells: Facts and Figures- Past Present and Future Perspectives for SOFC Technologies,” 2013.

[170] M. Han, J. Huang, S. Chen, "Behavior and mechanism of the stress buffer effect of the inside ceramic layer to the top ceramic layer in a double-ceramic-layer thermal barrier coating," Ceramics International, vol. 40, pp. 2901-2914, 2014. 
[171] D. B. Miracle, R. Darolia, "NiAl and its Alloys" in Intermetallic Compounds, Vol. 2: Practice, J. H. Westbrook and R. L. Fleischer, Retrieved from: www.knovel.com, 1995.

[172] T. Murotani, T. Yano, H. Hirose, “Applications of X-Ray Stress Measurement for Interface Area of Ni3Al System Intermetallic Compound Coating,” International Centre for Diffraction Data 2004, Advances in X-ray Analysis 47 (2004) 385-389. 